UNIVERSIDADE DE BRASÍLIA

FACULDADE DE TECNOLOGIA

DEPARTAMENTO DE ENGENHARIA MECÂNICA

CARBONIZAÇÃO E GASEIFICAÇÃO DE RESÍDUOS DA MACAÚBA, TUCUMÃ E CUPUAÇU PARA GERAÇÃO DE ELETRICIDADE

FÁBIO CORDEIRO DE LISBOA

ORIENTADOR: Dr. CARLOS ALBERTO GURGEL VERAS CO-ORIENTADOR: Dr. AUGUSTO CÉSAR DE MENDONÇA BRASIL

BRASÍLIA/DF: Junho - 2016 
UNIVERSIDADE DE BRASÍLIA

FACULDADE DE TECNOLOGIA

DEPARTAMENTO DE ENGENHARIA MECÂNICA

\author{
CARBONIZAÇÃO E GASEIFICAÇÃO DE RESÍDUOS DA \\ MACAÚBA, TUCUMÃ E CUPUAÇU PARA GERAÇÃO DE \\ ELETRICIDADE
}

FÁBIO CORDEIRO DE LISBOA

TESE DE DOUTORADO SUBMETIDA AO DEPARTAMENTO DE ENGENHARIA MECÂNICA DA FACULDADE DE TECNOLOGIA DA UNIVERSIDADE DE BRASÍLIA, COMO PARTE DOS REQUISITOS NECESSÁRIOS PARA A OBTENÇÃO DO GRAU DE DOUTOR EM CIÊNCIAS MECÂNICAS.

APROVADA POR:

Prof. Dr. Carlos Alberto Gurgel Veras (Orientador)

Prof. Dr. Antônio César Pinho Brasil Junior (Examinador)

Prof. Dr. Thiago Oliveira Rodrigues (Examinador)
Prof. Dr. Augusto César de Mendonça Brasil (Co-orientador)

Prof. Dra. Sandra Maria da Luz (Examinador)

Prof. Dr. José Dilcio Rocha

(Examinador Externo) 


\section{FICHA CATALOGRÁFICA}

\section{LISBOA, FÁBIO CORDEIRO DE}

CARBONIZAÇÃO E GASEIFICAÇÃO DE RESÍDUOS DA MACAÚBA, TUCUMÃ E CUPUAÇU PARA GERAÇÃO DE ELETRICIDADE, [Distrito Federal] 2016.

xvii, 120p., 210 x 297 mm (ENM/FT/UnB, Doutor, Ciências Mecânicas, 2016). Tese de Doutorado - Universidade de Brasília, Faculdade de Tecnologia, Departamento de Engenharia Mecânica.
1. Pirólise
2. Gaseificação
3. Biomassa Amazônica residual
4. Carvão ativado
I. ENM/FT/UnB.
II. Título (série)

\section{REFERÊNCIA BIBLIOGRÁFICA}

LISBOA, F. C. D. CARBONIZAÇÃO E GASEIFICAÇÃO DE RESÍDUOS DA MACAÚBA, TUCUMÃ E CUPUAÇU PARA GERAÇÃO DE ELETRICIDADE. Tese de Doutorado em Ciências Mecânicas, 2016. Programa de pós-graduação em Ciências Mecânicas, Universidade de Brasília UnB, Brasília DF, 120p.

\section{CESSÃO DE DIREITOS}

AUTOR: Fábio Cordeiro de Lisboa.

TÍTULO: Carbonização e Gaseificação de Resíduos Da Macaúba, Tucumã e Cupuaçu para Geração de Eletricidade

\section{GRAU: Doutor}

ANO: 2016

É concedida à Universidade de Brasília permissão para reproduzir cópias desta dissertação de mestrado e para emprestar ou vender tais cópias somente para propósitos acadêmicos e científicos. $\mathrm{O}$ autor reserva outros direitos de publicação e nenhuma parte desta dissertação de mestrado pode ser reproduzida sem a autorização por escrito do autor.

Fábio Cordeiro de Lisboa

e-mail: fabiodelisboa@gmail.com 


\section{DEDICATÓRIA}

"Dedico este trabalho à minha família: Yáskara, Isabelle, Júlia e Flávia e a minha mãe Aparecida. Que com muita paciência, amor e dedicação me apoiaram incondicionalmente em todos os momentos.

Com muita saudade dedico ao meu pai Osvaldo(†1945-2007) a quem sou grato pela formação e instrução."

Pois a sabedoria entrará em seu coração, e o conhecimento será agradável à sua alma.

Provérbios 2:10. 


\section{AGRADECIMENTOS}

Agradeço a Deus pela benção de concluir este trabalho e a minha esposa Yáskara e às minhas filhas Isabelle, Júlia e Flávia pela paciência e dedicação para comigo durante a elaboração desta tese.

Aos meus orientadores Carlos Gurgel e Augusto Brasil, pela disposição e diligência na coordenação desta pesquisa, aos quais aproveito para manifestar minha admiração pela carreira em curso.

Minha gratidão aos amigos que me ajudaram nas diversas etapas desta pesquisa: professora. Sandra Luz e seus alunos Janaine e Victor, pela ajuda nos ensaios de termogravimetria e na análise dos espectros de infravermelho. Aos amigos do LPF Thiago Rodrigues, Bruno Sant'Ana e Luiz Gustavo pela condução dos experimentos de pirólise, e caracterização. Igualmente manifesto minha gratidão aos amigos do IQ-UnB: professoras Grace Ghesti, Sara Brum e Andressa Velasques e aos colegas Munique e Paulo, pelo apoio nas atividades de laboratório e pelas valiosas dicas. Ao professor Ailton e equipe da fazenda água limpa pelos procedimentos de carbonização da biomassa e pelo apoio nas interpretações dos resultados. Os técnicos do laboratório de termociências e metrologia dinâmica José Filipe e Eurípedes pelo apoio na execução de experimentos e na acomodação do prédio do laboratório provendo toda infraestrutura necessária.

Pela abertura do laboratório de gaseificação do núcleo de catálise (NuCat) da COPPE UFRJ, agradeço ao Professor Victor Teixeira, e aos pesquisadores Evandro Perclat Otz, Maria Auxiliadora S. Baldanza e Alessandra Silva. Agradeço todo aprendizado recebido nos dias em que estivemos juntos.

Este trabalho foi desenvolvido com o apoio do Governo do Estado do Amazonas por meio Fundação de Amparo à Pesquisa do Estado do Amazonas, com a concessão de bolsa de estudo. 
RESUMO

\title{
CARBONIZAÇÃO E GASEIFICAÇÃO DE RESÍDUOS DA MACAÚBA, TUCUMÃ E CUPUAÇU PARA GERAÇÃO DE ELETRICIDADE
}

\author{
Autor: Fábio Cordeiro de Lisboa \\ Orientador: Prof. Dr. Carlos Alberto Gurgel Veras \\ Co-orientador: Prof. Dr. Augusto César de Mendonça Brasil \\ Programa de Pós-Graduação em Ciências Mecânicas \\ Brasília, Maio de 2016.
}

A viabilidade em se implementar modelos negócios na região amazônica é comprometida pelas dificuldades logísticas e de infraestrutura. Aproveitar ao máximo recursos naturais disponíveis, retirando deles o máximo de produtos com valor agregado é uma boa estratégia para ampliar a margem operacional das empresas ou mesmo como requisito de operação. Neste contexto, explorar as potencialidades da biomassa residual carbonizada pode representar um facilitador ao desenvolvimento regional por gerar empregos e concentrar renda. O uso do carvão vegetal proveniente de resíduos agrícolas abundantes representa um diferencial competitivo por armazenar energia na forma de carbono. Que pode ser usado na queima direta para cocção ou siderurgia, ou quando gaseificado, nos motores dos motogeradores já instalados, operando em modo duplo combustível. Ou ainda, quando ativados por processos físicos ou químicos, gerar um produto de altíssimo valor agregado como o carvão ativado. Que pode ser vendido ou usado em etapas intermediárias do processamento principal, servindo como um adsorvente em processos de purificação ou mesmo em processos catalíticos. O presente trabalho apresenta uma análise da viabilidade tecnológica da transformação de espécies de biomassa amazônica, em vetores energéticos. Foram analisados dois processos de transformação: a pirólise para obtenção de carvão, e a gaseificação da biomassa carbonizada para produção de gás de síntese. Adicionalmente investigou-se o uso dos finos de carvões arrastados, como um adsorvente, comparando-o aos carvões ativados quimicamente. As espécies escolhidas foram o epicarpo de Theobroma grandiflorum (cupuaçu) e os endocarpos do Astrocaryum aculeatum (tucumã) e da Acrocomia aculeata (macaúba). Como resultados obtém-se um comparativo entre os indicadores de desempenho nos processos de pirólise, gaseificação e dos indicadores de qualidade do carvão ativado obtido. Os carvões produzidos a partir do epicarpo do cupuaçu apresentaram melhores índices de rendimento gravimétrico e melhor reatividade na produção de gás de síntese que os demais carvões. Os carvões de tucumã e macaúba apresentaram resultados bem próximos um do outro, com excelente quantidade de carbono fixo e maior densidade que o primeiro, com destaque para as propriedades para os produtos a partir da macaúba, com maior densidade e carbono fixo do que os demais.

Palavras-chaves: Pirólise, Gaseificação, Biomassa residual, Carvão ativado. 


\title{
ABSTRACT
}

\section{CARBONIZATION AND GASIFICATION OF MACAUBA, TUCUMA AND CUPUASSU WASTES FOR ELECTRICITY GENERATION}

\author{
Author: Fábio Cordeiro de Lisboa \\ Supervisor: Dr. Carlos Alberto Gurgel Veras \\ Co-supervisor: Dr. Augusto César de Mendonça Brasil \\ Post-Graduation Program in Mechanical Sciences
}

\section{Brasília, June of 2016.}

The implementation of permanent bio business solutions in the Amazon region are hindered by the lack of local logistics and infrastructure. One strategy would be to increase the usage of natural resources, adding value to most of the by-products. As an example, considering the capacity of the biochar to retain energy, local development can be stimulated by creating jobs, regional concentration of income and the increase in the number of permanent inhabitants by adding value to the available feedstocks. This work presents a performance analysis, as energy vectors, of some biomasses from the Amazon region. Two important conversion technologies were investigated, pyrolysis and gasification for biochar and synthesis gas production, respectively. Furthermore, it was also investigated the activation level of fine particles of biochar. The studied biomasses were pericarp of Theobroma grandiflorum (cupuaçu) and the endocarps of Astrocaryum aculeatum (tucumã) and Acrocomia aculeata (macaúba). Cupuaçu showed the highest biochar yield $(36,8 \%)$ and particle reactivity in the gasification process as compared to the other two biomasses. Biochars from tucumã and macaúba showed similar gravimetric yields (30\%), high level of fixed carbon (66 a 71\%) and density (360 to $620 \mathrm{~kg} \mathrm{~m}^{-3}$ ). In the biochar gasification the $\mathrm{HHV}$ of syngas ranges from 2,4 to 4,3 $\mathrm{MJ} \mathrm{Nm}^{-3}$. The charcoal fines collected from the gasification process, as regard to the level of activation, presented similar performance to chemically activated carbons.

Key-words: Pyrolysis, Gasification, Amazon Biomass, Activated Carbon. 


\section{1 - Sumário}

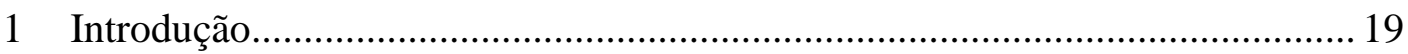

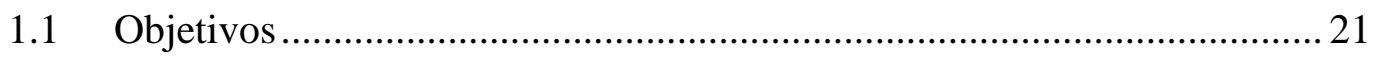

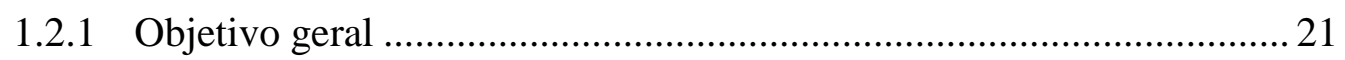

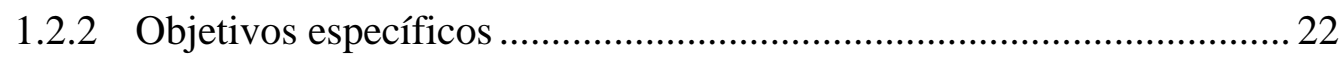

1.2 Organização do Trabalho .................................................................. 23

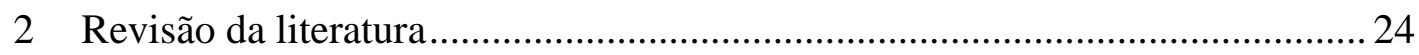

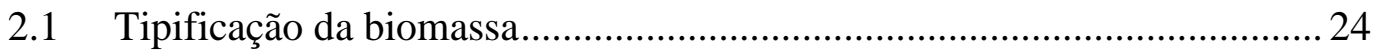

2.2 Conversão de biomassa em energia ......................................................29

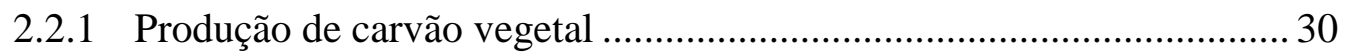

2.2.2 Caracterização da biomassa carbonizada............................................ 34

2.2.3 Gaseificação de biomassa ............................................................. 35

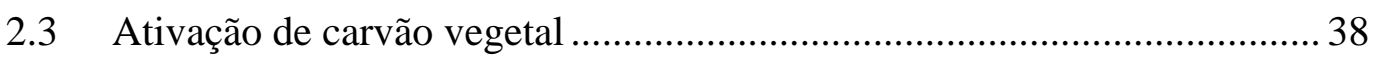

2.3.1 Mecanismo de adsorção ................................................................ 39

2.3.2 Processo de fabricação ................................................................ 40

2.3.3 Propriedades do carvão ativado ...................................................... 41

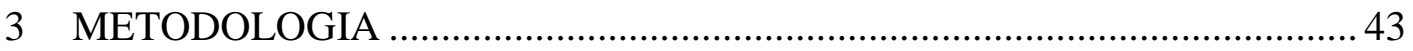

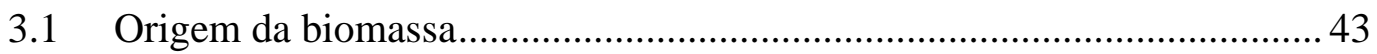

3.1.1 Caracterização da biomassa ............................................................ 44

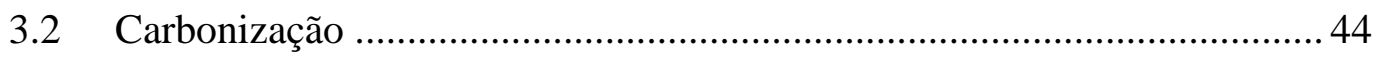

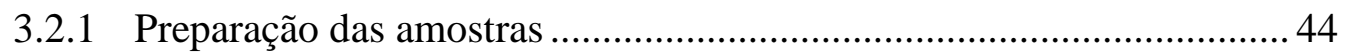

3.2.2 Termogravimetria e análise de gases .............................................. 45

3.2.3 Modelagem matemática da pirólise .................................................. 46

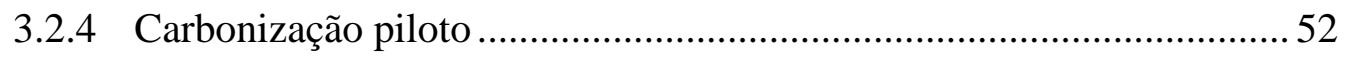

3.2.5 Carbonização de grandes massas ................................................... 53

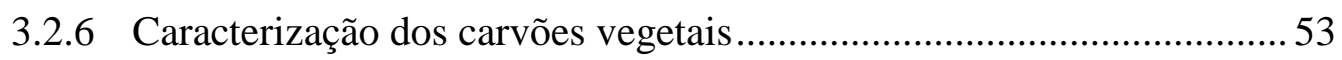

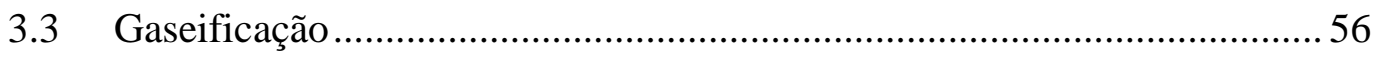


3.3.1 Modelagem matemática e simulação numérica da gaseificação

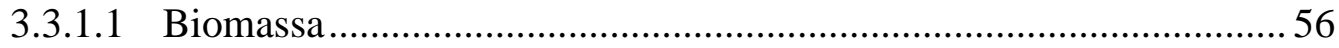

3.3.1.2 Equilíbrio químico e termodinâmico ................................................5 57

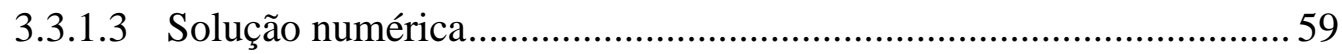

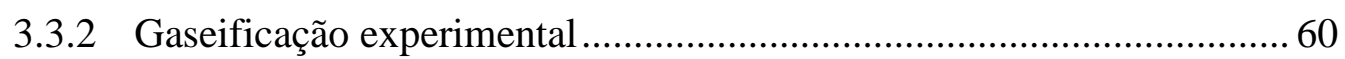

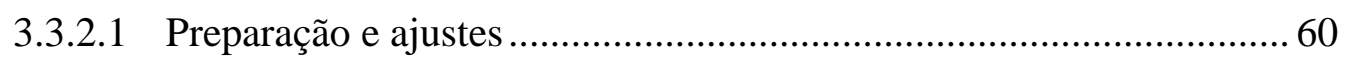

3.3.2.2 Descrição da unidade piloto de gaseificação PID............................. 61

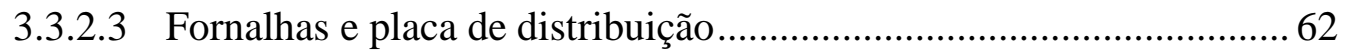

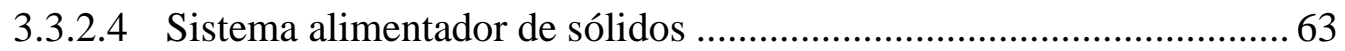

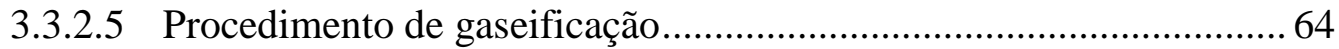

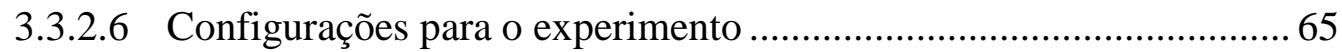

3.3.3 Análise dos gases da gaseificação …….............................................. 65

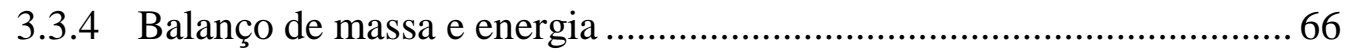

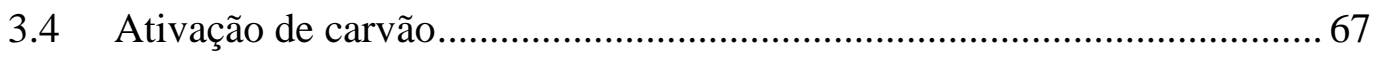

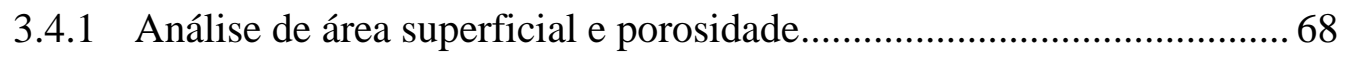

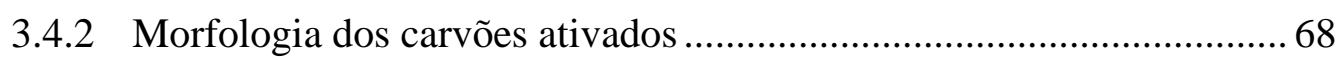

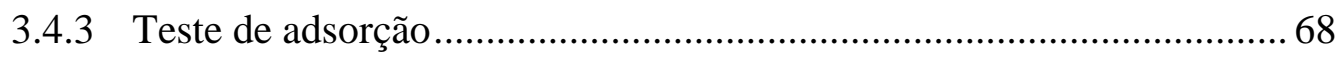

3.4.4 Estudo da cinética de adsorção de azul de metileno............................ 69

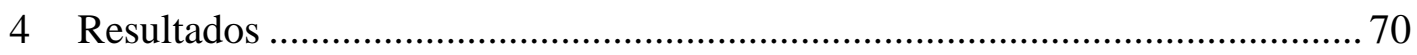

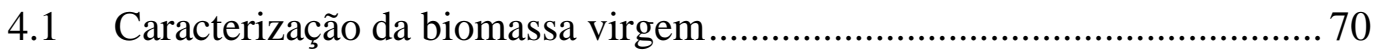

4.2 Análise da degradação térmica - TG-FTIR ........................................... 71

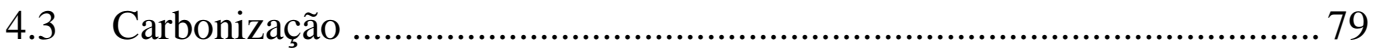

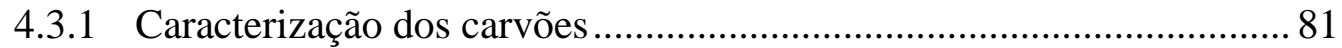

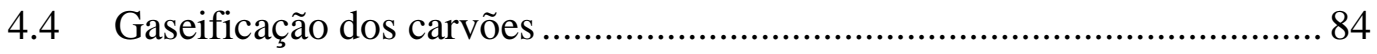

4.4.1 Levantamento das condições operacionais ....................................... 84

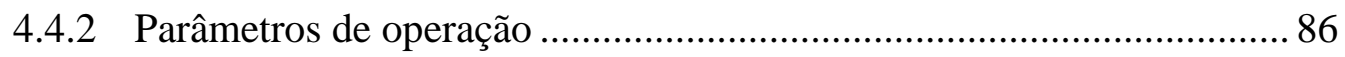

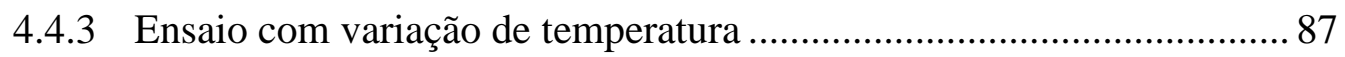


4.4.4 Ensaios com variação da razão de equivalência .................................. 90

4.4.5 Composição do gás de síntese ........................................................... 90

4.4.6 Balanço de massa e energia ............................................................. 93

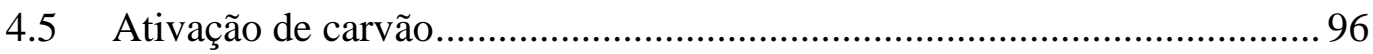

4.6 Geração de eletricidade a partir do gás de síntese ................................. 102

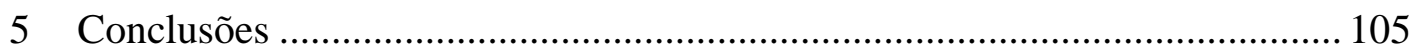

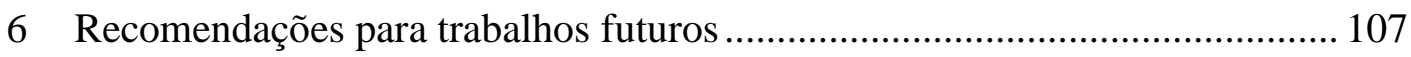

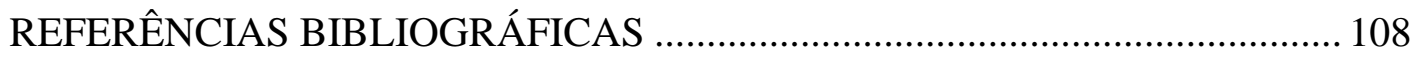

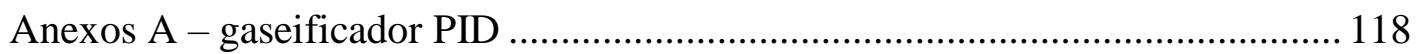

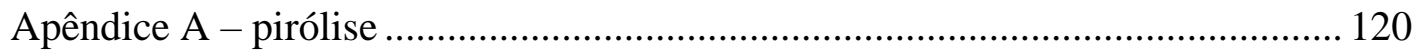

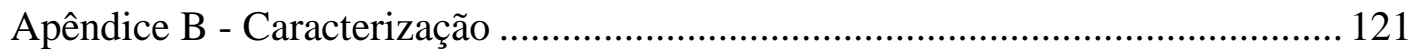

Apêndice B - simulação para gaseificação.......................................................... 122

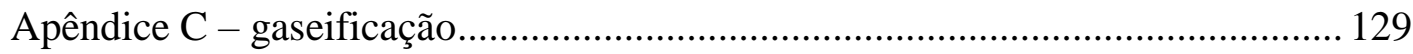

Apendice D - adsorção de cor .................................................................... 130 


\section{LISTA DE TABELAS}

Tabela 1 Nomenclatura da biomassa utilizada neste trabalho 28

Tabela 2 Constantes de equilíbrio para reações de carbono-água, Boudouard e formação do metano.

Tabela 3 Poder calorífico dos processos de gaseificação 38

Tabela 4 Configuração de dosagens de carvão e agente gaseificante. Reator a $900{ }^{\circ} \mathrm{C}$, granulometria do carvão entre 1 e 2mm, taxa de alimentação de sólidos a 0,02 $\mathrm{kg} \min -1$, velocidade do feeder a 57\% sem adição de água ao agente gaseificante. 65

Tabela 5 - Caracterização da biomassa virgem. .70

Tabela 6 Temperatura $(\mathrm{T})$, variação de massa $(\Delta \mathrm{m})$ e tempo $(\mathrm{t})$ de reação nos picos da curva DTG na degradação térmica da biomassa virgem. Resíduo sólido (R) ao final da análise.

Tabela 7 Correspondência entre o número de onda e compostos contidos no gás. . 74

Tabela 8 Configuração do reator para carbonização piloto 80

Tabela 9 Tempo de carbonização levantado para reator cilíndrico com 190mm de diâmetro.

Tabela 10 Caracterizações dos carvões dos endocarpos de tucumã e macaúba e do epicarpo do cupuaçu.

Tabela 11 - Fórmulas químicas equivalentes para biomassa virgem e carbonizada82

Tabela 12 Poder calorífico superior (PCS) e o poder calorífico inferior (PCI) das amostras

Tabela 13 Registro dos parâmetros do gaseificador para o CEFM. ........................ 86

Tabela 14 Registro dos parâmetros do gaseificador para o CEFT ..........................86

Tabela 15 Configuração do gaseificador para o CEFC

Tabela 16 Comparação dos resultados obtidos nos picos de produção. Nomenclatura utilizada: Sim - simulado segundo o modelo apresentado em 3.5.1; $\mathrm{Sw}$ - Dados obtidos com outros simuladores; Exp - Dados experimentais 92

Tabela 17 Propriedades dos carvões ativados. 97

Tabela 18 Consolidado comparativo dos resultados de adsorção de RR2 a $30{ }^{\circ} \mathrm{C}$ e PH 5,0 . 100 


\section{LISTA DE FIGURAS}

Figura 1 Sistema de transmissão de energia elétrica no Brasil e localização das termoelétricas no estado do Amazonas (ANEEL 2015)... 20

Figura 2 Representação gráfica do objetivo deste trabalho: Transformação de biomassa em derivados energéticos tais como gás de síntese isento de hidrocarbonetos pesados (alcatrões) e seu aproveitamento em motores de combustão interna (M) de grupogeradores.....

Figura 3 Astrocaryum aculeatum - Tucumã. .................................................... 24

Figura 4 Acrocomia aculeata - Macaúba........................................................... 25

Figura 5 Theobroma grandiflorum - Cupuaçu................................................... 27

Figura 6 Carbonização da biomassa e seus produtos............................................ 31

Figura 7 Frente de pirólise - modelo de Holmes (1977) ........................................ 33

Figura 8 Organização das técnicas empregadas neste estudo................................. 43

Figura 9 Decomposição das energias durante a carbonização. Fonte: (Kung, 1972)

Figura 10 Diagrama de funcionamento do reator de pirólise (retorta elétrica) S.L.F.I. com capacidade para 10L equipado com condensadores e controle de temperatura (Apêndice A). .52

Figura 11 Gaseificador em leito fluidizado marca PID Eng\&Tech com controle via software das temperaturas e fluxos de combustível e gases

Figura 12 Termogravimetria (TG/DTG) dos três resíduos, com temperaturas variando de $23^{\circ} \mathrm{C}$ a $450^{\circ} \mathrm{C}$ com rampa de $2^{\circ} \mathrm{C}$. min -1 sob fluxo de $100 \mathrm{ml} \mathrm{min}-1 \mathrm{de}$ nitrogênio. Nos picos da DTG são observadas três regiões onde foram analisados os espectros de infravermelho dos gases emitidos durante o ensaio

Figura 13 Curvas de TG e DTG dos carvões. O aquecimento foi de $23^{\circ} \mathrm{C}$ a $900^{\circ} \mathrm{C}$ com rampa de $20^{\circ} \mathrm{C} \min -1$ sob fluxo de ar sintético de $100 \mathrm{~mL} \min -1$. 73

Figura 14 Espectros de infravermelho dos gases das emissões durante a degradação térmica do $\mathrm{EFC}$ nas temperaturas de 54,203 e $289^{\circ} \mathrm{C}$. .74

Figura 15 Espectros de infravermelho dos gases das emissões durante a degradação térmica do EFM nas temperaturas de 58, 197 e $326^{\circ} \mathrm{C}$.

Figura 16 Espectros de infravermelho dos gases das emissões durante a degradação térmica do EFT nas temperaturas de 58, 198 e $329^{\circ} \mathrm{C}$. .76 
Figura 17 Espectros de infravermelho dos gases emitidos durante a degradação térmica dos carvões à temperatura de gaseificação sob fluxo de $100 \mathrm{~mL} \mathrm{~min} \mathrm{-} 1$ de ar sintético

Figura 18 DSC comparativa entre as amostras. Curvas com amplitude para baixo descrevem reações endotérmicas, enquanto que as com amplitude para cima descrevem reações exotérmicas.

Figura 19 DSC dos carvões com aquecimento de $23^{\circ} \mathrm{C}$ a $900{ }^{\circ} \mathrm{C}$ com rampa de $20{ }^{\circ} \mathrm{C} \min -1$ sob fluxo de ar sintético de $100 \mathrm{~mL} \min -1$. .78

Figura 20 Efeito do calor específico do carvão na taxa de pirólise. $l=9,5 \mathrm{~cm}$, temperatura do reator $T=470^{\circ} \mathrm{C}, Q p=-48,4 \mathrm{cal} \mathrm{g}-1$, ap $=1,19 \times 105 \mathrm{~min}-1$, $E p=15,14$ cal mol -1 .

Figura 21 Curvas de temperatura ao centro do reator cilíndrico com aquecimento elétrico. .80

Figura 22 Carvões de endocarpo de Tucumã (CEFT), endocarpo de Macaúba (CEFM) e epicarpo de Cupuaçu (CEFC).

Figura 23 Difração de raios $\mathrm{x}$ - estruturas amorfas............................................. 82

Figura 24 Morfologia dos carvões - fotomicrografias feitas em MEV. 83

Figura 25 Composição dos carvões medidos por espectroscopia de raios $\mathrm{X}$ por dispersão em energia (EDX)

Figura 26 Curvas de calibração do sistema de alimentação de sólidos em função do percentual da velocidade máxima dos motores do sistema de alimentação de sólidos.

Figura 27 Perfil da curva de fluidização da areia a quartzo à temperatura ambiente.

Figura 28 Perfil da curva de fluidização da areia a quartzo a $900{ }^{\circ} \mathrm{C}$. .85

Figura 29 Poder calorífico superior do gás de síntese obtido pela variação da temperatura. Reator carregado com 500g de areia de quartzo misturado com 500g de carvão. Vazão de ar de $12 \mathrm{NL} \min -1,5 \mathrm{~mL} \min -1$ de vapor de água a $400{ }^{\circ} \mathrm{C}$, ciclones a $500{ }^{\circ} \mathrm{C}$ e condensador a $38^{\circ} \mathrm{C}$.

Figura 30 Simulação numérica da gaseificação - em função da temperatura. (a) Resultados numéricos referentes ao modelo no equilíbrio químico e 0D. (b) Sobreposição dos valores simulados da figura 31a com os valores experimentais da figura 30 (à mesma razão de equivalência). 
Figura 31 Variação do PCS pela variação da razão de equivalência. Temperatura do leito a $900{ }^{\circ} \mathrm{C}$, alimentação de sólidos a $0,05 \mathrm{~kg} \min -1$, sem adição de vapor.

Figura 32 Fração volumétrica de $\mathrm{CO}$ e $\mathrm{H}_{2}$ em função de $\phi$ simulado em modelo 0D. Concentrações de $\mathrm{CO}$ representado em preto e concentrações de $\mathrm{H}_{2}$ representado em e azul.

Figura 33 Comparativo do PCS do syngas na simulação 0D com os valores reais medidos em cromatografia. Condições de ensaio conforme tabelas 11, 12 e 13. 92

Figura 34 Balanço de massa na gaseificação do CEFC ............................................. 93

Figura 35 Balanço de massa na gaseificação do CEFM.......................................... 94

Figura 36 Balanço de massa na gaseificação do CEFT ......................................... 94

Figura 37 Balanço de energia na gaseificação do CEFC....................................... 95

Figura 38 Balanço de energia na gaseificação do CEFM ...................................... 95

Figura 39 Balanço de energia na gaseificação do CEFT ......................................... 96

Figura 40 Isotermas de adsorção de nitrogênio a $77 \mathrm{~K}$ usando um equipamento NOVA 300 BET analisador da Quanta Chrome, USA. Os valores de área e tamanho médio de poro foram obtidos a partir da aplicação dos modelos de BET e BJH para os dados da isoterma .

Figura 41 Isotermas de adsorção de azul de metileno .98

Figura 42 Comparativo das isotermas de adsorção para o corante RR02 conduzido a $30{ }^{\circ} \mathrm{C}$ .99

Figura 43 Comparativo das fotomicrografias dos carvões ativados em diferentes processos com o não ativado 101

Figura 44 Modo de operação em duplo combustível. Fonte: adaptado de Cummins (2014).

Figura 45 Taxa de substituição do diesel pelo gás. Fonte: adaptado de Cummins (2014). 103

Figura 46 Foto do gaseificador usado nos experimentos................................... 118

Figura 47 Diagrama de funcionamento da unidade piloto de gaseificação 118

Figura 48 Faixas de operação do gaseificador e Taxa de alimentação de sólidos em função da velocidade dos parafusos

Figura 49 Sistema de alimentação e reator de gaseificação. 119

Figura 50 Fotos da retorta elétrica SLFI usada na carbonização piloto e do forno Linn Elektro Therm usado para a carbonização de grandes quantidades de biomassa virgem. Detalhes do cadinho do reator com poço para inserção do termopar e do sistema de xiv 
condensação de alcatrões. Detalhe da vedação da tampa do reator feita com pasta Molybras

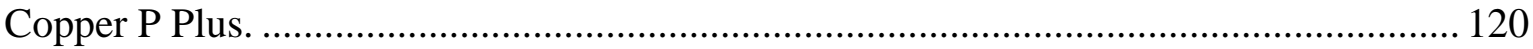

Figura 51 Sistemas de condensação de licor pirolenhoso...................................... 120

Figura 52 Sistema da moagem e classificação dos carvões .................................. 121

Figura 53 Medição do poder calorífico superior das amostras............................. 121

Figura 54 Planta piloto de gaseificação do NuCat - COPPE-UFRJ ...................... 129

Figura 55 Amostragem do gás de síntese, condensado e finos de carvão arrastado. 129

Figura 56 Cromatografia dos gases oriundos do gaseificador ............................ 129

Figura 57 Ensaio de adsorção de cor - corante RR02 .......................................... 130 


\section{LISTA DE SÍMBOLOS, NOMENCLATURAS E ABREVIAÇÕES}

$s f c$ - Consumo específico de combustível

$\dot{m}_{D}$ - Fluxo de massa de diesel

$\dot{m}_{G}$ - Fluxo de massa de gás

$\eta_{D G}$ - Rendimento térmico usando gás e diesel

$\bar{h}_{f, b}$ - Entalpia de formação da biomassa

$\bar{h}_{f, j}$ - Entalpia de formação do elemento “ $j$ ”

$\bar{g}_{T, i}^{0}$ - Função de Gibbs de formação

$\dot{q}^{\prime \prime}$ - Fluxo de calor

$h_{0}$ - Coeficiente de transferência de calor por convecção

$h_{a}$ - Entalpia específica ativa da biomassa

$h_{c}$ - Entalpia específica do carvão

$h_{g}$ - Entalpia específica dos gases

$\mathrm{v}_{m f}$ - Velocidade mínima de mínima de fluidização

$\varepsilon_{m f}$ - Porosidade do leito

$\rho_{L}$ - Densidade do leito

$\rho_{S}$ - Densidade do sólido

$A_{0}$ - Área da parede

$D_{p}$ - Diâmetro da partícula

$L_{m f}$ - Altura do leito

$Q_{p}$ - Energia endotérmica associada com a geração de massa unitária de vapor

$T_{c f}$ - Teor de carbono fixo

$T_{c z}$ - Teor de cinzas

$T_{v}$ - Teor de voláteis

$c_{p b}-$ Calor específico do material virgem à temperatura ambiente

$c_{p g}-$ Calor específico dos voláteis

$k_{1,2,3, \ldots}$ - Condutividade térmica dos materiais usados no gaseificador

$k_{a}$ - Condutividade térmica do material ativo

$k_{b}$ - Condutividade térmica do material virgem à temperatura ambiente

$k_{p}$ - constante de equilíbrio

$\eta_{g f}$ - Eficiência de gás frio 
$\eta_{g q}$ - Eficiência de gás quente

$\eta_{l}$ - Eficiência líquida

$v_{g a ́ s}-$ Volume específico do gás

$\rho_{a}$ - Densidade do material ativo

$\rho_{b}$ - Densidade da biomassa virgem

$\rho_{f}$ - Densidade final do carvão

ACEFC - Licor pirolenhoso do epicarpo da fruta do Theobroma grandiflorum

ACEFM - Licor pirolenhoso do endocarpo da fruta do Acrocomia aculeata

ACEFT - Licor pirolenhoso do endocarpo da fruta do Astrocaryum aculeatum

AM - Azul de metileno

CAEFC - Carvão ativado do epicarpo da fruta do Theobroma grandiflorum

CAEFM - Carvão ativado do endocarpo da fruta do Acrocomia aculeata

CAEFT - Carvão ativado do endocarpo da fruta do Astrocaryum aculeatum

CEFC - Carvão do epicarpo da fruta do Theobroma grandiflorum

CEFM - Carvão do endocarpo da fruta do Acrocomia aculeata

CEFT - Carvão do endocarpo da fruta do Astrocaryum aculeatum

DSC - Calorimetria exploratória diferencial

DTG - Derivada da termogravimetria

EFC - Epicarpo da fruta do Theobroma grandiflorum

EFM - Endocarpo da fruta do Acrocomia aculeata

EFT - Endocarpo da fruta do Astrocaryum aculeatum

FTIR - Infravermelho pela transformada de Fourier

GCEFC - Gás do carvão do epicarpo da fruta do Theobroma grandiflorum

GCEFM - Gás do carvão do endocarpo da fruta do Acrocomia aculeata

GCEFT - Gás do carvão do endocarpo da fruta do Astrocaryum aculeatum

$h$ - Umidade relativa

LPF - laboratório de produtos florestais

PCS - Poder calorífico superior

SFB - Serviço florestal brasileiro

TG - Termogravimetria

$\Delta G_{T}^{0}$ - Variação da função de Gibs

$C F$ - Carbono fixo

Ceq - Concentração de AM no equilíbrio 
$C z-$ Cinzas

$E p$ - Energia de ativação

$F / A$ - Razão combustível - ar

$H P$ - Entalpia dos produtos

$H R$ - Entalpia dos reagentes

$K L$ - Constante relacionada à energia de adsorção

$L$ - Comprimento do Reator

$L(T)$ - Calor de vaporização à temperatura $\mathrm{T}$

$M$ - Massa molar

$M g(x)$ - Fluxo de voláteis na direção do eixo x

PCI - Poder calorífico inferior

$R$ - Constante universal dos gases

$T$ - Temperatura

Vol - Voláteis

$a p$ - Fator pré-exponencial

$b$ - Capacidade de adsorção máxima

$g$ - Aceleração da gravidade

$g$ - Função de energia livre de Gibbs

$k$ - Condutividade da matriz porosa de sólido preenchida por gases

$m$ - Massa

qeq - Quantidade adsorvida de AM por grama de carvão

$t$ - Tempo

$x$ - Fração mássica

$y$ - Fração molar

$\Delta P$ - Queda de pressão do fluido através do leito

$v$ - Coeficientes estequiométricos

$\rho$ - Massa específica a granel

$\omega$ - Teor de umidade

$\phi$ - Razão de equivalência 


\section{INTRODUÇÃO}

A região amazônica possui predominantemente geração de eletricidade através de termoelétricas a óleo diesel ou gás natural (Figura 1), cujo custo de geração varia entre 200,00 a 300,00 $R \$ M W h^{-1}$ (Aneel, 2015), caro quando comparado à de fonte hidráulica com custo de geração abaixo de 100,00 $R \$ M W h^{-1}$. No entanto essa região é grande fonte de recursos naturais provenientes de biomassa, que podem ser usados para produção de energia elétrica, potencializando o desenvolvimento econômico regional com o uso de tecnologias adaptadas localmente, conforme suas características ambientais e agrícolas. $\mathrm{O}$ uso destes recursos pode representar um diferencial de custo importante, maximizando a lucratividade das atividades econômicas desenvolvidas localmente e reduzindo impactos ambientais.

Viabilizar um modelo de negócios competitivo em locais isolados não é uma tarefa fácil. Assim aproveitar ao máximo os recursos disponíveis, explorando todo o potencial da matéria-prima, retirando dela produtos primários e secundários, com foco na manutenção de uma margem de operação segura, mostra-se como uma prática necessária. Como exemplos citam-se indústrias de sucos e de extração de óleos, que precisam de potência elétrica para operar seus maquinários bem como de outros insumos para o beneficiamento de seus produtos. O tempo de transporte para grandes centros também é um fator importante na realidade amazônica, muitas vezes impeditiva dada às condições das rodovias e hidrovias. Neste contexto, explorar as potencialidades da biomassa residual carbonizadas pode representar um facilitador ao desenvolvimento regional por gerar empregos e concentrar renda. O uso do carvão vegetal proveniente de resíduos agrícolas abundantes representa um diferencial competitivo por armazenar energia na forma de carbono, que pode ser usado na queima direta para cocção ou siderurgia, ou quando gaseificado, nos motores dos motogeradores já instalados, operando em modo duplo combustível. Ou ainda, quando ativados por processos físicos ou químicos, gerar um produto de altíssimo valor agregado como o carvão ativado, que pode ser vendido ou usado em etapas intermediárias do processamento principal, servindo como um adsorvente em processos de purificação ou mesmo em processos catalíticos.

Alguns autores estudaram a viabilidade do uso de biomassa amazônica como recurso para geração de energia elétrica em sistemas isolados (Nogueira; et al., 2008; Xavier, 2009; Itai et al., 2014) atacando o problema e propondo soluções usando diferentes tecnologias. 
Em trabalhos de campo na região de Manaus (Lisboa et al., 2012; Maciel e Lisboa, 2013; Yoshida e De Lisboa, 2013) compararam diferentes vetores energéticos e evidenciam as potencialidades da biomassa amazônica para fins energéticos. Outros autores (Bridgwater, 1995; Mckendry, 2002b; Wetterlund e Söderström, 2010; Arena, 2012; Nickerson et al., 2015) também evidenciam os aspectos econômicos envolvidos na gaseificação e o potencial desta fonte renovável na produção de energia elétrica.

No entanto, o alcatrão produzido no processo de gaseificação é o principal inconveniente tecnológico para o uso de biomassa como recurso energético em sistemas isolados e, portanto, precisa ser removido por sistemas de condensação e filtragem, de forma a garantir um funcionamento seguro dos motores. Uma forma de resolver este problema é separar os processos: realizar a pirólise em um processo anterior ao da gaseificação, injetando no motor apenas os produtos da gaseificação provenientes da biomassa já previamente carbonizada, ou seja, isenta de alcatrões (Di Lascio e Fagundes Barreto, 2009).

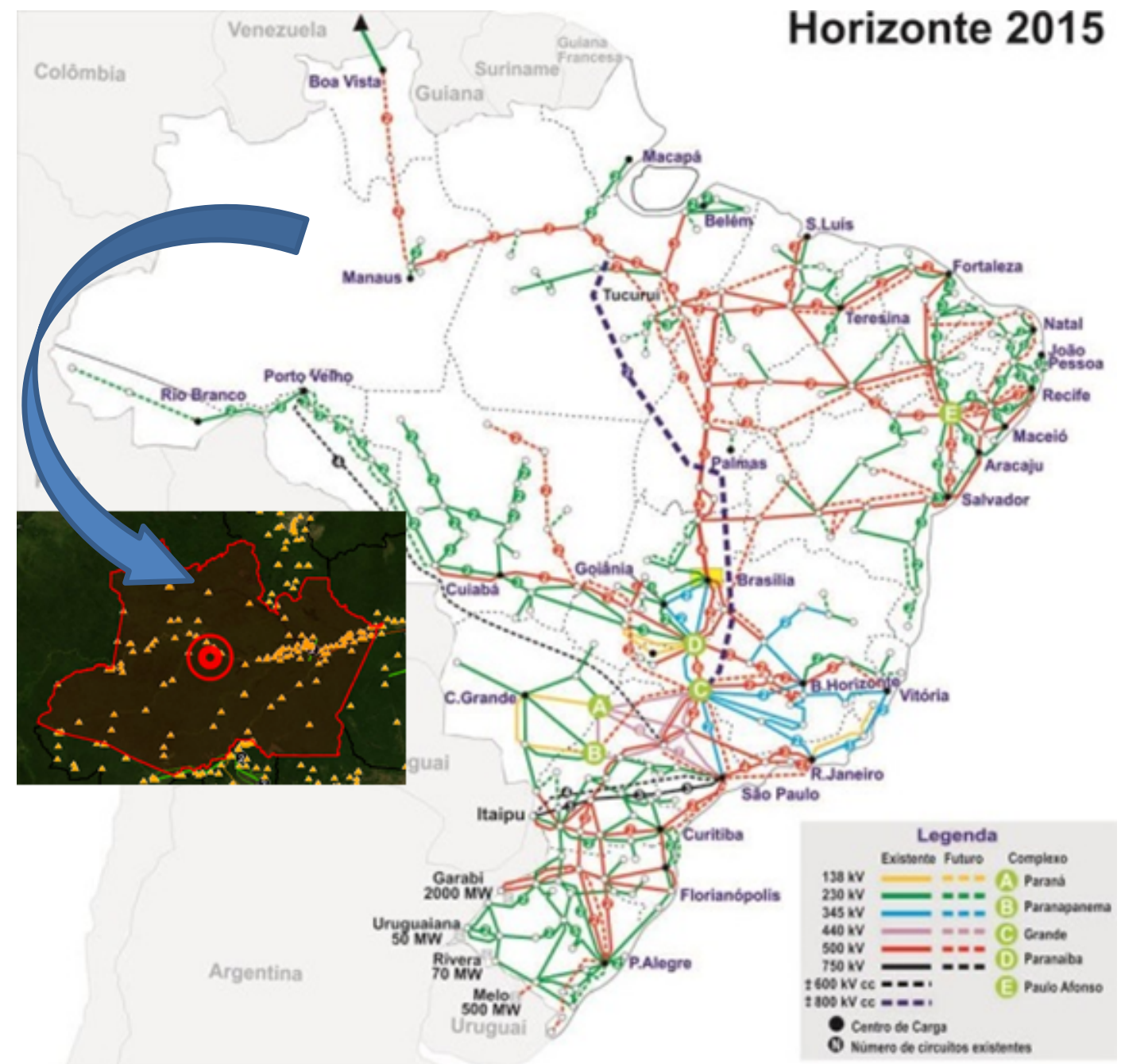

Figura 1 Sistema de transmissão de energia elétrica no Brasil e localização das termoelétricas no estado do Amazonas (ANEEL 2015) 
O detalhe da figura 1 mostra que a maior parte da Amazônia depende do consumo de diesel ou gás natural para a produção de eletricidade. Nas áreas onde estão instaladas estas termoelétricas possuem processos produtivos com geração de biomassa residual, que podem ser aproveitados para micro geração de eletricidade.

Entre alguns problemas relacionados à queima de combustíveis fósseis na Amazônia, está o fato dos insumos usados na produção de eletricidade não estarem relacionados à economia local. Com isso, os recursos financeiros necessários para atendimento da demanda e a pouca geração de empregos, podem gerar tensões econômicas e sociais graves. Do ponto de vista ambiental também existem impactos negativos, uma vez que um motor movido a diesel lança para a atmosfera cerca de 220 quilos de dióxido de carbono por hora por megawatt gerado. O lubrificante usado possui altos teores de metais pesados e o suprimento de diesel é transportado por via fluvial onde acidentes podem contaminar florestas e rios.

Com base neste contexto, o presente trabalho se propôs a analisar a viabilidade tecnológica da transformação de espécies de biomassa amazônica, em vetores energéticos. Foram analisados dois processos de transformação: a pirólise para obtenção de carvão, e a gaseificação da biomassa carbonizada para produção de gás de síntese. Adicionalmente investigou-se o uso dos finos de carvões arrastados, como um adsorvente, comparando-o aos carvões ativados quimicamente. As espécies escolhidas foram o epicarpo de Theobroma grandiflorum (cupuaçu) e os endocarpos do Astrocaryum aculeatum (tucumã) e da Acrocomia aculeata (macaúba).

\subsection{OBJETIVOS}

\subsubsection{Objetivo geral}

O objetivo geral deste trabalho é estudar a viabilidade tecnológica da conversão de três tipos de biomassa residual típicas da região amazônica, em recurso energético e em subprodutos com valor agregado. O diagrama apresentado na figura 2 , resume graficamente como os objetivos deste trabalho que vislumbram o uso da biomassa como recurso natural em sistemas isolados amazônicos. 


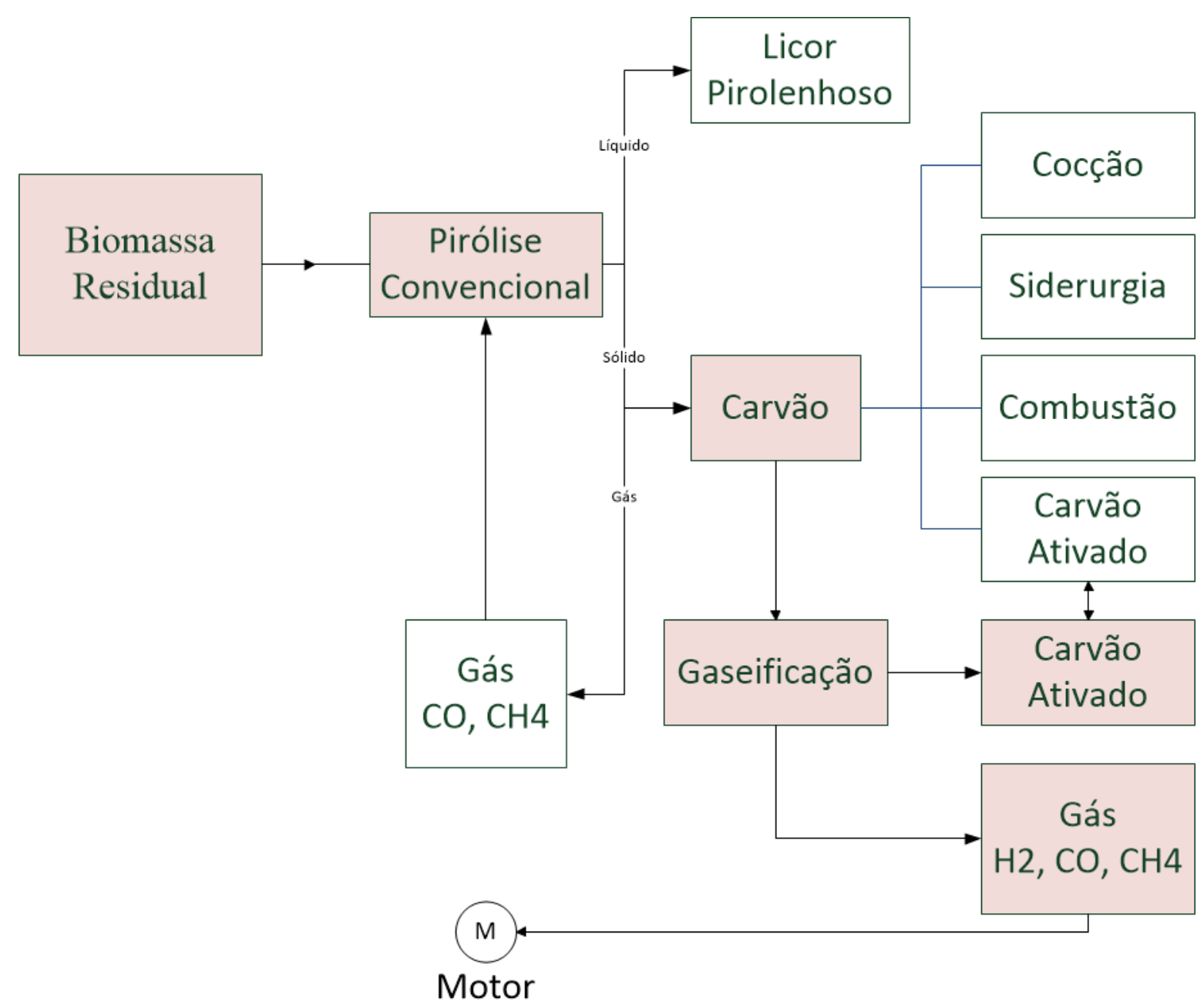

Figura 2 Representação gráfica do objetivo deste trabalho: Transformação de biomassa em derivados energéticos tais como gás de síntese isento de hidrocarbonetos pesados (alcatrões) e seu aproveitamento em motores de combustão interna (M) de grupo-geradores

\subsubsection{Objetivos específicos}

Os objetivos específicos deste trabalho são listados a seguir:

- Caracterizar as propriedades físico-químicas do epicarpo da fruta de T. grandiflorum e dos endocarpos das frutas de A. aculeatum e A. aculeata;

- Comparar as curvas de degradação térmica das amostras de biomassa, através de termogravimetria (TG);

- Obter os espectros de infravermelho dos gases gerados durante a pirólise das amostras de biomassa através de analisador simultâneo TG-FTIR;

- Caracterizar as propriedades físico-químicas da biomassa carbonizada;

- Calcular as concentrações dos constituintes do gás de síntese utilizando modelo de equilíbrio químico zero dimensional; 
- Comparar os resultados simulados numericamente para a gaseificação, com os resultados experimentais obtidos para as amostras;

- Comparar o estado de ativação dos finos de carvão arrastados durante a gaseificação com outros ativados quimicamente.

\subsection{ORGANIZAÇÃO DO TRABALHO}

Este trabalho está organizado em cinco capítulos, incluindo este introdutório. No capítulo dois, é apresentada uma visão geral do referencial teórico buscando apresentar o estado da arte para o assunto, a compreensão das tecnologias envolvidas. Este capítulo é dividido em três seções que abordam a tipificação dos tipos de biomassa estudados, a conversão da biomassa em energia e a ativação de carvão, com seus processos e propriedades.

O capítulo três detalha a metodologia utilizada. Neste capítulo são apresentados os materiais e os métodos utilizados para a obtenção dos resultados. Dividido em 4 seções, cada uma descrevendo o método experimental e analítico de um dos processos estudados: carbonização, gaseificação e ativação de carvão. O capítulo quatro apresenta os resultados obtidos em seis seções: caracterização da biomassa virgem, análise da degradação térmica, carbonização, gaseificação, ativação de carvão e geração de eletricidade. Por fim, no quinto capítulo são apresentadas as conclusões, seguidas pelas referências bibliográficas, pelos anexos e apêndices. 


\section{REVISÃO DA LITERATURA}

\subsection{TIPIFICAÇÃO DA BIOMASSA}

Astrocaryum aculeatum - Tucumã (Figura 3) é nativo do Amazonas, sendo comum em regiões descampadas, com solos pobres e degradados. Grande palmeira, estipe isolado, alcança de 10 a 15 metros de altura, sempre provida de espinhos longos e finos, dispostos na metade superior do tronco. Folhas com bainhas dilatadas, flores reunidas em inflorescência do tipo cacho, produz um fruto, tipo drupa, oval de casca alaranjada com polpa comestível, amarelada e oleosa. Seu fruto é muito apreciado pela população local, acompanhado de farinha de mandioca, sua polpa tem um sabor que lembra o do damasco, e são extremamente ricos em vitamina A. Sua frutificação ocorre de verão a outono e seus frutos podem ser consumidos na forma de sorvetes, doces e compotas bem como sob a forma de vinho de tucumã. Suas folhas, maceradas, fornecem uma fibra resistente utilizada no artesanato de malhadeiras e redes de dormir.

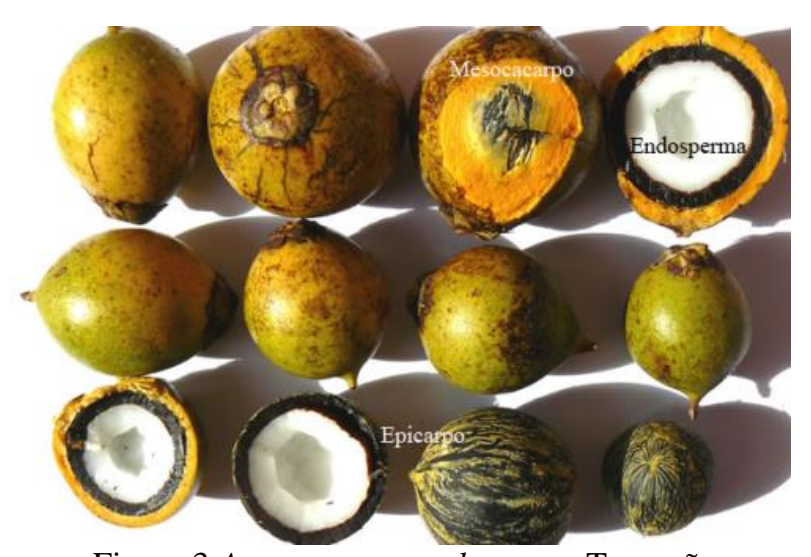

Figura 3 Astrocaryum aculeatum - Tucumã.

Explorada para uso do seu palmito e frutos comestíveis, o fruto do tucumã é composto por um caroço lenhoso de cor quase preta, que contém uma amêndoa de massa branca, oleaginosa, bastante dura e recoberta por uma polpa amarelo alaranjada, de pouca consistência. Dois tipos de óleos são produzidos por este fruto: o óleo da polpa externa (33\%) e o óleo da amêndoa (37\%). O primeiro com aplicações para óleos combustíveis e o segundo mais adequado para indústrias de cosméticos e produtos alimentícios (Lima et al., 1986). Os frutos do tucumã apresentaram diâmetros médios de 40,76mm, medido longitudinalmente e $34,72 \mathrm{~mm}$ medidos transversalmente. As espessuras médias da polpa, do endocarpo e da amêndoa foram de 4,64 mm, 3,02 mm e 8,56 mm, respectivamente. Peso médio de 30,44g com 61,3\% de mesocarpo e 38\% de endocarpo com endosperma (Souza et al., 2010). 
Caracterizado por (Lira et al., 2013) as sementes dos frutos de A. aculeatum apresentam as seguintes propriedades físicas e químicas: densidade de 1298,8 \pm $0,8 \mathrm{~kg} \mathrm{~m}^{-3}$, poder calorífico superior (PCS) de 21,08 $\pm 0,95 \mathrm{MJ} \mathrm{kg}^{-1}$, poder calorífico inferior (PCI) de 19,47 $\pm 0,31 \mathrm{MJ} \mathrm{kg}^{-1}$, na análise imediata o carbono fixo (base seca) de $18,67 \pm 0,24 \%$, voláteis de 69,35 $\pm 0,17 \%$, cinzas de 2,78 $\pm 0,21 \%$ e umidade de $9,2 \pm 0,1 \%$. Na análise elementar possui 54,87\% de carbono, 7,68\% de hidrogênio, 1,09\% de nitrogênio e 33,31\% de oxigênio. Na análise imediata do bio-óleo gerado por pirólise rápida encontrou $96,95 \%_{b s}$ de voláteis e $3,05 \%_{b s}$ de carbono fixo, não encontrando cinzas nas amostras. O pH médio do alcatrão foi de 2,66 o que representa sua caraterística ácida, na cromatografia de GC-MS do bio-óleo produzido a $550^{\circ} \mathrm{C}$, condição ótima do ponto de vista de energia, apresenta produtos típicos de pirólise incluindo furanos, fenóis, levoglucosano e alguns compostos ácidos de cadeia curta (ácido acético, ácido propanóico), o que é a causa de seu pH baixo.

Sua produtividade é de 20 ton $h \mathrm{a}^{-1}$ e no comércio anual é de cerca de 368 toneladas somente no comércio e feiras de Manaus, conforme avaliado por Didonet e Ferraz (2014), o que gera um resíduo de mais de 140 toneladas de caroços, que geralmente são descartados na natureza.

Acrocomia aculeata - Macaúba (Figura 4) é uma palmeira nativa das florestas tropicais da América do Sul. Uma grande quantidade de óleo é obtida a partir dos cocos dessa palmeira, com produtividade entre 1500 e $5000 \mathrm{~kg}$ de óleo por hectare por ano (Oliveira, 2008), que é a segunda maior produtividade após óleo de palma (Elaeis guineensis).

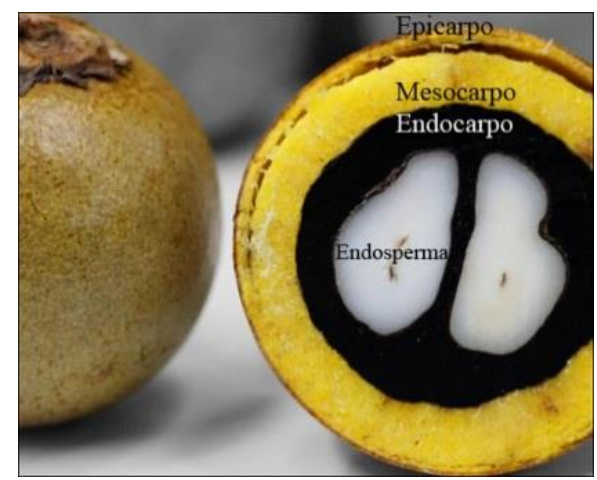

Figura 4 Acrocomia aculeata - Macaúba

A palmeira da A. aculeata atinge uma alta produtividade, após 4 anos de crescimento e mantem a produção de mais de 100 anos. Outras características importantes desta palmeira 
são a alta resistência a pragas e variações de temperatura e a capacidade de crescer em áreas de baixa precipitação (Motta et al., 2002; Andrade et al., 2006). Devido a estas características, a maioria das frutas processadas vem da atividade extrativista a partir de culturas não programadas de macaúba sem domesticação sistemática. Projeta-se que, se forem usadas técnicas de cultivo adequado associado a um processo eficiente para extração do óleo, a produtividade poderia facilmente chegar a $6000 \mathrm{~kg}$ de óleo por hectare (Andrade, 2006).

Vário autores (Andrade et al., 2006; Rodrigues, 2007; Coimbra e Jorge, 2011) caracterizaram a macaúba, descrevem os frutos formados por cerca de $20 \%$ de casca, $40 \%$ de polpa, $33 \%$ de endocarpo e $7 \%$ de amêndoa. Os teores de óleo são ligeiramente maiores na polpa (60\%), em relação à amêndoa (55\%) (Bhering, 2009). O óleo de macaúba não tem tradição como alimento, embora apresente um perfil de ácidos graxos comparável ao azeite de oliva com alto teor de compostos bioativos, como os carotenoides e tocoferóis.

No Brasil cerca de $80 \%$ do biodiesel é produzido a partir de óleo de soja (M.M.E., 2011), cujo preço atual é de cerca de US\$ 1.100 por tonelada, enquanto o preço do óleo de macaúba varia de US\$ 600 a US\$ 800 por tonelada (M.D.I.C., 2013), o que o habilita para a produção de biocombustível. Outro ponto favorável está no fato que o endocarpo da fruta é denso e rico em carbono, que lhe confere grande utilidade quando carbonizado.

Na caracterização da A. aculeata Silva et al. (1986) mediu a densidade do endocarpo com $1,161 \mathrm{~g} \mathrm{~cm}^{-3}$, ou seja, densidade maior que a madeira de eucalipto e do endocarpo de babaçu. Também apresenta $0,97 \%$ de cinzas, $36,6 \%$ de lignina, $10,8 \%$ de extrativos, $52,6 \%$ de hemicelulose. O rendimento gravimétrico da carbonização variando de 35,61 a 36,82\% com temperaturas variando entre 300 e $700{ }^{\circ} \mathrm{C}$ respectivamente, enquanto o percentual de líquido condensado, na mesma faixa de temperatura, variou entre 33,34 a 39\% com 22,42 a 24,74\% de gases incondensáveis. A densidade relativa do carvão ficou em $0,93 \mathrm{~g} . \mathrm{cm}^{-3}$ com porosidade de 26,84\%. Análise de CG-MS feiras por Fortes e Baugh (2004) apontam que a $700^{\circ} \mathrm{C}$, os principais produtos são aldeído, cicloalcano, alcenos e dienos que variam de 71 a $79 \%$ do total de produtos; os produtos secundários alquilbenzeno entre outros variam de 19 a $26 \%$ e os produtos restantes: alceno, alcano, cicloalceno de 3 a $4 \%$.

A produtividade da macaúba pode chegar a 30 ton $\mathrm{ha}^{-1}$ (Clement et al., 2005) o que representa um resíduo de 10 ton $h \mathrm{a}^{-1}$ de endocarpo. Considerando o alto rendimento da 
macaúba na produção óleos, o aproveitamento do resíduo na geração de eletricidade vem contribuir na redução de despesas no beneficiamento dos frutos.

Theobroma grandiflorum - Cupuaçu (Figura 5) espécie arbórea nativa da Amazônia ocidental muito apreciada pelas características organolépticas de sua polpa possui um grande potencial para indústria de alimentos na região. Originário das terras altas não inundáveis da floresta tropical úmida, onde as árvores mais altas proveem um sombreamento parcial. Atualmente seu cultivo no Brasil se estende desde São Paulo até o sul de Roraima. Outros países onde a T. gradiflorum é cultivada são: Equador, Guiana, Martinica, Costa Rica, São Tomé, Trinidad Tobago, Ghana, Venezuela, Peru e Colômbia (Müller et al., 1995).

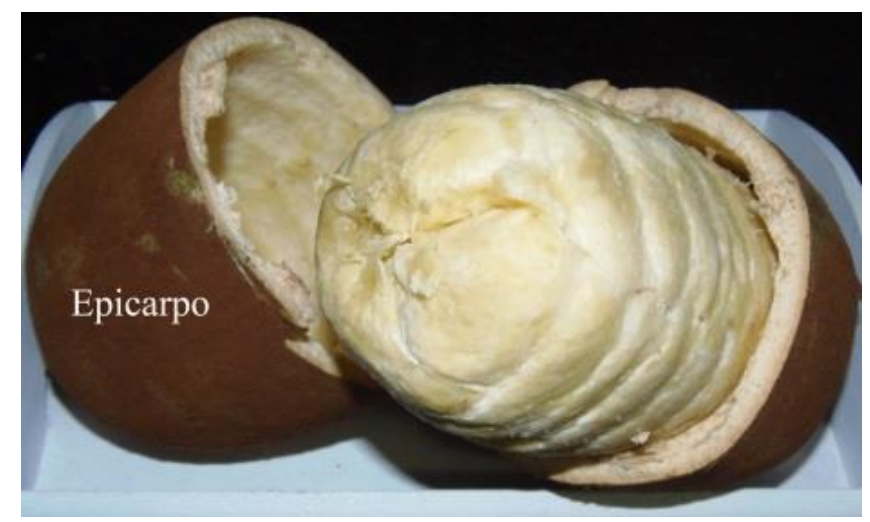

Figura 5 Theobroma grandiflorum - Cupuaçu

O seu fruto mede de 12 a $15 \mathrm{~cm}$ de comprimento e tem de 10 a $12 \mathrm{~cm}$ de diâmetro, apresentando em média peso de $1,5 \mathrm{~kg}$, sendo $43 \%$ de casca, $38,5 \%$ de polpa, $16 \%$ de sementes e $2,5 \%$ de placenta. O cupuaçu possui um epicarpo (casca) rígido e lenhoso de coloração ferruginosa de aproximadamente $5 \mathrm{~mm}$ de espessura. Em uma plantação típica, pode gerar até $22 t$ de casca por hectare, que normalmente é descartado de forma inadequada contribuindo para a proliferação de pragas e doenças típicas da cultura do cupuaçu. Atualmente seu cultivo possui significativa importância econômica para os estados da região norte, ganhando mercado nos grandes centros urbanos do Brasil. A polpa é acida, de cor amarela, branca, ou creme, de sabor agradável, sendo consumida, principalmente na forma de suco, picolé, creme, iogurte, doce entre outras iguarias. As sementes podem ser aproveitadas na fabricação de chocolate em pó e em tablete, são utilizadas também pela indústria de cosméticos na fabricação de cremes para pele (Suframa, 2003).

As áreas de maior concentração de produção de cupuaçu estão localizadas nos seguintes municípios: 
- No Amazonas: Itacoatiara, Manaus, Careiro, Presidente Figueiredo, Humaitá e Manacapuru;

- Em Rondônia: Porto Velho, Ariquemes, Rolim de Moura, Guajará-Mirim e JiParaná;

- Em Roraima: Caroebe e Rorainópolis;

- No Acre: Cruzeiro do Sul, Rio Branco, Xapuri, Brasiléia, Plácido de Castro e Senador Guiomaral.

Os Estados da Amazônia Ocidental possuem extensas áreas aptas ao cultivo da fruta do ponto de vista edafoclimático. No entanto, dadas as condições de perecibilidade do fruto, e necessidade de processamento o mais rápido possível, torna-se muito importante considerar aspectos como proximidade do mercado e facilidade de transporte da produção, para o plantio comercial dessa frutífera. No caso da agroindústria, deve-se procurar localização em áreas que concentram a produção da matéria-prima e tenham infraestrutura adequada como energia elétrica, estradas bem conservadas, etc.

A demanda crescente pelo cupuaçu e seus derivados pressionam a elevação do seu preço, o que reflete em uma necessidade crescente da implantação de agroindústrias especializadas.

De forma a simplificar a apresentação da biomassa, seus produtos e subprodutos a nomenclatura utilizada a partir deste ponto será conforme descrito na tabela 1 a seguir:

Tabela 1 Nomenclatura da biomassa utilizada neste trabalho

\begin{tabular}{|l|l|}
\hline Endocarpo da fruta do Astrocaryum aculeatum - Tucumã & EFT \\
\hline Carvão do endocarpo da fruta do A. aculeatum - Tucumã & CEFT \\
\hline Carvão ativado do endocarpo da fruta do A. aculeatum - Tucumã & CAEFT \\
\hline Gás do carvão do endocarpo da fruta do A. aculeatum - Tucumã & GCEFT \\
\hline Licor pirolenhoso do endocarpo da fruta do A. aculeatum - Tucumã & ACEFT \\
\hline Endocarpo da fruta do Acrocomia aculeata - Macaúba & EFM \\
\hline Carvão do endocarpo da fruta do A. aculeata - Macaúba & CEFM \\
\hline Carvão ativado do endocarpo da fruta do A. aculeata - Macaúba & CAEFM \\
\hline Gás do carvão do endocarpo da fruta do A. aculeata - Macaúba & GCEFM \\
\hline Licor pirolenhoso do endocarpo da fruta do A. aculeata - Macaúba & ACEFM \\
\hline Epicarpo da fruta do Theobroma grandiflorum - Cupuaçu & EFC \\
\hline Carvão do epicarpo da fruta do T. grandiflorum - Cupuaçu & CEFC \\
\hline Carvão ativado do epicarpo da fruta do T. grandiflorum - Cupuaçu & CAEFC \\
\hline Gás do carvão do epicarpo da fruta do $T$. grandiflorum - Cupuaçu & GCEFC \\
\hline Licor pirolenhoso do epicarpo da fruta do T. grandiflorum - Cupuaçu & ACEFC \\
\hline
\end{tabular}




\subsection{CONVERSÃO DE BIOMASSA EM ENERGIA}

De uma forma geral é possível representar uma biomassa através da análise elementar: carbono, hidrogênio e oxigênio, os quais combinados formam a celulose, a hemicelulose e a lignina. Saber quanto de cada constituinte está presente na fonte energética, significa conhecer o quanto de energia está disponível para conversão, uma vez que o poder calorífico é função da quantidade desses elementos na biomassa. Duas rotas são comumente aplicadas para esta conversão: rota termoquímica ou a rota bioquímica, a rota termoquímica será a estudada neste trabalho, mais especificamente os processos de pirólise e gaseificação serão mais aprofundados.

A quantificação da quantidade de energia contida no combustível é a etapa inicial para o dimensionamento de um sistema de potência por combustão ou gaseificação. Para tanto Netto et al. (2006), apresentou um estudo com 43 tipos de biomassa sólida produzidas no Amazonas, encontrando poder calorífico superior (PCS) entre 16,60 e 22,80 $\mathrm{MJ} \mathrm{kg}^{-1}$, com carbono fixo variando entre 9,05 e $24,67 \%$, voláteis entre 70,01 e 93,87\%, cinzas entre 0,0002 e 9,9105\% enquanto a densidade a granel variou entre 200 e $373 \mathrm{~kg} \mathrm{~m}^{-3}$. Também Seye et al. (2000), utilizaram complementarmente à determinação do PCS, a análise elementar, a análise imediata e a análise termogravimétrica para caracterizar três tipos de biomassa realizando assim uma avaliação comparativa entre elas, indicando quais podem servir como insumo na produção de carvão vegetal, e quais podem servir para produzir bio-óleo. Outros autores (Várhegyi et al., 1997; Quirino, 2000; Resende, 2003; Riegel et al., 2008), apresentaram trabalhos relacionados à análise da degradação térmica de biomassa variando as taxas de aquecimento. Como resultados obtiveram a influência da taxa de aquecimento na cinética de decomposição das amostras, bem como modelos matemáticos para predizer o comportamento cinético da biomassa quando degradada. Desta forma é possível prever o poder calorífico dos gases gerados.

De forma análoga, a previsibilidade do poder calorífico da biomassa é relevante para projetos de sistemas ou flexibilização de combustíveis. Demirbas e Demirbas (2004) caracterizaram 16 amostras diferentes por análise imediata e elementar, que determinam o PCS baseado na quantidade de carbono ou de carbono (C) e hidrogênio (H),

$$
P C S=0,3699(C)+1,3178 \quad[M J / k g],
$$




$$
P C S=0,3856(C+H)-1,6938 \quad[M J / k g] .
$$

Da mesma forma Parikh et al. (2005), utilizando os mesmos tipos de análises, propõe empiricamente a equação

$$
P C S=0,3536(C F)+0,1559(\mathrm{Vol})-0,0078(\mathrm{Cz}) \quad[\mathrm{MJ} / \mathrm{kg}],
$$

que relaciona carbono fixo $(\mathrm{CF})$, voláteis $(\mathrm{Vol})$ e cinzas $(\mathrm{Cz})$ com o PCS. Enquanto Friedl et al. (2005), aprimoram o modelo através dos resultados de análises elementares chegando na equação 4 , utilizando além do carbono $(\mathrm{C})$ e do hidrogênio $(\mathrm{H})$ a quantidade de nitrogênio $(\mathrm{N})$ presentes na biomassa

$$
P C S=3,55 C^{2}-232 C-2230 H+51,2(C \times H)+131 N+20600 \quad[k J / k g] .
$$

Do ponto de vista econômico, estudos com o uso de endocarpo de açaí e com material lenhoso carregado pelos rios amazônicos, apontam como viável o processo de gaseificação e sua queima em modo duplo combustível para geração de eletricidade. Com enorme potencial gerador de emprego e renda para a região e também como facilitador de uma operação obrigatória para a manutenção da navegação local (Bacellar e Rocha, 2010).

\subsubsection{Produção de carvão vegetal}

O carvão vegetal é obtido pela pirólise lenta da biomassa. A pirólise é a degradação térmica na completa ausência de agente oxidante, ou com um fornecimento limitado de oxigênio de forma que a gaseificação não ocorra em grande quantidade. Este processo é feito em temperaturas relativamente baixas, em torno de $400 a 800^{\circ} \mathrm{C}$, em comparação aos $800 a 1100{ }^{\circ} \mathrm{C}$ empregados na gaseificação (Bridgwater e Bridge, 1991). Três produtos são normalmente obtidos: gás, licor pirolenhoso e carvão vegetal em proporções relativas que dependem do método de pirólise e os parâmetros de reação. Pirólise rápida, por exemplo, é utilizada para maximizar a produção de produtos líquidos de acordo com a temperatura utilizada, enquanto que a pirólise lenta é conhecida como carbonização (Figura 6) e é utilizada para maximizar a produção de carvão sólido. 


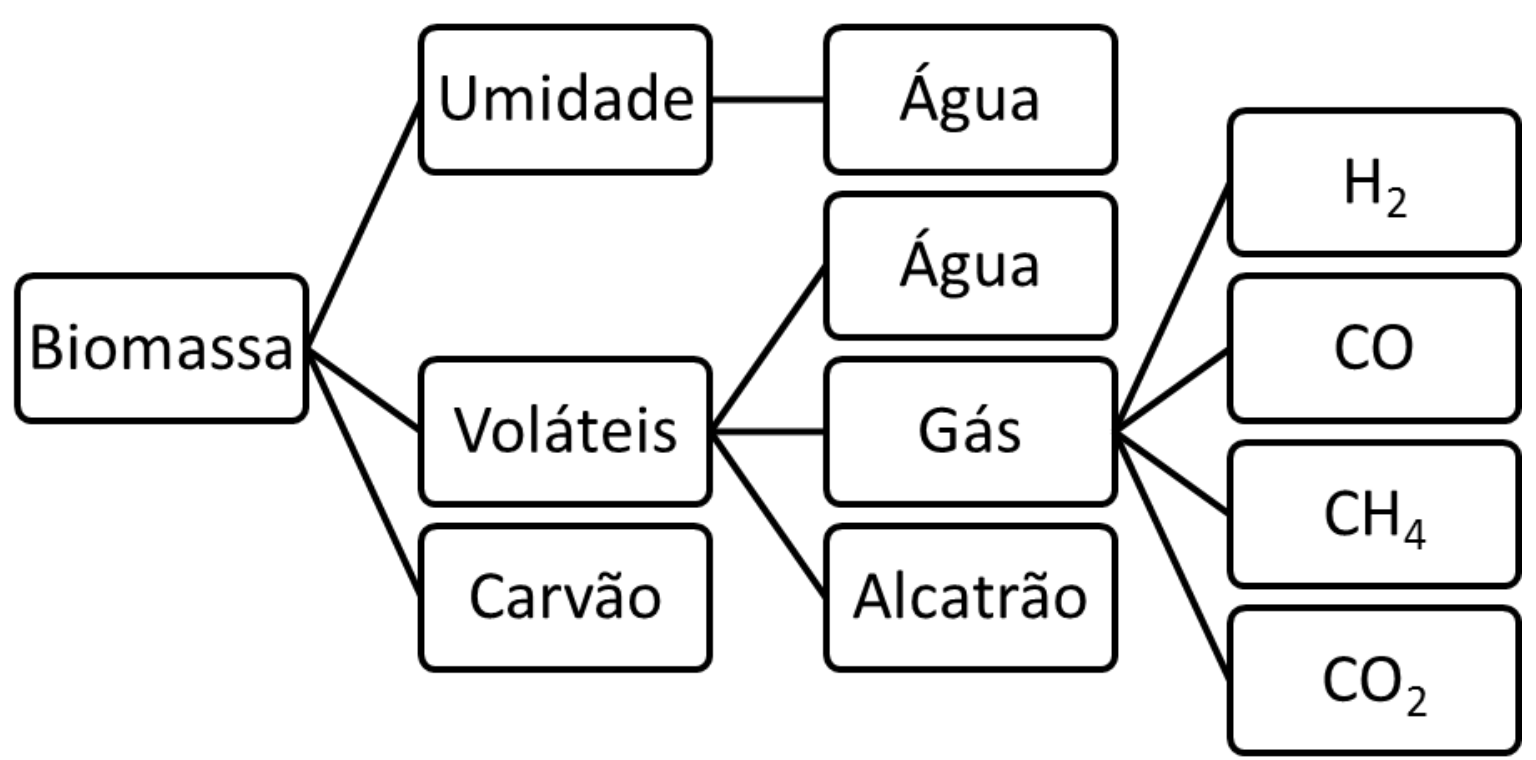

Figura 6 Carbonização da biomassa e seus produtos

A carbonização de biomassa envolve fenômenos complexos que geram uma grande variedade de compostos químicos. As frações mássicas, em base seca, dos principais produtos oriundos da pirólise lenta de madeiras obtidas na ausência de oxigênio e usando aquecimento externo são: $33 \%$ de carvão, 35,5\% de licor pirolenhoso, 6,5\% de alcatrão insolúvel e 25\% de gases. Dos componentes do licor pirolenhoso destacam-se o ácido acético (0,5\%), metanol (0,2\%), alcatrão solúvel (5,0\%) e água (23,5\%) enquanto que entre os componentes dos gases estão presentes o hidrogênio (0,16\%), $\mathrm{CO}(8,5 \%), \mathrm{CO}_{2}(15,5 \%)$, $\mathrm{CH}_{4}(0,61 \%)$, etano $(0,03 \%)$ e outros gases $(0,2 \%)$ (Oliveira et al., 2013). Os fenômenos que acontecem durante a carbonização podem ser agrupados em estágios segundo a temperatura, conforme descrito em quatro fases por De Oliveira Vilela et al. (2014):

1. Até $200^{\circ} \mathrm{C}$ há a produção de gases como vapor de água, $\mathrm{CO}_{2}$, ácido fórmico e ácido acético. Nesta fase ocorre a secagem e é regida tipicamente por reações endotérmicas.

2. Entre 200 e $280{ }^{\circ} \mathrm{C}$ além da emissão de vapor de água, $\mathrm{CO}_{2}$, ácido fórmico e ácido acético, inicia-se a emissão de CO e há uma redução na emissão de vapor de água. Nesta região as reações também são endotérmicas e caracteriza-se degradação das hemiceluloses.

3. Entre 280 e $400{ }^{\circ} \mathrm{C}$ a carbonização ocorre por reações exotérmicas e os produtos formados incluem gases combustíveis, alcatrão, $\mathrm{CO}$ e $\mathrm{CH}_{4}$. Caracterizada pela degradação da celulose 
4. Entre 400 e $470^{\circ} \mathrm{C}$ fase exotérmica onde ocorre a redução da emissão de gases e o aumento da concentração de carbono no carvão.

Já o modelo apresentado por Kanury e Blackshear Jr (1970), apresenta a carbonização dividida em cinco períodos em função do tempo de exposição ao calor, desde o material virgem até o processado, ou seja, carvão:

Período I - nessa fase o calor se propaga na madeira por condução. A madeira não sofre qualquer alteração, havendo apenas a liberação de água.

Período II - a madeira começa a sofrer as primeiras alterações, formando o que se denomina "Frente da Pirólise". Nessa fase se distingue dois estágios: um correspondente a zona de pirólise e outro em que a madeira continua aquecendo. Os gases quentes formados nessa zona transportam o calor para o exterior da madeira por convecção.

Período III - inicia-se a formação do carvão, existindo ainda uma camada interna de material não carbonizado. A transferência de calor na zona do carvão se processa através de condução e convecção, enquanto outros fenômenos ocorrem nessa zona. Os gases pesados sofrem uma decomposição catalisada pelo leito do carvão quente, enquanto os gases leves ao passarem para o exterior podem encontrar oxigênio da atmosfera, produzindo uma reação de combustão (reação exotérmica), fornecendo energia na superfície do carvão.

Período IV - essa fase é caracterizada pelo desaparecimento da madeira em seu estado original. A zona do carvão é predominante, restando apenas uma parte, da zona da pirólise.

Período V - corresponde a última fase da carbonização formada por uma única camada, a do carvão vegetal.

Modelos matemáticos (Kanury e Blackshear Jr, 1970; Kung, 1972; Kung e Kalelkar, 1973) permitem calcular a velocidade da frente de pirólise em madeiras, estes modelos são baseados na transferência de calor através do carvão formado até a área ativa do material. A imagem da figura 5 ilustra como se dá a penetração da frente de pirólise através do material durante a carbonização. Di Blasi (2008) relata o estado da arte em modelagem de processos químicos e físicos da pirólise de biomassa. Nesta revisão são abordadas questões relativas à cinética química, seus mecanismos e os modelos de energia de ativação que tentam explicar a formação de um único gasoso ou espécies líquidas (alcatrão). Silva et al. (2007) fez a caracterização físico química de carvões, medindo o rendimento gravimétrico, densidade 
aparente, poder calorífico superior e teores de carbono fixo, materiais voláteis e cinzas. Este autor constatou que a temperatura final de carbonização é o fator mais influente, e que o rendimento gravimétrico e o teor de carbono fixo aumentam com o aumento da temperatura final, a densidade e o teor de cinzas variam pouco com a variação de tempo e temperatura.

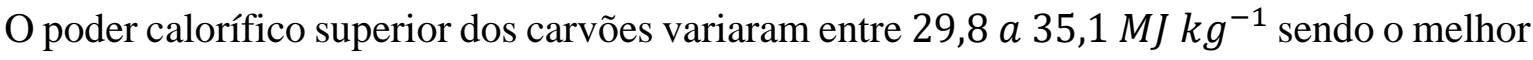
resultado obtido a $600{ }^{\circ} \mathrm{C}$ independente da espécie e do tempo de permanência.

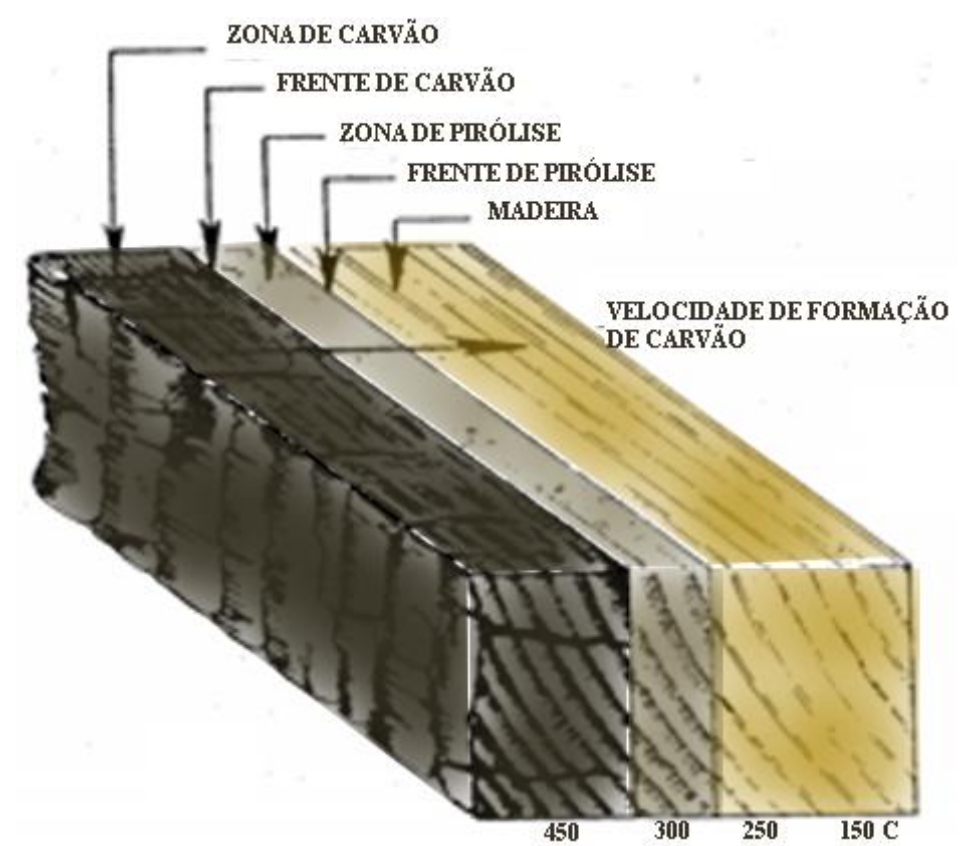

Figura 7 Frente de pirólise - modelo de Holmes (1977)

O processo de pirólise é caracterizado pela formação de camadas (Figura 7), que são impedidas pela formação de um isolante térmico - o carvão. Além disso os voláteis fluindo para fora da biomassa transportam calor de volta para a superfície, o que dificulta ainda mais o processo da pirólise. Por outro lado, com o passar do tempo a parte interna da biomassa recebe um pré-aquecimento considerável a ponto de aumentar a velocidade da frente de pirólise. Vários autores (Kung, 1972; Kung e Kalelkar, 1973; Di Blasi, 2008; White et al., 2011; Lam et al., 2012; Borello et al., 2014; Urych, 2014), estudaram modelos matemáticos capazes de prever o tempo de decaimento da densidade do material em função da temperatura. Neste trabalho utiliza-se o modelo de Kung e Kalelkar (1973) e seus resultados de forma a estimar o tempo de permanência na temperatura de carbonização, que serão apresentados com maior detalhe no capítulo 3.

Do ponto de vista termoquímico, Gurgel Veras et al. (1999) apresentaram um modelo de percolação química com objetivo de determinar os produtos da pirólise de partículas de carvão, inclusive sobre a influência de campos acústicos de alta intensidade. O modelo 
permitiu a cálculo da evolução dinâmica de $\mathrm{CO}, \mathrm{CO}_{2}, \mathrm{CH}_{4}, \mathrm{H}_{2} \mathrm{O}$, outros gases leves e alcatrão, importantes no processo de ignição e estabilização de chamas. Em adição o modelo também forneceu a quantidade e forma dos compostos nitrogenados liberados na pirólise, o que é importante no estabelecimento de estratégias de redução de emissões de $\mathrm{NO}_{\mathrm{x}}$. Também Gurgel Veras et al. (1998) apresentam evidências teóricas e experimentais de que o tempo de combustão de uma partícula de carvão nem sempre aumenta com o seu tamanho para condições ambientais constantes.

\subsubsection{Caracterização da biomassa carbonizada}

A análise imediata do carvão vegetal é comumente empregada para fornecer a qualidade dessa biomassa para fins energéticos, esta consiste em determinar os teores de umidade, de cinzas, de voláteis e de carbono fixo. Esta análise é normatizada pela norma a Norma NBR 8112/1986.

O controle de umidade da biomassa a ser utilizada é imprescindível para não gerar carvões friáveis e agregar maior valor comercial ao material combustível, já que ao ser liberada, a elevada quantidade de vapor d'água propicia um aumento da pressão nos poros, resultando em carvões extremamente quebradiços. O processo de evaporação da umidade absorve energia em combustão e, com isso, reduz o poder de combustão da madeira (De Assis et al., 2012). Denomina-se teor de cinza, ou teor de minerais, o material residual inorgânico da completa combustão do carvão vegetal. A cinza residual nas fornalhas das indústrias é indesejável, pois, além de reduzir o poder calorífico do carvão, enseja limpezas frequentes, podendo provocar corrosão nos equipamentos metálicos e comprometer a qualidade do ferro-gusa devido ao fenômeno da segregação. O teor de cinzas da madeira corresponde, geralmente, a menos de $1 \%$ bs e é influenciada pela idade do indivíduo (Machado et al., 2014), com o aumento da idade, há forte tendência de redução do nível de minerais na biomassa virgem e, consequentemente, no carvão. Além disso, as diferentes técnicas de plantio associadas aos inúmeros insumos empregados podem influenciar no teor de cinza da madeira e do carvão.

A matéria volátil propriamente dita não inclui a umidade livre e é composta pela água derivada da decomposição química do carvão e pela complexa mistura de gases combustíveis liberados durante o aquecimento (Paulucio, 2013). O teor de matéria volátil é o responsável pela estabilidade da chama e pela velocidade da combustão, pois dele decorre o aumento da permeabilidade e a diminuição da reatividade do carvão em alto-forno. $\mathrm{O}$ 
carbono fixo, por sua vez, é o combustível residual da liberação do material volátil e resumese, principalmente, a carbono, embora se possam observar alguns elementos voláteis não liberados. Ao analisar a aplicação, conclui-se que carvões com maiores percentuais de carbono fixo proporcionam maior produtividade por unidade de massa, por outro lado, índices muito elevados de carbono fixo causam maior degradação térmica, reduzindo consequentemente, a resistência mecânica do material combustível.

\subsubsection{Gaseificação de biomassa}

A gaseificação é a oxidação térmica parcial, que resulta numa alta proporção de produtos gasosos $\left(\mathrm{CO}_{2}, \mathrm{H}_{2} \mathrm{O}, \mathrm{CO}, \mathrm{H}_{2}\right.$ e hidrocarbonetos gasosos), pequenas quantidades de carvão, cinzas e compostos condensáveis (alcatrão e óleos). Os agentes gaseificantes fornecidos para a reação podem ser ar, vapor em estado superaquecido ou oxigênio. O gás produzido pode ser convertido em produtos comercializáveis e desta forma tem uma maior versatilidade de uso do que a biomassa de origem. Estes processos termoquímicos são complexos e envolvem várias reações químicas, processos de transferência de calor e massa e exigem um controle da quantidade de calor dissipada pelo sistema, de forma a obter uma maior eficiência energética de conversão. O tipo de agente gaseificante e a temperatura da reação, também influencia na qualidade do gás de síntese obtido, devendo ser estes parâmetros acompanhados com cuidado pelo projetista (Basu, 2010; Puig-Arnavat et al., 2010; Basu, 2013b).

O processo de gaseificação pode ser dividido em 4 etapas: secagem, pirólise, oxidação e redução. Cada etapa pode ser modelada com base na cinética química das reações, gerando modelos que ajudam os projetistas a preverem seus resultados (Mckendry, 2002a; Ratnadhariya e Channiwala, 2009), cada etapa pode ser modelada por zonas de reação como se segue:

1. Aquecimento e Secagem da biomassa: Nesta fase, o teor de umidade da biomassa que varia de 5 a $35 \%$ é reduzido.

2. Pirólise da biomassa (devolatilização): Esta fase consiste na decomposição térmica da biomassa, na ausência de oxigênio ou ar. Neste processo, o material volátil da biomassa é reduzido e isto resulta na liberação de gases. Estes hidrocarbonetos gasosos podem condensar a uma temperatura suficientemente baixa para gerar alcatrões líquidos. Nesta etapa ocorre a decomposição dos carboidratos tais como a hemicelulose, celulose e lignina 
a partir dos $200^{\circ} \mathrm{C}$. Os produtos dessas etapas são: Gases condensáveis, Gases não condensáveis $\left(\mathrm{CO}, \mathrm{CO}_{2}, \mathrm{H}_{2}, \mathrm{CH}_{4}\right)$ e Carvão vegetal.

3. Oxidação: Esta é uma reação entre a biomassa carbonizada sólida e o oxigênio, o que resulta na formação de $\mathrm{CO}_{2}$. O hidrogênio presente na biomassa também é oxidado para gerar água.

4. Redução: Na ausência (ou presença estequiométrica) de oxigênio, várias reações de redução ocorrem numa faixa de temperatura de 800 a $1.100{ }^{\circ} \mathrm{C}$. Estas reações são na sua maioria endotérmicas.

Vários autores (Di Lascio e Fagundes Barreto, 2009; Basu, 2010; Puig-Arnavat et al., 2010; Higman e Van Der Burgt, 2011; Basu, 2013a) apresentam as principais reações divididas em heterogêneas (sólido - gás) e homogêneas (gás - gás) que são descritas nas equações 5 a 21, a seguir:

\section{Reações heterogêneas (sólido - gás)}

$$
\begin{aligned}
& \text { Oxidação do carbono } \\
& \mathrm{C}+\frac{1}{2} \mathrm{O}_{2} \rightarrow \mathrm{CO} \quad \Delta H=-110,6 \mathrm{~kJ} . \mathrm{mol}^{-1} \\
& \mathrm{C}+\mathrm{O}_{2} \rightarrow \mathrm{CO}_{2} \quad \Delta \mathrm{H}=-393,8{\mathrm{~kJ} . \mathrm{mol}^{-1}}^{-1} \\
& \text { Reação de Boudouard } \\
& \mathrm{C}+\mathrm{CO}_{2} \rightarrow 2 \mathrm{CO} \quad \Delta \mathrm{H}=+172,6{\mathrm{~kJ} . \mathrm{mol}^{-1}}^{-1} \\
& \text { Reação de carbono-água } \\
& \mathrm{C}+\mathrm{H}_{2} \mathrm{O} \rightarrow \mathrm{CO}+\mathrm{H}_{2} \quad \Delta \mathrm{H}=+131,4{\mathrm{~kJ} . \mathrm{mol}^{-1}}^{-1} \\
& \mathrm{C}+2 \mathrm{H}_{2} \mathrm{O} \rightarrow \mathrm{CO}_{2}+2 \mathrm{H}_{2} \Delta \mathrm{H}=+96,0{\mathrm{~kJ} . \mathrm{mol}^{-1}}^{-1} \\
& \text { Formação do metano } \\
& \mathrm{C}+2 \mathrm{H}_{2} \rightarrow \mathrm{CH}_{4} \Delta \mathrm{H}=-74,9{\mathrm{~kJ} . \mathrm{mol}^{-1}}^{-1} \\
& \mathrm{C}+\frac{2}{3} \mathrm{H}_{2} \mathrm{O} \rightarrow \frac{1}{3} \mathrm{CH}_{4}+\frac{2}{3} \mathrm{CO} \Delta \mathrm{H}=+62,0{\mathrm{~kJ} . \mathrm{mol}^{-1}}^{-1} \\
& \mathrm{C}+\mathrm{H}_{2} \mathrm{O} \rightarrow \frac{1}{2} \mathrm{CH}_{4}+\frac{1}{2} \mathrm{CO}_{2} \quad \Delta \mathrm{H}=+6,0{\mathrm{~kJ} . \mathrm{mol}^{-1}}^{-1}
\end{aligned}
$$

Reações homogêneas (gás - gás)

$$
\begin{gathered}
\text { Oxidação do hidrogênio } \\
2 \mathrm{H}_{2}+\mathrm{O}_{2} \rightarrow 2 \mathrm{H}_{2} \mathrm{O} \quad \Delta \mathrm{H}=-286 \mathrm{~kJ} . \mathrm{mol}^{-1} \\
\text { Reação de shift } \\
\mathrm{CO}+\mathrm{H}_{2} \mathrm{O} \rightarrow \mathrm{CO}_{2}+\mathrm{H}_{2} \quad \Delta H=-38,0 \mathrm{~kJ} . \mathrm{mol}^{-1}
\end{gathered}
$$




$$
\begin{aligned}
& \text { Metano - água } \\
& \mathrm{CH}_{4}+\mathrm{H}_{2} \mathrm{O} \rightarrow \mathrm{CO}_{2}+3 \mathrm{H}_{2} \quad \Delta \mathrm{H}=+201,9 \mathrm{~kJ} \cdot \mathrm{mol}^{-1} \\
& \text { Monóxido de carbono - oxigênio }
\end{aligned}
$$

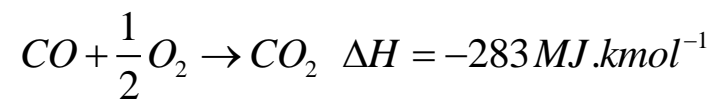

$$
\begin{aligned}
& 2 \mathrm{CO}+2 \mathrm{H}_{2} \rightarrow \mathrm{CH}_{4}+\mathrm{CO}_{2} \quad \Delta \mathrm{H}=-247,3{\mathrm{MJ} . \mathrm{kmol}^{-1}}^{-1}
\end{aligned}
$$

Formação do metano

$$
\begin{gathered}
\mathrm{CO}_{2}+3 \mathrm{H}_{2} \rightarrow \mathrm{CH}_{4}+\mathrm{H}_{2} \mathrm{O}-206 \mathrm{~kJ} / \mathrm{mol} \\
\mathrm{CO}_{2}+4 \mathrm{H}_{2} \rightarrow \mathrm{CH}_{4}+2 \mathrm{H}_{2} \mathrm{O}-165 \mathrm{~kJ} / \mathrm{mol} \\
\text { Craqueamento do alcatrão } \\
\text { Alcatrão }+ \text { Vapor }+ \text { Calor } \rightarrow \mathrm{CO}_{2}+\mathrm{CO}+\mathrm{CH}_{4}+\ldots \\
\frac{1}{3}\left(\mathrm{CO}+\mathrm{H}_{2}+\mathrm{CH}_{4}\right)+\mathrm{O}_{2} \rightarrow \frac{2}{3} \mathrm{CO}_{2}+\mathrm{H}_{2} \mathrm{O}
\end{gathered}
$$

As reações 15 e 16 são fortemente exotérmicas e rápidas, podem ser consideradas irreversíveis nas temperaturas normais de gaseificação, ou seja, entre $750^{\circ} \mathrm{C}$ e $1000^{\circ} \mathrm{C}$. A reação 20, também exotérmica, juntamente com as reações 15 e 16 fornecem o calor necessário para as reações endotérmicas 17 e 18, sendo estas as reações mais frequentes no reator. Entre $800^{\circ} \mathrm{C}$ a $900^{\circ} \mathrm{C}$ a reação de Boudouard (17) é a mais importante, ocorrendo em todo leito ao contrário das reações 15 e 16 que só ocorrem nas regiões onde há presença de oxigênio, ou seja, nas proximidades dos distribuidores de ar. Para reatores em leito fluidizado, não se observam zonas separadas para pirólise, oxidação e redução - todas as reações acontecem em todo o volume do leito simultaneamente.

As reações de gaseificação são afetadas por diversos fatores como temperatura, pressão, características do combustível e teor de oxigênio no agente gaseificante. A constante de equilíbrio $k_{p}$ é influenciada pela temperatura ao ponto de aumentar as concentrações de $\mathrm{H}_{2}$ e $\mathrm{CO}$ enquanto existe um decréscimo da concentração de $\mathrm{CO}_{2}$, para aumento de temperatura até $900^{\circ} \mathrm{C}$, conforme mostrado na tabela 2 . O ar é um agente gaseificante barato e amplamente utilizado, porém contém uma grande quantidade de nitrogênio, o que reduz o poder calorífico do gás de síntese produzido. $\mathrm{Se}_{2} \mathrm{O}_{2}$ puro é usado em seu lugar, o poder calorífico do gás síntese irá aumentar, mas os custos de operação também aumentarão muito, devido aos custos de produção do $\mathrm{O}_{2}$ (Basu, 2006). 
Tabela 2 Constantes de equilíbrio para reações de carbono-água, Boudouard e formação do metano. Fonte: (Basu, 2006).

\begin{tabular}{|l|c|c|c|}
\hline Temperatura $(\mathrm{K})$ & $\mathrm{K}_{\mathrm{p}}($ Equação 18) & $\mathrm{K}_{\mathrm{p}}($ Equação 17) & $\mathrm{K}_{\mathrm{p}}($ Equação 28) \\
\hline 400 & $7,709 \times 10^{-11}$ & $5,225 \times 10^{-14}$ & $2,989 \times 10^{5}$ \\
\hline 600 & $5,058 \times 10^{-5}$ & $1,870 \times 10^{-6}$ & $9,235 \times 10^{1}$ \\
\hline 800 & $4,406 \times 10^{-2}$ & $1,090 \times 10^{-2}$ & $1,339 \times 10^{0}$ \\
\hline 1000 & $2,617 \times 10^{0}$ & $1,900 \times 10^{0}$ & $9,632 \times 10^{-2}$ \\
\hline 1500 & $6,081 \times 10^{2}$ & $1,622 \times 10^{3}$ & $2,505 \times 10^{-3}$ \\
\hline
\end{tabular}

Valores típicos da composição do gás produzido são da ordem de $22 \%$ (vol. bs) de CO, $10,2 \%$ (vol. bs) de $\mathrm{CO}_{2}, 15,2 \%$ (vol. bs) de $\mathrm{H}_{2}, 1,7 \%$ (vol. bs) de $\mathrm{CH}_{4}$ e $50,8 \%$ (vol. bs) de $\mathrm{N}_{2}$. O poder calorífico do gás varia entre 4,9 $\mathrm{MJ} \mathrm{Nm}^{-3}$ a 7,3 $\mathrm{MJ} \mathrm{Nm}^{-3}$ que dependem da perda de calor no reator, da umidade do combustível e do arraste de carbono. O poder calorífico pode ser calculado usando as concentrações volumétricas de cada componente multiplicados, respectivamente pelos seus poderes caloríficos, sendo $12,11 \mathrm{MJ} \mathrm{Nm}^{-3}$ do hidrogênio, $11,97 \mathrm{MJ} \mathrm{Nm}^{-3}$ do $\mathrm{CO}$ e 37,72 $\mathrm{MJ} \mathrm{Nm}^{-3}$ do $\mathrm{CH}_{4}$. A razão de equivalência típica para a gaseificação é 2,38 [ $\left.k g_{c o m b} k g_{a r}^{-1}\right]$ (Reed et al., 1988).

O poder calorífico do gás combustível formado em processos de gaseificação com ar é significativamente afetado pela presença de nitrogênio $\left(\mathrm{N}_{2}\right)$. Na Tabela 3 são fornecidos os valores médios do poder calorífico do gás combustível, para processos conduzidos com ar, oxigênio puro e vapor de água, como agentes de gaseificação.

Tabela 3 Poder calorífico dos processos de gaseificação Fonte: (Belgiorno et al., 2003)

\begin{tabular}{|l|l|l|}
\hline Processo & Agente Gaseificação & PCS $\left(\mathrm{MJ} \mathrm{Nm}^{-3}\right)$ \\
\hline Gaseificação direta & Ar & $4-7$ \\
\hline Gaseificação com oxigênio puro & Oxigênio & $10-12$ \\
\hline Gaseificação indireta & Vapor de água & $15-20$ \\
\hline
\end{tabular}

\subsection{ATIVAÇÃO DE CARVÃO VEGETAL}

Carvão ativado é o adsorvente microporoso mais importante usado pela indústria. Possui uma complexa estrutura com poros classificados de microporos $(<20 \AA)$ a macroporos (> 500@), e vários tipos de superfícies, impurezas e irregularidades. Pode ser produzido a partir de carvão, turfa, endocarpo de coco ou qualquer outro material com alto teor de carbono, a partir da queima controlada à temperatura entre 700 e $1000^{\circ} \mathrm{C}$ (Ismadji et al., 2005). Esta forma de carbono puro de grande porosidade apresenta notáveis propriedades para remoção de impurezas dissolvidas em solução e pode ser empregado em pó ou granulado, conforme a necessidade. Com a capacidade de coletar seletivamente gases, 
líquidos e impurezas no interior dos seus poros, sendo por isso vastamente utilizado em sistemas de filtragem.

A utilização de carvões ativados como adsorventes data de milhares de anos, quando os egípcios, por volta de 1.550 a C., empregavam o carvão de madeira para a purificação de água para fins medicinais. No entanto em 3.750 a C., este já era utilizado na redução de cobre, zinco e estanho, na manufatura de bronze e também como combustível doméstico (Claudino, 2003). Um maior desenvolvimento de carvões ativados surgiu durante a Primeira Guerra Mundial, quando os carvões granulados eram utilizados em máscaras de gás. No entanto, foram nos últimos 50 anos que a tecnologia de produção de carvões ativados evoluiu significativamente.

No tratamento de água, com o objetivo de adequá-la aos parâmetros de potabilidade exigido para o consumo humano, o carvão ativado pode ser usado para eliminação de cor, odor, mau gosto e na remoção de substâncias orgânicas e inorgânicas dissolvidas na água.

Bons resultados foram obtidos por Rios et al. (2014) na adsorção de fenol usando carvão ativado a partir do endocarpo da macaúba, com concentrações entre 200 e 40 ppm simulando a adsorção em série em temperaturas de $30{ }^{\circ} \mathrm{C}, 40{ }^{\circ} \mathrm{C}$ e $50{ }^{\circ} \mathrm{C}$. Em todas as temperaturas, o modelo de isoterma de Langmuir melhor se ajustou aos dados, indicando que o carvão apresenta sítios idênticos entre si, com uma molécula adsorvida por sítio e sem interações relevantes entre as mesmas. Os resultados deste trabalho indicam que a adsorção de fenol utilizando carvão ativado proveniente do endocarpo do fruto da macaúba ocorre de forma eficiente, e que esse método possui potencial para ser utilizado na descontaminação de efluentes contendo fenol.

Em outro estudo, Junior (2010) avalia tipos de biomassa tipicamente amazônicas como a epicarpo da fruta do cupuaçu e da castanha do Brasil e endocarpo de açaí, e mostram a viabilidade técnico-econômica da sua utilização. A maior microporosidade foi conseguida com carvão ativado do ouriço da castanha com valores na ordem de $780 \mathrm{mg} \mathrm{g}^{-1}$, seguido pelo carvão do caroço do açaí com $600 \mathrm{mg} \mathrm{g}^{-1}$ e então pela casca do cupuaçu $480 \mathrm{mg} \mathrm{g}^{-1}$.

\subsubsection{Mecanismo de adsorção}

Adsorção é a propriedade das moléculas contidas no fluido de aderirem sobre a superfície de um sólido. As aplicações industriais do carvão ativado fundamentam-se nesta 
propriedade, para fase líquida ou gasosa. Na adsorção ocorre uma acumulação de moléculas (soluto) sobre a superfície do adsorvente. Quando o carvão ativado é colocado em contato com o soluto, há um decréscimo de sua concentração na fase líquida e um aumento correspondente sobre a superfície do carvão ativado, até se obter uma condição de equilíbrio.

Apesar da superfície e adsorção estarem interligadas, a superfície sozinha não é medida suficiente da capacidade adsorvente de um determinado carvão. Para cada adsorção específica, a distribuição e volume de poros são também importantes para controlar o acesso das moléculas do adsorbato para a superfície interna do carvão ativado (Mucciacito, 2006). Quando acontece o compartilhamento ou troca de elétrons entre o adsorbarto e o adsorvente, a adsorção é denominada química.

$\mathrm{Na}$ adsorção em fase líquida, as moléculas aderem-se fisicamente sobre o adsorvente através destas forças relativamente fracas, que são as mesmas responsáveis pela liquefação e condensação de vapores, no caso de adsorção de gases. No caso de adsorção física, a natureza do adsorvente não é alterada. Quase sempre a adsorção em carvão ativado é o resultado de forças atrativas chamadas "Van der Walls". Neste caso é chamado de adsorção física. A reversibilidade da adsorção física depende das forças atrativas entre o adsorbato e o adsorvente. Se estas forem fracas, a reversão ocorre com certa facilidade.

No caso de adsorção química, as ligações são mais fortes e mais energia seria necessária para reverter o processo. Além da característica do adsorvente e adsorbato, a natureza da fase líquida, como $\mathrm{pH}$ e viscosidade, a temperatura e o tempo de contato podem afetar a adsorção de modo significativo.

\subsubsection{Processo de fabricação}

Mucciacito (2006) também descreve os processos de ativação de carvões são comumente definidos por químicos ou físicos. Nos processos físicos de ativação, o material carbonáceo é submetido a um estágio denominado carbonização. Neste estágio, a umidade e materiais voláteis são removidos através da elevação da temperatura sob condições atmosféricas controladas. Na etapa seguinte são injetados no material os agentes ativantes, normalmente ar, vapor ou gás carbônico, a altas temperaturas. Nesta fase ocorrem reações e uma mistura de gases, composta principalmente de monóxido de carbono e o hidrogênio são liberados. Os gases são produzidos como consequência da reação do agente ativante com o material carbonáceo, sendo que o consumo do carvão resultante produz a estrutura porosa. 
Após a ativação, o carvão é submetido a etapas subsequentes, como resfriamento, peneiramento, lavagem, secagem, moagem, polimento, separação granulométrica e a embalagem. No processo químico de ativação, o material é colocado em contato com um agente ativante químico, como ácido fosfórico, carbonato de potássio ou cloreto de zinco. A mistura é submetida ao aquecimento sob condições controladas para ocorrer a ativação. $\mathrm{O}$ agente ativante deve ser removido posteriormente pela lavagem do material.

\subsubsection{Propriedades do carvão ativado}

Os carvões ativados são avaliados por suas propriedades físicas e através de testes experimentais da sua capacidade de adsorção, os parâmetros de avaliação mais comuns são:

- Teor de cinzas: as cinzas são dependentes do tipo de matéria-prima e do processo de fabricação. Compreende o resíduo após a ignição da substância, sob condições específicas.

- Umidade ou perda por secagem: é determinada com o propósito de produção e embarque. É o resultado da redução do peso quando a substância é aquecida, sob condições específicas.

- $\mathrm{pH}$ : depende da matéria-prima e processo de fabricação. É obtido pela análise do extrato aquoso.

- Tamanho da partícula: é uma forma de expressar o tamanho dos grãos do carvão ativado. Deve possuir tamanho de partícula que permita o melhor desempenho de adsorção e, ao mesmo tempo, boas condições de filtração. Nos carvões pulverizados normalmente é expresso como percentual em peso passante, por uma malha pré-determinada, como malha 325 ou 400 ASTM. Nos carvões granulados, define-se normalmente o tamanho nominal quando se demonstra as duas malhas limitantes da distribuição granulométrica, ou se demonstra diretamente a distribuição percentual em peso retida, ou passante em cada malha daquela distribuição.

- Peso específico ou densidade aparente: é a relação de massa por unidade de volume, incluindo o seu volume de poros e espaços interpartículas.

- Número de azul de metileno: indica a capacidade de adsorção do carvão ativado em relação às moléculas de tamanho semelhante às de azul de metileno. 
- Área superficial: é a área superficial total do carvão ativado, calculada pela equação B.E.T. (Brunauer, Emmett, Teller), pelos dados de adsorção e dessorção de nitrogênio, sob condições específicas. É expressa, comumente, em $\left[m^{2} g^{-1}\right]$.

- Volume de poros: é o volume de poros na unidade de peso do adsorvente. Pode ser obtido através da adsorção de mercúrio nos poros sob alta pressão. É expresso, comumente, em $\left[\mathrm{cm}^{3} \mathrm{~g}^{-1}\right]$.

- Capacidade de adsorção: é a quantidade de um determinado componente adsorvido de um fluido. Pode ser medida através de testes com o fluido a purificar, obtendo-se curvas de adsorção para aquelas condições específicas. 


\section{METODOLOGIA}

A seguir são descritas as metodologias utilizadas para obtenção dos resultados apresentados no capítulo 4, o gráfico da figura 8 apresenta uma visão geral deste capítulo na ordem em que as técnicas forma empregadas.

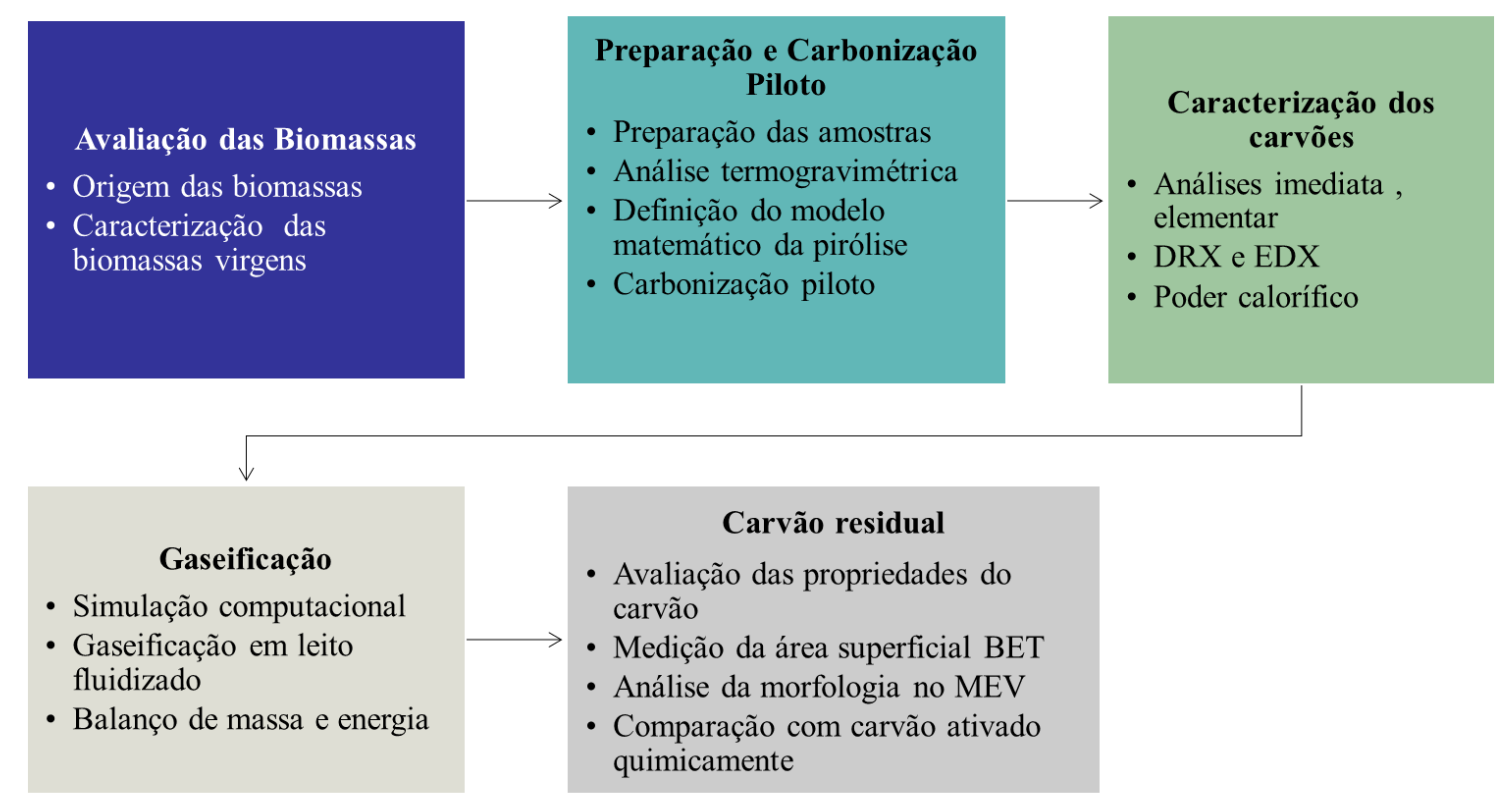

Figura 8 Organização das técnicas empregadas neste estudo.

\subsection{ORIGEM DA BIOMASSA}

Amostras de biomassa apresentadas no item 2.1, foram coletadas e enviadas para estudo como o descrito a seguir:

- Sementes do fruto de A. aculeatum (EFT) foram recolhidos diretamente nos restaurantes e cafés regionais de Manaus, secados a sombra e enviados pelos correios para Brasília;

- Cascas do fruto de T. grandiflorum (EFC) foram coletadas em indústrias de processamento de sucos em Manaus, secados a sombra e enviados pelo correio para Brasília;

- Frutos de A. aculeata (EFM) por não dispor de frutos de macaúba provenientes da Amazônia, foram utilizadas amostras colhidas em Brasília. Os frutos foram secados em estufas a $65^{\circ} \mathrm{C}$ por 4 dias para desidratação. 
Todas as amostras foram encaminhadas para caracterização e pirólise na área de energia da biomassa do Laboratório de Produtos Florestais (LPF) do Serviço Florestal Brasileiro (SFB).

\subsubsection{Caracterização da biomassa}

Amostras de biomassa foram identificadas, medidas e pesadas, em seguida submetidas à secagem em estufa a $103 \pm 2{ }^{\circ} \mathrm{C}$ por 24 horas. Após a secagem as amostras foram novamente medidas e pesadas para avaliação do teor de umidade. Estas amostras secas foram então trituradas em moinhos de martelo e de facas até a granulometria entre $150 \mu \mathrm{m}$ e $250 \mu m$, classificadas em peneiras ABNT/ASTM 100 e 60, respectivamente.

Na sequência são feitas as análises elementares das amostras para determinação dos elementos constitutivos de cada biomassa. Esses elementos foram determinados pelo equipamento Perkin Elmer Series 2400 II CHN Análise Elementar em triplicata e as concentrações de cada elemento foram calculadas pela média simples dos dois valores mais representativos.

\subsection{CARBONIZAÇÃO}

A carbonização foi feita em duas etapas: a primeira, carbonização piloto, aplica os resultados numéricos de tempo e temperatura para pirólise em um reator elétrico monitorado e controlado por software dedicado. Dos resultados obtidos nesta etapa, configura-se os equipamentos para a segunda etapa, onde são carbonizadas grandes quantidades de biomassa. Os carvões obtidos são comparados pelos resultados da análise imediata, para verificação da eficácia das melhorias propostas.

\subsubsection{Preparação das amostras}

As amostras foram preparadas de acordo com o "método A" da norma ASTM E 1757-01, para amostras com quantidades acima de $20 \mathrm{~g}$. As amostras foram espalhadas para secagem em temperatura ambiente, em uma bandeja metálica. Na sequência o material foi colocado na estufa Marconi MA035, durante pelo menos $12 \mathrm{~h}$. Em seguida o material seco foi colocado do dessecador para resfriar. Após o resfriamento o material foi pesado para a obtenção da massa seca da biomassa $m_{s}$.

A biomassa foi medida em três momentos: antes da secagem, após a secagem e após a carbonização de forma a obter o decaimento volumétrico decorrente da carbonização. $\mathrm{O}$ 
volume ocupado no reator e o peso também são medidos de forma a se calcular a densidade a granel da biomassa para aquele reator.

\subsubsection{Termogravimetria e análise de gases}

Para a configuração do processo de carbonização e para a análise dos constituintes dos gases emitidos durante o processo valeu-se da técnica de acoplamento dos equipamentos analisador simultâneo modelo SDT Q600 da TA Instruments, que proporciona uma medição instantânea da variação de massa (TG) e a calorimetria exploratória diferencial (DSC) de uma amostra da temperatura ambiente até a temperatura desejada. No presente trabalho as análises de TG-FTIR foram feitas em duas etapas: a primeira usando biomassa virgem variando a temperatura desde a ambiente até a temperatura de carbonização $\left(450{ }^{\circ} \mathrm{C}\right) \mathrm{com}$ taxas de aquecimento lentas $\left(2{ }^{\circ} \mathrm{C} \mathrm{min}^{-1}\right)$ e, a segunda, usando biomassa carbonizada variando a temperatura até a temperatura de gaseificação $\left(900^{\circ} \mathrm{C}\right)$ com taxas de aquecimento rápidas $\left(20^{\circ} \mathrm{C} \mathrm{min}^{-1}\right)$, mantendo a temperatura final até o consumo total do material.

A interface entre TGA-FTIR oferece a capacidade de monitorar a evolução de gases em tempo real a partir de uma amostra aquecida. Neste experimento foi utilizado o instrumento de interface THERMO SCIENTIFIC TGA-FTIR, esta unidade permite que os gases provenientes da análise termogravimétrica sejam guiados através de uma linha de transferência aquecida, os gases passam por dentro de uma célula de fluxo onde os espectros de infravermelho são recolhidos. A célula de gás é niquelada, com $100 \mathrm{~mm}$ de comprimento e volume interno de $23 \mathrm{~mL}$ com janelas de $\mathrm{KBr}$, capaz de suportar temperaturas de até $325^{\circ} \mathrm{C}$. A linha de transferência é de vidro revestido de aço inoxidável é conectada diretamente ao tubo do forno TGA, proporcionando uma passagem de gases totalmente inerte para a célula de gás.

A termogravimetria foi realizada com as amostras em forma de pó com massas de aproximadamente $10 \mathrm{mg}$. As amostras de biomassa virgem foram colocadas em cadinho de alumina e foram aquecidas a uma temperatura de $23{ }^{\circ} \mathrm{C}$ até $450{ }^{\circ} \mathrm{C}$ com taxa de aquecimento de $2{ }^{\circ} \mathrm{C} \mathrm{min}^{-1}$ sob um fluxo de nitrogênio de $100 \mathrm{~mL} \mathrm{~min}^{-1}$. A temperatura da interface THERMO SCIENTIFIC entre TGA-FTIR foi definida como $200^{\circ} \mathrm{C}$ para a célula e $190{ }^{\circ} \mathrm{C}$ para a linha de transferência do gás. Para as amostras de biomassa carbonizada, cerca de $10 \mathrm{mg}$ de cada amostra foram depositados em cadinhos de alumina. $\mathrm{O}$ aquecimento foi de $23{ }^{\circ} \mathrm{C}$ a $900{ }^{\circ} \mathrm{C}$ com rampa de $20^{\circ} \mathrm{C} \mathrm{min}^{-1}$ sob fluxo de ar sintético de $100 \mathrm{~mL} \mathrm{~min}^{-1}$. 


\subsubsection{Modelagem matemática da pirólise}

O modelo matemático usado para descrever a pirólise neste trabalho, foi desenvolvido e apresentado por Kung (1972), com ele é possível prever o decaimento da densidade da biomassa em função do tempo e da temperatura. Neste modelo define-se um elemento parcialmente pirolisado por material ativo, sendo ele parte carvão e parte material virgem. À medida que o material ativo de densidade $\rho_{\mathrm{a}}$, pelo processo de pirólise, vai gradualmente desaparecendo dando lugar ao carvão, com densidade final $\rho_{\mathrm{f}}$. Em um dado instante, $t$, a densidade total pode ser assumida como:

$$
\rho(t)=\left(1-\frac{\rho_{f}}{\rho_{b}}\right) \rho_{a}(t)+\rho_{f}
$$

onde $\rho_{\mathrm{b}}$ é a densidade da biomassa virgem.

A decomposição de Arrhenius é considerada como

$$
\frac{\partial \rho}{\partial t}=-a_{p} \rho_{a} e^{\left(-E_{p} / R T\right)}
$$

onde $\mathrm{a}_{\mathrm{p}}$ é o fator pré-exponencial, $\mathrm{R}$ constante universal dos gases e $\mathrm{E}_{\mathrm{p}}$ a energia de ativação. Combinando das equações 22 e 23 , tem-se:

$$
\frac{\partial \rho}{\partial t}=-a_{p} \frac{\left(\rho-\rho_{f}\right) e^{\left(-E_{p} / R T(t)\right)}}{\left(1-\frac{\rho_{f}}{\rho_{b}}\right)}
$$

Na superfície exposta $(x=0)$ é recebido fluxo de calor $\dot{q}^{\prime \prime}$, enquanto que em $x=l$ temse $\frac{\partial T}{\partial x}=0$ e o fluxo de voláteis na direção do eixo $x\left(M_{g}(x)\right)$, sai do interior da biomassa. Por conservação de massa tem-se:

$$
\frac{\partial M_{g}}{\partial x}=\frac{\partial \rho}{\partial t}
$$

como a densidade do gás é muito menor do que a do sólido é ignorado a acumulação de vapores no sólido. Do ponto de vista das entalpias, pode-se dividir em três partes: 


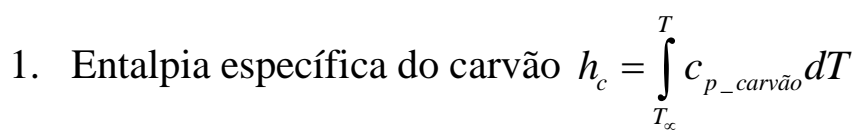

2. Entalpia específica ativa da biomassa $h_{a}=\int_{T_{\infty}}^{T} c_{p_{-} a \text { ativa }} d T$

3. Entalpia específica dos gases $h_{g}=\int_{T_{\propto}}^{T} c_{p_{-} \text {gases }} d T$

A conservação da energia implica na equação

$$
\frac{\partial}{\partial t}\left(\rho_{a} h_{a}+\rho_{c} h_{c}\right)=\frac{\partial}{\partial x}\left(\frac{k \partial T}{\partial x}\right)+\frac{\partial}{\partial x}\left(M_{g} h_{g}\right)-Q_{p}\left(-\frac{\partial \rho}{\partial t}\right)
$$

onde o primeiro termo $\left[\frac{\partial}{\partial t}\left(\rho_{a} h_{a}+\rho_{c} h_{c}\right)\right]$ representa a entalpia do sólido por unidade de volume e o segundo $\left[\frac{\partial}{\partial x}\left(\frac{k \partial T}{\partial x}\right)\right]$ o fluxo líquido de energia devido à condução. $\mathrm{O}$ termo $\frac{\partial}{\partial x}\left(M_{g} h_{g}\right)$, sempre negativo, representa a energia térmica transferida para fora da unidade de volume, por convecção dos voláteis. A variável $Q_{p}$ é a energia endotérmica associada com a geração de massa unitária de vapor e $k$ é a condutividade da matriz porosa de sólido preenchida por gases. Para solução são assumidas as seguintes hipóteses:

a. A matriz sólida não se movimenta na direção $x$ por expansão nem contração.

b. São ignoradas a acumulação de energia das espécies gasosas com o sólido, o que significa: $\rho_{g} h_{g} \ll \rho_{c} h_{c}+\rho_{a} h_{a}$.

Assim a equação 26 pode ser rearranjada obtendo-se:

$$
\rho c_{p s} \frac{\partial T}{\partial t}=\frac{\partial}{\partial x}\left(\frac{k \partial T}{\partial x}\right)+\left(M_{g} \frac{\partial h_{c}}{\partial x}\right)+\frac{\partial \rho}{\partial t}\left[Q_{p}-\frac{\rho_{b}}{\rho_{b}-\rho_{f}} h_{a}+\frac{\rho_{f}}{\rho_{b}-\rho_{f}} h_{c}+h_{g}\right],
$$

onde $c_{p s}=\rho_{c} c_{p_{-} \text {carvão }}+\rho_{a} c_{p_{-} \text {ativo }}$. 


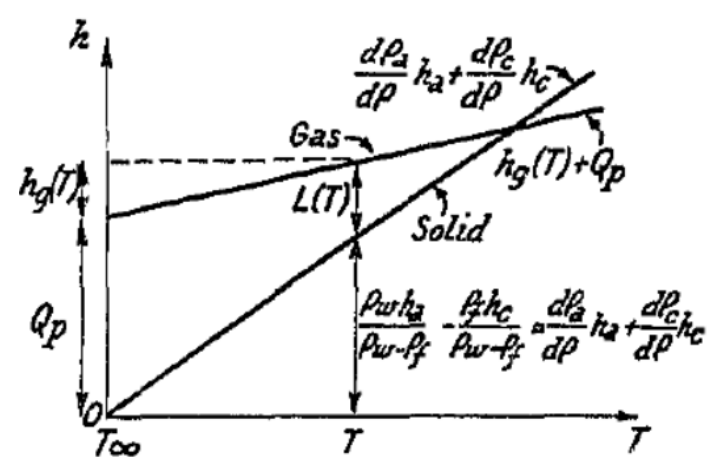

Figura 9 Decomposição das energias durante a carbonização. Fonte: (Kung, 1972)

Na equação 27 os 3 primeiros termos descrevem os efeitos das alterações transitórias e espaciais pela temperatura enquanto o último grupo de termos descreve a absorção de energia local instantânea associada à geração de voláteis. A energia mostrada na Figura 5

$$
L(T)=Q_{p}-\frac{\rho_{b}}{\left(\rho_{b}-\rho_{f}\right) h_{a}}+\frac{\rho_{f}}{\left(\rho_{b}-\rho_{f}\right) h_{c}}+h_{g},
$$

representa o calor de vaporização à temperatura $T$, o que representa a energia por unidade de massa de voláteis gerados que teria que fornecer a um elemento sólido se estivesse a uma temperatura uniforme e constante. O termo $\frac{\rho_{b}}{\left(\rho_{b}-\rho_{f}\right)}$ é a massa de material ativo, consumido por unidade de voláteis gerados, e o termo $\frac{\rho_{f}}{\left(\rho_{b}-\rho_{f}\right)}$ é a massa de carvão gerado.

Como o calor específico do material ativo $\left(\sim 0,6 \mathrm{cal} \mathrm{g}^{-1}\right)$ é bem menor que o calor específico dos voláteis $\left(\sim 0,25 \mathrm{cal} \mathrm{g}^{-1}\right)$, a função $L(T)$ decresce com a temperatura.

As condições de contorno apropriadas são:

$$
\begin{aligned}
& T=T_{\infty}, \rho=\rho_{b}, M_{g}=0 \rightarrow \text { para } t=0, \\
& k \frac{\partial T}{\partial x}=\dot{q}^{\prime \prime} \rightarrow \text { para } x=0, \\
& \frac{\partial T}{\partial x}=0, M_{g}=0 \rightarrow \text { para } x=l,
\end{aligned}
$$

onde $\dot{q}^{\prime \prime}$ é o fluxo líquido de calor recebido pela superfície exposta e $l$ é o comprimento total na direção $x$. 
Adimensionalizando:

$$
\begin{gathered}
\overline{\rho_{a}}=\frac{\rho_{a}}{\rho_{b}}, \quad \bar{\rho}=\frac{\rho}{\rho_{b}}, \quad \overline{\rho_{f}}=\frac{\rho_{f}}{\rho_{b}}, \\
\bar{T}=\frac{T}{T_{\infty}}, \quad \overline{T_{c}}=\frac{E_{p}}{R T_{\infty}}, \\
\bar{C}_{p_{-} a}=\frac{c_{p_{-} a}}{c_{p_{-} b}}, \quad \bar{C}_{p_{-} c}=\frac{c_{p_{-} c}}{c_{p_{-} b}}, \quad \bar{C}_{p s}=\frac{c_{p s}}{c_{p_{-} b}}, \quad \bar{C}_{p_{-} g}=\frac{c_{p_{-} g}}{c_{p_{-} b}} \mathrm{e} \\
\bar{k}=\frac{k}{k_{b}}, \quad \bar{x}=\frac{x}{l}, \quad \bar{t}=\frac{t \times k_{b}}{c_{p_{-} b} \times \rho_{b} \times l^{2}}, \\
\bar{M}_{g}=\frac{M_{g} \times c_{p_{-} b} \times l}{k_{b}}, \quad \bar{a}_{p}=\frac{a_{p} \times c_{p_{-} b} \times \rho_{b} \times l^{2}}{k_{b}\left(1-\bar{\rho}_{f}\right)}, \\
\bar{Q}_{p}=\frac{Q_{p}}{c_{p_{-} b} \times T_{\infty}} .
\end{gathered}
$$

Substituindo os termos de 30 e 31 nas equações 24,25 e 27 temos o sistema de três variáveis: $\bar{\rho}_{a}(\bar{x}, \bar{t}) ; \bar{M}_{g}(\bar{x}, \bar{t})$ e $\bar{T}(\bar{x}, \bar{t})$ e três equações governantes

$$
\begin{gathered}
\frac{\partial \bar{\rho}}{\partial t}=-a_{p}\left(\bar{\rho}-\bar{\rho}_{f}\right) e^{\left(-\bar{T}_{c} / \bar{T}\right)}, \\
\frac{\partial \bar{M}_{g}}{\partial x}=\frac{\partial \bar{\rho}}{\partial \bar{t}}, \\
\bar{\rho} \bar{C}_{p s} \frac{\partial \bar{T}}{\partial \bar{t}}=\frac{\partial}{\partial \bar{x}}\left(\frac{\bar{k} \partial \bar{T}}{\partial \bar{x}}\right)+\bar{M}_{g} \bar{C}_{p_{-} g} \frac{\partial \bar{T}}{\partial \bar{x}}+\frac{\partial \bar{\rho}}{\partial \bar{t}}\left[\bar{Q}_{p}-\int_{1}^{\bar{T}}\left(\frac{\bar{C}_{p_{-} a}}{1-\bar{\rho}_{f}}-\frac{\bar{\rho}_{f} \times \bar{C}_{p_{-} c}}{1-\bar{\rho}_{f}}-\bar{C}_{p_{-} g}\right) d \bar{T}\right] .
\end{gathered}
$$

As condições de contorno adequadas são:

$$
\begin{aligned}
& \bar{T}=1, \bar{\rho}_{a}=1, \bar{M}_{g}=0 \rightarrow \text { para } t=0, \\
& k \frac{\partial \bar{T}}{\partial \bar{x}}=\frac{-l \times \dot{\mathrm{q}}^{\prime \prime}(\mathrm{t})}{k_{b} \times T_{\infty}} \rightarrow \text { para } t=0, \\
& \frac{\partial \bar{T}}{\partial \bar{x}}=0, \bar{M}_{g}=0 \rightarrow \text { para } x=1 .
\end{aligned}
$$

Estas equações podem ser resolvidas entrando com os valores de $\bar{k}, \bar{c}_{p s}$ e $\bar{c}_{p_{\_} g}$. Neste modelo (Kung, 1972) se estabelecem relações para tipos de biomassa desconhecidas, para tanto são utilizadas interpolações lineares entre as propriedades da biomassa virgem e as do carvão. 


$$
\begin{gathered}
\bar{\rho} \times \bar{c}_{p s}=\frac{\left(\bar{\rho}-\bar{\rho}_{f}\right) \bar{c}_{p_{-} a}}{1-\bar{\rho}_{f}}+\frac{1-\bar{\rho}}{1-\bar{\rho}_{f}} \bar{\rho}_{f} \times \bar{c}_{p_{-} c}, \\
\bar{k}=\frac{k}{k_{b}}=\frac{\left(\bar{\rho}-\bar{\rho}_{f}\right) \bar{k}_{a}}{1-\bar{\rho}_{f}}+\frac{(1-\bar{\rho}) \bar{k}_{c}}{1-\bar{\rho}_{f}},
\end{gathered}
$$

onde $\bar{k}_{a}$ é a condutividade térmica do material ativo e $\mathrm{C}_{\mathrm{pb}}$ e $\mathrm{k}_{\mathrm{b}}$ são respectivamente o calor específico e a condutividade térmica do material virgem à temperatura ambiente. A solução numérica ignora a dependência da temperatura de $C_{p a}, C_{p c}$ e $k_{a}$, fazendo $k_{a}=C_{p a}=1$. Por fim assume-se que os voláteis têm calor específico igual ao do ar, ou seja,

$$
\bar{C}_{p_{-} g}=\frac{C_{p_{-} g}}{C_{p_{-} b}}=0,4 .
$$

O conjunto de equações governantes 32 são resolvidas usando o método de diferenças finitas de Crank-Nicolson. Em especial são tratados os resultados em função da espessura do material, da condutividade térmica do carvão e da endotermicidade da decomposição. Como constantes são usados: fator pré-exponencial $a_{p}=5,25 \times 10^{7} s^{-1}$, energia de ativação $E_{p}=30 \mathrm{kcal} \mathrm{mol}^{-1}$, constante dos gases $R=1,987 \mathrm{cal} \mathrm{mol}^{-1}{ }^{\circ} \mathrm{C}^{-1}$, temperatura ambiente $T_{\infty}=300 \mathrm{~K}$, condutividade térmica do material virgem $k_{b}=3 \times$ $10^{-4} \mathrm{cal} \mathrm{cm}^{-1} \mathrm{~s}^{-1 \circ} \mathrm{C}^{-1}$, calor específico do material virgem $C_{p_{-} b}=0,6 \mathrm{cal} \mathrm{g}^{-1}{ }^{\circ} \mathrm{C}^{-1}$, calor específico do carvão $C_{p_{-} c}=0,6 \mathrm{cal} \mathrm{g}^{-1}{ }^{\circ} \mathrm{C}^{-1}$, calor específico dos voláteis $C_{p_{-} b}=$ $0,24 \mathrm{cal} \mathrm{g}^{-1}{ }^{\circ} \mathrm{C}^{-1}$, densidade do material virgem $\rho_{b}=0,21 \mathrm{~g} \mathrm{~cm}^{-3}$, densidade do carvão $\rho_{f}=0,125 \mathrm{~g} \mathrm{~cm}^{-3}$ (Boas e Carneiro, 2010).

Considerando que o presente trabalho usa um reator cilíndrico, convém apresentar esta dinâmica de carbonização em coordenadas cilíndricas, de forma a prever o calor de reação da biomassa e o decaimento da densidade em função do tempo e da temperatura (Kung e Kalelkar, 1973), seguindo o mesmo raciocínio apresentado anteriormente (Kung, 1972), obtém-se um conjunto de equações governantes em coordenadas cilíndricas:

$$
\begin{gathered}
\frac{\partial \bar{\rho}}{\partial t}=-\bar{a}_{p} \bar{\rho}_{a} e^{\left(-\bar{T}_{e} / \bar{T}\right)} \\
\frac{\partial \bar{M}_{g}}{\partial \bar{r}}+\frac{\bar{M}_{g}}{\bar{r}}=-\left(1-\bar{\rho}_{f}\right) \frac{\partial \bar{\rho}_{a}}{\partial \bar{t}}, \\
\frac{1}{\bar{r}} \frac{\partial}{\partial \bar{r}}\left(\bar{r} \overline{\frac{\partial}{T}} \frac{\partial \bar{r}}{\partial \bar{r}}\right)=\frac{\partial}{\partial \bar{t}} \int_{1}^{\bar{T}} \bar{H} d \bar{T}+\frac{1}{\bar{r}} \frac{\partial}{\partial \bar{r}}\left(\bar{r}_{\bar{M}_{g}} \int_{1}^{\bar{T}} \bar{C}_{p_{-} g} d \bar{T}\right)+\left(1-\bar{\rho}_{f}\right) \bar{Q}_{p} \frac{\partial \bar{\rho}_{a}}{\partial \bar{t}}
\end{gathered}
$$


Onde

$$
\begin{gathered}
\bar{r}=\frac{r}{l}, \quad \bar{t}=\frac{t}{t^{*}}, \quad t^{*}=\frac{C_{w} \rho_{w} l^{2}}{k_{w}}, \\
\bar{T}=\frac{T}{T_{\infty}}, \quad \bar{\rho}_{a}=\frac{\rho_{a}}{\rho_{w}}, \quad \bar{M}_{g}=\frac{M_{g} C_{w} l}{k_{w}}, \\
\bar{T}=\frac{E_{p}}{R T_{\infty}}, \quad \bar{a}_{p}=a_{p} t^{*}, \quad \bar{Q}_{p}=\frac{Q_{p}}{C_{w} T_{\infty}}, \\
\bar{k}=\frac{k}{k_{w}}, \quad \bar{H}=\frac{H}{\rho_{w} C_{w}}, \quad \bar{C}_{p_{-} g}=\frac{C_{p_{-} g}}{C_{w}} .
\end{gathered}
$$

As condições de contorno são:

$$
\begin{gathered}
\bar{T}=1, \quad \bar{\rho}_{a}=1, \quad \bar{M}_{g}=0, \text { em } \quad \bar{t}=0 ; \\
\frac{\partial \bar{T}}{\partial \bar{r}}=0, \quad \bar{M}_{g}=0, \text { em } \quad \bar{r}=0 ; \\
\bar{k} \frac{\partial \bar{T}}{\partial \bar{r}}=-\frac{l \dot{q}^{\prime \prime}(t)}{k_{w} T_{\infty}}, \quad \text { em } \quad \bar{r}=1 ;
\end{gathered}
$$

Estas equações governantes (35) e condições de contorno (37) representam bem o modelo para um tronco cilíndrico com densidade uniforme, como o usado neste trabalho. Neste caso os reatores continham caroços de frutas ou pedaços de cascas, é conveniente considerar a modelagem matemática para um meio poroso, ou seja, considerar um leito empacotado composto por um número finito de partículas individuais, que podem ter tamanhos ou propriedades diferentes. Cada uma destas partículas é submetida a uma sequência de processos tais como de pré-aquecimento, a secagem e pirólise. Este último está descrito com precisão suficiente por um conjunto de equações de conservação unidimensionais e transientes para a massa e energia (Equação 35). Assim, a soma de todos estes processos consiste na conversão de um leito compactado, onde o conjunto de partículas possui uma fase sólida e um espaço vazio entre eles e a transferência de calor e massa acopla o fluxo dentro dos espaços vazios às partículas (Peters, 2002; Gawin et al., 2006; AlarconRuiz et al., 2010).

Neste trabalho são usados os resultados obtidos por (Kung, 1972; Kung e Kalelkar, 1973) (Anexo B), para estimar os tempos de pirólise, usados para a todas as amostras na carbonização piloto. Os dados de entrada para esta simulação foram os obtidos nas caracterizações da biomassa virgem e do carvão. 


\subsubsection{Carbonização piloto}

A carbonização de cada biomassa foi feita em retorta com aquecimento elétrico SLFI, com cadinho medindo $19 \mathrm{~cm}$ de diâmetro por $35 \mathrm{~cm}$ de altura, com capacidade máxima para 10 litros com controle e registro das temperaturas do forno e do centro do reator (Figura 10). Foram empregados média $630 \mathrm{~g}$ de biomassa em cada experimento e a aquisição e controle dos parâmetros de processo foram feitos de forma automática pelo software Pyrolise 10L, que permite a configuração das rampas de aquecimento e resfriamento bem como o tempo de patamar. Os gases voláteis são condensados e o licor pirolenhoso recolhido em balão para análise química posterior.

Para as carbonizações, realizadas em triplicatas, são usados valores de configuração do sistema baseados nos resultados da análise de termogravimetria (TG/DTG). Para o EFT e EFM utilizam-se rampa de aquecimento de $2{ }^{\circ} \mathrm{C} \min ^{-1}$ até a temperatura de $430{ }^{\circ} \mathrm{C}$ então mantida por $420 \mathrm{~min}$. $\mathrm{O}$ resfriamento se deu pelo resfriamento natural do forno até $60{ }^{\circ} \mathrm{C}$, quando, então, se pode abrir com segurança o reator. Para o EFC, o procedimento de pirólise é diferenciado, com rampa de aquecimento de $2{ }^{\circ} \mathrm{C} \mathrm{min}^{-1}$ até a temperatura de $300{ }^{\circ} \mathrm{C}$ mantida por 420 min. O tempo de patamar foi calculado conforme método descrito na seção anterior.

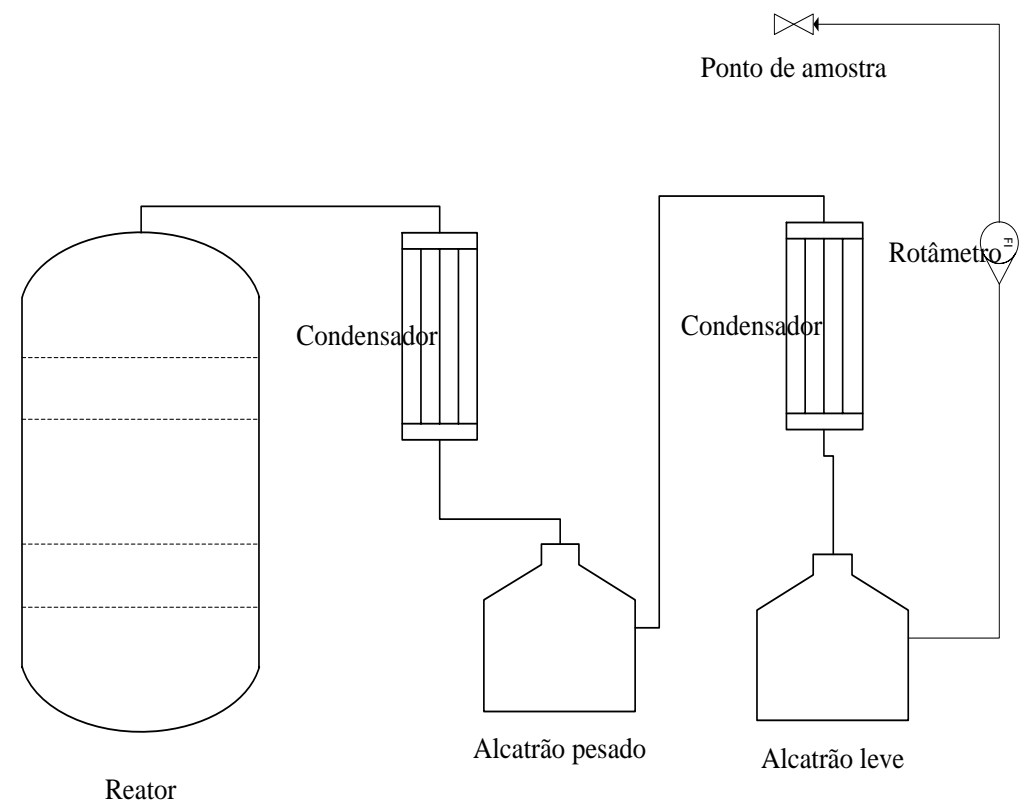

Figura 10 Diagrama de funcionamento do reator de pirólise (retorta elétrica) S.L.F.I. com capacidade para 10L equipado com condensadores e controle de temperatura (Apêndice A).

Para a avaliação dos rendimentos ao final da carbonização, foram pesados na balança Marte A5000, tanto o material sólido quanto o líquido condensado em ambos os balões: 
alcatrão pesado e leve. A fração gasosa foi calculada pela diferença entre a soma todas as massas medidas pela massa de material seco carregado no reator. O rendimento gravimétrico de sólido é dado pela relação entre a massa de carvão obtido em relação à massa de biomassa seca carregada no reator, da mesma forma o rendimento de líquido é dado pela relação da massa líquida gerada pela massa seca inserida e, por diferença, foi calculado o rendimento de gases incondensáveis.

\subsubsection{Carbonização de grandes massas}

Para atender a demanda de material requerido para o processo de gaseificação, utilizaram-se fornos e reatores maiores, carbonizando cerca de $30 \mathrm{~kg}$ de biomassa a cada batelada. O procedimento de preparação das amostras é similar ao feito na carbonização piloto, os valores de configuração das temperaturas são os mesmos usados na carbonização piloto, no entanto os tempos de patamar são ajustados conforme a velocidade da frente de pirólise medidos na carbonização piloto. Estas reações foram feitas no laboratório de carbonização da fazenda água limpa - UnB, situado em Vargem Bonita DF, usando o forno Linn Elektro Therm (Anexo A), configurado as rampas de aquecimento para $2{ }^{\circ} \mathrm{C} \mathrm{min}^{-1}$ para todas as amostras e patamares com tempo de $338 \mathrm{~min}$ para EFT e EFM e de $264 \mathrm{~min}$ para o EFC.

O reator cilíndrico em aço carbono com $474 \mathrm{~mm}$ de diâmetro por $590 \mathrm{~mm}$ de altura com tampa removível em aço zincado com fecho rápido. Todos os pontos onde poderia haver entrada de ar foram vedados com pasta veda escape - vedante anaeróbico, inorgânico, de cor cinza cuja cura se dá sobre superfícies metálicas, na ausência de ar e a $200^{\circ} \mathrm{C}$. Esta vedação suporta temperaturas até $500^{\circ} \mathrm{C}$, vibrações e umidade.

\subsubsection{Caracterização dos carvões vegetais}

O material carbonizado foi mantido seco e preparado conforme o "método A" da norma ASTM E 1757-01, após resfriado levado ao triturador Ika Werke mod. M20 e classificado pela a granulometria. As peneiras foram colocadas no agitador na seguinte ordem: tampa superior, peneira ASTM 60 (0,250 mm de abertura), peneira ASTM 100 $(0,150 \mathrm{~mm}$ de abertura) e fundo, sendo então agitadas por $15 \pm 1 \mathrm{~min}$ no agitador Bectel. Ao fim do período a fração retida na peneira ASTM 60 foi reprocessada, a fração retida na peneira ASTM 100 foi retirada para ser usada na análise imediata (voláteis e carbono fixo) e os "finos" que ficaram no fundo da peneira foram separados para análise de cinzas. 
Procedeu-se, então, a análise imediata do carvão vegetal, que é comumente empregada para medir a qualidade dessa biomassa para fins energéticos. Esta consiste em determinar os teores de umidade, cinzas, voláteis e de carbono fixo. Para esta análise seguiuse a norma NBR 8112/1986 e todas as análises foram feitas em triplicata, tendo por resultado a média simples entre os dois resultados mais próximos. Utilizaram-se para o experimento duas muflas Quimis Q318A24, uma balança de precisão BEL AS200 e dessecadores.

A análise de umidade foi realizada conforme norma NBR 8112 e E871 em triplicata e base úmida com aproximadamente $1 \mathrm{~g}$ de carvão triturado e classificado em peneiras ASTM 60. As amostras foram colocadas em uma estufa, previamente aquecidas a $103 \pm$ $2{ }^{\circ} \mathrm{C}$ onde permaneceram por 12 horas. As amostras foram retiradas e estocadas em um dessecador após resfriamento completo. Após a pesagem foi realizado o cálculo da quantidade de água que estava associada à biomassa conforme a equação:

$$
\omega=\left(\frac{m_{1}-m_{2}}{m_{1}}\right) \times 100
$$

onde $\mathrm{m}_{1}[g]$ é a massa inicial da amostra; $\mathrm{m}_{2}[g]$ é massa final da amostra e $\omega[\%]$ o teor de umidade.

O teor de voláteis foi realizado conforme norma NBR 8112 e E872 em triplicata e base seca. Para estas análises foram utilizados 3 cadinhos tampados com $1 \pm 0,003 \mathrm{~g}$ de amostras cada. A mufla foi aquecida à $900^{\circ} \mathrm{C}$ e em seguida, já com a temperatura estável, posicionadas as amostras por 3 minutos na porta da mufla e por 7 minutos dentro da mufla. Os cadinhos foram colocados em dessecador até resfriamento completo. O teor de voláteis é expresso em base seca $\left(\%_{b s}\right)$ e determinado conforme a equação

$$
T_{v}=\left(\frac{m_{2}-m_{3}}{m_{2}}\right) \times 100,
$$

onde $\mathrm{T}_{\mathrm{v}}[\%]$ é o teor de materiais voláteis; $\mathrm{m}_{2}$ [g] é a massa inicial do cadinho mais amostra, e $\mathrm{m}_{3}[g]$ a massa final do cadinho mais amostra.

O teor de cinzas foi realizado conforme norma NBR 8112 e D1102 em triplicata e base seca. Para esta análises foram utilizados 3 cadinhos previamente calcinados com $1 \pm$ $0,03 \mathrm{~g}$ de carvões em cada um, que após a mufla aquecida à $700^{\circ} \mathrm{C}$, foram colocados em 
seu interior por 5 horas. Ao final os cadinhos foram colocados em dessecador até resfriamento completo. $\mathrm{O}$ teor de cinzas é expresso em base seca $\left(\%_{b s}\right)$ e é determinado conforme a equação

$$
T_{c z}=\left(\frac{m_{1}-m_{0}}{m_{1}}\right) \times 100,
$$

onde $T_{c z}[\%]$ é o teor de cinzas; $m_{0}[g]$ a massa do cadinho e $m_{1}[g]$ a massa do cadinho mais o resíduo. O teor de carbono fixo $T_{c f}[\%]$ foi realizado conforme norma NBR $8112 \mathrm{e}$ é expresso pela diferença entre a quantidade inicial de carbono presente na amostra e a quantidade remanescente nas cinzas

$$
T_{c f}=100-\left(T_{v}+T_{c z}\right)
$$

A análise elementar fornece as frações em peso dos principais elementos que compõem a biomassa: carbono $(\mathrm{C})$, oxigênio $(\mathrm{O})$, nitrogênio $(\mathrm{N})$ e hidrogênio $(\mathrm{H})$. Esses elementos foram determinados pelo equipamento Perkin Elmer Series 2400 II CHN Análise Elementar do Instituto de Química da UnB. Foram caracterizadas as amostras in natura e carbonizadas de forma a obter as fórmulas químicas equivalentes, requisito necessário para simulações usando cinética química. Os demais elementos, exceto o oxigênio, foram determinados por espectrometria de fluorescência de raio-X (FRX/EDX), modelo 720, Shimadzu, com tubo de ródio como fonte de raios-X.

A determinação da densidade a granel foi utilizada a norma NBR/NM 52:2009, usando um recipiente em forma de cubo com volume de $1 \mathrm{~cm}^{3}$. Cada amostra é triturada e classificada em peneiras analíticas ASTM 60 e secas em estufa por 24h à temperatura de $103 \pm 2{ }^{\circ} \mathrm{C}$, depois levadas ao dessecador para resfriar. Então as amostras são depositadas sem compactação no recipiente e então pesadas em triplicatas. A massa específica é dada pela equação

$$
\rho=\frac{M_{B}}{V_{S}},
$$

onde $M_{B}[g]$ é a massa da biomassa e $V_{S}\left[\mathrm{~cm}^{3}\right]$ é o volume do sólido.

O poder calorífico superior foi determinado segundo a norma NBR 8.633/1984. Os carvões vegetais e a biomassa in natura, classificado em peneiras de ASTM 60, foram colocados em pratos de alumínio e seco em estufa a $103 \pm 2^{\circ} \mathrm{C}$ até atingir massa constante. 
Finalizada essa etapa, acondicionou-se o material em dessecador para, posteriormente, pesar três amostras de, aproximadamente, $0,4500 \mathrm{~g}$ que depois de compactado no cadinho é levado ao calorímetro Parr 6400. O resultado apresentado na tela do equipamento reporta o poder calorífico superior PCS, para obtenção do poder calorífico inferior se faz necessário o emprego da equação 43, onde \%H é o percentual de hidrogênio e $\omega$ é a umidade da amostra.

$$
P C I=P C S-(2440 \times(9 \times \% H)+\omega) .
$$

\subsection{GASEIFICAÇÃO}

A gaseificação foi feita somente com a biomassa carbonizada e dividida em duas partes: simulação numérica da reação, procedimento computacional que visa levantar os valores de ajuste e a predição dos resultados esperados e a gaseificação experimental em leito fluidizado, experimento realizado no equipamento instalado no núcleo de catálise (NuCAT) da COPPE / UFRJ.

\subsubsection{Modelagem matemática e simulação numérica da gaseificação}

Para a simulação da gaseificação desenvolveu-se rotinas para o Engineering Equation Solver (EES) versão 9.911. Estas rotinas de cálculo têm por objetivo resolver o modelo matemático apresentado a seguir. Este modelo pode ser descrito pelo aspecto do equilíbrio, onde as expressões para a constante de equilíbrio são estabelecidas e pelo aspecto cinético relacionado às reações elementares, onde as taxas de uma reação procedem somente de um estado de transição e é proporcional ao produto das concentrações das moléculas participantes.

O modelo implementado compreende a equação de conservação de energia, equações de conservação de massa das espécies atômicas e equações de minimização de energia livre de Gibbs. Assume-se que todos os produtos produzidos no gaseificador são gases de massa molar baixa, tais como $\mathrm{CO}_{2}, \mathrm{CO}, \mathrm{H}_{2}, \mathrm{H}_{2} \mathrm{O}, \mathrm{CH}_{4}$ e $\mathrm{N}_{2}$. Neste caso específico assume-se que não há produção de alcatrões uma vez que se trata de simulações de gaseificação de biomassa carbonizada e que a totalidade do carbono é convertida no reator. As secções seguintes descrevem o modelo utilizado no presente trabalho.

\subsubsection{Biomassa}

Em posse da equação equivalente do carvão $\mathrm{C}_{\mathrm{c} 1} \mathrm{H}_{\mathrm{c} 2} \mathrm{O}_{\mathrm{c} 3} \mathrm{~N}_{\mathrm{c} 4}$, onde os coeficientes são determinados através de análise elementar dos carvões através da equação 


$$
c_{i}=\frac{y_{i}}{y_{1}} \frac{M_{1}}{M_{i}} ; i=1,2 \text { e } 3,
$$

onde os termos $y_{i}$ e $M_{i}$ são respectivamente fração mássica e massa molar em base seca de cada espécie e $c_{1}=1$. A massa molar da biomassa é dada por:

$$
M_{b}=\sum_{i} c_{i} M_{i}
$$

e a fração molar de água presente na biomassa está relacionada com sua humidade relativa $h$, de acordo com a equação 46

$$
w=\frac{M_{b} h}{M_{H_{2} O}(1-h)} .
$$

A entalpia de formação da biomassa é calculada (Equação 47) a partir do poder calorífico superior, obtido experimentalmente

$$
\bar{h}_{f, b}=P C S_{b} M_{b}+\sum_{i=p r o d} v_{i} \bar{h}_{f, i}
$$

onde $v_{i}$ são os coeficientes estequiométricos dos produtos na reação estequiométrica da biomassa e $\bar{h}_{f, j}$ sua entalpia de formação.

\subsubsection{Equilíbrio químico e termodinâmico}

A reação global dentro do gaseificador pode ser escrita como:

$$
\begin{aligned}
\mathrm{CH}_{\mathrm{C}_{2}} \mathrm{H}_{c_{3}}+a\left(\mathrm{O}_{2}+3,76 \mathrm{~N}_{2}\right)+w \mathrm{H}_{2} \mathrm{O} & \\
& \rightarrow b \mathrm{CO}_{2}+c \mathrm{CO}+d \mathrm{H}_{2} \mathrm{O}+e \mathrm{~N}_{2}+\mathrm{fO}_{2}+\mathrm{lH}_{2}+k \mathrm{CH}_{4}
\end{aligned}
$$

Assume-se que o equilíbrio químico é conseguido e que o conteúdo de alcatrões e carvões no gás final pode ser desprezado. Também se presume que não há oxigénio nos produtos, já que a razão de equivalência de alta. A razão de equivalência $\phi$ é definida como mostrado na equação 49, e estabelece uma proporção entre a quantidade de ar e combustível na reação em relação à quantidade estequiométrica necessária.

$$
\Phi=\frac{(F / A)_{s}}{F / A}=\frac{a_{S}}{a},
$$

onde F/A é a razão combustível - ar e o índice $s$ indica a reação estequiométrica.

As equações de conservação de massa das espécies atômicas resultam no conjunto de equações 50: 


$$
\begin{gathered}
1=b+c+k \\
c_{2}+2 w=2 d+2 l+4 k \\
c_{3}+w+2 a=2 b+c+d \\
c_{4}+7,52 a=2 e
\end{gathered}
$$

Para que a solução seja possível serão necessárias mais duas equações de equilíbrio: a reação de shift (Equação 14) que descreve o equilíbrio entre $\mathrm{CO}$ e $\mathrm{H}_{2}$ na presença de água e a oxidação do hidrogênio (Equação 13) onde o hidrogênio é oxidado formando água.

A constante de equilíbrio é função da composição molar, assumindo que o gás produzido é um gás ideal e que a pressão no gaseificador é a pressão atmosférica.

$$
\begin{aligned}
\mathrm{K}_{1} & =\frac{b l}{c d} \\
\mathrm{~K}_{2} & =\frac{d}{l \sqrt{f}}
\end{aligned}
$$

Os valores das constantes são calculados pela minimização da função de energia livre de Gibbs, onde

$$
g=h-(T . s),
$$

e a função de Gibbs de formação fornecida pela equação

$$
\bar{g}_{T, i}^{0}=\bar{g}_{i}^{0}(T)-\sum_{\text {jelementos }} v_{j}^{\prime} \bar{g}_{j}^{0}(T) .
$$

Para o equilíbrio químico, a variação da função de Gibs

$$
\Delta G_{T}^{0}=-R_{u} T \ln K_{p},
$$

enquanto a constante de equilíbrio dada por

$$
K_{p}=\exp \left(\frac{-\Delta G_{T}^{0}}{R_{u} T}\right) .
$$

Assim $K_{1}$ e $K_{2}$ podem ser escritas como:

$$
K_{1}=\exp \left(-\frac{\bar{g}_{T, \mathrm{H}_{2}}^{0}+\bar{g}_{T, \mathrm{CO}_{2}}^{0}-\bar{g}_{T, \mathrm{CO}}^{0}-\bar{g}_{T, \mathrm{H}_{2} \mathrm{O}}^{0}}{R T}\right) \mathrm{e}
$$




$$
K_{2}=\exp \left(-\frac{2 \bar{g}_{T, \mathrm{H}_{2} \mathrm{O}}^{0}-2 \bar{g}_{T, \mathrm{H}_{2}}^{0}-\bar{g}_{T, \mathrm{O}_{2}}^{0}}{R T}\right)
$$

É utilizada a equação de conservação da energia em regime permanente, para determinar a temperatura do gás produzido $T_{P}$. Considerando que o trabalho produzido durante a gaseificação é zero e as perdas de calor são pequenas, temos

$$
\sum_{\text {reag }} v_{i}\left(\bar{h}_{f, 298}^{0}+\int_{298}^{T_{R}} \bar{c}_{p} d T\right)_{i}=\sum_{\text {prod }} v_{i}\left(\bar{h}_{f, 298}^{0}+\int_{298}^{T_{R}} \bar{c}_{p} d T\right)_{i},
$$

onde $v_{i}$ são os coeficientes da reação global de gaseificação (Equação 45), $\bar{h}_{f, 298}^{0}$ e $c_{p}$ são a entalpia de formação a $298 \mathrm{~K}$ e o calor específico a pressão constante, respectivamente.

\subsubsection{Solução numérica}

As equações 50(a-d), 57, 58 e 59 definem um sistema com sete equações não lineares com os quais determinam-se os seis coeficientes da reação global e a temperatura da reação.

Para fins de cálculo considera-se para o gás produzido, $1,7 \%_{\text {vol }}$ de metano $(\mathrm{k}=0,04998)$ e desprezível a quantidade de oxigênio $\left(f=10^{-24}\right)$, dada a baixa produção de metano nestas reações e baixas quantidades de oxigênio nos reagentes $(\Phi<0,44)$. Nos reagentes é acrescentada uma pequena quantidade de água $(w=0,1)$, de forma a melhorar a produção de hidrogênio.

Como funcionalidade do software EES, são obtidos os valores do número de Gibbs, entalpia, entalpia de formação das substâncias elementares e da entropia, através da subrotina NASA, inclusa no pacote do software. Os valores das massas molares e da constante dos gases, também são obtidos diretamente do software. Isso permite a determinação da temperatura dos gases produzidos.

Assim a variação do número de Gibbs para as duas reações são descritas pelas equações:

$$
\begin{gathered}
\Delta G_{1}^{0}=0,5 \cdot g_{\mathrm{O}_{2}}^{0}+g_{\mathrm{CO}}^{0}-g_{\mathrm{CO}_{2}}^{0} ; \\
\Delta G_{2}^{0}=g_{\mathrm{H}_{2} \mathrm{O}}^{0}-g_{\mathrm{H}_{2}}^{0}-0,5 \cdot g_{O_{2}}^{0} ; \\
\Delta G_{1}^{0}=-R \cdot T \cdot \ln \left(K_{1}\right) \mathrm{e} \\
\Delta G_{2}^{0}=-R \cdot T \cdot \ln \left(K_{2}\right) .
\end{gathered}
$$


As entalpias dos reagentes e dos produtos são dadas respectivamente pelas equações 64 e 65 .

$$
\begin{gathered}
H R=h_{f\left(\mathrm{C}_{x} \mathrm{H}_{y} \mathrm{O}_{z}\right)}+a \cdot h_{f\left(\mathrm{O}_{2}\right)}+3,76 \cdot a \cdot h_{f\left(\mathrm{~N}_{2}\right)}+w \cdot h_{f\left(\mathrm{H}_{2} \mathrm{O}\right)} \\
H P=b \cdot h_{\left(\mathrm{CO}_{2}\right)}+c \cdot h_{(\mathrm{CO})}+d \cdot h_{\left(\mathrm{H}_{2} \mathrm{O}\right)}+e \cdot h_{\left(\mathrm{N}_{2}\right)}+f \cdot h_{\left(\mathrm{O}_{2}\right)}+l \cdot h_{\left(\mathrm{H}_{2}\right)}+k \cdot h_{\left(\mathrm{CH}_{4}\right)}
\end{gathered}
$$

Como a entalpia dos produtos é igual à entalpia dos reagentes, consegue-se uma formulação no EES de 52 equações para 52 variáveis tornando possível a solução. Ao fim o programa retorna os valores das frações molares dos produtos, que após convertidas em frações mássicas $\left(x_{j}\right)$, é possível calcular o PCS através da equação 66

$$
\begin{aligned}
& P C S=120 x_{\mathrm{H}_{2}}+10,1 x_{C O}+55,5 x_{\mathrm{CH}_{4}}\left[M J \mathrm{~kg}^{-1}\right] \\
& P C S=12,0 \frac{x_{H_{2}}}{\rho_{H_{2}}}+12,1 \frac{x_{C O}}{\rho_{C O}}+37,7 \frac{x_{C H_{4}}}{\rho_{C_{4}}}\left[\mathrm{MJ} \mathrm{Nm}^{-3}\right]
\end{aligned}
$$

\subsubsection{Gaseificação experimental}

\subsubsection{Preparação e ajustes}

A gaseificação dos carvões em estudo foi realizada no gaseificador de leito fluidizado PID Eng\&Tech (Anexo C) instalado no NuCAT da COPPE / UFRJ. A unidade de gaseificação é uma planta piloto projetada para pesquisas em gaseificação de diferentes sólidos usando $\mathrm{CO}_{2}$, oxigênio, ar e vapor como agentes gaseificantes. O equipamento conta com um dispositivo para alimentação de sólidos para taxas até $1,5 \mathrm{~kg} \cdot \mathrm{h}^{-1}$ e com sistemas de limpeza do gás em vários estágios.

Para o presente estudo foram aplicadas duas metodologias de alimentação do reator: a primeira por batelada misturando $500 \mathrm{~g}$ de carvão com granulometria entre 1 e $2 \mathrm{~mm}$ a 500 $\mathrm{g}$ de areia de quartzo com granulometria entre 0,3 e 0,5 $\mathrm{mm}$ fazendo o carregamento pela parte superior do gaseificador. A segunda utilizando o alimentador da unidade a uma taxa fixa calibrada previamente, as curvas obtidas para os carvões com granulometria de 1 a $2 \mathrm{~mm}$ são usadas, juntamente com o controle de vazão de ar, para controlar a razão de equivalência $\Phi$.

Os carvões armazenados em um vaso cônico, alimentam o gaseificador através de 2 parafusos sem fim vedados com nitrogênio a uma vazão de $2000 \mathrm{NL} \mathrm{min}^{-1}$, este sistema 
controla a taxa de alimentação do gaseificador prevenindo que a reação ocorra antes que seja introduzido no reator. Agentes gaseificantes pré-aquecidos a $500{ }^{\circ} \mathrm{C}$ são introduzidos pela parte de baixo do reator e também são usados para fluidização do leito.

Para determinação do perfil de fluidização, foi utilizando $1 \mathrm{~kg}$ de areia de quartzo. Cada vazão de ar foi mantida por 30 minutos. Foram realizados testes à temperatura ambiente e a $900{ }^{\circ} \mathrm{C}$.

Outro método para obter a velocidade de mínima fluidização é por meio da composição da queda de pressão do leito ao igualar-se ao peso aparente do leito por unidade de área transversal:

$$
\frac{\Delta P}{L_{m f}}=g\left(1-\varepsilon_{m f}\right)\left(\rho_{s}-\rho\right)
$$

onde $\Delta P$ é a queda de pressão do fluido através do leito [atm]; $L_{m f}$ a altura do leito [m]; $g$ é a aceleração da gravidade $\left[\mathrm{m} \mathrm{s}^{-2}\right] ; \varepsilon_{m f}$ é a porosidade do leito [ ]; $\rho_{s}$ a densidade do sólido [ $\left.\mathrm{kg} \mathrm{m}^{-3}\right] ; \rho$ a densidade do leito $\left[\mathrm{kg} \mathrm{m}^{-3}\right]$.

A equação de Ergun para o regime turbulento calcula a velocidade mínima de fluidização por:

$$
v_{m f}=0,756\left[\frac{\rho_{s}-\rho}{\rho} g\left(\varepsilon_{m f}\right)^{3} D p\right]^{1 / 2}
$$

onde $v_{m f}$ é a velocidade mínima de mínima de fluidização e $D p$ é o diâmetro da partícula.

\subsubsection{Descrição da unidade piloto de gaseificação PID}

O gaseificador é um reator de $1515 \mathrm{~mm}$ de altura, dividido em duas zonas: leito, com $770 \mathrm{~mm}$ de altura por 82,8 $\mathrm{mm}$ de diâmetro interno, e bordo livre (freeboard), com $535 \mathrm{~mm}$ de altura por 134,5 $\mathrm{mm}$ de diâmetro interno. A alimentação de sólidos é feita por baixo do reator enquanto que os gases saem por cima e são conduzidos por tubos de $38,1 \mathrm{~mm}$ aos ciclones (Figura 9). 


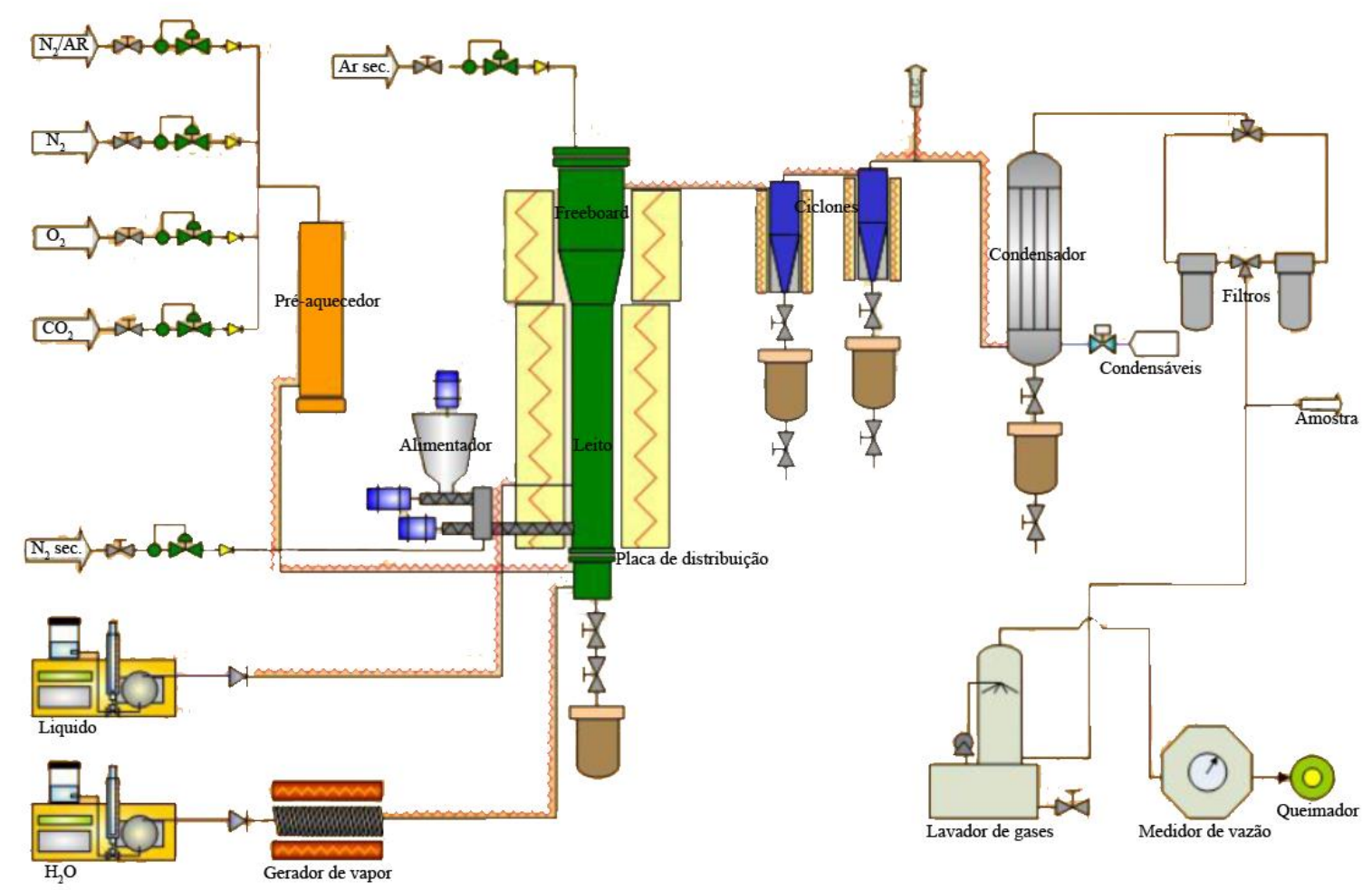

Figura 11 Gaseificador em leito fluidizado marca PID Eng\&Tech com controle via software das temperaturas e fluxos de combustível e gases

O reator é instrumentado com três termopares na zona do leito e um no freeboard, enquanto que a pressão é medida por transdutores posicionados em baixo, logo acima da placa de distribuição, e no topo do freeboard. O diferencial de pressão permite inferir sobre a formação do leito.

Os agentes gaseificantes são introduzidos abaixo da placa de distribuição, a cerca de $65 \mathrm{~mm}$ da base do reator e para a descarga do leito é utilizada uma válvula manual acima da placa de distribuição. $\mathrm{O}$ ar secundário é injetado por uma tubulação acima do leito e abaixo do freeboard.

\subsubsection{Fornalhas e placa de distribuição}

Duas fornalhas são necessárias para alcançar as temperaturas de processo. Cada fornalha tem duas resistências Kanthal que alcançam até $1150^{\circ} \mathrm{C}$. A fornalha inferior aquece a zona do leito e é dividida em duas partes, de forma a distribuir uniformemente o calor no reator, possui $700 \mathrm{~mm}$ de altura e potência de $7200 \mathrm{~W}$. A fornalha superior aquece a zona do freeboard e tem $430 \mathrm{~mm}$ com potência de $6000 \mathrm{~W}$. 
As temperaturas no interior do leito podem chegar a $900^{\circ} \mathrm{C}$ e o controle é feito através de um sensor posicionado dentro do reator, enquanto dois outros sensores registram as temperaturas. Para a proteção das resistências dos fornos, três sensores são posicionados próximos delas de forma a não ultrapassar a temperatura de segurança $\left(950^{\circ} \mathrm{C}\right)$.

A placa de distribuição é um cilindro fabricado em aço inox posicionado na parte inferior do reator e é a responsável pelo aquecimento do leito, uma vez que está posicionada em uma zona dentro do forno. O gás circula através da placa e é aquecido rapidamente pela sua superfície. Na parte superior do distribuidor existe um conjunto de malhas, uma de $100 \mu m$ e duas de $300 \mu m$, através das quais o gás é distribuído no reator.

\subsubsection{Sistema alimentador de sólidos}

O sistema alimentador é baseado em dois parafusos sem fim que controlam e regulam a taxa de sólidos para a parte inferior do leito fluidizado, e é composto por:

1. Vaso armazenador com capacidade para $10 \mathrm{~L}$ de biomassa, opera com pressão de até $50 \mathrm{kPa}$. Ele carrega o cone alimentador por batelada, através da abertura de uma válvula de esfera de $38,1 \mathrm{~mm}$ localizada entre os dois armazenadores;

2. Cone alimentador com capacidade para $10 \mathrm{~L}$ a $50 \mathrm{kPa}$, dotado de agitador para facilitar a dosagem de sólidos;

3. Parafuso dosador medindo $300 \mathrm{~mm}$ de comprimento por $16 \mathrm{~mm}$ de diâmetro, movido por motor elétrico MAE, modelo 23HS3432-01. A taxa de adição de sólidos no reator é regulada pela variação da velocidade do parafuso dosador;

4. Parafuso alimentador, similar na construção ao parafuso dosador, porém opera com velocidade 30\% maior, para evitar entupimentos. Este parafuso é encamisado e um sistema de arrefecimento o mantém frio o suficiente para evitar a pirólise dentro do tubo.

A velocidade dos alimentadores depende da granulometria e da taxa de alimentação de sólidos no reator, para o presente experimento foi usada calibração própria e o gráfico de referência pode ser visto no anexo A. 
A preparação do carvão para gaseificação é feita com a moagem no triturador Ika Werke mod. M20 e classificação dos carvões quanto a sua granulometria. São classificados em três tipos: finos, com grãos menores que $0,5 \mathrm{~mm}$; médios, com grãos entre 0,5 $\mathrm{mm}$ e 1,0 $\mathrm{mm}$ e grossos, com grãos entre $1 \mathrm{~mm}$ e $2 \mathrm{~mm}$. Para tanto são utilizadas peneiras na seguinte ordem: ABNT/ASTM 10, ABNT/ASTM 18, ABNT/ASTM 35 e fundo. Todo o conjunto é colocado sobre o agitador Bectel por $5 \pm 1 \mathrm{~min}$, ao fim do processo todo o carvão retido na primeira peneira (ABNT/ASTM 10) é moído e peneirado novamente até que não haja mais carvões com grãos maiores que $2 \mathrm{~mm}$.

\subsubsection{Procedimento de gaseificação}

O reator é o principal equipamento da planta piloto, e para sua operação são necessários alguns procedimentos:

1. Verificar se todas as conexões e cabos estão devidamente conectados;

2. Certificar que os parafusos alimentadores estão instalados;

3. Colocar o material de leito. Nunca preencher o leito antes de instalar o sistema alimentador;

4. Introduzir ar/nitrogênio;

5. Aquecer o reator até $700{ }^{\circ} \mathrm{C}$, sendo que a partir de $200{ }^{\circ} \mathrm{C}$ deverá ser feito obrigatoriamente sob fluxo de gás;

6. Iniciar a alimentação de sólidos com alta razão de equivalência $(\Phi)$;

7. Elevar a temperatura até $800{ }^{\circ} \mathrm{C}$ e estabeleçer as condições de operação (fluxo de vapor, temperatura de estabilização, fluxo de sólidos);

8. Realizar os experimentos.

Ao final do experimento serão necessários os seguintes passos:

1. Desligar os agentes gaseificantes;

2. Introduzir nitrogênio para tornar o sistema inerte;

3. Desligar o alimentador;

4. Abaixar a temperatura ao mínimo. Quando a temperatura estiver abaixo de $300{ }^{\circ} \mathrm{C}$ pode-se introduzir ar no lugar de $\mathrm{N}_{2}$. 


\subsubsection{Configurações para o experimento}

i. Ensaio feito com carregamento por batelada e variação da temperatura entre 500 a $900{ }^{\circ} \mathrm{C}$. Fluxo de ar a $12 \mathrm{NL} \mathrm{min}^{-1}$, Fluxo de nitrogênio a

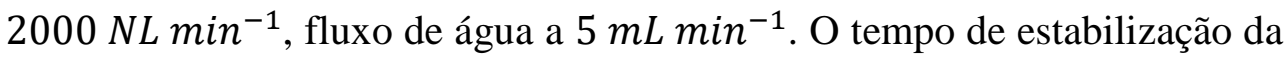
reação foi de $10 \mathrm{~min}$ para cada corrida e o tempo entre injeções para cromatografia foi de $43 \mathrm{~min}$.

ii. Carregamento feito com o alimentador da unidade, a taxa de alimentação de sólido e de gaseificantes é ajustada de acordo com a razão de equivalência desejada. A tabela 4 a seguir mostra as taxas usadas no experimento.

Tabela 4 Configuração de dosagens de carvão e agente gaseificante. Reator a $900{ }^{\circ} \mathrm{C}$, granulometria do carvão entre 1 e $2 \mathrm{~mm}$, taxa de alimentação de sólidos a $0,02 \mathrm{~kg} \mathrm{~min}^{-1}$, velocidade do feeder a $57 \%$ sem adição de água ao agente gaseificante.

\begin{tabular}{|l|l|l|}
\hline Biomassa & Razão de equivalência $(\Phi)$ & Fluxo de ar $\left(N L . \mathrm{min}^{-1}\right)$ \\
\hline \multirow{4}{*}{ CEFT } & 0,42 & 10 \\
\cline { 2 - 3 } & 0,49 & 12 \\
\cline { 2 - 3 } & 0,51 & 25 \\
\hline \multirow{4}{*}{ CEFM } & 0,41 & 9 \\
\cline { 2 - 3 } & 0,47 & 12 \\
\cline { 2 - 3 } & 0,52 & 25 \\
\hline \multirow{3}{*}{ CEFC } & 0,2 & 12 \\
\cline { 2 - 3 } & 0,57 & 28 \\
\cline { 2 - 3 } & 0,9 & 31 \\
\hline
\end{tabular}

\subsubsection{Análise dos gases da gaseificação}

Amostras de gases foram coletadas no ponto de amostragem, logo após o condensador do gaseificador, já resfriado à temperatura ambiente. Os gases acondicionados em coletores tipo saco com válvula de retenção, previamente evacuados por bomba de vácuo, foram transferidos para cromatografia.

A análise dos gases foi realizada no equipamento Shimadzu CG-2014 equipado com dois detectores TCD.

o $\quad$ Detector 1: Com hélio como gás de arraste e coluna Carboxen 1010;

o Detector 2: Usando ar como gás de arraste e coluna Peneira Molecular 5A. 
Os cromatogramas foram integrados de forma a obter a área equivalente de cada pico, o que pelo método aplicado, equivale à concentração molar de cada gás constituinte: CO, $\mathrm{H}_{2}, \mathrm{CH}_{4}, \mathrm{CO} 2, \mathrm{~N}_{2}$ e $\mathrm{O}_{2}$.

\subsubsection{Balanço de massa e energia}

O balanço de massa e energia seguiu a metodologia detalhada a seguir, com o objetivo de quantificar as grandezas, que permitirão determinação da eficiência do equipamento possibilitando dessa forma avaliar e comparar o seu desempenho.

O balanço de massa considera que a massa que entra no reator é a mesma que sai, assim:

$$
\sum \dot{m}_{r}=\sum \dot{m}_{p} \rightarrow \dot{m}_{\text {comb }}+\dot{m}_{a r}+\dot{m}_{\text {vapor }}=\dot{m}_{\text {gas }}+\dot{m}_{c}+\dot{m}_{\text {cinzas }}+\dot{m}_{H_{2} O} .
$$

O balanço de energia avalia as perdas durante o processo com objetivo de obter o calor útil do combustível. Considerando um determinado instante tem-se

$$
\dot{Q}_{\text {total }}=\dot{Q}_{\text {gas }}+\dot{Q}_{\text {residuos }}+\dot{Q}_{p m r}+\dot{Q}_{c p g}+\dot{Q}_{p c c}
$$

Onde $\dot{Q}_{\text {total }}=\dot{m}_{b} P C I_{b}+\dot{m}_{a r} h_{a r}+\dot{m}_{v} h_{v}$ e as perdas associadas ao gás gerado, das cinzas para o meio ambiente são dadas pelas equações e as perdas relacionadas ao calor cedido pelo reator são respectivamente:

$$
\begin{aligned}
& \dot{Q}_{c p g}=\dot{m}_{\text {gás }} C p_{\text {gás }}\left(T_{\text {gás }}-T_{\infty}\right), \\
& \dot{Q}_{\text {resíduos }}=\dot{m}_{\text {residuos }} C p_{\text {residuos }}\left(T_{\text {residuos }}-T_{\infty}\right), \\
& \dot{\mathrm{Q}}_{p m r}=\frac{T_{r}-T_{\infty}}{\frac{1}{h_{0} A_{0}}+\frac{\ln \left(r_{2} / r_{1}\right)}{2 \pi k_{2} L}+\frac{\ln \left(r_{3} / r_{2}\right)}{2 \pi k_{3} L}} .
\end{aligned}
$$

Onde: $T_{r}$ é a Temperatura do leito $[\mathrm{K}] ; T_{\infty}$ a Temperatura Ambiente $[\mathrm{K}] ; h_{0}$ o coeficiente de transferência de calor por convecção; $k_{1,2,3}$ a Condutividade térmica dos materiais (refratário do reator, lã de vidro usado no isolamento térmico e aço do gaseificador); $A_{0}$ Área da parede e $L$ o Comprimento do Reator.

As perdas pela não conversão do carbono são

$$
\begin{aligned}
& \dot{Q}_{p c c}=\dot{m}_{\text {cinzas }} \dot{C}_{\text {cinzas }} P C I_{\text {carbono }}+\dot{m}_{\text {gas }} \dot{C}_{\text {gas }} P C I_{\text {carbono }} \text { e o balanco de carbono } \\
& \mathrm{C}_{b}=C O+\mathrm{CH}_{4}+C_{x} H_{y}+C_{\text {cinzas }}+C_{\text {alcatrão }}
\end{aligned}
$$


O desempenho gaseificador é medido em termos da qualidade e da quantidade de gás produzido, ou seja, se o combustível sólido com poder calorífico superior $P C S_{b}\left[M J \mathrm{~kg}^{-1}\right]$ é gaseificado para produzir um produto gasoso com um $P C S_{g a s}\left[\mathrm{MJ} \mathrm{Nm}^{-3}\right]$ com volume específico $v_{g a s}\left[\mathrm{Nm}^{3} \mathrm{~kg}^{-1}\right]$ a eficiência de gás frio $\eta_{g f}$ é expressa pela equação

$$
\eta_{g f}=\frac{P C S_{g a s} v_{g a s}}{P C S_{b}}
$$

A eficiência com gás quente usado quando ele é queimado numa fornalha ou caldeira sem arrefecimento, criando uma maior utilização da energia. Portanto, a eficiência de gás quente, $\eta_{g q}$, pode ser definida pela equação 74 .

$$
\eta_{g q}=\frac{P C S_{g a s} v_{g a s}+P C S_{a} y_{a}}{P C S_{b}}
$$

onde $P C S_{a}\left[M J k^{-1}\right]$ é o PCS do alcatrão e $y_{a}\left[k_{k g} g_{b}^{-1}\right]$ a taxa específica de produção de alcatrão por quilo de biomassa consumida no reator.

Eficiência líquida quando o teor de entalpia ou energia do meio de gaseificação pode ser substancial, e assim, para uma análise rigorosa, estas entradas devem ser tomadas em consideração. Ao mesmo tempo, uma parte da energia de entrada é devolvida (crédito de energia) pelo alcatrão produzido, bem como por qualquer recuperação do calor de vaporização no produto gasoso. Um balanço energético mais rigoroso pode ser escrito como:

$$
\eta_{l}=\frac{\text { Energia_líquida_do_gás }}{\text { Total_de_energia_inserida }}
$$

\subsection{ATIVAÇÃO DE CARVÃO}

A produção de carvão ativado foi realizada no laboratório de catálise do Instituto de Química da UnB (IQ-UnB) e tem por finalidade, comparar o estado de ativação entre um carvão ativado quimicamente com o estado dos finos de carvão arrastado durante o processo de gaseificação. Utilizando os indicadores listados em 2.3.3, é possível, então, comparar resultados de carvões ativados quimicamente com os arrastados no processos de gaseificação.

Para a ativação química a biomassa virgem foi impregnada de carbonato de potássio $\left(\mathrm{K}_{2} \mathrm{CO}_{3}\right)$ em meio aquoso na proporção de 1:1 (em massa) e em seguida seca em estufa por 
$24 \mathrm{~h}$ a $103 \pm 2{ }^{\circ} \mathrm{C}$. Para comparação a biomassa já carbonizada também é impregnada com $K_{2} \mathrm{CO}_{3}$ na proporção de 3:1. Os procedimentos seguintes são iguais para ambas as metodologias.

O material preparado foi colocado em cadinhos cerâmicos com tampa e levados ao forno mufla a $700^{\circ} \mathrm{C}$ por uma hora e então resfriados por 4 horas dentro com a porta fechada. Após a carbonização as amostras, colocadas em filtros de papel, foram lavadas com água morna, para retirar o excesso de $\mathrm{K}_{2} \mathrm{CO}_{3}$ e em seguida com água destilada à temperatura ambiente até PH neutro. Após a ativação os carvões seguiram para análise de área superficial e morfologia.

Para a ativação física dos carvões, aproveita-se o rejeito de carvões arrastados e recuperados nos ciclones da unidade de gaseificação. O carvão, assim como coletado, é encaminhado para caracterização.

\subsubsection{Análise de área superficial e porosidade}

Os valores de área superficial específica e porosidade foram determinados a partir de isotermas de adsorção de $\mathrm{N}_{2}$ a $77 \mathrm{~K}$ usando um equipamento NOVA 300 BET analisador da Quanta Chrome, USA. Os valores de área e tamanho médio de poro foram obtidos a partir da aplicação dos modelos de BET e BJH para os dados da isoterma.

\subsubsection{Morfologia dos carvões ativados}

A morfologia dos materiais foi obtida por microscopia eletrônica de varredura (MEV), utilizando-se um aparelho JEOL JSM-7100F, usando uma tensão de $15 \mathrm{kV}$. As amostras foram colocadas sobre a superfície do suporte de alumínio fixadas com fita de carbono dupla face.

\subsubsection{Teste de adsorção}

Para os ensaios de adsorção na fase líquida foi utilizada a mesma metodologia apresentada por (Brum et al., 2008; Vasques, 2008; Vasques et al., 2011), utilizado como adsorbato o corante azul de metileno (AM) da Merck e o corante reativo vermelho - reactive Red 2 (RR2). Para os testes, $10 \mathrm{mg}$ de cada carvão foram colocados em contato com $10 \mathrm{~mL}$ de soluções de AM e RR02 em várias concentrações (10, 25, 50, 100, 250, 500 e 1000 mg $\mathrm{L}^{-1}$ ) por $24 \mathrm{~h}$ à temperatura de $30^{\circ} \mathrm{C}$ e pH 5,0. A concentração restante do AM ou RR02 foi 
analisada em um espectrofotômetro de UV/VIS (Biosystems SP-2000) no comprimento de onda de $645 \mathrm{~nm}$.

Para determinar a capacidade máxima de adsorção de AM / RR02 nos carvões, a isoterma de adsorção foi conduzida analisando os dados através do modelo de Langmuir pelas Equações 76 e 77:

$$
q_{e q}=\frac{K_{L} \cdot C_{e q} \cdot b}{1+K_{L} \cdot C_{e q}}
$$

E após a linearização

$$
\frac{C_{e q}}{q_{e q}}=\frac{1}{K_{L} \cdot b}+\frac{C_{e q}}{b}
$$

onde $q_{e q}\left(m g g^{-1}\right)$ é a quantidade adsorvida de AM por grama de carvão; $C_{e q}\left(\mathrm{mg} \mathrm{L}^{-1}\right)$ é a concentração de AM / RR02 no equilíbrio; $b\left(m g ~ g^{-1}\right)$ é a capacidade de adsorção máxima e $K_{L}\left(m L m o l^{-1}\right)$ é uma constante relacionada à energia de adsorção, ambos ( $b$ e $\left.K_{L}\right)$ podem ser determinados através do gráfico de qeq versus $\mathrm{C}_{\mathrm{eq}}$.

\subsubsection{Estudo da cinética de adsorção de azul de metileno}

O estudo foi feito para determinar o tempo necessário para se atingir o equilíbrio de adsorção. Neste experimento $10 \mathrm{mg}$ de carvão juntamente com $10 \mathrm{~mL}$ de solução de azul de metileno a 10, 50, 100, 250 ou $500 \mathrm{mg} \mathrm{L}^{-1}$ foram mantidos em contato por diferentes tempos $(0,5 ; 1,0 ; 2,0 ; 4,0 ; 6,0 ; 12$ e 24,0 h) e a concentração de AM / RR02 restante, após a adsorção, foi determinada por espectrofotometria UV/VIS no comprimento de onda de $645 \mathrm{~nm}$. 


\section{RESULTADOS}

\subsection{CARACTERIZAÇÃO DA BIOMASSA VIRGEM}

Como descrito nos objetivos desse trabalho, a biomassa residual, ou biomassa virgem, é um recurso natural que pode ser transformado em derivados energéticos ou derivados de valor agregado. Portanto, a caracterização mais básica dessa biomassa é a avaliação da Densidade, Poder Calorífico, Análise Imediata e Análise Elementar mostrados na Tabela 5. Tais propriedades dão uma primeira ideia das diferenças entre os tipos de biomassa avaliados neste estudo.

Tabela 5 - Caracterização da biomassa virgem

\begin{tabular}{|c|c|c|c|}
\hline Propriedades - biomassa virgem & EFT & EFM & EFC \\
\hline Densidade a granel $\left(\mathrm{kg} \mathrm{m}^{-3}\right)^{\mathrm{a}}$ & 340 & 580 & 290 \\
\hline PCS (MJ kg $\left.{ }^{-1}\right)$ & 21,32 & 24,26 & 19,27 \\
\hline Fórmula química equivalente & $\mathrm{CH}_{1,67} \mathrm{O}_{0,47} \mathrm{~N}_{0,01}$ & $\mathrm{CH}_{1,51} \mathrm{O}_{0,64} \mathrm{~N}_{0,04}$ & $\mathrm{CH}_{1,53} \mathrm{O}_{0,77} \mathrm{~N}_{0,02}$ \\
\hline Análise imediata & EFT & EFM & EFC \\
\hline Carbono Fixo (\%) & 20,56 & 22,45 & 18,06 \\
\hline Voláteis (\%) & 66,54 & 66,69 & 70,01 \\
\hline Cinzas $(\%)$ & 2,78 & 1,54 & 2,8 \\
\hline Umidade $(\%)$ & 10,12 & 9,32 & 9,13 \\
\hline Análise elementar & EFT & EFM & EFC \\
\hline Carbono (C) (\%) & 56,13 & 49,43 & 46,13 \\
\hline Hidrogênio $(\mathrm{H})(\%)$ & 7,85 & 6,27 & 5,94 \\
\hline Oxigênio $(\mathrm{O})(\%)$ & 35,01 & 42,15 & 47,07 \\
\hline Composição química & EFT & EFM & EFC \\
\hline Extrativos $\left(\%_{b s}\right)$ & 4,6 & $10,8^{c}$ & $8,8^{\mathrm{e}}$ \\
\hline Hemicelulose $\left(\%_{b s}\right)$ & $17,4^{\mathrm{b}}$ & $15,2^{\mathrm{d}}$ & $18,0^{\mathrm{e}}$ \\
\hline Celulose $\left(\%_{b s}\right)$ & $40,8^{b}$ & 48,9 & 62,8 \\
\hline Lignina $\left(\%_{b s}\right)$ & $37,1^{\mathrm{b}}$ & $36,6^{\mathrm{c}}$ & $10,4^{\mathrm{e}}$ \\
\hline
\end{tabular}

${ }^{a}$ Medição feita com material com granulometria entre $150 \mu \mathrm{m}$ e $250 \mu \mathrm{m} .{ }^{\mathrm{b}}$ (Nascimento, 2012). ${ }^{\mathrm{c}}$ (Silva et al., 1986). ${ }^{\mathrm{d}}$ (Quintana, 2013). ${ }^{\mathrm{e}}$ (Cerón et al., 2015)

Observa-se que o endocarpo da fruta da macaúba (EFM) é a biomassa com maior densidade a granel entre as três avaliadas e a que possui maior quantidade de carbono fixo. Também é a biomassa com o maior PCS, seguido pelo endocarpo da fruta do Tucumã (EFT) e por último o epicarpo da fruta do Cupuaçu (EFC). O maior PCS alcançado pela EFM, a torna a melhor alternativa, entre as três, para queima direta. Na produção de carvão vegetal o teor de lignina oferece um indicador importante para o rendimento do processo, neste contexto o EFT oferece maiores teores de lignina. 
Na seção 3.1.1 foi descrito que após a caracterização dos tipos de biomassa fez-se a avaliação da degradação térmica, e a caracterização dos produtos e subprodutos gerados nos processos de pirólise e gaseificação respectivamente. Para tanto a análise da degradação térmica foi dividido em duas partes: a primeira conduzida em taxas de aumento de temperatura lenta $\left(2^{\circ} \mathrm{C} \mathrm{min}^{-1}\right)$ sob fluxo de nitrogênio até a temperatura de carbonização $\left(450^{\circ} \mathrm{C}\right)$, e a segunda em taxas rápidas, sob fluxo de ar sintético, objetivando a investigação sob temperaturas típicas da gaseificação, ou seja, superiores a $700{ }^{\circ} \mathrm{C}$. Ambas as investigações são discutidas na seção 4.2 a seguir.

\subsection{ANÁLISE DA DEGRADAÇÃO TÉRMICA - TG-FTIR}

As análises de TG e DTG (Figura 12), foram realizadas para determinação dos parâmetros da pirólise e avaliar o rendimento para a carbonização de cada biomassa.

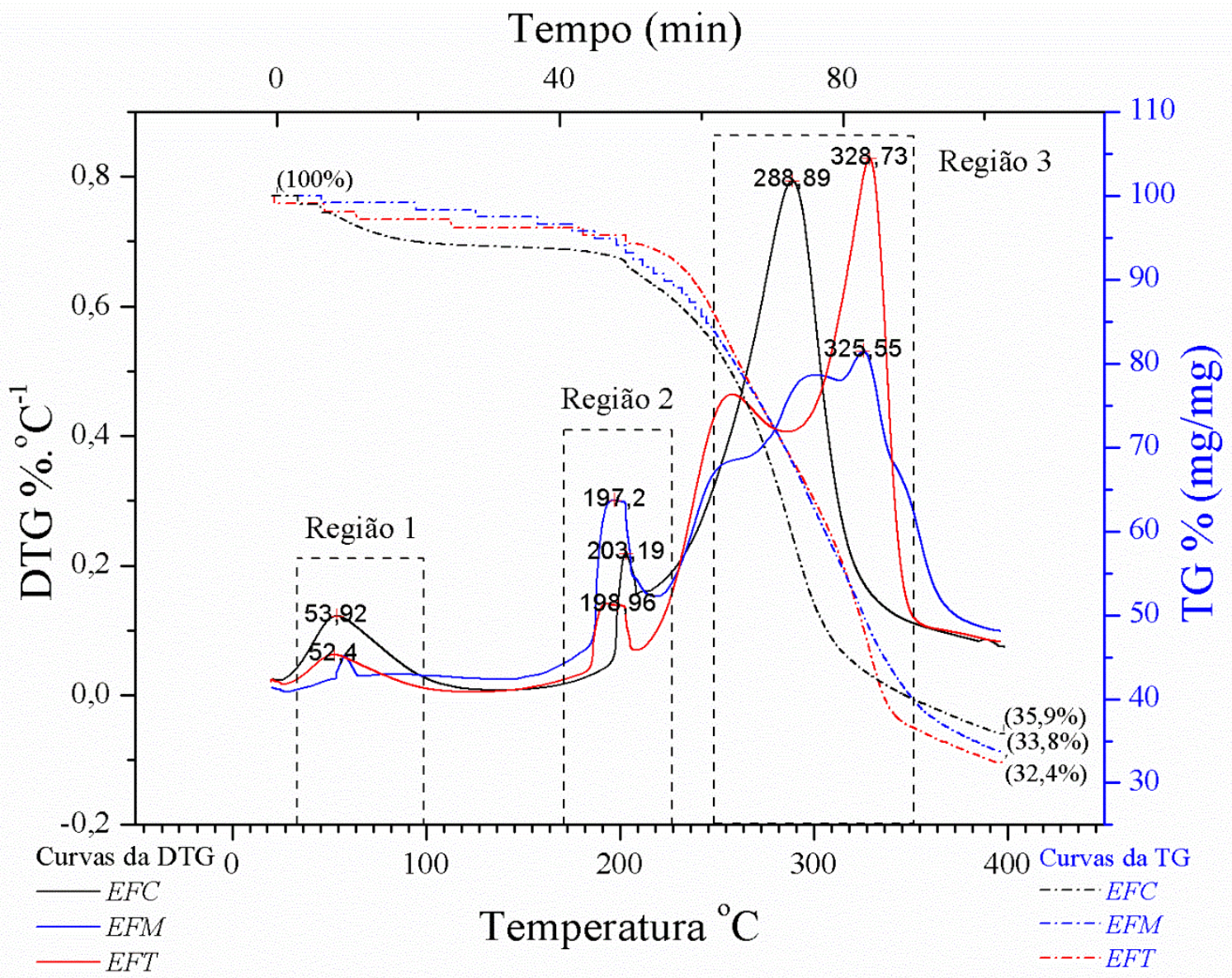

Figura 12 Termogravimetria (TG/DTG) dos três resíduos, com temperaturas variando de $23^{\circ} \mathrm{C}$ a $450^{\circ} \mathrm{C}$ com rampa de $2^{\circ} \mathrm{C}$. $\mathrm{min}^{-1}$ sob fluxo de $100 \mathrm{ml} \mathrm{min}^{-1}$ de nitrogênio. Nos picos da DTG são observadas três regiões onde foram analisados os espectros de infravermelho dos gases emitidos durante o ensaio.

O maior resíduo percentual de massa, pela degradação térmica em condição de pirólise, foi observado para o EFC (36\%), seguido do EFM (34\%) e EFT (32\%) (Figura 10). 
Contudo, há uma inflexão na curva do EFC a partir de $289^{\circ} \mathrm{C}$, confirmando o comportamento esperado em relação aos EFM e EFT, por possuir maior teor de hemicelulose e menor teor de lignina em sua composição química (Seye et al., 2000). Teores de lignina com valores próximos, conferem às curvas dos EFT e EFM, pontos de inflexão na curva a temperaturas mais elevadas, quando comparadas ao EFC. O último pico da DTG para o EFC ocorreu a $288,9^{\circ} \mathrm{C}$, o que sugere que para processos de carbonização deve-se usar temperaturas acima desta para a completa degradação dos componentes da biomassa (celulose, lignina e hemicelulose). Da mesma forma a degradação do EFM precisará de temperaturas superiores a $325,6^{\circ} \mathrm{C}$, enquanto o EFT carbonizará em temperaturas superiores a $328,7^{\circ} \mathrm{C}$.

Pelos resultados das curvas de TG e DTG (Figura 12), de maneira geral observam-se três regiões de degradação térmica, sendo o primeiro entre a temperatura ambiente até os $100{ }^{\circ} \mathrm{C}$ com pico aos $10 \mathrm{~min}$ do início do ensaio, o segundo próximo aos $200{ }^{\circ} \mathrm{C}$, com pico aos 50 min e o terceiro com temperaturas entre 289 e $329^{\circ} \mathrm{C}$ com picos variando entre 78 e $89 \mathrm{~min}$, diferentemente para os tipos de biomassa. Na tabela 6 são mostrados especificamente os valores de temperatura e tempo dos picos da DTG para cada biomassa. Estas regiões estão relacionadas à degradação térmica dos componentes da biomassa, sendo o primeiro atribuído à perda de água, o segundo à degradação das hemicelulose e o terceiro devido à degradação da celulose e da lignina.

Tabela 6 Temperatura $(T)$, variação de massa $(\Delta \mathrm{m})$ e tempo $(\mathrm{t})$ de reação nos picos da curva DTG na degradação térmica da biomassa virgem. Resíduo sólido $(\mathrm{R})$ ao final da análise.

\begin{tabular}{|l|l|l|l|l|l|l|l|l|l|l|}
\hline DTG & \multicolumn{3}{|l|}{ Região 1 } & \multicolumn{3}{l|}{ Região 2} & \multicolumn{2}{l|}{ Região 3 } & Final \\
\hline Esp. & $\begin{array}{r}\mathrm{T} \\
{ }^{\circ} \mathrm{C}\end{array}$ & $\begin{array}{l}\Delta \mathrm{m} \\
\%\end{array}$ & $\begin{array}{l}\mathrm{t} \\
\min \end{array}$ & $\begin{array}{l}\mathrm{T} \\
{ }^{\circ} \mathrm{C}\end{array}$ & $\begin{array}{l}\Delta \mathrm{m} \\
\%\end{array}$ & $\begin{array}{l}\mathrm{t} \\
\min \end{array}$ & $\begin{array}{l}\mathrm{T} \\
{ }^{\circ} \mathrm{C}\end{array}$ & $\begin{array}{l}\Delta \mathrm{m} \\
\%\end{array}$ & $\begin{array}{l}\mathrm{t} \\
\min \end{array}$ & $\begin{array}{l}\mathrm{R} \\
\%\end{array}$ \\
\hline EFC & 53,9 & 5,4 & 10 & 203,2 & 3,6 & 53 & 288,9 & 47,3 & 78 & 35,9 \\
\hline EFM & 58,4 & 7,0 & 11 & 197,2 & 13,7 & 51 & 325,6 & 44,8 & 89 & 33,8 \\
\hline EFT & 53,2 & 2,6 & 10 & 199,0 & 2,6 & 52 & 328,7 & 57,9 & 89 & 32,4 \\
\hline
\end{tabular}

Para a biomassa carbonizada, semelhante ao método usado para a biomassa virgem, foi conectado o equipamento de TG a um analisador de infravermelho, conforme descrito no item 2.3. A figura 13 mostra a curva da TG e DTG para a degradação dos carvões, as quais apresentam uma única região de degradação térmica no gráfico, e consequentemente um pico na DTG, na faixa de temperatura entre 300 e $700{ }^{\circ} \mathrm{C}$. 


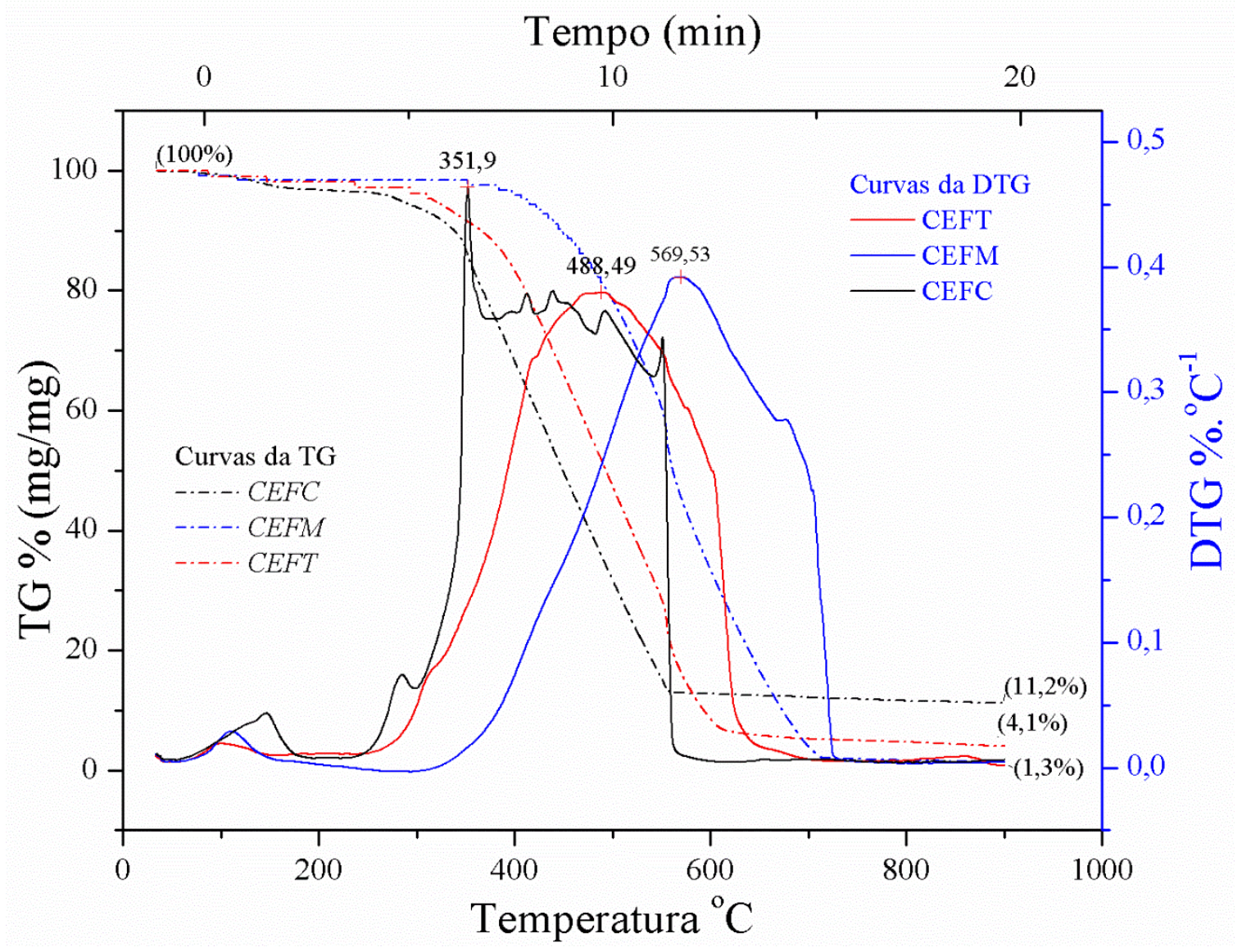

Figura 13 Curvas de TG e DTG dos carvões. $\mathrm{O}$ aquecimento foi de $23^{\circ} \mathrm{C}$ a $900^{\circ} \mathrm{C}$ com rampa de $20^{\circ} \mathrm{C} \mathrm{min}^{-1}$ sob fluxo de ar sintético de $100 \mathrm{~mL} \mathrm{~min}^{-1}$

Da análise do gráfico da figura 13 percebe-se que o CEFC é o que produz o maior residual $11,2 \%$ da massa inicial, basicamente constituído por cinzas. Em seguida o tucumã com 4,1\% e a macaúba com 1,3\%. Na investigação destes tipos de biomassa em temperaturas típicas de gaseificação, observou-se que o CEFC se degrada termicamente a temperatura mais baixa que o CEFT e o CEFM, tipicamente relacionado à sua estrutura mais porosa que os demais.

Dos gráficos (Figuras 12 e 13) é possível inferir que os pontos onde a análise dos gases emitidos melhor representa a amostra, são os de pico da DTG. Para tanto, nos tempos e temperaturas medidos nestes pontos são analisados, por espectrometria de infravermelho (Figuras 12, 13 e 14), as composições dos gases conforme descrito a seguir. Os gases emitidos durante o ensaio foram identificados seguindo a tabela 7 , que apresenta um resumo dos compostos encontrados em função do número de onda baseados nas interpretações dos espectros constantes na literatura (Stuart, 2005; Yang et al., 2007; Liu et al., 2008; Cao et al., 2013; Edreis et al., 2013; Silverstein et al., 2014). 
Tabela 7 Correspondência entre o número de onda e compostos contidos no gás.

\begin{tabular}{|l|l|l|l|}
\hline $\begin{array}{c}\text { Número de } \\
\text { onda }\left(\mathrm{cm}^{-1}\right)\end{array}$ & \multicolumn{1}{|c|}{ Compostos } & $\begin{array}{c}\text { Número de } \\
\text { onda }\left(\mathrm{cm}^{-1}\right)\end{array}$ & \multicolumn{1}{|c|}{ Compostos } \\
\hline $3500-3750$ & $\mathrm{H}_{2} \mathrm{O}$ & $1610-1650$ & Aromáticos \\
\hline $2860-3000$ & $\mathrm{CH}_{4}, \mathrm{CH}_{\mathrm{x}}$ & $1365-1600$ & Propanol \\
\hline $2250-2500$ & $\mathrm{CO}_{2}$ & $1280-1360$ & Alquilas \\
\hline $2000-2250$ & $\mathrm{CO}$ & $1000-1100$ & Furanos \\
\hline $1880-2000$ & Sais de amina & $950-1058$ & R-OH \\
\hline $1540-1870$ & $\begin{array}{l}\text { Cetonas, aldeídos, ácidos carboxílicos, } \\
\text { ésteres carboxílicos, aminas, etc. }\end{array}$ & 866 & $\mathrm{C}-\mathrm{H}$ \\
\hline $1640-1667$ & Alcanos & $400-700$ & Alifático C-C \\
\hline
\end{tabular}

Fonte: adaptado de (Silverstein et al., 2014)

Para o epicarpo da fruta do cupuaçu (EFC) os espectros medidos foram os apresentados na figura 14 a seguir.

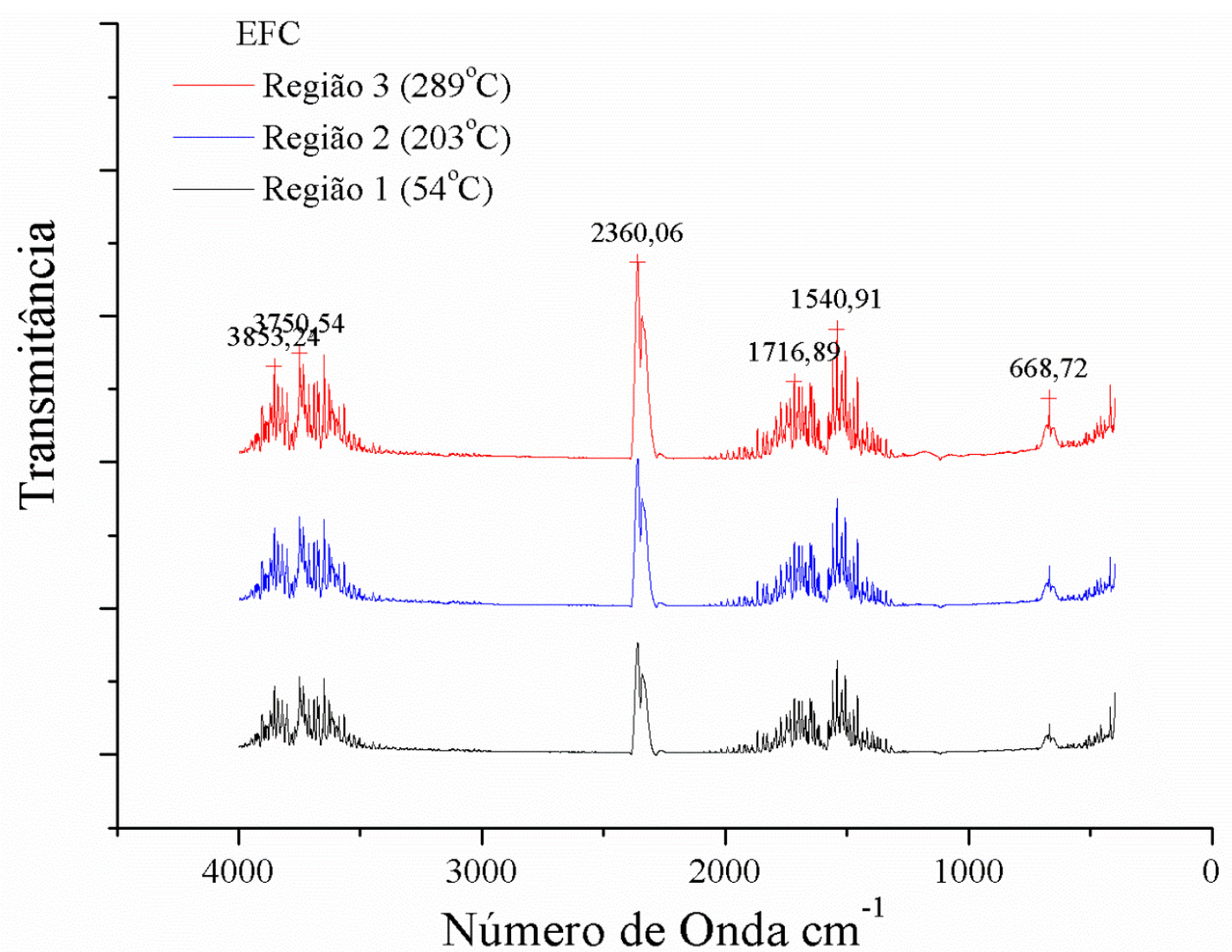

Figura 14 Espectros de infravermelho dos gases das emissões durante a degradação térmica do EFC nas temperaturas de 54,203 e $289^{\circ} \mathrm{C}$.

Com relação às espécies obtidas no processo de degradação térmica, observou-se para a região 1 (Figura 12), espectros da transmitância dos gases compostos por água $\left(3500-3750 \mathrm{~cm}^{-1}\right)$ e $\mathrm{CO}_{2}\left(2250-2500 \mathrm{~cm}^{-1}\right)$ com traços de ácidos carboxílicos $\left(1750-2000 \mathrm{~cm}^{-1}\right)$. Em uma segunda região além da transmitância de vapor de água, em menor quantidade, $\mathrm{CO}_{2}$ e ácidos carboxílicos, observa-se também a presença de $\mathrm{CO}$ 
(2000 - $\left.2250 \mathrm{~cm}^{-1}\right)$, nesta fase da degradação térmica as reações são endotérmicas (Figura 15) e caracteriza-se pela degradação das hemiceluloses. Uma terceira região é caracterizada pela transmitância do alcatrão $\left(1540-1870 \mathrm{~cm}^{-1}\right), \mathrm{CO}$ e $\mathrm{CH}_{4}(2860-$ $3000 \mathrm{~cm}^{-1}$ ), esta fase da degradação térmica é caracterizada pela degradação da celulose e da lignina em reações exotérmicas (Figura 18).

Os espectros dos gases emitidos durante a degradação térmica do endocarpo da fruta da macaúba (EFM) (Figura 15), mostra menor intensidade de transmitância a temperaturas mais baixas e aumentando com o incremento da temperatura.

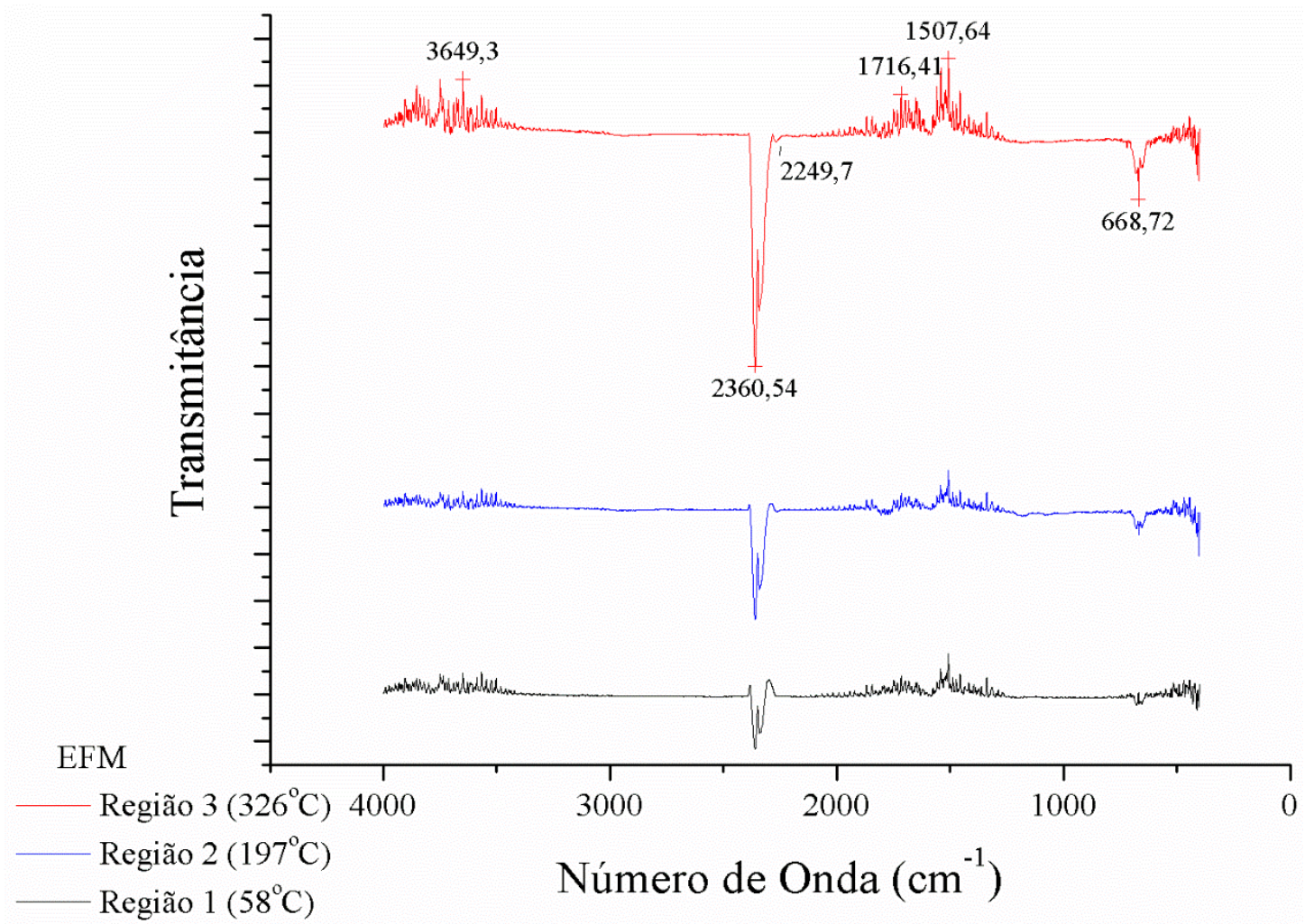

Figura 15 Espectros de infravermelho dos gases das emissões durante a degradação térmica do EFM nas temperaturas de 58,197 e $326^{\circ} \mathrm{C}$.

Para os resíduos da macaúba apresenta evidência de emissão de água, $\mathrm{CO}_{2}$ e ácidos carboxílicos na área da região 1 (Figura 12), passando nas temperaturas da região 2 a emitir, além dos gases da região 1, CO e compostos alifáticos caracterizados pela ligação C-C e CH. Finalmente na região 3 apresenta-se com expressiva emissão de $\mathrm{CO}$ e Cetonas, aldeídos, ácidos carboxílicos, ésteres carboxílicos e aminas (substâncias que caracterizam o licor pirolenhoso), além de maior quantidade de compostos alifáticos. 


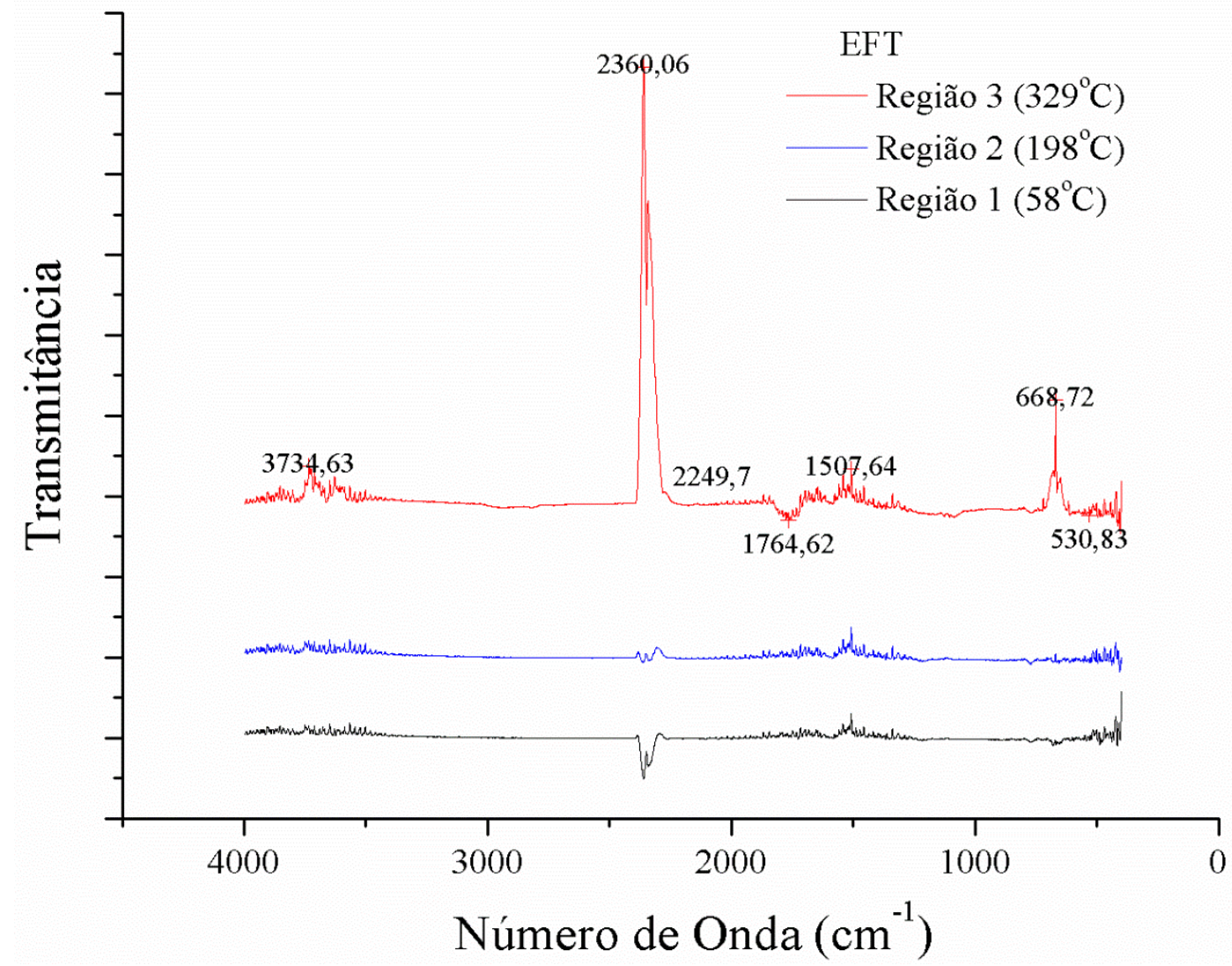

Figura 16 Espectros de infravermelho dos gases das emissões durante a degradação térmica do EFT nas temperaturas de 58,198 e $329^{\circ} \mathrm{C}$.

Por fim, os espectros dos gases provenientes da degradação dos resíduos de tucumã (EFT), apresentam na região 1 (Figura 12) água, $\mathrm{CO}_{2}$, e compostos alifáticos. Na região 2 $\left(198^{\circ} \mathrm{C}\right)$, observou-se a produção das mesmas substâncias da região 1 e o início das emissões de $\mathrm{CO}$ e na região 3 é caracterizada pela presença de água, grande quantidade de $\mathrm{CO}_{2}, \mathrm{CO}$, Cetonas, aldeídos, ácidos carboxílicos, ésteres carboxílicos, aminas, alcanos e compostos alifáticos caracterizados pela ligação C-C.

Observou-se ainda pela comparação direta dos espectrogramas das figuras 14, 15 e 16, que o resultado que mais se evidenciou foi o aumento da transmitância na faixa do alcatrão $\left(1540-1870 \mathrm{~cm}^{-1}\right)$ com o consequente aumento da temperatura na degradação térmica da biomassa in natura.

Para a degradação térmica dos carvões, no entanto, observou-se que os espectros dos gases, apresentavam picos em posições similares, conforme mostrado na figura 17 a seguir. 


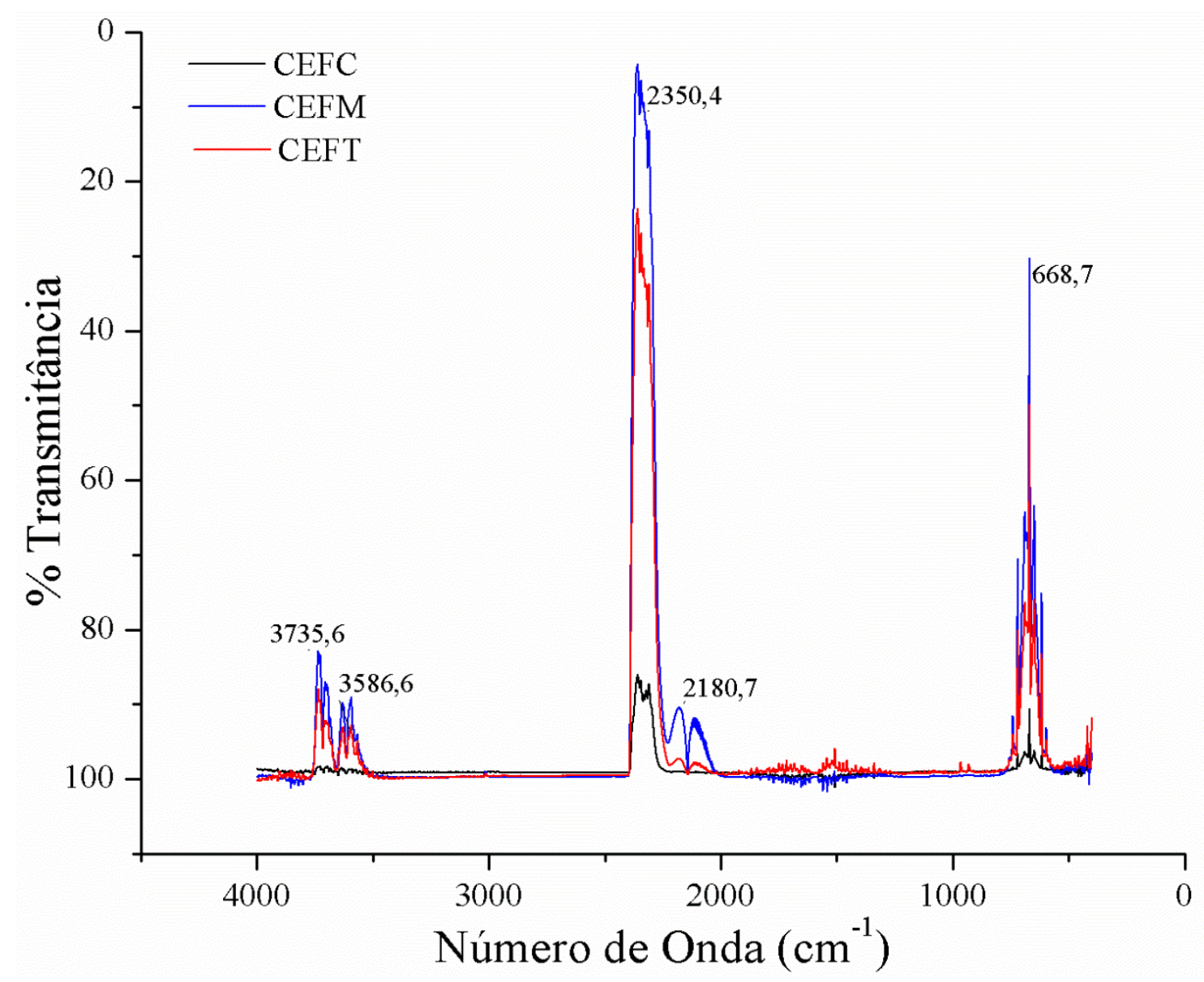

Figura 17 Espectros de infravermelho dos gases emitidos durante a degradação térmica dos carvões à temperatura de gaseificação sob fluxo de $100 \mathrm{~mL} \mathrm{~min}^{-1}$ de ar sintético.

Os gases provenientes da degradação térmica dos carvões apresentaram à temperatura de típica de gaseificação, a presença de água $\left(3500-3750 \mathrm{~cm}^{-1}\right), \mathrm{CO}_{2}$ $\left(2250-2500 \mathrm{~cm}^{-1}\right), \operatorname{CO}\left(2000-2250 \mathrm{~cm}^{-1}\right)$ e compostos alifáticos $(400-$ $700 \mathrm{~cm}^{-1}$ ). Pela análise dos espectros não há evidência de presença de hidrocarbonetos pesados $\left(1540-1870 \mathrm{~cm}^{-1}\right)$ durante o processo, diferentemente do que foi visto para os resultados das carbonizações dos resíduos ainda virgens. Tal observação sugere que não haverá emissão de alcatrões no processo de gaseificação desses carvões, o que permite o uso do gás de síntese em motores ciclo diesel sem a necessidade de filtros ou sistemas de eliminação destas substâncias. Análise dos resíduos condensáveis durante a gaseificação, no item 4.4 a seguir, trará mais informações sobre esta característica.

Pela das curvas da calorimetria exploratória diferencial - DSC (Figura 18), caracterizada pela medida de fluxo de calor do reator, revelou as faixas de temperatura para as reações endotérmicas e exotérmicas. As normas ASTM E793 e E794 sugere a representação de processos endotérmicos com a orientação da amplitude para baixo. 


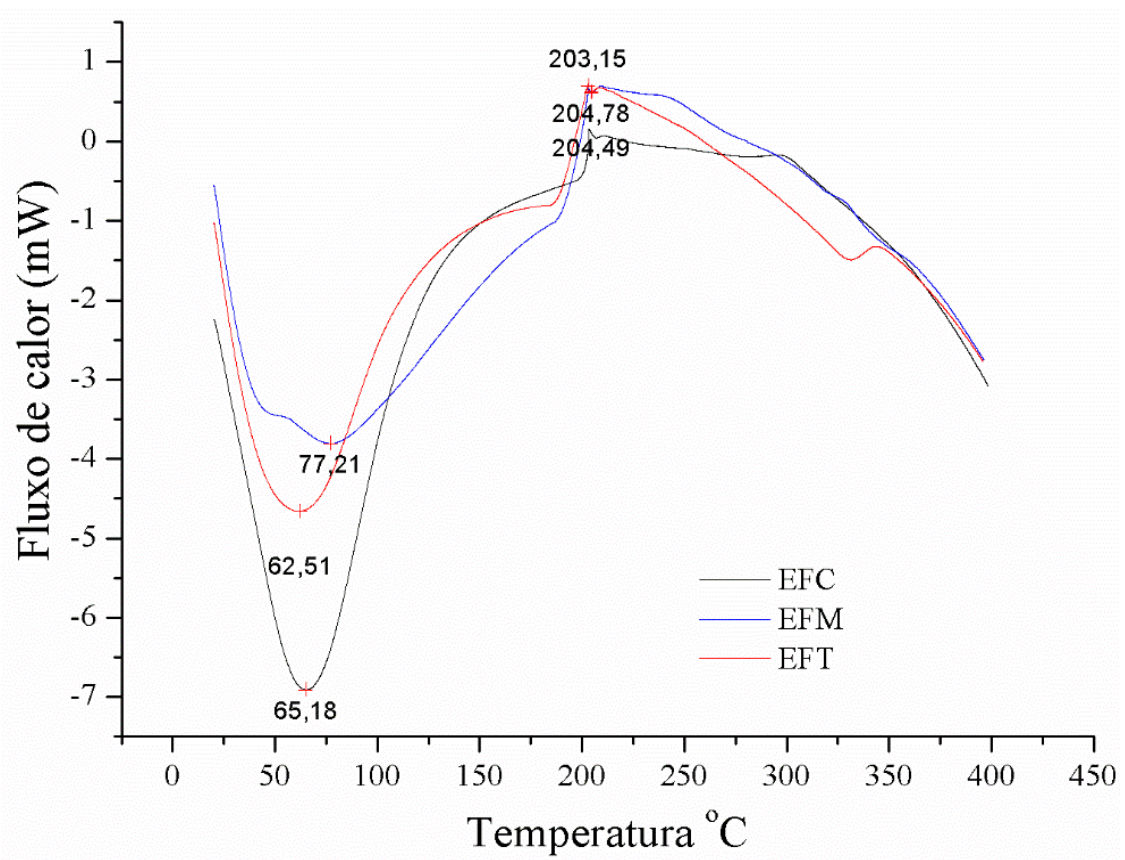

Figura 18 DSC comparativa entre as amostras. Curvas com amplitude para baixo descrevem reações endotérmicas, enquanto que as com amplitude para cima descrevem reações exotérmicas.

O gráfico da figura 16 mostra a característica endotérmica presente no processo de secagem da biomassa e tipicamente exotérmica para a degradação da hemicelulose, celulose e lignina. O gráfico da figura 17 evidencia o caráter exotérmico da degradação dos carvões.

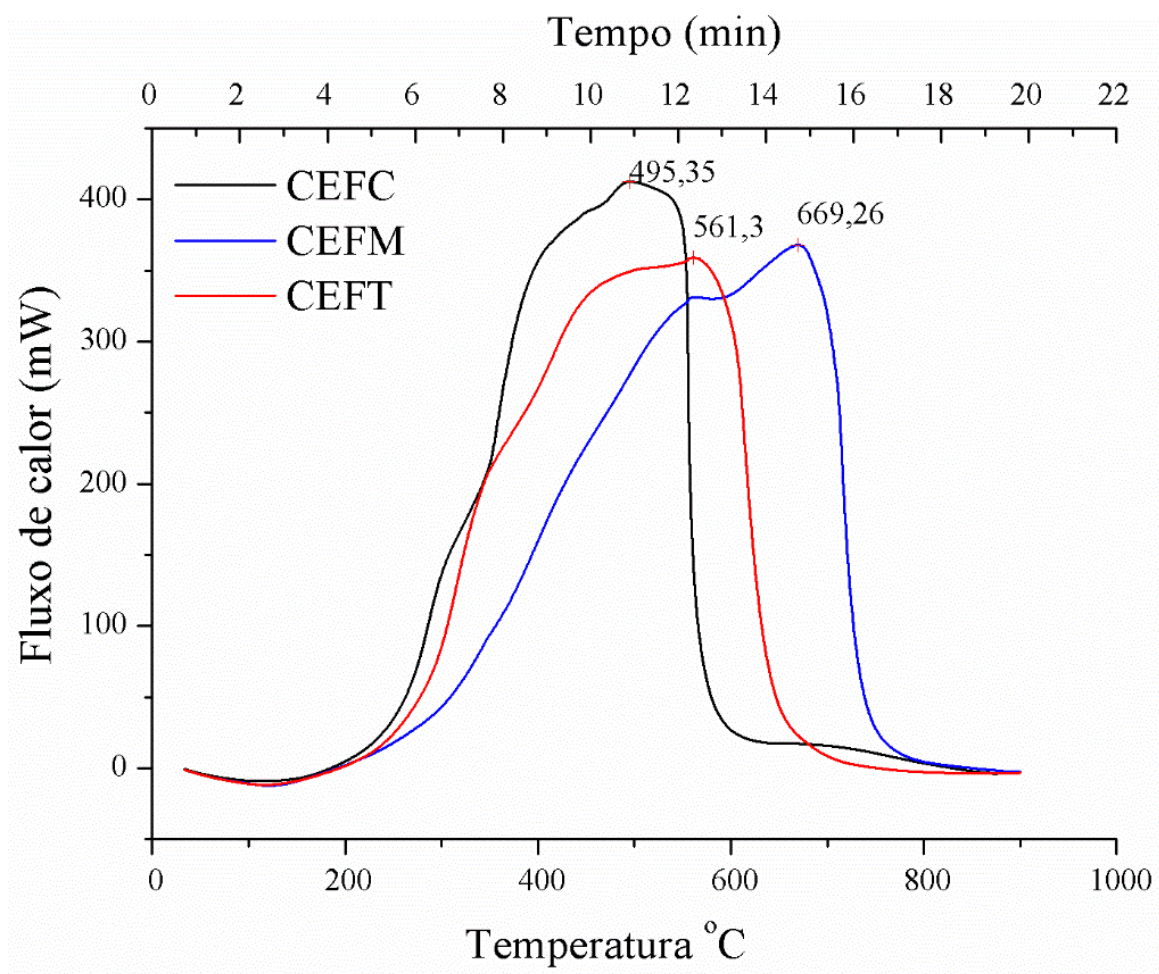

Figura 19 DSC dos carvões com aquecimento de $23{ }^{\circ} \mathrm{C}$ a $900{ }^{\circ} \mathrm{C}$ com rampa de $20{ }^{\circ} \mathrm{C} \mathrm{min}^{-1}$ sob fluxo de ar sintético de $100 \mathrm{~mL} \mathrm{~min}^{-1}$. 
Com os resultados apresentados nesta seção 4.2, é possível estimar a temperatura de carbonização para cada biomassa, bem como, o quanto esperar em termos de produção de carvão, licor pirolenhoso e gases. Também é possível inferir qualitativamente sobre os compostos produzidos durante o processo de pirólise. No entanto, para determinação do tempo exato de pirólise para cada biomassa, foi realizado um ensaio de carbonização piloto em um reator elétrico com 10 litros de capacidade, como apresentado a seguir.

\subsection{CARBONIZAÇÃO}

Com base nas informações das análises de TG/DTG, são preparadas amostras conforme descrito em 3.2.4, para carbonização piloto em retorta elétrica. A primeira estimativa de tempo é feita usando o modelo descrito em 3.2.3, e resolvendo o sistema de equações (Equação 35) e suas condições de contorno (Equação 37). Para a primeira estimativa de tempo usou-se o gráfico da figura 20 para um leito com densidade de $0,74 \mathrm{~g} \mathrm{~cm}^{-3}$, onde $\tau=\bar{t}=\frac{t k_{b}}{C p_{b} \rho_{b} l^{2}}$ e $\psi=\frac{d \bar{M}}{d t}=\frac{t^{*}}{\pi l \rho_{b}} \frac{d}{d t} \int_{0}^{l} 2 \pi \rho l r d r$, usando o ponto de máximo da curva. O tempo obtido foi de $t=419,8 \mathrm{~min}$ que foi aplicado inicialmente para todas as amostras na carbonização piloto.

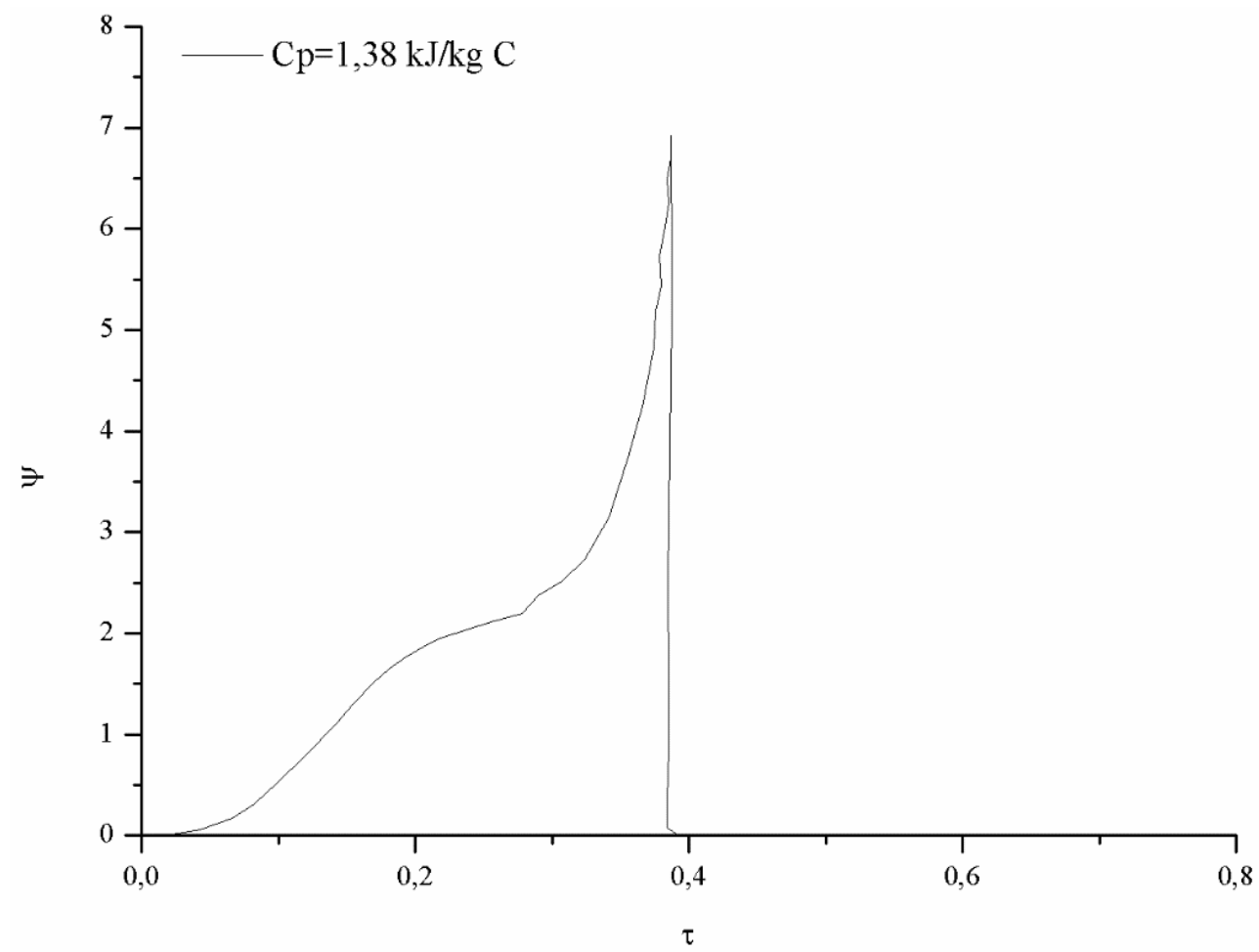

Figura 20 Efeito do calor específico do carvão na taxa de pirólise. $l=9,5 \mathrm{~cm}$, temperatura do reator $T=$ $470^{\circ} \mathrm{C}, Q_{p}=-48,4 \mathrm{cal} \mathrm{g}^{-1}, a_{p}=1,19 \times 10^{5} \mathrm{~min}^{-1}, \mathrm{Ep}=15,14 \mathrm{cal} \mathrm{mol}^{-1}$.

Fonte: adaptado de (Kung e Kalelkar, 1973) 
A configuração do reator na carbonização piloto é mostrada na tabela 8 a seguir, usando as temperaturas superiores às do último pico da curva da DTG e o tempo de patamar (tempo onde a temperatura se mantém constante) de $420 \mathrm{~min}$.

Tabela 8 Configuração do reator para carbonização piloto

\begin{tabular}{|c|c|c|c|c|}
\hline \multirow{2}{*}{ Biomassa } & DTG & \multicolumn{3}{|c|}{ Configuração do reator } \\
\hline & Último pico & Rampa & Patamar & Tempo total \\
\hline EFC & $288,89^{\circ} \mathrm{C}$ & $2^{\circ} \mathrm{C} \mathrm{min}^{-1}$ & $360^{\circ} \mathrm{C}$ & $600 \mathrm{~min}$ \\
\hline EFM & $325,55^{\circ} \mathrm{C}$ & $2^{\circ} \mathrm{Cmin}^{-1}$ & $430^{\circ} \mathrm{C}$ & $645 \mathrm{~min}$ \\
\hline EFT & $328,73^{\circ} \mathrm{C}$ & $2^{\circ} \mathrm{C} \mathrm{min}^{-1}$ & $430^{\circ} \mathrm{C}$ & $645 \mathrm{~min}$ \\
\hline
\end{tabular}

Para a otimização do tempo do processo de pirólise, buscou-se a medição das temperaturas da reação no interior do reator, inicialmente configurado em tempo único para todas as amostras. O gráfico da figura 21 ilustra as curvas de temperatura no interior do reator de pirólise.

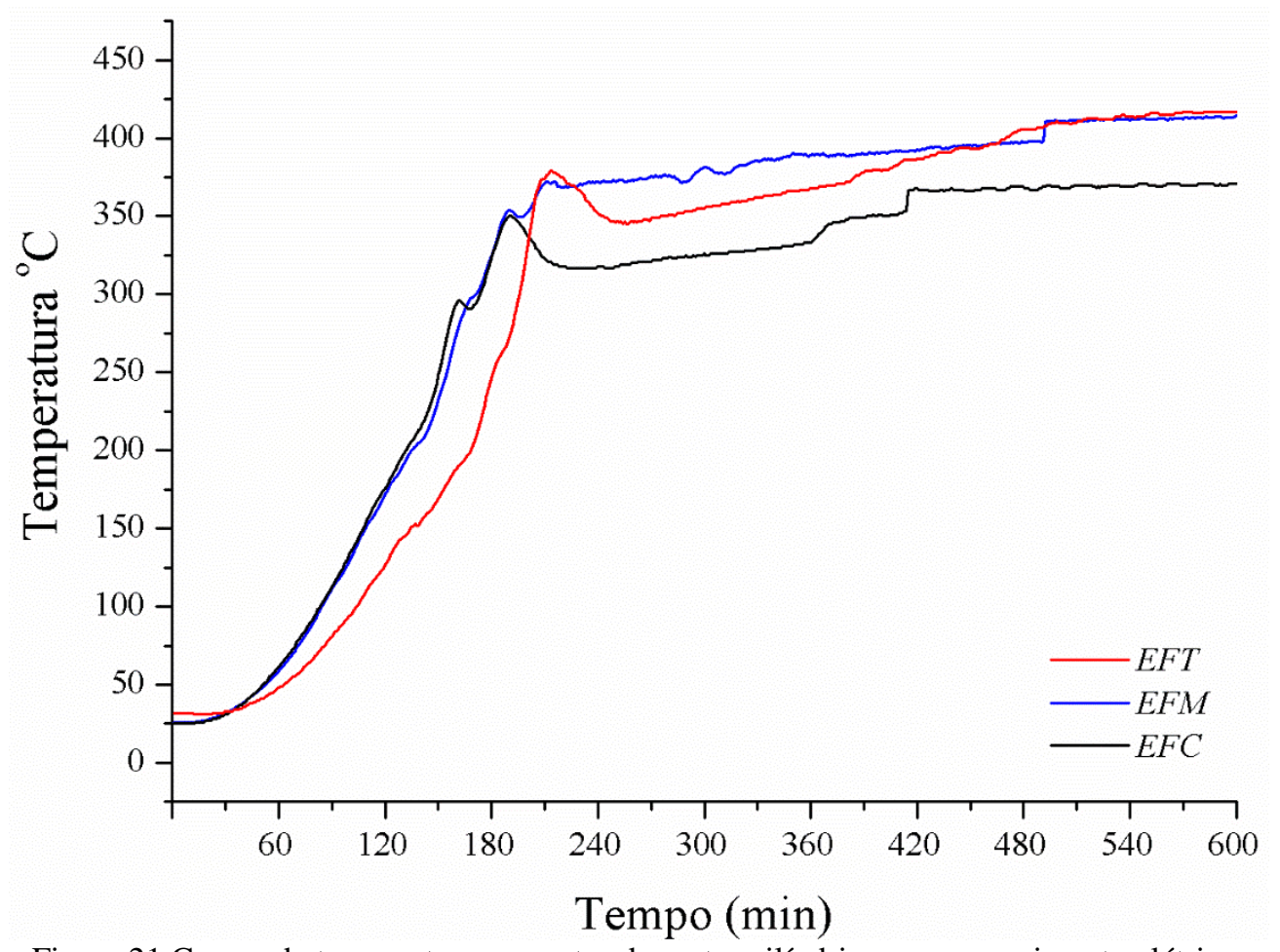

Figura 21 Curvas de temperatura ao centro do reator cilíndrico com aquecimento elétrico.

A melhoria nos tempos de carbonização para reatores cilíndricos se deu pela medição do tempo entre os picos do gráfico (Figura 21), ou seja, entre o instante em que o início da temperatura de patamar e o momento em que as temperaturas do centro do reator e forno são iguais e constantes. Isso representa o início da fase exotérmica e o final das emissões dos voláteis para a temperatura de carbonização. A tabela 9 a seguir apresenta os resultados levantados após a carbonização piloto, incluindo o percentual de tempo que pode ser reduzido da configuração inicial. 
Tabela 9 Tempo de carbonização levantado para reator cilíndrico com 190mm de diâmetro.

\begin{tabular}{|c|c|c|c|c|c|}
\hline Biomassa & Rampa & Patamar & $\begin{array}{c}\text { Tempo } \\
\text { total }\end{array}$ & $\begin{array}{c}\text { Velocidade de } \\
\text { carbonização }\end{array}$ & $\begin{array}{c}\text { Redução de } \\
\text { tempo }\end{array}$ \\
\hline $\mathrm{EFC}$ & $2{ }^{\circ} \mathrm{C} \mathrm{\textrm {min } ^ { - 1 }}$ & $\begin{array}{c}360^{\circ} \mathrm{C} \text { Por } \\
225 \mathrm{~min}\end{array}$ & $420 \mathrm{~min}$ & $\begin{array}{c}0,09 \\
\mathrm{~mm} \mathrm{~min}^{-1}\end{array}$ & $30 \%$ \\
\hline $\mathrm{EFM}$ & $2{ }^{\circ} \mathrm{C} \mathrm{\textrm {min } ^ { - 1 }}$ & $\begin{array}{c}430^{\circ} \mathrm{C} \text { Por } \\
281 \mathrm{~min}\end{array}$ & $494 \mathrm{~min}$ & $\begin{array}{c}0,07 \\
\mathrm{~mm} \mathrm{~min}^{-1}\end{array}$ & $23 \%$ \\
\hline $\mathrm{EFT}$ & $2{ }^{\circ} \mathrm{C} \mathrm{\textrm {min } ^ { - 1 }}$ & $\begin{array}{c}430{ }^{\circ} \mathrm{C} \text { Por } \\
268 \mathrm{~min}\end{array}$ & $493 \mathrm{~min}$ & $\begin{array}{c}0,07 \\
\mathrm{~mm} \mathrm{~min}^{-1}\end{array}$ & $24 \%$ \\
\hline
\end{tabular}

Como resultado obteve-se carvões esféricos íntegros de boa resistência mecânica para o CEFM e para o CEFT, enquanto para CEFC, um carvão frágil e leve, conforme mostrado a seguir (Figura 22). Esta diferença se deve ao menor teor de lignina encontrado no EFC em relação aos EFT e EFM, este componente fornece rigidez, impermeabilidade e resistência às plantas.

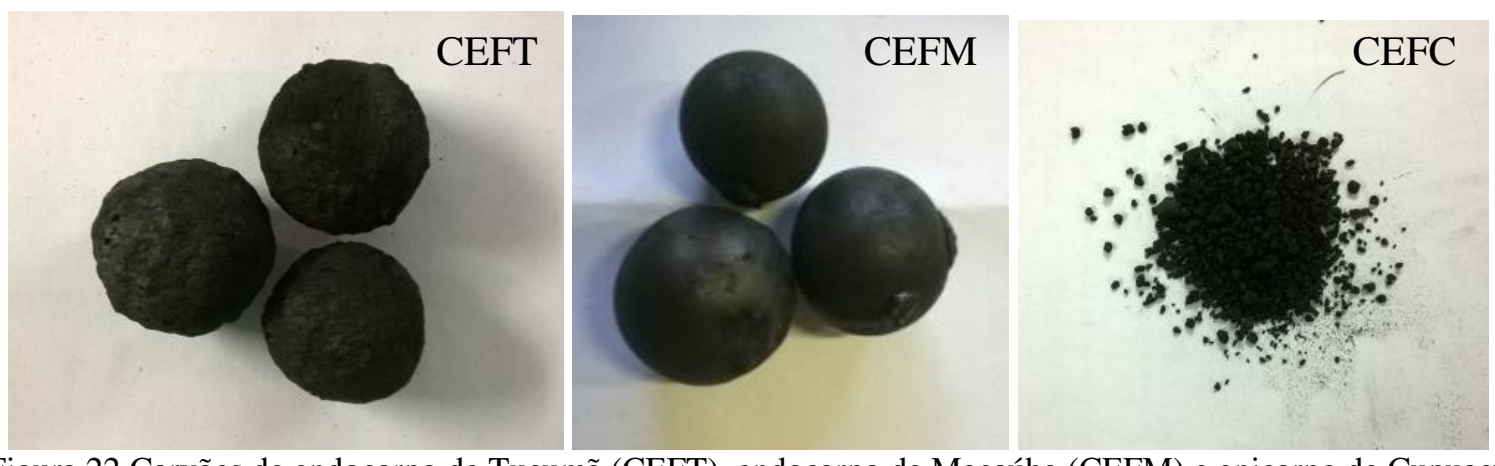

Figura 22 Carvões de endocarpo de Tucumã (CEFT), endocarpo de Macaúba (CEFM) e epicarpo de Cupuaçu (CEFC).

Ao final das carbonizações os rendimentos mássicos obtidos foram acima de $30 \%$, mostrados na tabela 10 a seguir, assim como o observado nos resíduos dos ensaios da TG. O maior rendimento gravimétrico alcançado no processo para a casca do cupuaçu (CEFC) deve-se à característica homogênea do material rico em celulose, enquanto que no tucumã foram carbonizados juntos o endosperma e o endocarpo, e a macaúba, onde a fruta foi carbonizada inteira, apresentam maiores rendimento de líquido devido à grande quantidade de óleos presentes no mesocarpo e endosperma.

\subsubsection{Caracterização dos carvões}

A análise imediata dos carvões feita em base seca nota-se um maior teor de carbono fixo para o CEFM enquanto os CEFC e CEFT apresentam valores próximos. O teor de cinzas medido no carvão de casca de cupuaçu apresenta um valor elevado em comparação às demais amostras. 
Tabela 10 Caracterizações dos carvões dos endocarpos de tucumã e macaúba e do epicarpo do cupuaçu.

\begin{tabular}{|c|c|c|c|}
\hline Análise & \multirow{2}{*}{ CEFT } & \multirow{2}{*}{ CEFM } & \multirow{2}{*}{ CEFC } \\
\hline Rendimento da pirólise & & & \\
\hline Rendimento Gravimétrico (\% de sólido) & 30,0 & 30,54 & 36,80 \\
\hline Licor pirolenhoso (\% de líquido) & 54,04 & 48,00 & 41,40 \\
\hline Gases incondensáveis (\% de gases) & 15,96 & 21,30 & 21,80 \\
\hline Análise imediata do carvão & CEFT & CEFM & CEFC \\
\hline Carbono Fixo (\%) & 66,11 & 71,05 & 66,17 \\
\hline Umidade $(\%)$ & 5,11 & 3,88 & 5,32 \\
\hline Voláteis (\%) & 29,57 & 23,54 & 24,42 \\
\hline Cinzas $(\%)$ & 4,32 & 5,42 & 9,42 \\
\hline Análise elementar - carvões & CEFT & CEFM & CEFC \\
\hline Carbono (C) (\%) & 77,73 & 79,14 & 76 \\
\hline Hidrogênio $(\mathrm{H})(\%)$ & 4,59 & 3,44 & 2,15 \\
\hline Oxigênio $(\mathrm{O})(\%)$ & 13,17 & 15,15 & 16 \\
\hline Propriedades dos carvões & CEFT & CEFM & CEFC \\
\hline Densidade a granel carvão $\left(\mathrm{kg} \mathrm{m}^{-3}\right)^{\mathrm{a}}$ & 480 & 620 & 360 \\
\hline BET área superficial específica $\left(m^{2} g^{-1}\right)$ & 6,07 & 2,57 & 11,40 \\
\hline Raio de poros $\operatorname{Dv}(r)(\AA)$ & 16,71 & 15,38 & 17,03 \\
\hline Volume de poros $\left(c c g^{-1}\right)$ & 0,075 & 0,004 & 0,021 \\
\hline
\end{tabular}

${ }^{a}$ Medição feita com material com granulometria entre $150 \mu \mathrm{m}$ e $250 \mu \mathrm{m}$.

Com os resultados da análise elementar, a formulação da equação química equivalente do combustível (Tabela 11) foi determinada, permitindo a simulação de reações químicas como as de gaseificação mostradas na seção 4.4. Destaque para a concentração de carbono apresentado pelo CEFM, que supera os resultados do CEFC e CEFT.

Tabela 11 - Fórmulas químicas equivalentes para biomassa virgem e carbonizada

\begin{tabular}{|l|l|l|l|}
\hline Biomassa & Tucumã & Macaúba & Cupuaçu \\
\hline Virgem & $\mathrm{CH}_{1,67} \mathrm{O}_{0,47} \mathrm{~N}_{0,01}$ & $\mathrm{CH}_{1,51} \mathrm{O}_{0,64} \mathrm{~N}_{0,04}$ & $\mathrm{CH}_{1,53} \mathrm{O}_{0,77} \mathrm{~N}_{0,02}$ \\
\hline Carbonizada & $\mathrm{CH}_{0,70} \mathrm{O}_{0,13}$ & $\mathrm{CH}_{0,52} \mathrm{O}_{0,14}$ & $\mathrm{CH}_{0,34} \mathrm{O}_{0,16}$ \\
\hline
\end{tabular}

Todos os carvões apresentaram estruturas cristalinas amorfas, conforme mostrado na análise da difração de raios-x (Figura 23), enquanto a morfologia dos carvões é melhor visualizada através da microscopia eletrônica de varredura (MEV), cujas fotomicrografias são apresentadas na figura 24 a seguir.
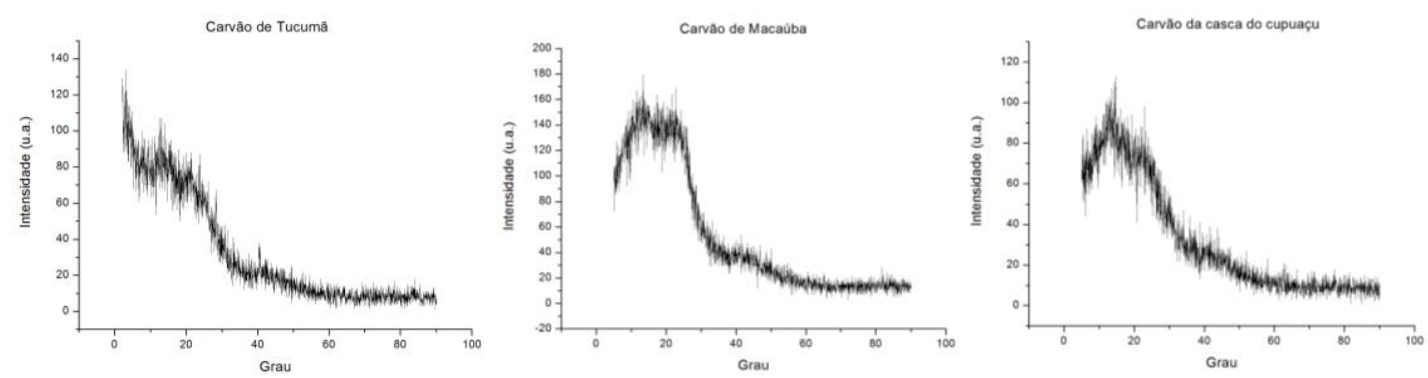

Figura 23 Difração de raios $\mathrm{x}$ - estruturas amorfas. 

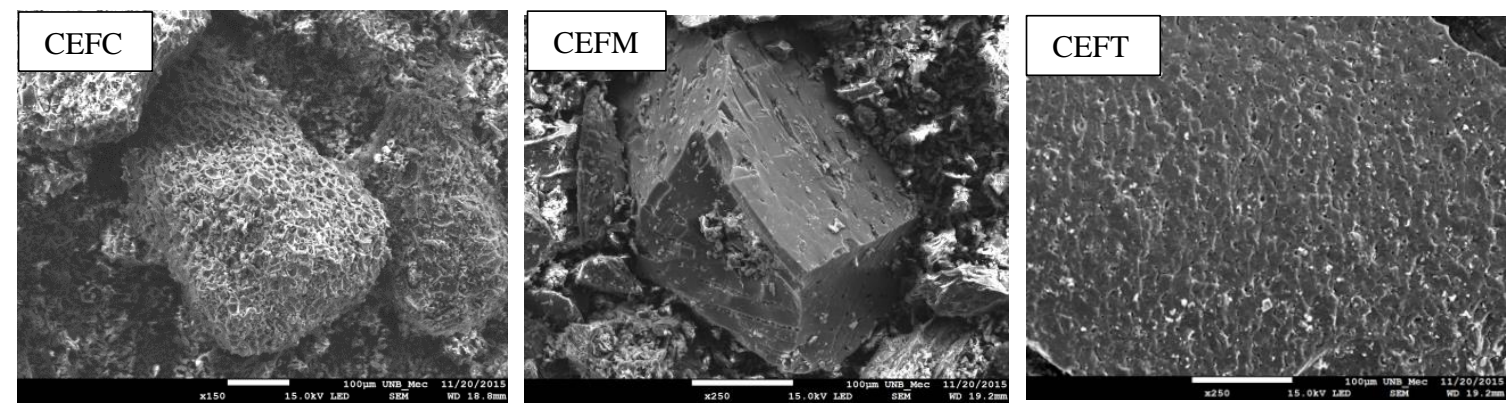

Figura 24 Morfologia dos carvões - fotomicrografias feitas em MEV.

O poder calorífico superior (PCS) foi medido segundo o procedimento descrito em 3.2.4, tanto para o material virgem quanto para o carbonizado (Tabela 12). O carvão da macaúba apresentou o PCS com valor acima dos demais, devido principalmente à maior concentração de carbono em sua estrutura.

Tabela 12 Poder calorífico superior (PCS) e o poder calorífico inferior (PCI) das amostras

\begin{tabular}{|l|l|l|l|l|l|l|}
\hline \multirow{2}{*}{ Análise } & Tucumã & \multicolumn{3}{l|}{ Macaúba } & \multicolumn{2}{l|}{ Cupuaçu } \\
\cline { 2 - 8 } & Virgem & Carvão & Virgem & Carvão & Virgem & Carvão \\
\hline PCS $\left(M J \mathrm{~kg}^{-1}\right)$ & 21,32 & 30,63 & 24,26 & 31,23 & 19,27 & 29,43 \\
\hline PCI $\left(M J \mathrm{~kg}^{-1}\right)$ & 20,31 & 29,62 & 23,50 & 30,47 & 18,80 & 28,96 \\
\hline
\end{tabular}

Complementarmente à análise elementar, o ensaio de EDX mostra as concentrações de outros compostos, além do carbono, oxigênio, hidrogênio e nitrogênio, em cada carvão estudado (Figura 25). Nenhum elemento nocivo para o uso humano foi encontrado, ou seja, não possui elementos radioativos ou tóxicos presentes na composição dos carvões estudados. É possível destacar a predominância de $\mathrm{K}_{2} \mathrm{O}$ em todas as amostras carbonizadas analisadas e a grande quantidade de $\mathrm{SIO}_{2}$ no carvão da macaúba e nenhuma no carvão da casca do cupuaçu

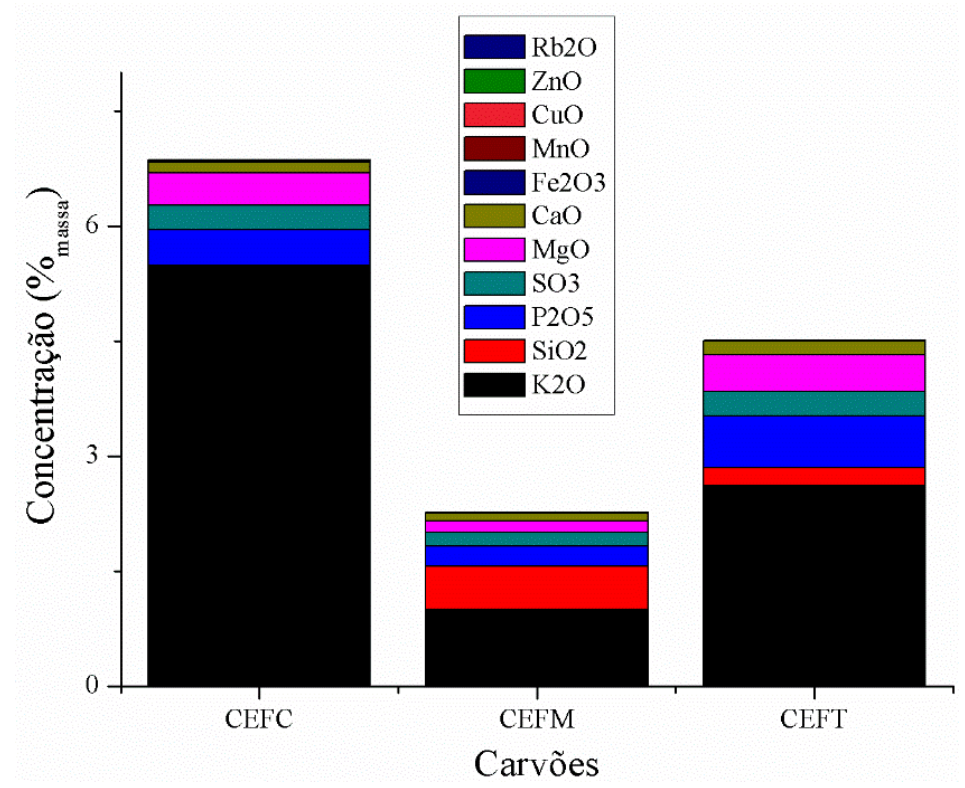

Figura 25 Composição dos carvões medidos por espectroscopia de raios X por dispersão em energia (EDX) 


\subsection{GASEIFICAÇÃO DOS CARVÕES}

\subsubsection{Levantamento das condições operacionais}

Para a avaliação da gaseificação dos carvões, aqui denominados de CEFC, CEFT e CEFM, foram empregados os procedimentos descritos no item 3.3.2. O sistema de alimentação de carvão ao reator foi controlado pela velocidade de rotação do motor do fuso do alimentador, e a vazão do ar ao reator controlada por válvula comandada pelo supervisório da unidade. Os ajustes de alimentação de carvão resultaram em diferentes razões de equivalência nos ensaios de gaseificação. A figura 26 mostra que, para velocidades do fuso de alimentação ajustadas a 10\%, 30\% e 57\% da velocidade máxima, existem três correlações lineares da massa de carvão alimentada em função do tempo.

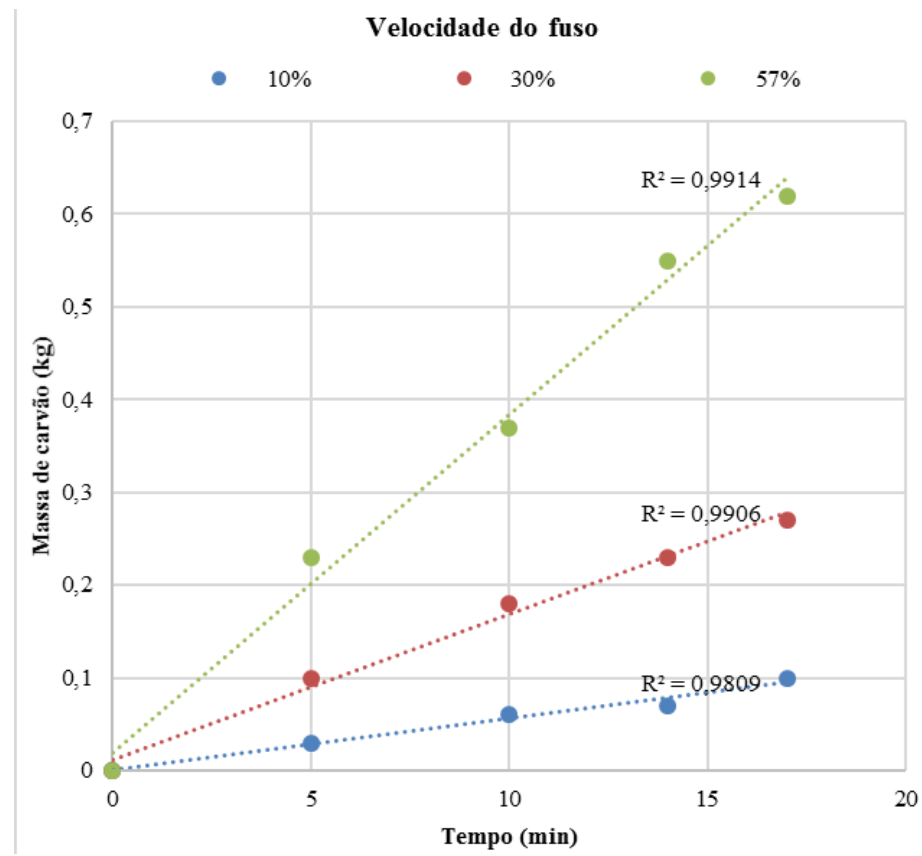

Figura 26 Curvas de calibração do sistema de alimentação de sólidos em função do percentual da velocidade máxima dos motores do sistema de alimentação de sólidos.

O ajuste da vazão de ar no reator serviu para controlar não somente a razão de equivalência, mas principalmente para garantir a fluidização do leito. Portanto, fez-se uma análise da influência da vazão sobre a diferença de pressão à entrada e saída. Isso foi feito à temperatura ambiente e aos $900{ }^{\circ} \mathrm{C}$. Na figura 27 observa-se que para vazões menores que $16 \mathrm{NL} \mathrm{min}^{-1}$ a diferença de pressão aumenta linearmente com a vazão, e a partir de

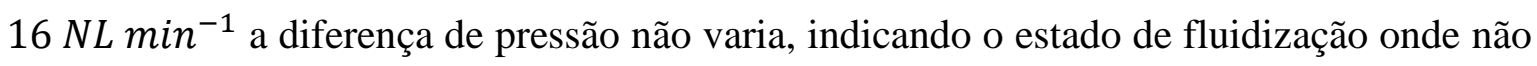
há mais aumento de perda de carga. 


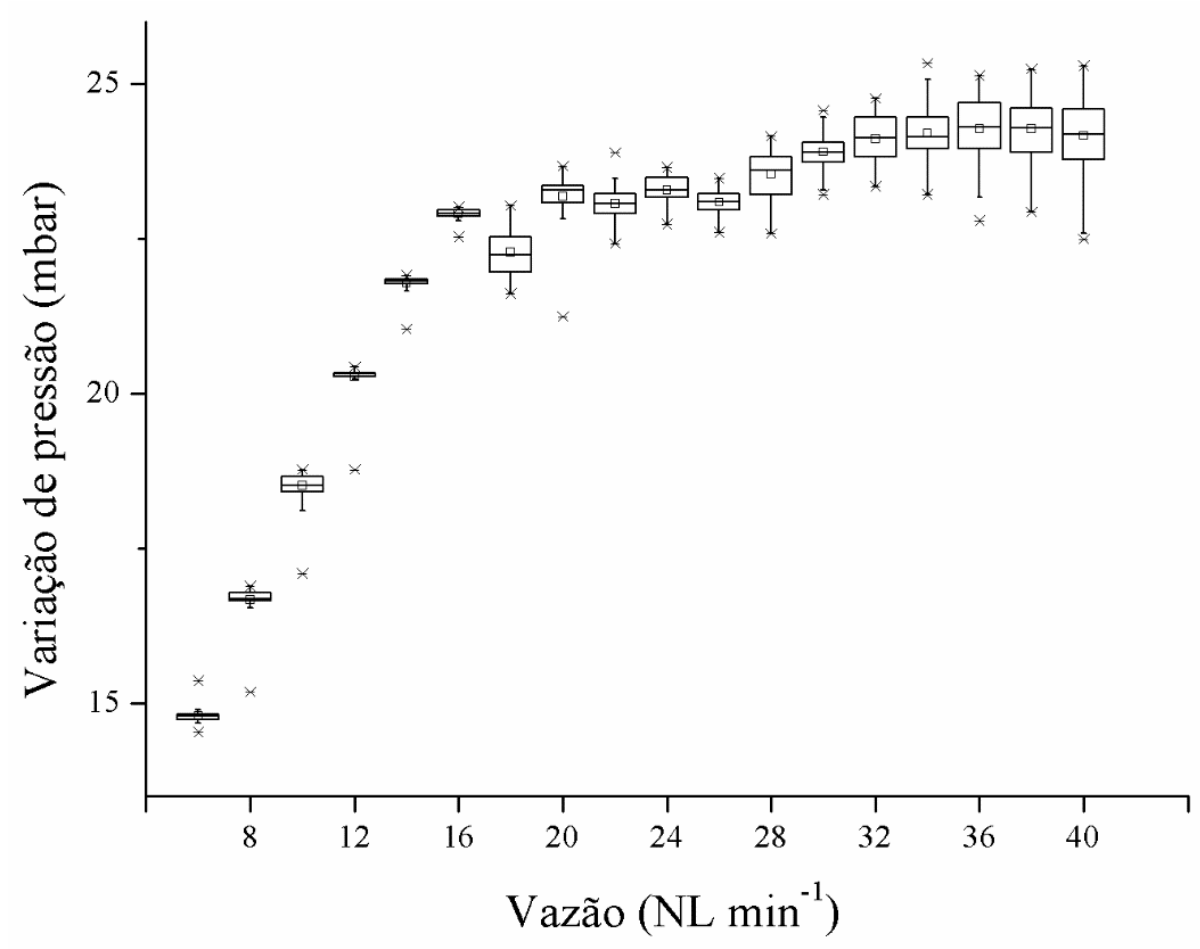

Figura 27 Perfil da curva de fluidização da areia a quartzo à temperatura ambiente.

Contudo, com o do leito à temperatura de $900^{\circ} \mathrm{C}$, mostrado no gráfico da figura 28 , a fluidização ocorre já em baixas vazões.

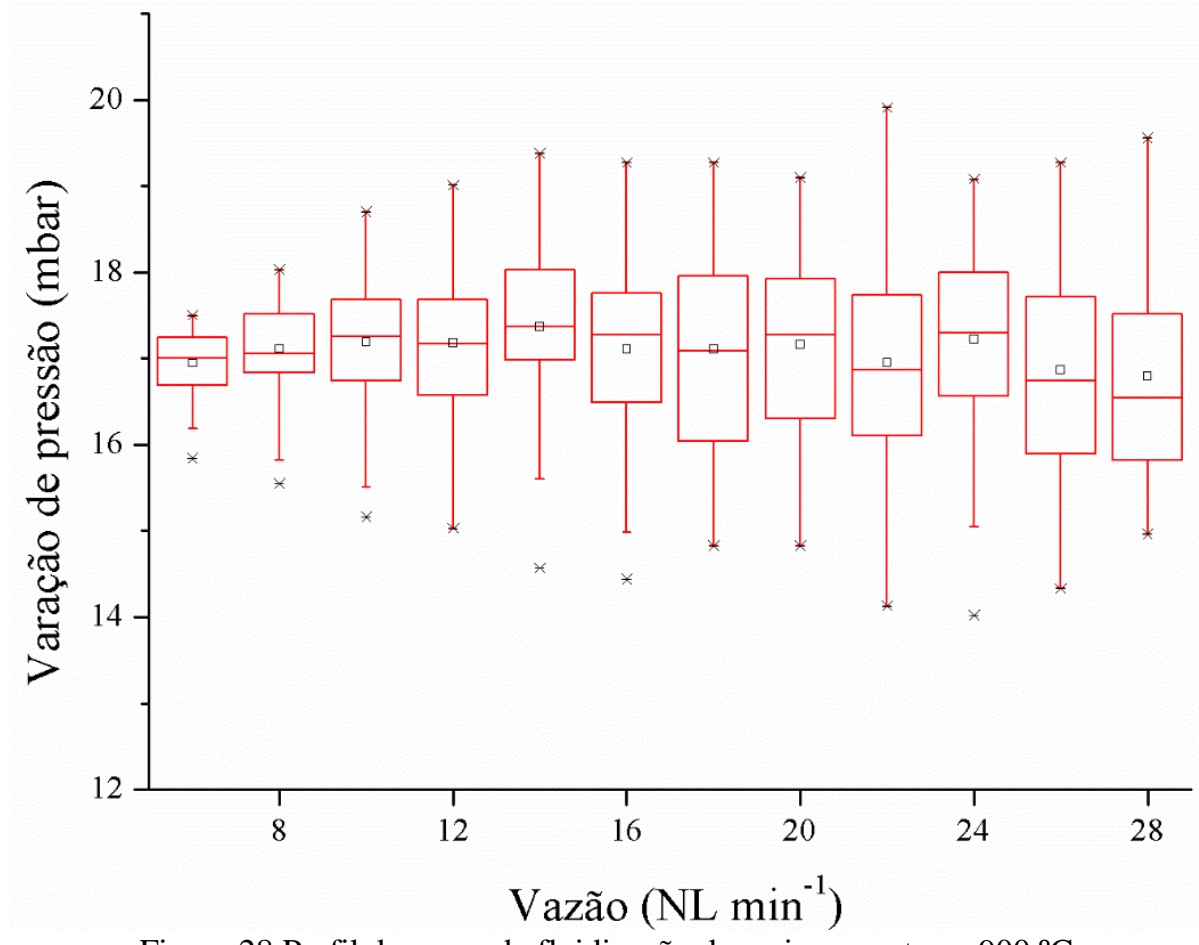

Figura 28 Perfil da curva de fluidização da areia a quartzo a $900^{\circ} \mathrm{C}$.

As gaseificações dos carvões foram divididas em duas abordagens: carregamento por batelada com variação da temperatura em fluxo constante de agente gaseificante e, a 
segunda, variando a razão de equivalência pela variação do fluxo de agente gaseificante a uma taxa constante de alimentação de sólidos usando o alimentador da unidade.

\subsubsection{Parâmetros de operação}

As tabelas 13, 14 e 15 a seguir, mostram os valores obtidos através do supervisório da unidade de gaseificação no instante da amostragem de gases para cromatografia. Os valores em destaque são aqueles obtidos sem adição de água e com o uso do alimentador de sólidos do gaseificador. Na tabela 13 estão os dados reais no momento da coleta das amostras da gaseificação do CEFM.

Tabela 13 Registro dos parâmetros do gaseificador para o CEFM.

\begin{tabular}{|c|c|c|c|}
\hline $\begin{array}{c}\text { Amostra } \\
\#\end{array}$ & $\begin{array}{c}\text { Temperatura do leito } \\
\left({ }^{\circ} \mathrm{C}\right)\end{array}$ & $\begin{array}{c}\text { Fluxo de ar } \\
\left(\mathrm{NL} \mathrm{min}^{-1}\right)\end{array}$ & $\begin{array}{c}\text { Temperatura }\left({ }^{\circ} \mathrm{C}\right) / \text { vazão de } \\
\text { água }\left(\mathrm{m} L \mathrm{~min}^{-1}\right)\end{array}$ \\
\hline 1 & 520 & 12 & $360 / 5$ \\
\hline 2 & 565 & 12,1 & $419 / 5$ \\
\hline 3 & 614 & 12 & $442 / 5$ \\
\hline 4 & 658 & 11,9 & $424 / 5$ \\
\hline 5 & 668 & 12 & $423 / 5$ \\
\hline 6 & 755 & 12,1 & $424 / 5$ \\
\hline 7 & 817 & 12 & $413 / 5$ \\
\hline 8 & 860 & 12,1 & $400 / 5$ \\
\hline 9 & 903 & 12,1 & $407 / 5$ \\
\hline 10 & 905 & 11,9 & $202 / 0$ \\
\hline 11 & 912 & 9,0 & $204 / 0$ \\
\hline 12 & 902 & 24,5 & $198 / 0$ \\
\hline
\end{tabular}

Dados da tabela 14 mostram a reposta do gaseificador aos ajustes iniciais programados na gaseificação do CEFT.

Tabela 14 Registro dos parâmetros do gaseificador para o CEFT

\begin{tabular}{|c|c|c|c|}
\hline $\begin{array}{c}\text { Amostra } \\
\#\end{array}$ & $\begin{array}{c}\text { Temperatura do leito } \\
\left({ }^{\circ} \mathrm{C}\right)\end{array}$ & $\begin{array}{c}\text { Fluxo de ar } \\
\left(N L \mathrm{~min}^{-1}\right)\end{array}$ & $\begin{array}{c}\text { Temperatura }\left({ }^{\circ} \mathrm{C}\right) / \text { vazão de } \\
\text { água }\left(\mathrm{mL} \mathrm{min}{ }^{-1}\right)\end{array}$ \\
\hline 1 & 509 & 12 & $108 / 5$ \\
\hline 2 & 567 & 11,9 & $435 / 5$ \\
\hline 3 & 600 & 11,8 & $413 / 5$ \\
\hline 4 & 649 & 12,1 & $416 / 5$ \\
\hline 5 & 716 & 11,8 & $401 / 5$ \\
\hline 6 & 751 & 11,9 & $402 / 5$ \\
\hline 7 & 810 & 12,2 & $439 / 5$ \\
\hline 8 & 853 & 11,9 & $417 / 5$ \\
\hline 9 & 879 & 12,1 & $444 / 5$ \\
\hline 10 & 929 & 12,1 & $398 / 5$ \\
\hline 11 & 926 & 11,9 & $198 / 0$ \\
\hline 12 & 900 & 9,9 & $193 / 0$ \\
\hline 13 & 905 & 24,5 & $196 / 0$ \\
\hline
\end{tabular}


Igualmente na tabela 15 são mostrados os dados reais lidos no gaseificador durante as reações com o carvão do endocarpo da fruta do cupuaçu (CEFC), onde a parte destacada em cinza foram os ensaios com variação da razão de equivalência sem adição de água ao agente gaseificante.

Tabela 15 Configuração do gaseificador para o CEFC

\begin{tabular}{|c|c|c|c|}
\hline $\begin{array}{c}\text { Amostra } \\
\#\end{array}$ & $\begin{array}{c}\text { Temperatura do leito } \\
\left({ }^{\circ} \mathrm{C}\right)\end{array}$ & $\begin{array}{c}\text { Fluxo de ar } \\
\left(\mathrm{NL} \mathrm{min}^{-1}\right)\end{array}$ & $\begin{array}{c}\text { Temperatura }\left({ }^{\circ} \mathrm{C}\right) / \text { vazão de } \\
\text { água }\left(\mathrm{m} L \mathrm{~min}^{-1}\right)\end{array}$ \\
\hline 1 & 610 & 12 & $320 / 5$ \\
\hline 2 & 710 & 11,9 & $463 / 5$ \\
\hline 3 & 805 & 12,2 & $466 / 5$ \\
\hline 4 & 850 & 12,1 & $403 / 5$ \\
\hline 5 & 907 & 12 & $175 / 5$ \\
\hline 6 & 900 & 11,9 & $181 / 5$ \\
\hline 7 & 904 & 27,6 & $232 / 0$ \\
\hline 8 & 909 & 31 & $240 / 0$ \\
\hline 9 & 956 & 12 & $210 / 0$ \\
\hline
\end{tabular}

\subsubsection{Ensaio com variação de temperatura}

Nos ensaios feitos com carga de carvão de granulometria entre 1 e $2 \mathrm{~mm}$ misturado ao leito de quartzo entre 0,3 e $0,5 \mathrm{~mm}$ na proporção de $1: 1$, observa-se a relação entre o PCS do gás e a temperatura de gaseificação conforme o gráfico da figura 29. O GCEFC apresenta o resultado com maior PCS entre as três amostras, para temperaturas menores que $800{ }^{\circ} \mathrm{C}$, confirmando o resultado da termogravimetria do CEFC onde obteve as menores temperaturas para degradação. Sua maior área superficial $\left(11,4 \mathrm{~m}^{2} \mathrm{~g}^{-1}\right)$ lhe confere melhor reatividade que os carvões CEFT $\left(6,07 \mathrm{~m}^{2} \mathrm{~g}^{-1}\right)$ e CEFM $\left(2,57 \mathrm{~m}^{2} \mathrm{~g}^{-1}\right)$. 


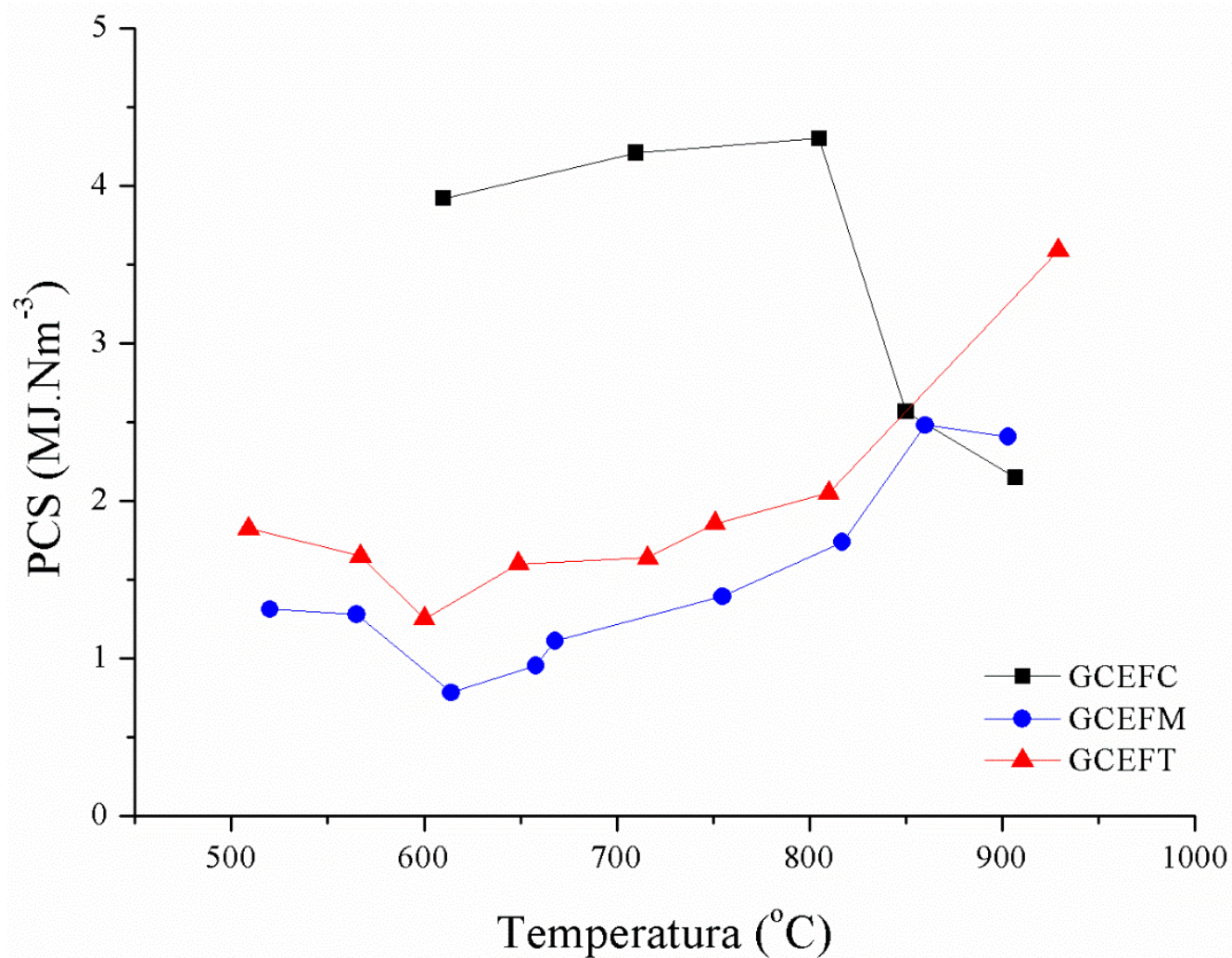

Figura 29 Poder calorífico superior do gás de síntese obtido pela variação da temperatura. Reator carregado com $500 \mathrm{~g}$ de areia de quartzo misturado com $500 \mathrm{~g}$ de carvão. Vazão de ar de $12 \mathrm{NL} \mathrm{min}{ }^{-1}, 5 \mathrm{~mL} \mathrm{~min}^{-1}$ de vapor de água a $400{ }^{\circ} \mathrm{C}$, ciclones a $500^{\circ} \mathrm{C}$ e condensador a $38^{\circ} \mathrm{C}$.

A simulação numérica serviu para analisar mais detalhadamente os resultados experimentais. Os resultados numéricos (Figura 30a) são referentes ao modelo no equilíbrio químico e 0D, com variação da temperatura em função da razão de equivalência. $\mathrm{O}$ gás produzido a partir do carvão CEFC (GCEFC) apresentou maior PCS em comparação aos outros para temperaturas menores que $800{ }^{\circ} \mathrm{C}$, confirmando parcialmente os resultados experimentais da figura 29. Contudo, na figura 30a somente um ponto tem a mesma razão de equivalência dos resultados apresentados anteriormente na figura 29 e, portanto, a figura $30 \mathrm{~b}$ combina os valores simulados da figura 30a com os valores experimentais da figura 29 (à mesma razão de equivalência). Na figura 30b, para os produtos GCEFC e GCEFT, os valores de PCS simulados do gás estão de acordo com os valores experimentais. Já os resultados experimentais de gaseificação do carvão CEFM não atingiram a temperatura de $1125{ }^{\circ} \mathrm{C}$ com PCS de 3,3 $\mathrm{MJ} \mathrm{Nm}^{-3}$, o que segundo os resultados numéricos, seria a condição para a mesma razão de equivalência observada experimentalmente. 

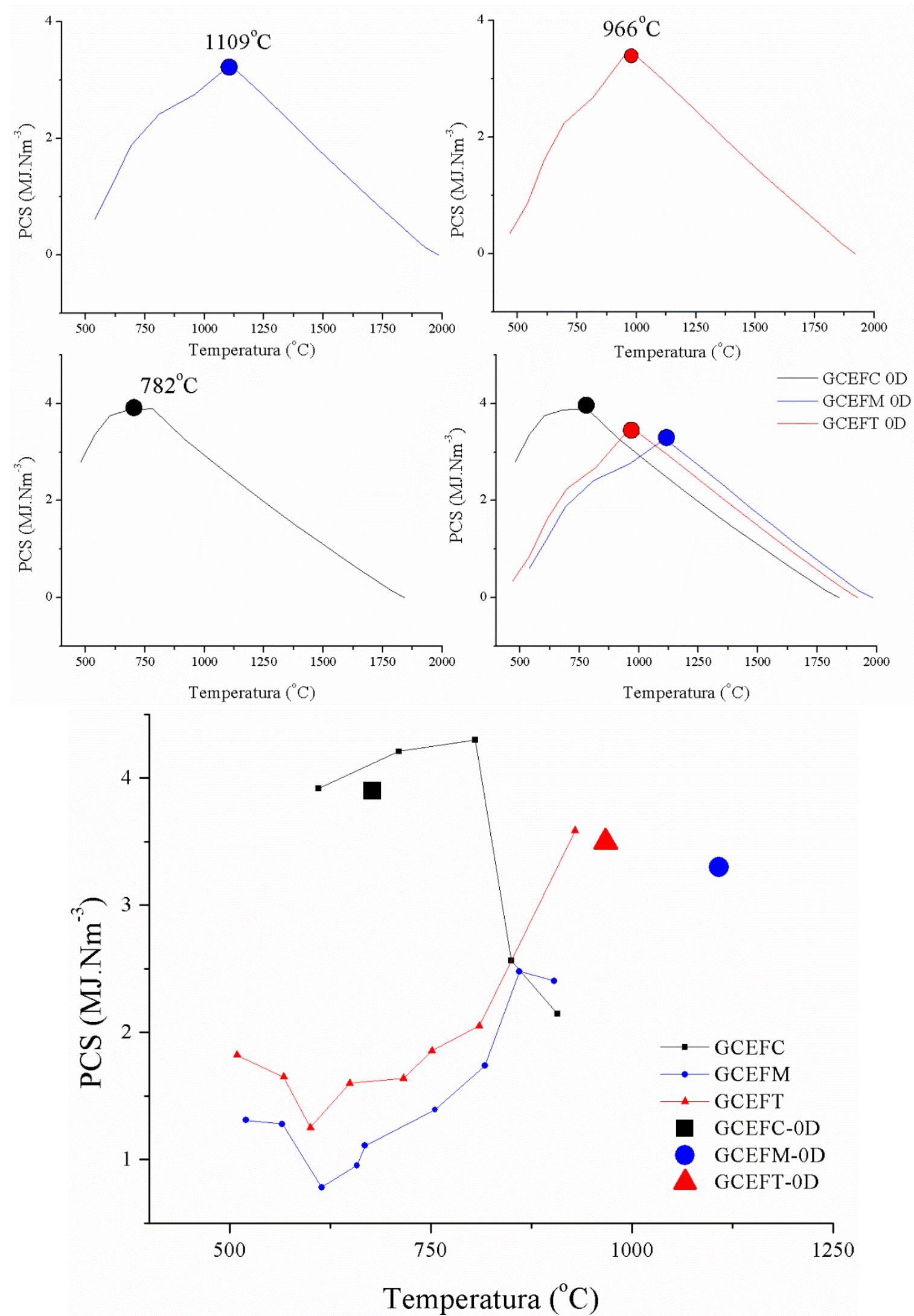

Figura 30 Simulação numérica da gaseificação - em função da temperatura. (a) Resultados numéricos referentes ao modelo no equilíbrio químico e 0D. (b) Sobreposição dos valores simulados da figura 31a com os valores experimentais da figura 30 (à mesma razão de equivalência). 
$\mathrm{O}$ melhor resultado do CEFC pode melhor ser entendido comparando as áreas superficiais de cada biomassa. A maior área superficial sugere uma maior quantidade de sítios reativos, tornando a reação de gaseificação do ECFC mais rápida e eficiente do que as demais.

\subsubsection{Ensaios com variação da razão de equivalência}

Nos ensaios realizados com a variação da razão de equivalência (Figura 31), o leito se manteve à temperatura constante de $900{ }^{\circ} \mathrm{C}$, alimentação de sólidos a $57 \%$ $\left(0,05 \mathrm{~kg} \mathrm{~min}^{-1}\right)$ e sem adição de vapor de água ao agente gaseificante (ar). Novamente o CEFC apresenta o resultado com maiores valores do PCS entre as três amostras, mesmo sem adição de água ao agente gaseificante.

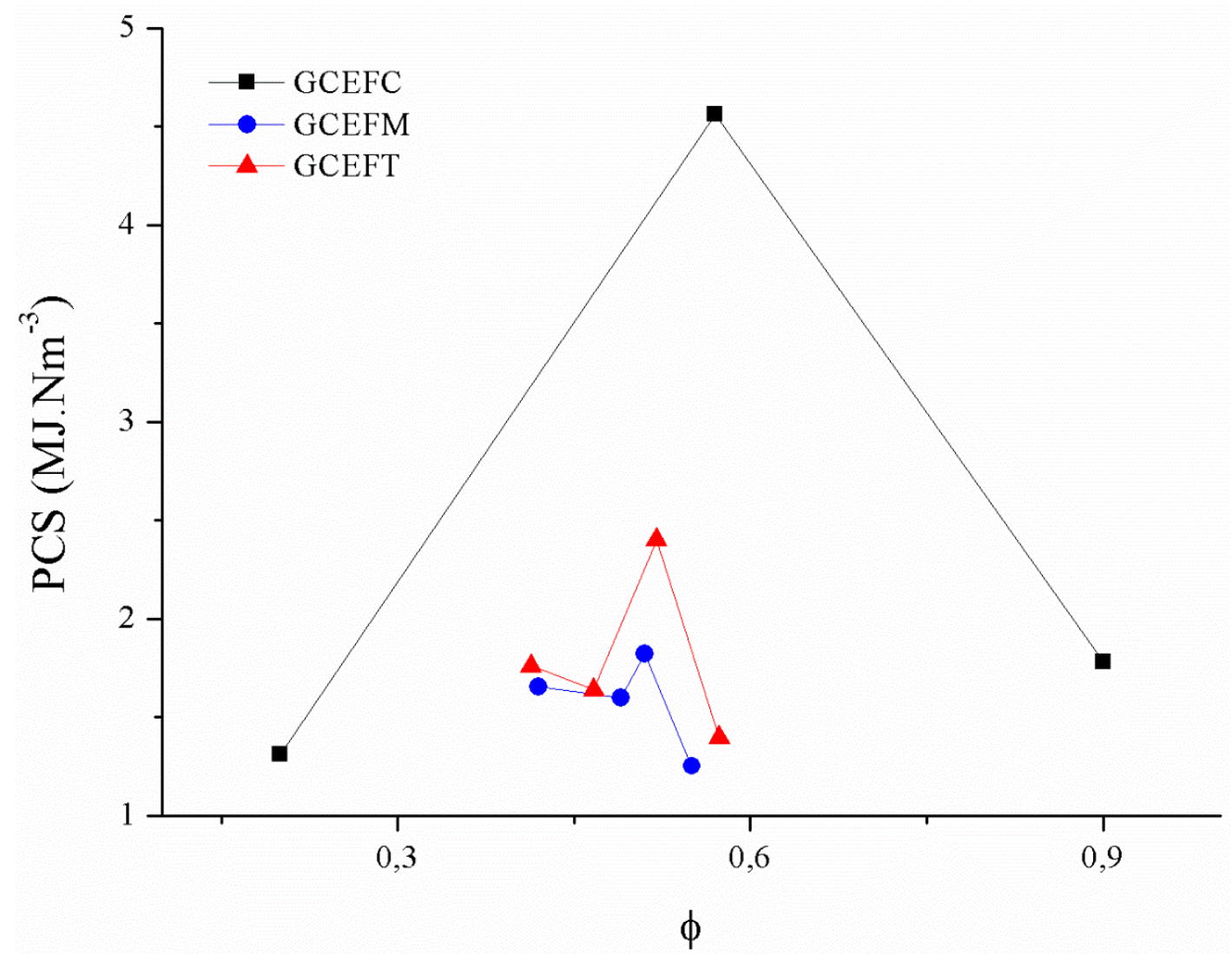

Figura 31 Variação do PCS pela variação da razão de equivalência. Temperatura do leito a $900{ }^{\circ} \mathrm{C}$, alimentação de sólidos a $0,05 \mathrm{~kg} \mathrm{~min}^{-1}$, sem adição de vapor.

\subsubsection{Composição do gás de síntese}

Para o cálculo do PCS do gás foi necessário medir as concentrações dos gases constituintes do produto gasoso. Como uma forma de prever estas concentrações, foram simuladas as gaseificações usando um script escrito para EES (Apêndice B) resolvendo o modelo matemático baseado em equilíbrio químico descrito na seção 3.3. O agente 
gaseificante usado foi o ar com $0,21\left(\mathrm{O}_{2}\right)+0,79\left(\mathrm{~N}_{2}\right)$ a $298 \mathrm{~K}$. A simulação determinou as concentrações do gás de síntese composto por $\mathrm{CO}, \mathrm{H}_{2}$ e $\mathrm{CH}_{4}$, prevendo então, o poder calorífico superior do gás ao final do processo. O gráfico a seguir mostra comparativamente as concentrações de gases simulados para cada carvão desde a queima estequiométrica $(\phi=$ 1) até a zona de pirólise $(\phi<0,3)$, onde as temperaturas estão abaixo dos $800{ }^{\circ} \mathrm{C}$ (Figura 32). Por este gráfico é possível verificar que a simulação numérica também aponta o GCEFC como a amostra com maior concentração de $\mathrm{CO}$ e $\mathrm{H}_{2}$, o que lhe confere maior PCS que os demais, especialmente para as condições de gaseificação e pirólise, com razão de equivalência menores que 0,5 .

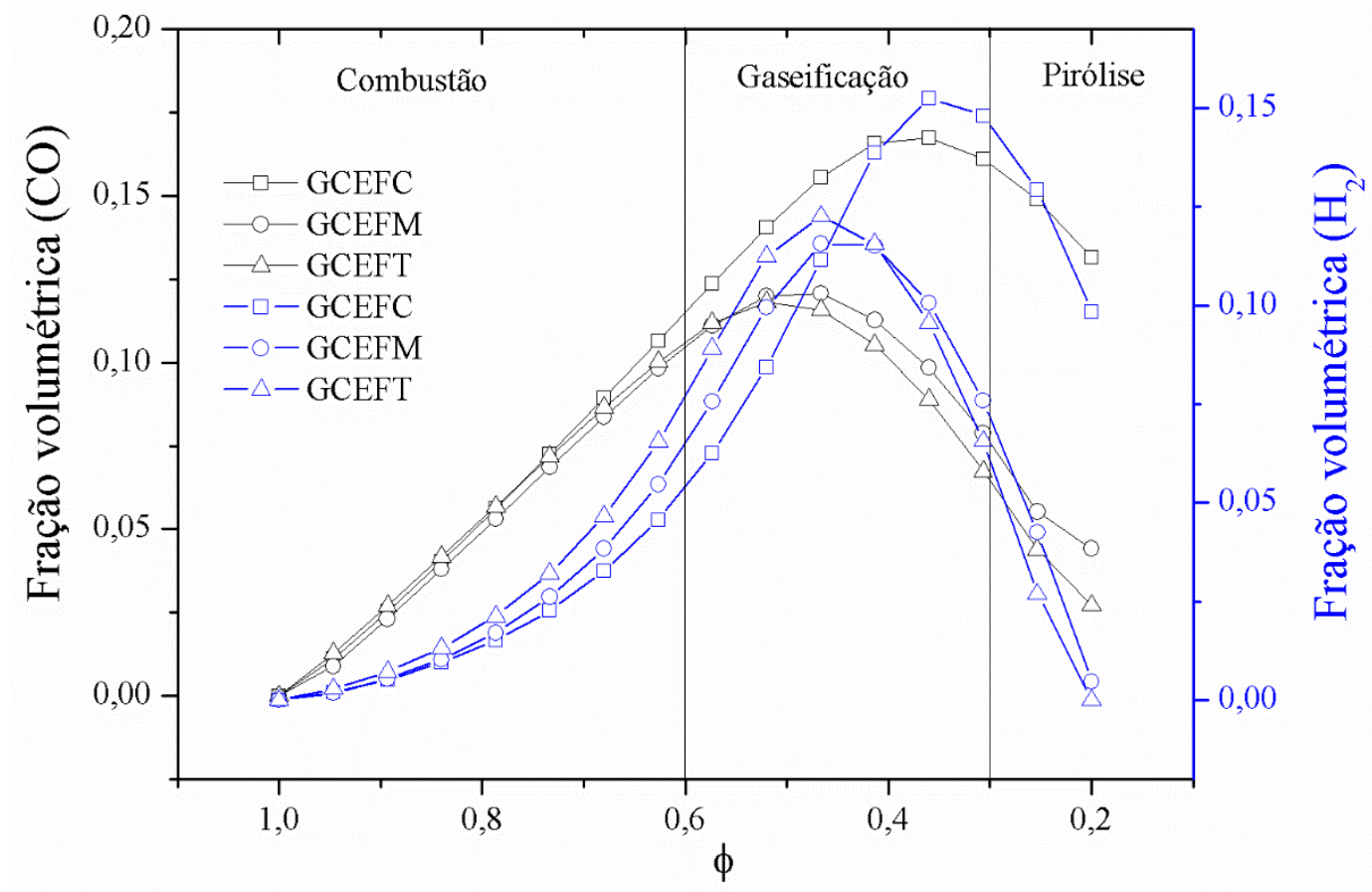

Figura 32 Fração volumétrica de $\mathrm{CO}$ e $\mathrm{H}_{2}$ em função de $\phi$ simulado em modelo 0D. Concentrações de $\mathrm{CO}$ representado em preto e concentrações de $\mathrm{H}_{2}$ representado em e azul.

Os resultados experimentais foram então comparados aos simulados (Figura 33), e consolidados e comparados com a literatura na tabela 16, que apresenta um comparativo com outros trabalhos disponíveis na literatura como os softwares ComGas (Nogueira et al., 2009) e o Gasifier (Fock e Thonsen, 2000), e os dados experimentais de outro trabalho (Li et al., 2004), que gaseificou 15 diferentes tipos de biomassa em um equipamento similar ao usado nesta tese. Na coluna "Exp" na tabela a seguir comparam-se os dados experimentais obtidos neste trabalho com a biomassa com características mais próximas encontradas na literatura, já que não foram encontrados dados da gaseificação de carvões CEFC, CEFM ou CEFT em leito fluidizado para comparação direta. 

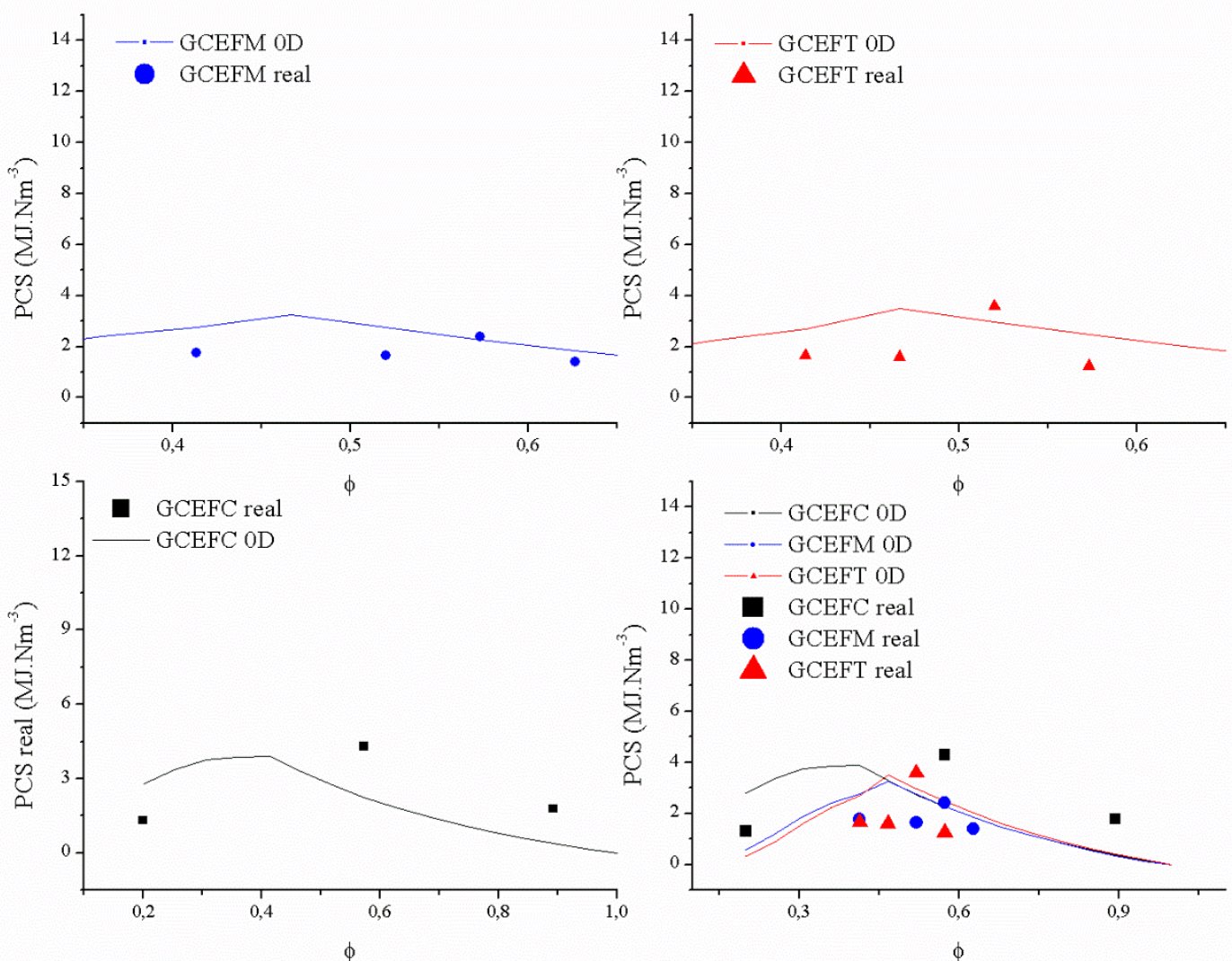

Figura 33 Comparativo do PCS do syngas na simulação OD com os valores reais medidos em cromatografia. Condições de ensaio conforme tabelas 11, 12 e 13.

Tabela 16 Comparação dos resultados obtidos nos picos de produção. Nomenclatura utilizada: Sim simulado segundo o modelo apresentado em 3.5.1; Sw - Dados obtidos com outros simuladores; Exp Dados experimentais.

\begin{tabular}{|c|c|c|c|c|c|c|c|c|c|}
\hline & \multicolumn{3}{|c|}{ GCEFC } & \multicolumn{3}{|c|}{ GCEFM } & \multicolumn{3}{|c|}{ GCEFT } \\
\hline & Sim & Sw & Exp & Sim & Sw & Exp & Sim & $\mathrm{Sw}$ & Exp \\
\hline \multirow{2}{*}{$\mathrm{PCS}\left(\mathrm{MJ} \cdot \mathrm{Nm}^{-3}\right)$} & \multirow{2}{*}{3,25} & $3,89^{\mathrm{a}}$ & 4,3 & \multirow{2}{*}{3,73} & $4,04^{\mathrm{a}}$ & 2,4 & \multirow{2}{*}{3,46} & $3,64^{\mathrm{a}}$ & 3,6 \\
\hline & & $6,39^{b}$ & $4,14^{\mathrm{c}}$ & & $5,93^{\mathrm{b}}$ & $2,43^{\mathrm{c}}$ & & $5,88^{\mathrm{b}}$ & $3,59^{\mathrm{c}}$ \\
\hline \multirow{2}{*}{$\eta_{g f}(\%)$} & \multirow{2}{*}{73} & $91^{\mathrm{a}}$ & 75 & \multirow{2}{*}{55} & $81^{\mathrm{a}}$ & 69 & \multirow{2}{*}{72} & $71^{\mathrm{a}}$ & 50 \\
\hline & & $88^{\mathrm{b}}$ & $64^{\mathrm{c}}$ & & $86^{\mathrm{b}}$ & $53^{c}$ & & $85^{\mathrm{b}}$ & $54^{\mathrm{c}}$ \\
\hline \multirow{2}{*}{$\Phi(\mathrm{kg} / \mathrm{kg})$} & \multirow{2}{*}{0,50} & $0,41^{\mathrm{a}}$ & 0,57 & \multirow{2}{*}{0,47} & $0,41^{\mathrm{a}}$ & 0,57 & \multirow{2}{*}{0,45} & $0,47^{\mathrm{a}}$ & 0,52 \\
\hline & & $0,69^{\mathrm{b}}$ & $0,38^{\mathrm{c}}$ & & $0,64^{b}$ & $0,54^{\mathrm{c}}$ & & $0,61^{\mathrm{b}}$ & $0,40^{\mathrm{c}}$ \\
\hline \multirow{2}{*}{ Temperatura } & \multirow{2}{*}{661} & $782^{\mathrm{a}}$ & 805 & \multirow{2}{*}{924} & $960^{a}$ & 860 & \multirow{2}{*}{914} & $967^{a}$ & 929 \\
\hline & & $780^{b}$ & $772^{\mathrm{c}}$ & & $920^{\mathrm{b}}$ & $740^{\mathrm{c}}$ & & $920^{\mathrm{b}}$ & $815^{\mathrm{c}}$ \\
\hline Alcatrões & $0 \%$ & $0 \%$ & $0 \%$ & $0 \%$ & $0 \%$ & $0 \%$ & $0 \%$ & $0 \%$ & $0 \%$ \\
\hline Sólido arrastado & & - & $2,5 \%$ & - & & $5 \%$ & - & - & $2 \%$ \\
\hline
\end{tabular}

${ }^{\mathrm{a}}$ ComGas . ${ }^{\mathrm{b}}$ Gasifier. c (Li et al., 2004).

Dos subprodutos da gaseificação, observou-se que não houve produção de alcatrão em nenhum caso. Essa característica confirma o observado nos espectros de infravermelho dos gases produzidos durante a termogravimetria dos carvões. A isenção de alcatrões no gás de síntese habilita seu uso em motores de combustão interna sem que sejam necessários 
processos de condensação e filtragem. Observa-se também uma boa convergência dos resultados com o encontrado na literatura de referência.

\subsubsection{Balanço de massa e energia}

O balanço de massa para o cupuaçu (Figura 34) apresenta o fluxo de entrada e saída de material no reator. Os valores apresentados são os medidos nos pontos de melhor resultado qualitativo para gás de síntese.

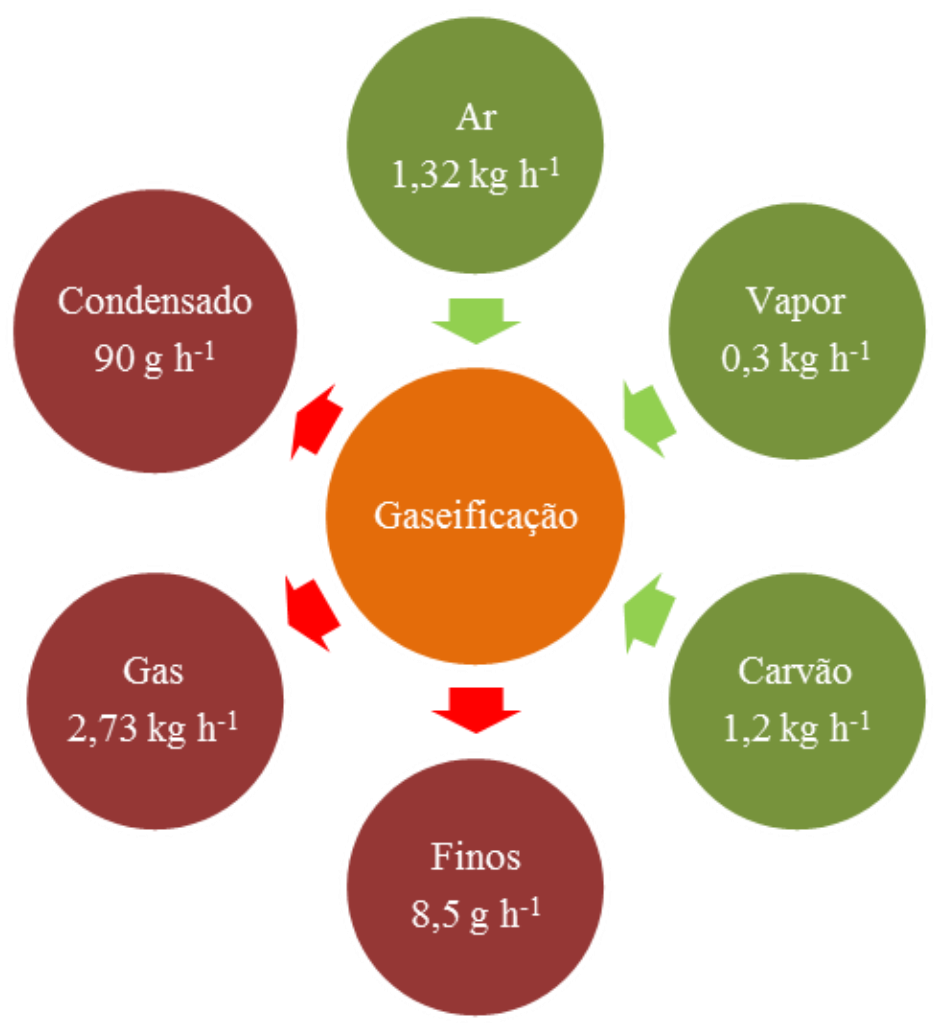

Figura 34 Balanço de massa na gaseificação do CEFC

O balanço para CEFM (Figura 35) mostra que esta biomassa é o que apresenta menores quantidades de resíduos quando submetido à gaseificação. 


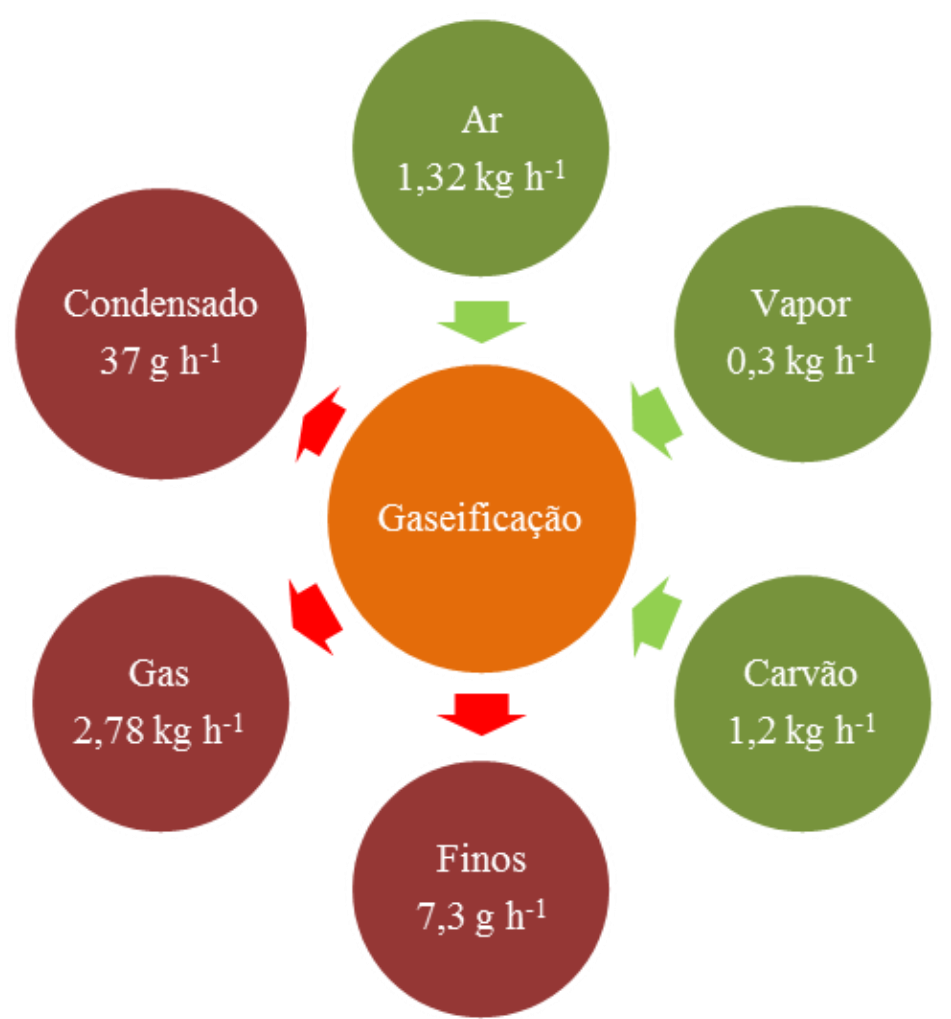

Figura 35 Balanço de massa na gaseificação do CEFM

$\mathrm{Na}$ análise do processo para CEFT (Figura 36) mostra que esta biomassa quando gaseificada é a que apresenta maiores quantidades de condensados e finos de carvão residuais.

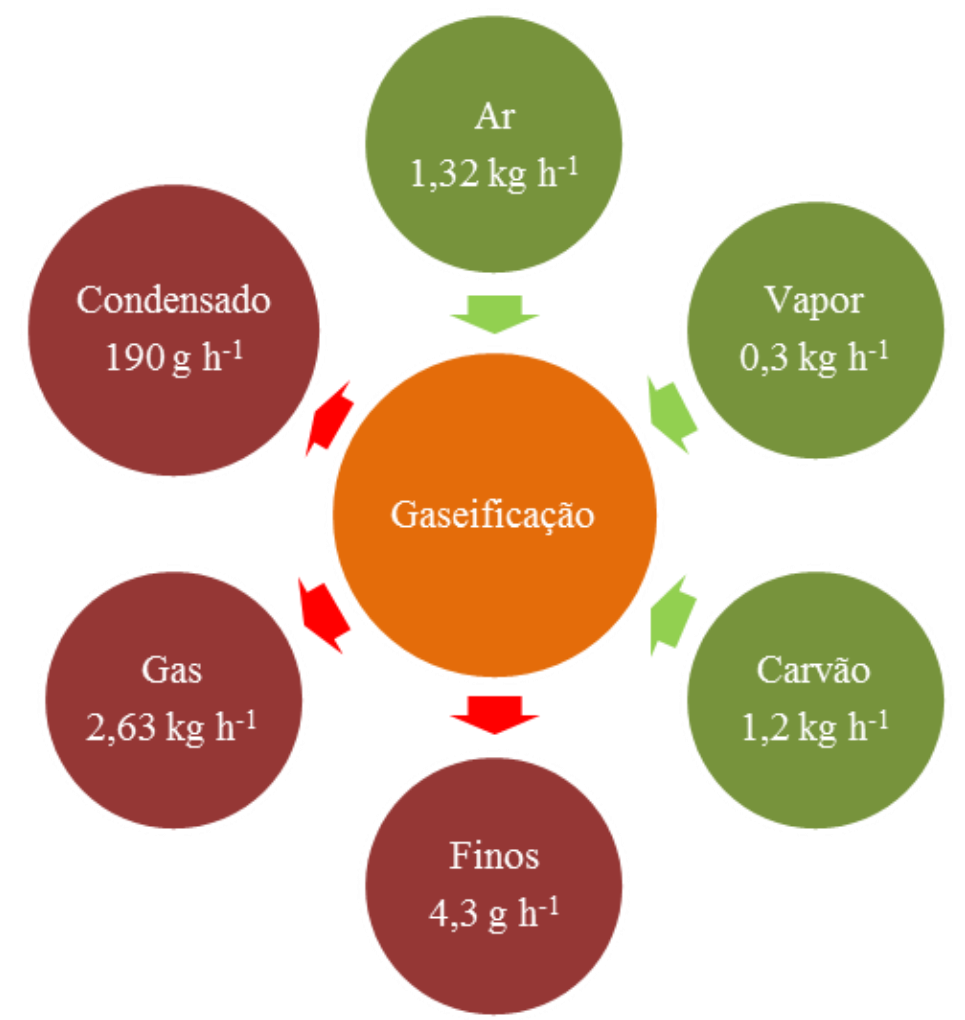

Figura 36 Balanço de massa na gaseificação do CEFT 
No balanço de energia na gaseificação do CEFC, 75\% da energia está contida no gás de síntese enquanto $12 \%$ é gasto para resfriá-lo e 11,3\% nos rejeitos sólidos e líquidos. O calor perdido pela isolação do reator soma $1,2 \%$ do total e $0,5 \%$ são devidos à outras perdas no processo.

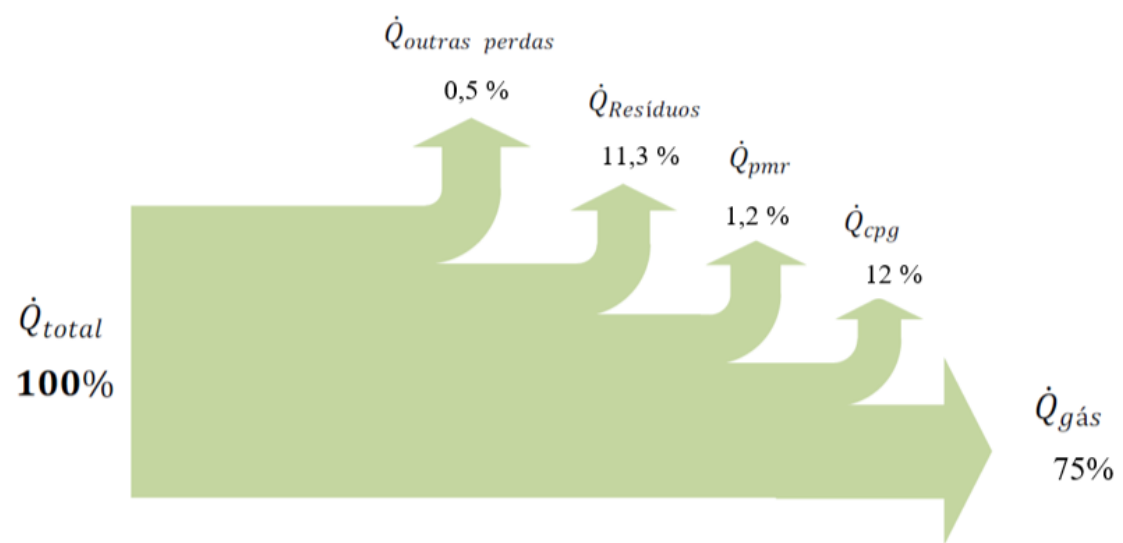

Figura 37 Balanço de energia na gaseificação do CEFC

Para o CEFM 69\% da energia do carvão é aproveitada no gás de síntese, enquanto $23 \%$ é cedida pelo gás ao ambiente durante seu resfriamento, $1,2 \%$ perdidos no isolamento do reator e $5 \%$ são descartados junto com condensados e sólidos arrastados no processo.

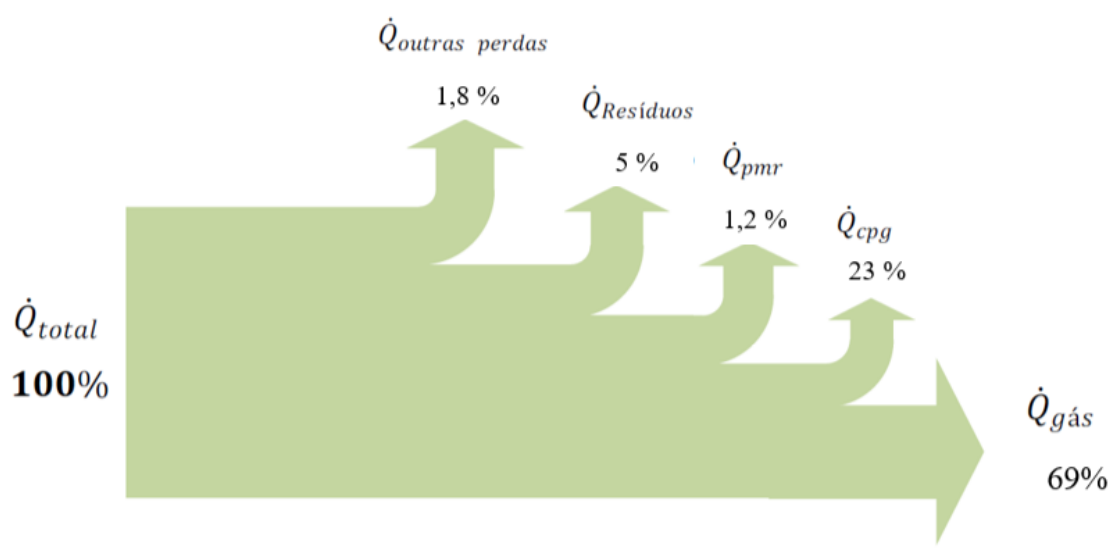

Figura 38 Balanço de energia na gaseificação do CEFM

Na gaseificação do CEFT, $50 \%$ da energia permanece no gás de síntese enquanto $25 \%$ são devidos à refrigeração do gás e $23 \%$ dispensados com os resíduos. No reator são cedidos ao ambiente $1,2 \%$ da energia total, enquanto $0,2 \%$ são devidos a outras perdas no processo. 


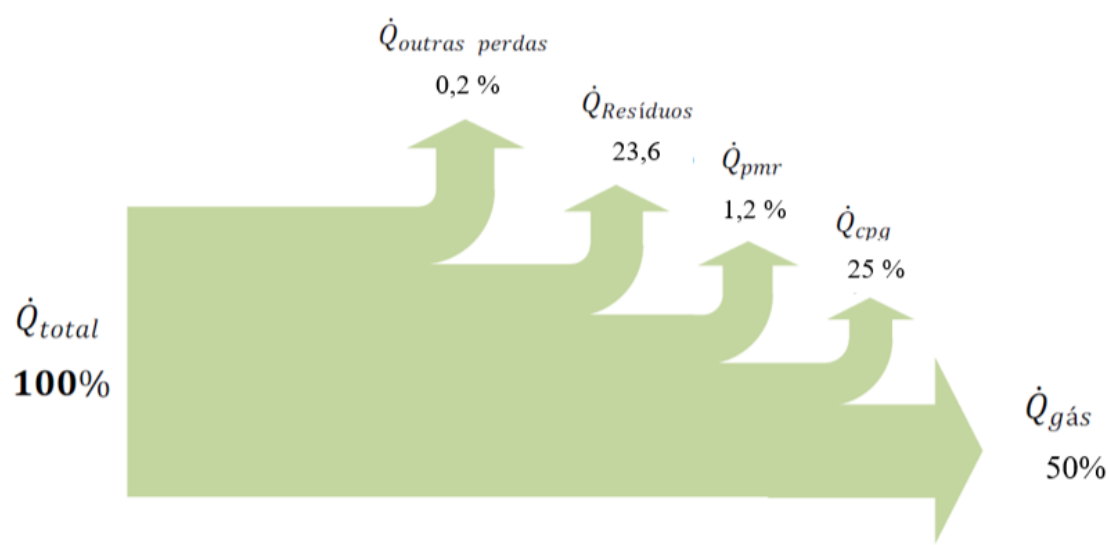

Figura 39 Balanço de energia na gaseificação do CEFT

Entre os resíduos, de 2 a 5\% massa são de finos de carvões arrastado e capturados nos ciclones. A seção seguinte analisa-se o uso deste rejeito como adsorvente usados, inclusive, em processos de filtração de água.

\subsection{ATIVAÇÃO DE CARVÃO}

O carvão arrastado durante o processo de gaseificação possui características que habilitam seu uso para aplicações de purificação de água para consumo humano, tanto na remoção de cloro devido ao seu alto carbono fixo, quanto na adsorção de cor, devido à sua estrutura microporosa. Uma característica predominante dos rios da Amazônia é a coloração escura de suas águas. Nas seções seguintes são apresentados os resultados das comparações entre o carvão ativado quimicamente a partir da biomassa virgem e da biomassa carbonizada com o carvão arrastado no processo de gaseificação em leito fluidizado.

Para medição da área superficial e volume de poros, usou-se os procedimentos apresentados na seção 3.4.1 e para avaliar seu potencial de adsorver cor os procedimentos da seção 3.4.4. As isotermas de adsorção de $\mathrm{N}_{2}$ dos carvões ativados (Figura 40) mostram comportamentos similares para as três amostras, onde todas são do tipo I - típica de materiais microporosos, onde os poros excedem em pouco o diâmetro molecular do adsorbato. 


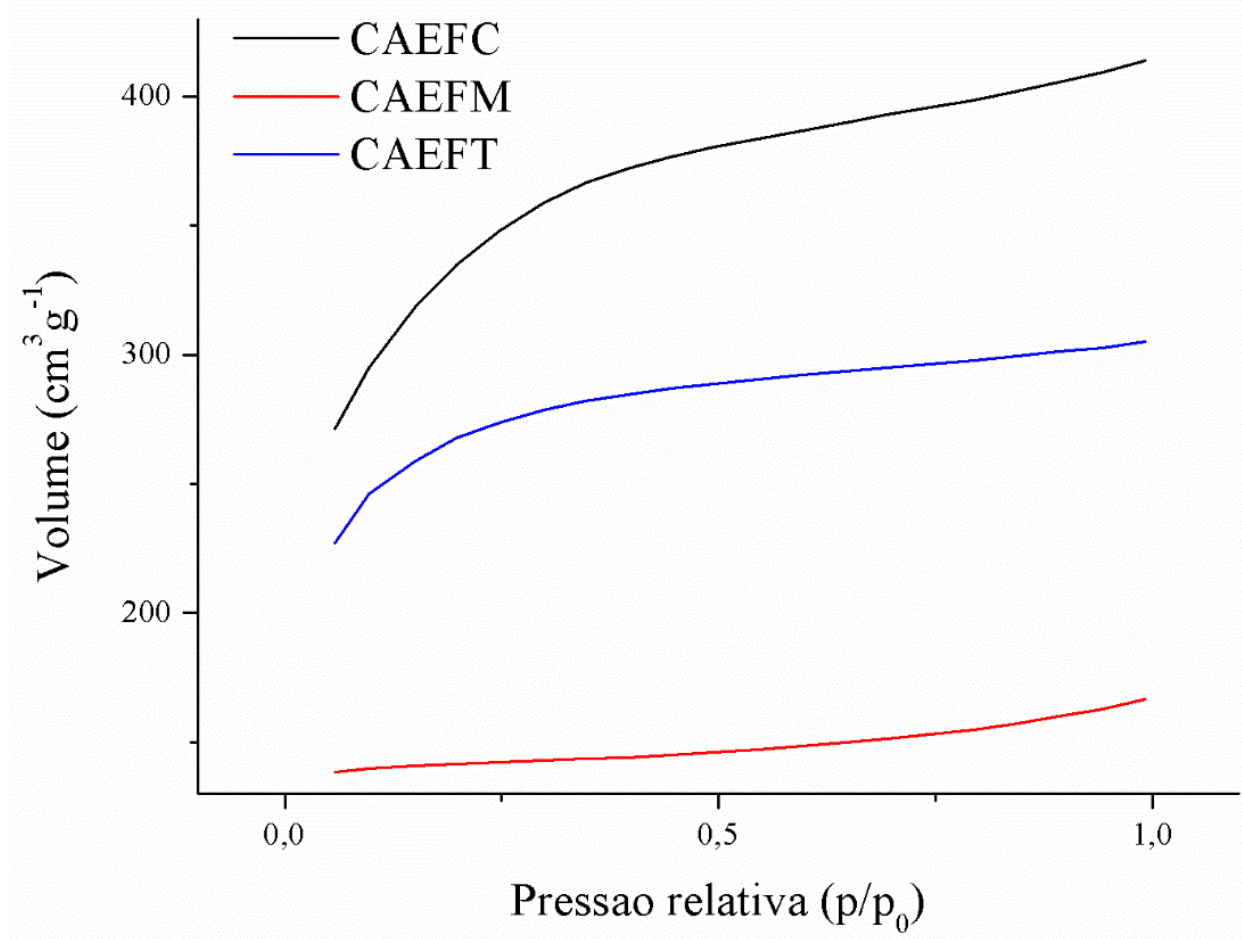

Figura 40 Isotermas de adsorção de nitrogênio a 77 K usando um equipamento NOVA 300 BET analisador da Quanta Chrome, USA. Os valores de área e tamanho médio de poro foram obtidos a partir da aplicação dos modelos de BET e BJH para os dados da isoterma

Com excelentes características para uso em tratamento de água, os carvões obtidos são comparados aos da literatura na tabela 17 a seguir. É possível observar que os carvões ativados das amostras em estudo apresentaram propriedades superiores aos comerciais nos indicadores de área superficial e na adsorção de azul de metileno.

Tabela 17 Propriedades dos carvões ativados.

\begin{tabular}{|l|c|c|c|}
\hline Propriedade & CAEFT & CAEFM & CAEFC \\
\hline BET área superficial específica $\left(\mathrm{m}^{2} \mathrm{~g}^{-1}\right)$ & $\begin{array}{c}853,6 \\
835,7^{\mathrm{c}}\end{array}$ & $\begin{array}{c}420,9 \\
286,1^{\mathrm{a}}\end{array}$ & $\begin{array}{c}1108,0 \\
933^{\mathrm{c}}\end{array}$ \\
\hline Raio de poros Dv(r) $(\AA)$ & 16,84 & $\begin{array}{c}21,47 \\
19,48^{\mathrm{a}}\end{array}$ & $\begin{array}{c}16,880 \\
22,31^{\mathrm{c}}\end{array}$ \\
\hline Volume de poros $\left(c c g^{-1}\right)$ & \multirow{2}{*}{0,047} & $\begin{array}{c}0,047 \\
0,158^{\mathrm{a}}\end{array}$ & $\begin{array}{c}0,0952 \\
0,259^{\mathrm{c}}\end{array}$ \\
\hline \multirow{2}{*}{ Adsorção de azul de metileno $\left(m g g^{-1}\right)$} & 493 & $\begin{array}{c}384 \\
227^{\mathrm{c}}\end{array}$ & $\begin{array}{c}452 \\
480^{\mathrm{a}}\end{array}$ \\
\hline
\end{tabular}

a (Rios et al., 2014); b (Junior, 2010); c Carvão ativado comercial (Brum et al., 2008; Schimmel, 2008; Brum, 2013)

Para avaliação da capacidade em adsorver moléculas de azul de metileno (AM) aplica-se o modelo desenvolvido em 3.4.4. As isotermas de Langmir (Figura 41) mostram o comportamento dos carvões ativados quimicamente desde a biomassa virgem, na adsorção de cor. O carvão CEFT foi o que melhor adsorveu as moléculas de AM. 

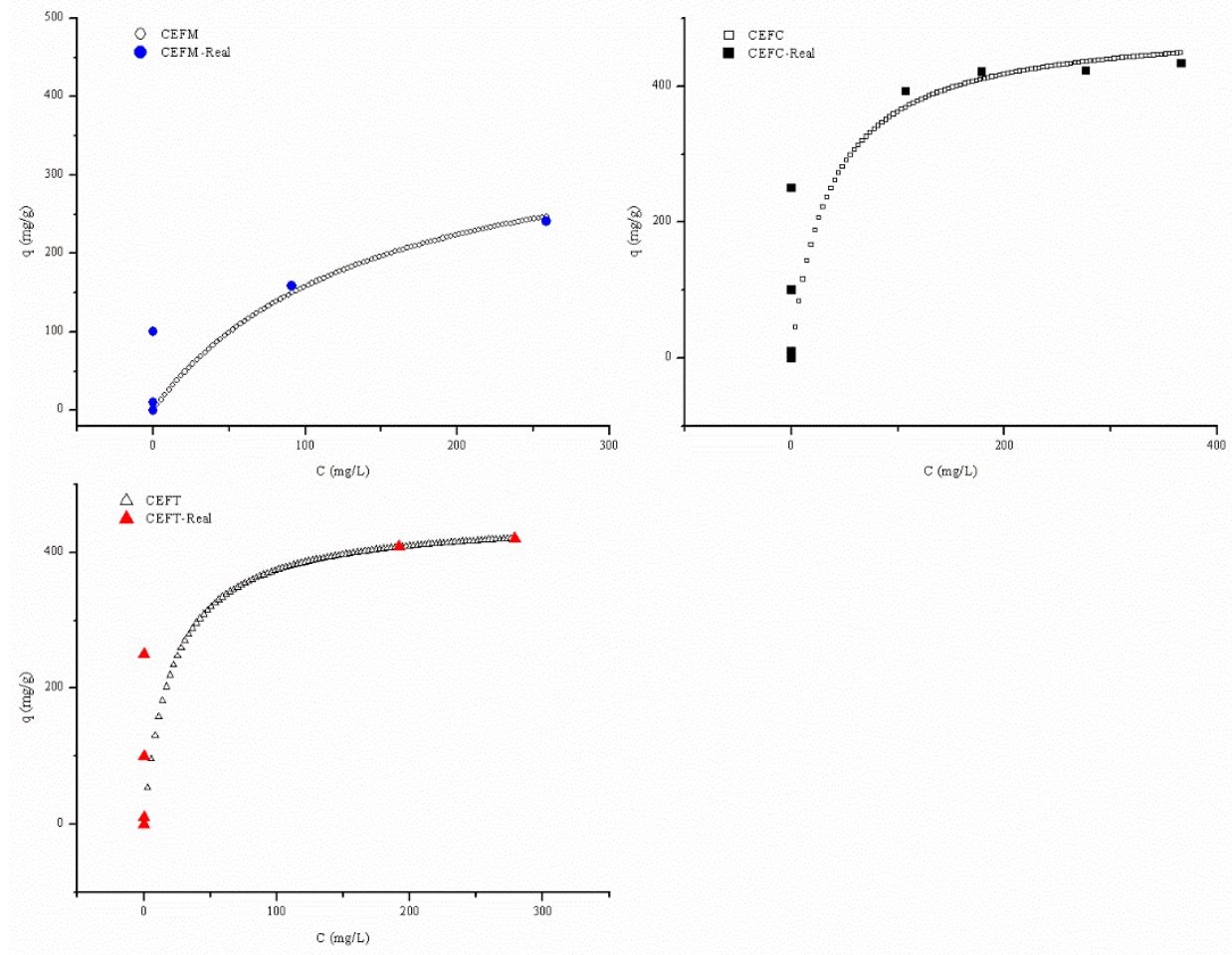

Figura 41 Isotermas de adsorção de azul de metileno

O comparativo a seguir mostra os resultados entre carvões ativados quimicamente a partir da biomassa carbonizada e os recolhidos do ciclone no processo de gaseificação (Figura 42), identificados por $C A E F_{-C i c}$. Neste comparativo foi utilizado o corante reativo RR2 para o levantamento das isotermas. O resultado mostra que os finos de carvão recolhido dos ciclones possuem propriedades próximas aos carvões ativados quimicamente desde a biomassa carbonizada. 

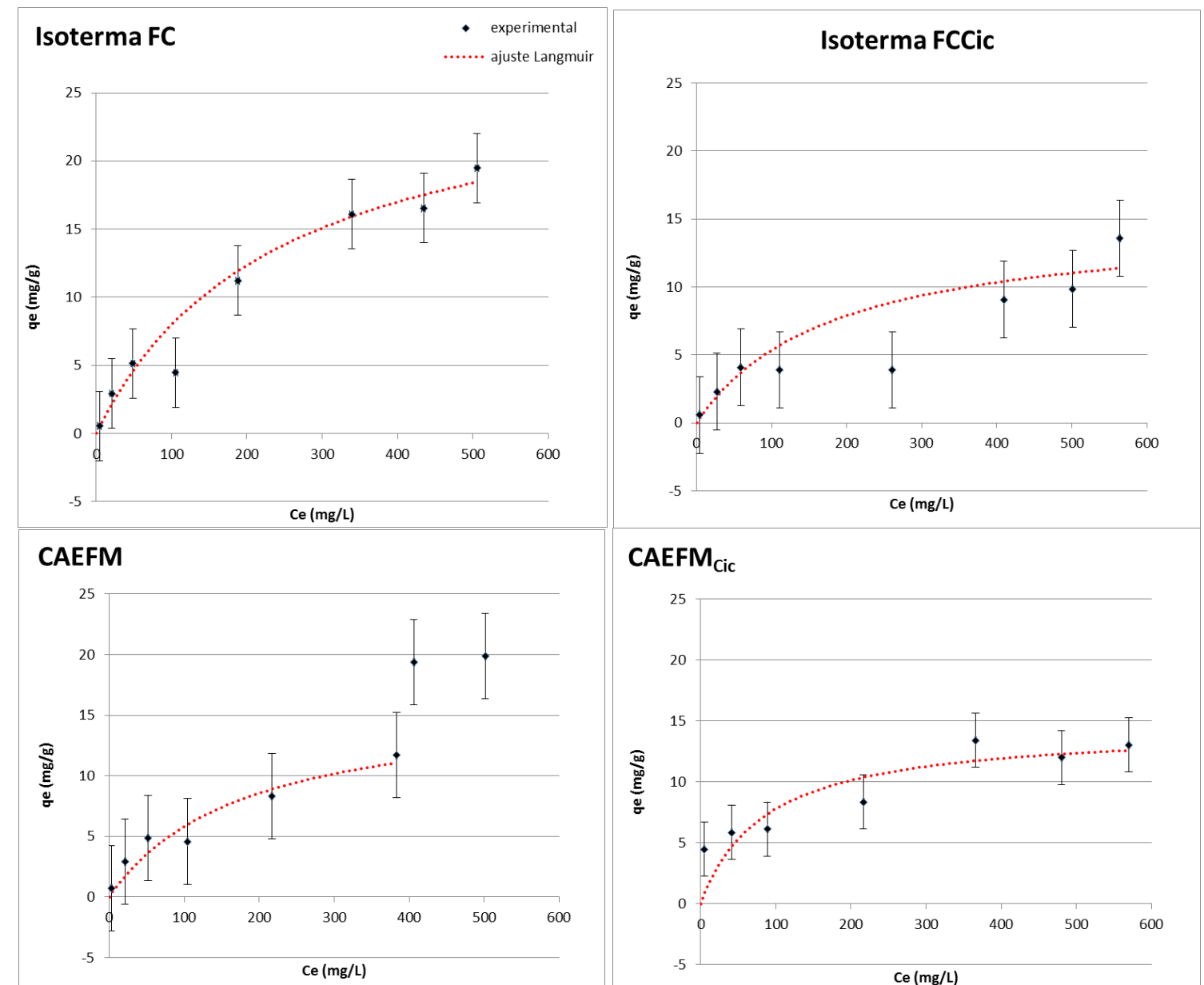

CAEFM $_{\text {Cic }}$

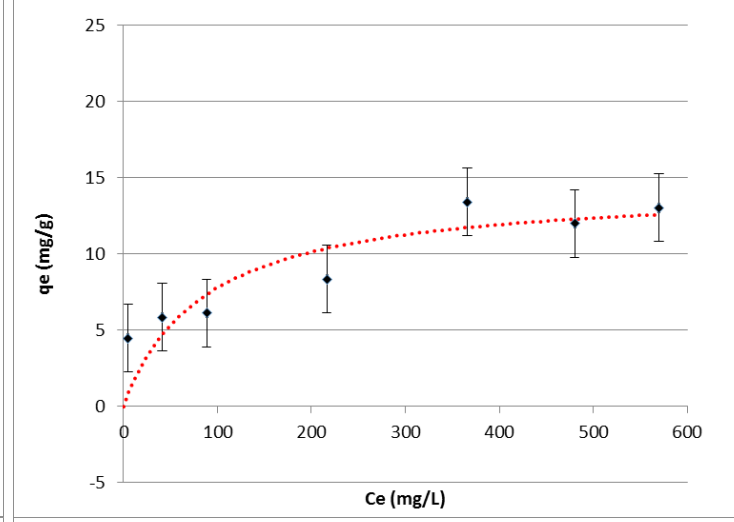

\section{CAEFT}

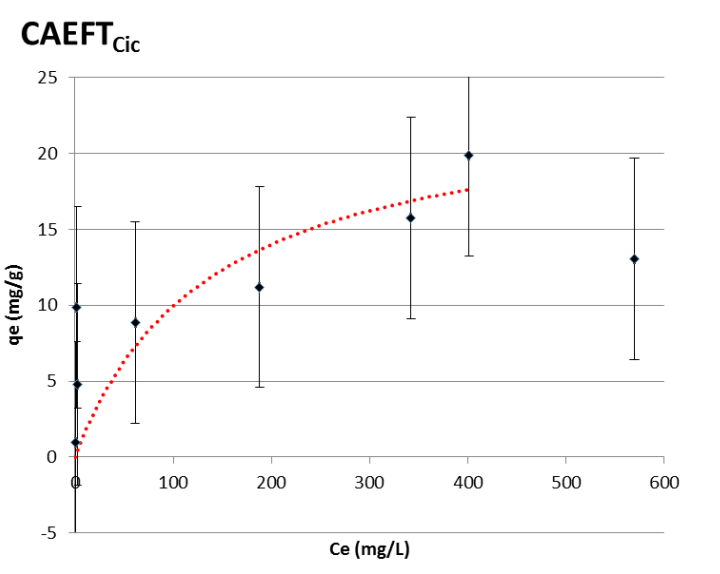

Figura 42 Comparativo das isotermas de adsorção para o corante RR02 conduzido a $30{ }^{\circ} \mathrm{C}$.

Os resultados da figura 42 comparados aos encontrados na literatura confirmam os bons resultados alcançados pelos carvões estudados (tabela 18). Da análise dos dados, observa-se que o melhor carvão para adsorção do corante RR2 é o oriundo da casca do cupuaçu, seguido pelo derivado do endocarpo de tucumã e por fim pelo carvão da macaúba. A diferença entre os indicadores de adsorção de cor entre os carvões ativados quimicamente para os coletados no ciclone do gaseificador, mostram que estes possuem propriedades similares. Enquanto que a reinserção destes finos como combustível é desaconselhada, uma 
vez que possuem baixa reatividade e necessitaria de temperaturas bem maiores (Jing et al., 2013). A aplicação da casca do cupuaçu como adsorvente de corantes orgânicos reativos também foi comprovada pelo trabalho conduzido por Cardoso et al. (2011), que alcançou bons resultados para a remoção dos corantes reativos RR-194 e DB-53 de soluções aquosas, com adsorção máximas de $64,1 \mathrm{mg} \mathrm{g}^{-1}$ e $37,5 \mathrm{mg} \mathrm{g}^{-1}$, respectivamente.

Tabela 18 Consolidado comparativo dos resultados de adsorção de RR2 a $30^{\circ} \mathrm{C}$ e PH 5,0.

\begin{tabular}{|c|c|c|c|}
\hline Carvão & $K_{L}\left(\mathrm{~L} \mathrm{mg}^{-1}\right)$ & $q_{\max }\left(\mathrm{mg} \mathrm{g}^{-1}\right)$ & $R^{2}$ \\
\hline CAEFC & 0,00413 & 27,28 & 0,99 \\
\hline CAEFC $_{\text {Cic }}$ & 0,00553 & 15,02 & 0,94 \\
\hline CAEFM & 0,0056 & 16,21 & 0,93 \\
\hline CAEFM $_{\text {Cic }}$ & 0,01159 & 14,50 & 0,82 \\
\hline CAEFT & 0,00151 & 21,12 & 0,99 \\
\hline CAEFT $_{\text {Cic }}$ & 0,00724 & 23,70 & 0,87 \\
\hline
\end{tabular}

$K_{L}$ : Constante de equilíbrio de Langmuir $\left(\mathrm{L} \mathrm{mg}^{-1}\right) ; q_{\max }$ : quantidade máxima de corante adsorvida.

As morfologias dos carvões foram observadas através de imagens de microscopia eletrônica de varredura (MEV) (Figura 43). O CAEFC é o que apresenta a estrutura visivelmente mais porosa entre as três amostras. 


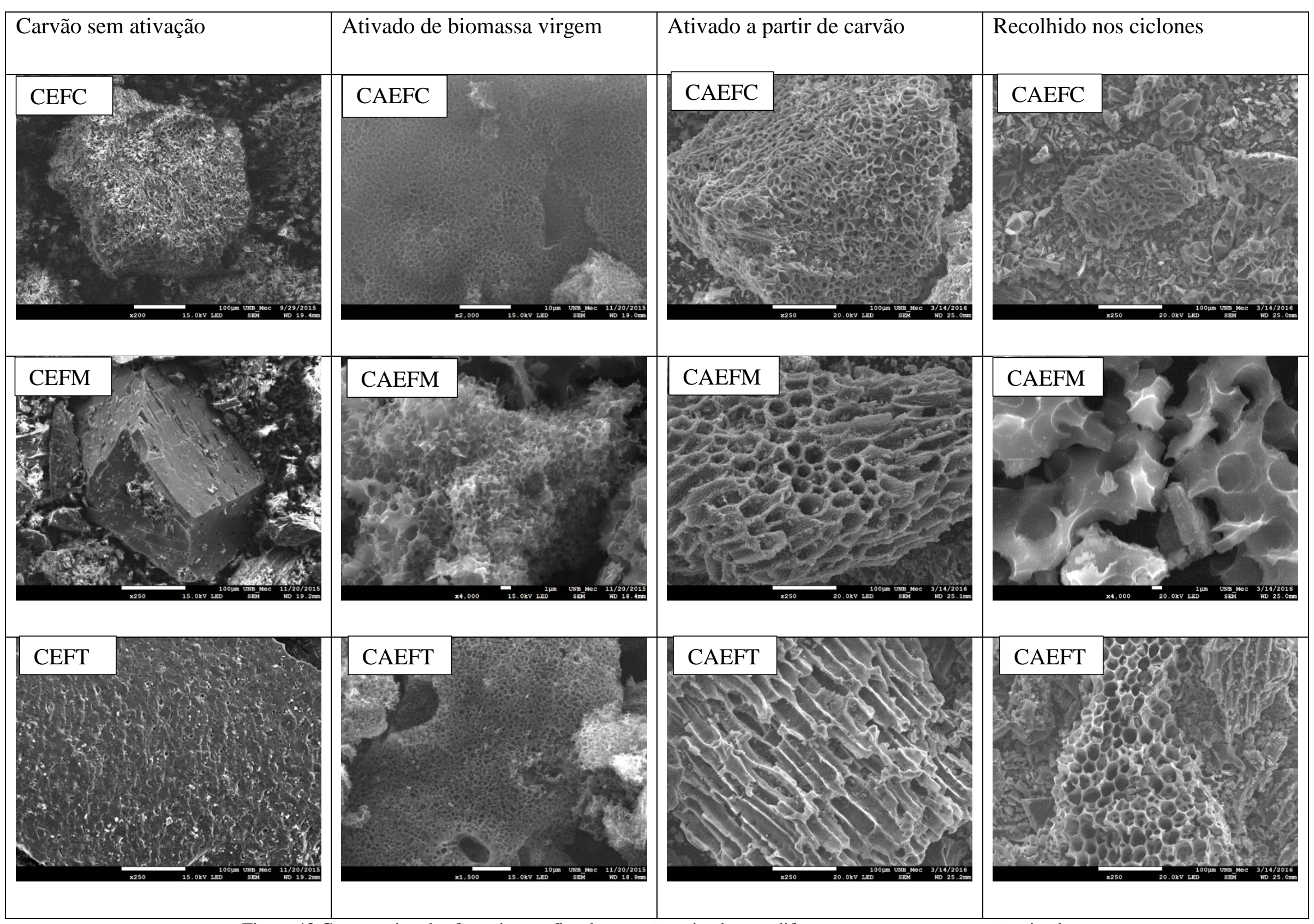

Figura 43 Comparativo das fotomicrografias dos carvões ativados em diferentes processos com o não ativado 
As fotomicrografias da figura 43 mostram a ação do carbonato de potássio na ativação química e dos agentes gaseificantes na ativação física. $O$ aumento da área superficial é visível em ambos os casos, fato esse comprovado pelos resultados das análises de BET e da adsorção de azul de metileno e do RR02. Para o CAEFM nota-se que sua elevada dureza e maior quantidade de carbono fixo reduzem a área superficial após a ativação. Enquanto que o carvão ativado produzido a partir do endocarpo da fruta do tucumã (CAEFT) apresenta excelente área superficial BET e boa quantidade de carbono fixo. $\mathrm{O}$ CAEFC foi o que apresentou melhores indicadores o que o coloca como uma excelente oportunidade de produto, uma vez que $43 \%$ da massa do fruto são cascas.

Assim os carvões ativados das amostras estudadas apresentam boas características para uso comercial. Considerando que o mesmo reator de gaseificação pode produzir tanto gás de síntese quanto carvão ativado, a produção deste pode ampliar o portfólio de produtos produzidos nas comunidades rurais da região amazônica.

\subsection{GERAÇÃO DE ELETRICIDADE A PARTIR DO GÁS DE SÍNTESE}

A partir do gás de síntese a geração de eletricidade pode ser feita em máquinas térmicas como turbinas a gás ou em motores de combustão interna. A maior parte dos motogeradores instalados na Amazônia são alimentados por diesel, assim segue a análise de motores diesel operando em modo duplo combustível com a admissão de gás de síntese juntamente com ar atmosférico (Figura 44).

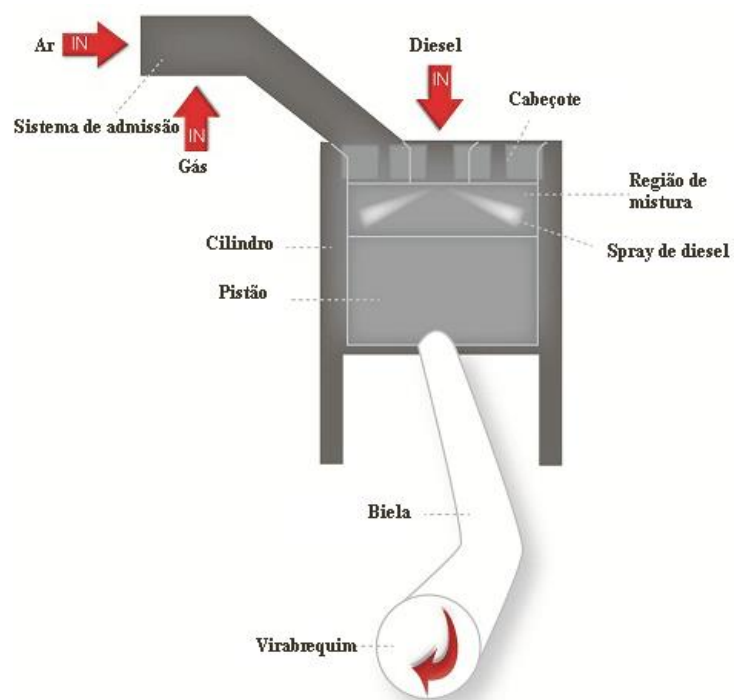

Figura 44 Modo de operação em duplo combustível. Fonte: adaptado de Cummins (2014). 
Conhecendo o poder calorífico do gás de síntese e do diesel é possível calcular a potência gerada usando motogeradores diesel operando em modo duplo combustível usando a equação

$$
P=\frac{\left(\dot{m}_{D}+\frac{P C I_{G}}{P C I_{D}} \dot{m}_{G}\right) P C I_{D}}{\eta_{D G}},
$$

onde $\eta_{D G}$ é o rendimento da máquina térmica operando com gás e diesel, $P[\mathrm{~kW}]$ é a potência gerada, $\dot{m}_{D}$ e $\dot{m}_{G}\left[\mathrm{~g} \mathrm{~s}^{-1}\right]$ são os fluxos de diesel e gás de síntese respectivamente, enquanto o $P C I_{D}$ e $P C I_{G}\left[\mathrm{~kJ} \mathrm{~kg}^{-1}\right]$ são o poder calorífico inferior, do diesel e do gás, calculado a partir da equação 43. Em termos de consumo específico $s f c\left[\mathrm{~g} \mathrm{kWh}^{-1}\right]$ temos

$$
s f c=\frac{3,6 \times 10^{6}}{\eta_{D G}\left(\dot{m}_{D}+\frac{P C I_{G}}{P C I_{D}} \dot{m}_{G}\right) P C I_{D}} .
$$

Dados típicos de operação de motores em duplo combustível apontam a proporção de $70 \%$ de gás para 30\% de diesel (Cummins, 2014), a figura 45 a seguir mostra o taxa de substituição do diesel pelo gás em função da carga do motor. O poder calorífico dos combustíveis são $P C I_{D}=42.700 \mathrm{~kJ} \mathrm{~kg}^{-1}$ e $P C I_{G}$ variando de $2.400 \mathrm{a} 4.300 \mathrm{~kJ} \mathrm{~kg}^{-1} \mathrm{e} \quad$ o rendimento térmico para estes motores $\eta_{D G}=25 \%$.

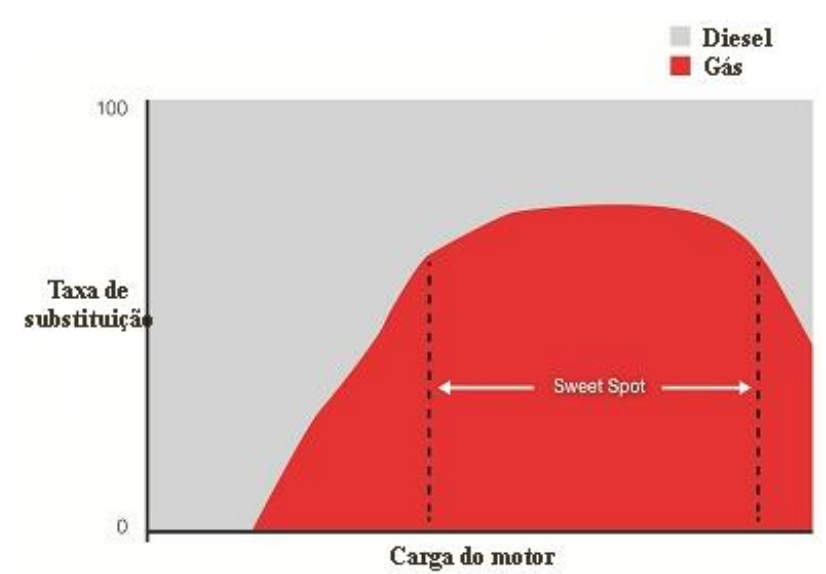

Figura 45 Taxa de substituição do diesel pelo gás. Fonte: adaptado de Cummins (2014).

Assim usando os dados da tabela 16 na equação 79, temos que usando casca de cupuaçu carbonizada são necessários $1,4 \mathrm{~kg} \mathrm{kWh}^{-1}$ de diesel para 3,4 $\mathrm{kg} \mathrm{kWh}^{-1}$ de GCEFC. Da mesma forma para macaúba, 2,6 $\mathrm{kg} \mathrm{kWh}^{-1}$ de diesel para 6,0 $\mathrm{kg} \mathrm{kWh}^{-1}$ de GCEFM e para o tucumã 1,7 $\mathrm{kg} \mathrm{kWh}^{-1}$ de diesel para 4,0 $\mathrm{kg} \mathrm{kWh}^{-1}$ de GCEFT. 
Com os dados de produtividade apresentado em 2.1, é possível calcular que para a casca do cupuaçu podem ser produzidos 8,1 ton de carvão por hectare, gerando 22,2 ton de gás combustível. Ou seja, para cada hectare plantado com cupuaçu, o aproveitamento da casca gera 6,2 $\mathrm{kWh} \mathrm{ha}^{-1}$ de eletricidade, usando os mesmos equipamentos movidos por diesel já instalados acoplados a um gaseificador. Os resíduos da macaúba podem produzir 1,4 $k W h h a^{-1}$ e os do tucumã 1,1 $k W h h a^{-1}$, o que mostra o grande potencial energético destes três resíduos. 


\section{CONCLUSÕES}

A partir dos resultados apresentados ao longo deste trabalho, conclui-se que há viabilidade tecnológica no uso de biomassa residual carbonizada na produção de eletricidade para sistemas isolados na Amazônia. Outros produtos com alto valor agregado, como o carvão vegetal e o carvão ativado, também podem ser explorados utilizando os mesmos processos estudados nesta tese: pirólise e gaseificação.

Análises preliminares usando TG-FTIR simulando condições de carbonização e gaseificação, são extremamente úteis no planejamento dos experimentos, Análises dos resultados ajudam a prever taxas de decaimento e composição qualitativa dos gases emitidos durante os ensaios. Igualmente importante, a modelagem numérica do processo de gaseificação, ajuda na configuração do gaseificador, tornando a parte experimental mais ágil e de fácil controle.

O ensaio de degradação térmica mostrou para a biomassa virgem, três áreas distintas de degradação: uma primeira relativa à secagem do material, a segunda característica da degradação da hemicelulose e, por fim, a terceira relacionada à degradação da celulose e da lignina. Na análise dos espectros de infravermelho feitos nas temperaturas de carbonização evidenciou-se o aumento da produção de alcatrões com o aumento da temperatura, enquanto no ensaio feito à temperatura de gaseificação não foi identificado alcatrões pesados nos gases emitidos.

As carbonizações foram feitas em retortas elétricas com temperaturas máximas distintas para a casca do cupuaçu e para os endocarpos de tucumã e macaúba. O rendimento da carbonização do EFC foi o que apresentou melhor resultado (36\%), seguido pelos endocarpos da macaúba e tucumã (30\%). Valores bem próximos aos valores encontrados na análise de TG em temperatura de carbonização.

$\mathrm{Na}$ caracterização físico-química das amostras de biomassa carbonizada, observa-se que o carvão do endocarpo da fruta da macaúba (CEFM) é a que apresenta melhores características para queima direta: maior densidade, maior quantidade de carbono e maior PCS. No entanto, para o processo de gaseificação sua menor área superficial reduz seu rendimento, quando comparada às demais amostras de biomassa. A gaseificação do CEFC é a que apresentou melhor desempenho, com PCS do gás maior que as demais amostras e 
melhor eficiência a gás frio. Todos os carvões apresentaram estruturas cristalinas amorfas, conforme mostrado na análise da difração de raios-x (RDX) e não contém substâncias tóxicas ou radioativas em sua composição, habilitando-os para uso em cocção ou em meios filtrantes.

Nos ensaios de gaseificação em leito fluidizado, observou-se que existe uma relação entre o PCS do gás e a temperatura de gaseificação. O gás do carvão do epicarpo da fruta do cupuaçu (GCEFC) apresenta o melhor resultado de PCS entre as três amostras $\left(4,3 \mathrm{MJ} \mathrm{Nm}^{-3}\right)$, para temperaturas menores que $800^{\circ} \mathrm{C}$, confirmando o resultado da termogravimetria do CEFC que apresentou as menores temperaturas para degradação. Sua maior área superficial $\left(11,4 \mathrm{~m}^{2} \mathrm{~g}^{-1}\right)$ lhe confere melhor reatividade que os carvões CEFT $\left(6,1 \mathrm{~m}^{2} \mathrm{~g}^{-1}\right)$ e CEFM $\left(2,6 \mathrm{~m}^{2} \mathrm{~g}^{-1}\right)$. Os resultados numéricos referentes ao modelo no equilíbrio químico e $0 \mathrm{D}$, aproximou satisfatoriamente os resultados experimentais alcançados. Contudo não fio possível atingir a temperatura calculada numericamente para a melhor gaseificação do CEFM de $1125^{\circ} \mathrm{C}$, devido às proteções existentes no gaseificador. O melhor rendimento a gás frio foi alcançado pela reação que produziu o GCEFC com $73 \%$, sendo que os desempenhos das reações que produziram os GCEFM e GCEFT ficaram com $69 \%$ e $50 \%$ respectivamente.

Os subprodutos da gaseificação foram os finos de carvões arrastados recolhidos nos ciclones (entre 2 a 5\% massa) e líquidos condensados no condensador da unidade (entre 1 e 6\% massa). Foi evidenciado que as partículas de carvão possuem propriedades adsorventes, similares aos carvões quando ativados quimicamente. Para os carvões ativados estudados o CAEFC é o que possui a maior área superficial com $1108 \mathrm{~m}^{2} \mathrm{~g}^{-1}$, seguido do CAEFT com $854 \mathrm{~m}^{2} \mathrm{~g}^{-1}$ e do CAEFM com $421 \mathrm{~m}^{2} \mathrm{~g}^{-1}$. No material líquido não foi evidenciada a presença de alcatrões, sendo o liquido constituído por água e partículas de carvão.

De um modo geral os processos desenvolvidos mostraram-se capazes de gerar produtos com alto valor agregado. Como os gases combustíveis isentos de alcatrão, o que possibilita seu uso em motogeradores diesel operando em modo duplo combustível, sem a necessidade de sistemas complexos de limpeza dos gases. O carvão com excelente densidade e poder calorífico, podendo ser empregado tanto para cocção, quanto na siderurgia, e o carvão ativado que tanto nos processos de ativação química ou física mostraram-se capazes de adsorver impurezas no tratamento água. 


\section{RECOMENDAÇÕES PARA TRABALHOS FUTUROS}

- Investigação de um modelo de negócios baseado da produção conjugada de carvão para fins energéticos e para fins de produção de carvão ativado, concentrando renda na região amazônica;

- Modelagem matemática da pirólise buscando prever os produtos produzidos e os tempos do processo;

- Estudo da relação da qualidade do gás de síntese, produzido na gaseificação, em função da temperatura de carbonização da biomassa durante o processo de carbonização;

- Estudo econômico do impacto do uso do gás de síntese proveniente de biomassa residual, em comunidades amazônicas típicas. 


\section{REFERÊNCIAS BIBLIOGRÁFICAS}

ALARCON-RUIZ, L. et al. Size effect in concrete intrinsic permeability measurements. Transport in porous media, v. 85, n. 2, p. 541-564, 2010. ISSN 0169-3913.

ANDRADE, M. H. et al. Óleo do Fruto da Palmeira Macaúba-Parte I: Uma Aplicação Potencial para Indústrias de Alimentos, Fármacos e Cosméticos. I TECNIQ Seminário sobre Tecnologia na Indústria Química 2006.

ANDRADE, M. H. E. A. Óleo do fruto da palmeira macaúba. Parte II: Processo de extração do óleo. II ENBTEQ-Encontro Brasileiro sobre Tecnologia na Indústria Química/III Seminário ABIQUIM de Tecnologia. São Paulo SP: ABEQ 2006.

ANEEL. 23ํㄴILÃO DE ENERGIA NOVA A-5. p. Resumo do leilão de energia A5, 2015. Disponível em:

http://www.epe.gov.br/leiloes/Documents/Leil\%C3\%A3o\%20de\%20Energia\%20A5\%202016/Resultado_completo_site_23_len.pdf >. Acesso em: 04/05/2016.

ARENA, U. Process and technological aspects of municipal solid waste gasification. A review. Waste Management, v. 32, n. 4, p. 625-639, 4// 2012. ISSN 0956-053X. Disponível em: < http://www.sciencedirect.com/science/article/pii/S0956053X11004314 >.

BACELLAR, A. A.; ROCHA, B. R. P. Wood-fuel biomass from the Madeira River: A sustainable option for electricity production in the Amazon region. Energy Policy, v. 38, n. 9, p. 5004-5012, 9// 2010. ISSN 0301-4215. Disponível em: < http://www.sciencedirect.com/science/article/pii/S0301421510002971 >.

BASU, P. Combustion and gasification in fluidized beds. CRC press, 2006. ISBN 1420005154.

Biomass gasification and pyrolysis: practical design and theory. Academic press, 2010. ISBN 0080961622.

Chapter 7 - Gasification Theory. In: BASU, P. (Ed.). Biomass Gasification, Pyrolysis and Torrefaction (Second Edition). Boston: Academic Press, 2013a. p.199-248. ISBN 978-0-12-396488-5.

Chapter 8 - Design of Biomass Gasifiers. In: BASU, P. (Ed.). Biomass Gasification, Pyrolysis and Torrefaction (Second Edition). Boston: Academic Press, 2013b. p.249-313. ISBN 978-0-12-396488-5.

108 
BELGIORNO, V. et al. Energy from gasification of solid wastes. Waste management, v. 23, n. 1, p. 1-15, 2003. ISSN 0956-053X.

BHERING, L. Macaúba: matéria-prima nativa com potencial para a produção de biodiesel. EMBRAPA AGROENERGIA (CNPAE), 2009.

BOAS, M. A. V.; CARNEIRO, A. D. C. O. Efeito da temperatura de carbonização e dos resíduos de macaúba na produção de carvão vegetal Effect of carbonization temperature and the macaúba residues in the production of charcoal. Engenharia Agrícola, p. 481-490, 2010 .

BORELlO, D. et al. A 3D Packed Bed Model for Biomass Pyrolysis: Mathematical Formulation and Experimental Validation. Energy Procedia, v. 61, p. 958-961, 2014. Disponível em: < http://linkinghub.elsevier.com/retrieve/pii/S1876610214028343 >.

BRIDGWATER, A. The technical and economic feasibility of biomass gasification for power generation. Fuel, v. 74, n. 5, p. 631-653, 1995. ISSN 0016-2361.

BRIDGWATER, A. V.; BRIDGE, S. A. A Review of Biomass Pyrolysis and Pyrolysis Technologies. Biomass Pyrolysis Liquids. Upgrading and Utilisation, p. 11-92, 1991. ISSN 185166565X.

BRUM, S. S. Catalisadores de zircônia sulfatada e compósitos carvão ativado/zircônia sulfatada para produção de biodiesel e etanol. 2013. 156p. Tese de Doutorado Agroquímica, UFLA, Lavras MG.

BRUM, S. S. et al. Preparação e caracterização de carvão ativado produzido a partir de resíduos do beneficiamento do café. Quim. Nova, v. 31, n. 5, p. 1048-1052, 2008.

CAO, J. et al. Study on carbonization of lignin by TG-FTIR and high-temperature carbonization reactor. Fuel Processing Technology, v. 106, p. 41-47, 2013. ISSN 03783820. Disponível em: 〈 http://dx.doi.org/10.1016/j.fuproc.2012.06.016 >.

CARDOSO, N. F. et al. Application of cupuassu shell as biosorbent for the removal of textile dyes from aqueous solution. Journal of Environmental Management, v. 92, n. 4, p. 1237-1247, 2011. ISSN 0301-4797. 
CERÓN, I.; HIGUITA, J.; CARDONA, C. Analysis of a biorefinery based on Theobroma grandiflorum (copoazu) fruit. Biomass Conversion and Biorefinery, v. 5, n. 2, p. 183-194, 2015. ISSN 2190-6815.

CLAUDINO, A. Preparação de carvão ativado a partir de turfa e sua utilização na remoção de poluentes. 2003. Dissertação de Mestrado Programa de Pós-Graduação em Engenharia Química, UFSC, Florianópolis SC.

CLEMENT, C.; LLERAS, E.; VAN LEEUWEN, J. O potencial das palmeiras tropicais no Brasil: acertos e fracassos das últimas décadas. Agrociencia, v. 9, n. 1-2, p. 67-71, 2005. ISSN 2301-1548.

COIMBRA, M. C.; JORGE, N. Proximate composition of guariroba (Syagrus oleracea), jerivá (Syagrus romanzoffiana) and macaúba (Acrocomia aculeata) palm fruits. Food Research International, v. 44, n. 7, p. 2139-2142, 2011. ISSN 0963-9969.

CUMMINS. Cummins Dual Fuel Engines for Drilling. 2014. Disponível em: < https://cumminsengines.com/dual-fuel >. Acesso em: 21/06/2016.

DE ASSIS, M. R. et al. Qualidade e rendimento do carvão vegetal de um clone híbrido de Eucalyptus grandis x Eucalyptus urophylla. Pesquisa Florestal Brasileira, v. 32, n. 71, p. 291, 2012. ISSN 1983-2605.

DE OLIVEIRA VILELA, A. et al. A new technology for the combined production of charcoal and electricity through cogeneration. Biomass and Bioenergy, v. 69, p. 222-240, 2014. Disponível em: http://www.sciencedirect.com/science/article/pii/S0961953414003274 >.

DEMIRBAS, A.; DEMIRBAS, H. Estimating the calorific values of lignocellulosic fuels. Energy, Exploration \& Exploitation, v. 22, n. 2, p. 135-143, 2004. ISSN 0144-5987.

DI BLASI, C. Modeling chemical and physical processes of wood and biomass pyrolysis. Progress in Energy and Combustion Science, v. 34, n. 1, p. 47-90, 2008. ISSN 03601285.

DI LASCIO, M. A.; FAGUNDES BARRETO, E. J. Energia e Desenvolvimento Sustentável para a Amazônia Rural Brasileira : Eletrificação de Comunidades Isoladas. Brasília DF: Ministério de Minas e Energia, 2009. 192p. ISBN 9788562491009. 
DIDONET, A. A.; FERRAZ, I. D. K. O comercio de frutos de tucumã (Astrocaryum aculeatum G. Mey) nas feiras de Manaus. 2014. ISSN 0100-2945.

EDREIS, E. M. A. et al. CO2 co-gasification of lower sulphur petroleum coke and sugar cane bagasse via TG-FTIR analysis technique. Bioresource Technology, v. 136, p. 595$603,2013$.

FOCK, F.; THONSEN, K. Gasifier. Denmark: DTU, MEK: Simulador para gaseificadores estacionários down draft p. 2000.

FORTES, I. C. P.; BAUGH, P. J. Pyrolysis-GC/MS studies of vegetable oils from Macauba fruit. Journal of Analytical and Applied Pyrolysis, v. 72, p. 103-111, 2004.

FRIEDL, A. et al. Prediction of heating values of biomass fuel from elemental composition. Analytica Chimica Acta, v. 544, n. 1, p. 191-198, 2005. ISSN 0003-2670.

GAWIN, D.; PESAVENTO, F.; SCHREFLER, B. A. Towards prediction of the thermal spalling risk through a multi-phase porous media model of concrete. Computer Methods in Applied Mechanics and Engineering, v. 195, n. 41-43, p. 5707-5729, 8/15/ 2006. ISSN 0045-7825. Disponível em:

http://www.sciencedirect.com/science/article/pii/S0045782505005141 >.

GURGEL VERAS, C. A. et al. Overlapping of the devolatilization and char combustion stages in the burning of coal particles. Combustion and Flame, v. 116, n. 4, p. 567-579, 3// 1999. ISSN 0010-2180. Disponível em: http://www.sciencedirect.com/science/article/pii/S0010218098000649 >.

GURGEL VERAS, C. A.; SAASTAMOINEN, J.; DE CARVALHO JR, J. A. Effect of particle size and pressure on the conversion of fuel $\mathrm{N}$ to no in the boundary layer during devolatilization stage of combustion. Symposium (International) on Combustion, v. 27, n. 2, p. 3019-3025, // 1998. ISSN 0082-0784. Disponível em: < http://www.sciencedirect.com/science/article/pii/S0082078498801628 >.

HIGMAN, C.; VAN DER BURGT, M. Gasification. Gulf professional publishing, 2011. ISBN 0080560903.

ISMADJI, S. et al. Activated carbon from char obtained from vacuum pyrolysis of teak sawdust: Pore structure development and characterization. Bioresource Technology, v. 96, p. 1364-1369, 2005. ISSN 0960-8524. 
ITAI, Y. et al. Numerical and experimental assessment of a downdraft gasifier for electric power in Amazon using açaí seed (Euterpe oleracea Mart.) as a fuel. Renewable Energy, v. 66, p. 662-669, 2014. ISSN 09601481.

JING, X. et al. Experimental and kinetic investigations of $\mathrm{CO} 2$ gasification of fine chars separated from a pilot-scale fluidized-bed gasifier. Energy \& Fuels, v. 27, n. 5, p. 24222430, 2013. ISSN 0887-0624.

JUNIOR, O. F. C. Produção de carvão ativado a partir de produtos residuais de espécies nativas da região amazônica. 2010. 101p. Dissertação de Mestrado Engenharia Mecânica, UTFPr Universidade Tecnológica Federal do Paraná, Curitiba - PR.

KANURY, A. M.; BLACKSHEAR JR, P. L. Some considerations pertaining to the problem of wood-burning. Combustion Science and Technology, v. 1, n. 5, p. 339-356, 1970. ISSN 0010-2202.

KUNG, H.-C. A mathematical model of wood pyrolysis. Combustion and Flame, v. 18, $\mathrm{n}$. 2, p. 185-195, 1972. ISSN 0010-2180.

KUNG, H.-C.; KALELKAR, A. S. On the heat of reaction in wood pyrolysis. Combustion and Flame, v. 20, n. 1, p. 91-103, 1973/02/01 1973. ISSN 0010-2180. Disponível em: < http://www.sciencedirect.com/science/article/pii/S001021807381260X >.

LAM, K. L.; OYEDUN, A. O.; HUI, C. W. Experimental and modelling studies of biomass pyrolysis. Chinese Journal of Chemical Engineering, v. 20, n. 3, p. 543-550, 2012. ISSN 1004-9541. Disponível em: < http://dx.doi.org/10.1016/S1004-9541(11)60217-6 >.

LI, X. T. et al. Biomass gasification in a circulating fluidized bed. Biomass and Bioenergy, v. 26, n. 2, p. 171-193, 2004. ISSN 09619534.

LIMA, R. R.; TRASSATO, L. C.; COELHO, V. O tucumã (Astrocaryum vulgare Mart.) principais características e potencialidade agroindustrial. EMBRAPA-CPATU. Belem. 1986. (75)

LIRA, C. S. et al. Fast pyrolysis of Amazon tucumã (Astrocaryum aculeatum) seeds in a bubbling fluidized bed reactor. Journal of Analytical and Applied Pyrolysis, v. 99, p. 2331, 2013. ISSN 0165-2370. Disponível em: < http://dx.doi.org/10.1016/j.jaap.2012.11.005 $>$. 
LISBOA, F. C. D. et al. USO DE GÁS DE SÍNTESE COMO COMBUSTÍVEL ALTERNATIVO NA PRODUÇÃO DE ENERGIA ELÉTRICA PARA COMUNIDADES ISOLADAS DO AMAZONAS. In: ABCM, VII Congresso Nacional de Engenharia Mecânica - CONEM2012, 2012, São Luis - Maranhão. ABCM, 31/07 a 03/08/2012.

LIU, Q. et al. Mechanism study of wood lignin pyrolysis by using TG-FTIR analysis. Journal of Analytical and Applied Pyrolysis, v. 82, p. 170-177, 2008. ISSN 0165-2370.

M.D.I.C., M. D. D. I. E. C. E. Análise das Informações do Comércio Exterior (ALICEweb). 2013. Disponível em: < http://aliceweb2.mdic.gov.br/index/home\# >.

M.M.E., M. D. M. E. E. Plano Decenal de Expansão de Energia-PDE 2021. M.M.E. 2011

MACHADO, G. D. O.; VOGEL, F.; MORAES E SILVA, M. Influence of temperature carbonization in physical, chemical and energy of charcoal from cinamomo (Melia azedarach L.). Ambiência, v. 10, n. 1, p. 83-96, 2014. ISSN 1808-0251.

MACIEL, M. F. P.; LISBOA, F. C. D. COMPARATIVE STUDY OF PERFORMANCE BETWEEN MILLER CYCLE ENGINE AND DIESEL CYCLE ENGINE. In: ABCM, 22nd International Congress of Mechanical Engineering (COBEM 2013), 2013, Ribeirão Preto, SP, Brazil. ABCM, November 3-7, 2013.

MCKENDRY, P. Energy production from biomass (part 2): conversion technologies. Bioresource technology, v. 83, n. 1, p. 47-54, 2002a. ISSN 0960-8524.

Energy production from biomass (part 3): gasification technologies. Bioresource technology, v. 83, n. 1, p. 55-63, 2002b. ISSN 0960-8524.

MOTTA, P. E. F. D. et al. Occurrence of macaúba in Minas Gerais, Brazil: Relationship with climatic, pedological and vegetation attributes. Pesquisa Agropecuária Brasileira, v. 37, n. 7, p. 1023-1031, 2002. ISSN 0100-204X.

MUCCIACITO, J. C. CONCEITOS E APLICAÇÕES DO CARVÃO ATIVADO. Meio Filtrante, n. 22, 10/2006 2006. $\quad$ Disponível em: < http://www.meiofiltrante.com.br/edicoes.asp?id=254\&link=ultima\&fase $=\mathrm{C}>$.

MÜLLER, C. H. et al. A Cultura do Cupuaçu. EMBRAPA-SPI. Brasília, p.9-18. 1995 
NASCIMENTO, V. F. Caracterização de biomassas amazônicas - ouriço de castanhado-brasil, ouriço de sapucaia e caroço do fruto do tucumã - visando sua utilização em processos de termoconversão. 2012. 143p. Dissertação de Mestrado Faculdade de Engenharia Química, Universidade Estadual de Campinas, Campinas SP.

NETTO, G. B. F. et al. CARACTERIZAÇÃO ENERGÉTICA DE BIOMASSAS AMAZÔNICAS. ENCONTRO DE ENERGIA NO MEIO RURAL. Campinas 2006.

NICKERSON, T. A. et al. Economic assessment of solar and conventional biomass gasification technologies: Financial and policy implications under feedstock and product gas price uncertainty. 2015.

NOGUEIRA, M. F. M.; ROCHA, H. M. Z.; ITAI, Y. ComGas: EBMA

UFPA: Software para simulação de combustão e gaseificação usando equilíbrio químico modelo zero dimensional p. 2009.

NOGUEIRA;, M. F. M. et al. Combustão e gasificação de biomassa sólida: soluções energéticas para a Amazônia. Brasília DF: Ministério das Minas e Energia MME, 2008. 194p.

OLIVEIRA, A.; CARNEIRO, A.; PEREIRA, B. Otimização Da Produção Do Carvão Vegetal Por Meio Do Controle De Temperaturas De Carbonização1. Revista Árvore, p. 557-566, 2013. Disponível em: 〈http://www.scielo.br/pdf/rarv/v37n3/a19v37n3.pdf $>$.

OLIVEIRA, E. S. D. E. Gaseificação da macaúba. 2008. 83p. Dissertação de Mestrado Programa de Pós-Graduação de Mestrado em Engenharia de Alimentos,, UESB, Itapetinga BA.

PARIKH, J.; CHANNIWALA, S.; GHOSAL, G. A correlation for calculating HHV from proximate analysis of solid fuels. Fuel, v. 84, n. 5, p. 487-494, 2005. ISSN 0016-2361.

PAULUCIO, F. F. Qualidade do carvão vegetal de madeiras do cerrado em comparação ao Eucalyptus sp. 2013.

PETERS, B. Measurements and application of a discrete particle model (DPM) to simulate combustion of a packed bed of individual fuel particles. Combustion and Flame, v. 131, n. $1-2$, p. 132-146, 10// 2002. ISSN 0010-2180. Disponível em: < http://www.sciencedirect.com/science/article/pii/S0010218002003930 >. 
PUIG-ARNAVAT, M.; BRUNO, J. C.; CORONAS, A. Review and analysis of biomass gasification models. Renewable and Sustainable Energy Reviews, v. 14, n. 9, p. 28412851, 2010. ISSN 1364-0321.

QUINTANA, L. G. Composição química e decomposição de resíduos vegetais da Acrocomia aculeata sob condições de lençol freático. 2013. 54p. Dissertação de Mestrado Departamento de Engenharia Florestal, UNIVERSIDADE DE BRASÍLIA, Brasília DF.

QUIRINO, W. F. Valorisation énergétique de déchets de bois par pyrolyse étagée. 2000. Tese de Doutorado Nancy 1

RATNADHARIYA, J.; CHANNIWALA, S. Three zone equilibrium and kinetic free modeling of biomass gasifier-a novel approach. Renewable energy, v. 34, n. 4, p. 10501058, 2009. ISSN 0960-1481.

REED, T. et al. Handbook of biomass downdraft gasifier engine systems. Biomass Energy Foundation, 1988. ISBN 1890607002.

RESENDE, F. L. P. D. Comparação entre as técnicas de análise termogravimétrica e leito fluidizado para pirólise de biomassa. 2003. Dissertação de Mestrado Programa de Pós-Graduação em Engenharia Mecânica, Universidade Estadual de Campinas, Campinas, SP.

RIEGEL, I. et al. Análise termogravimétrica da pirólise da acácia-negra (Acacia mearnsii de Wild.) cultivada no Rio Grande do Sul, Brasil. Revista Árvore, v. 32, n. 3, p. 533-543, 2008. ISSN 0100-6762.

RIOS, R. D. F. et al. ADSORÇÃO DE FENOL NO CARVÃO ATIVADO PRODUZIDO A PARTIR DO ENDOCARPO DO FRUTO DA MACAÚBA. XX Congresso Brasileiro de Engenharia Química, 2014, Florianópolis SC. COBEQ, 19/10/2014. p.1-8.

RODRIGUES, H. D. S. Obtenção de ésteres etílicos e metílicos, por reações de transesterificação, a partir do óleo da palmeira Latino Americana macaúbaAcrocomia aculeata. 2007. Tese de Doutorado Universidade de São Paulo, São Paulo.

SCHIMMEL, D. Adsorção dos corantes reativos azul 5G e azul turquesa QG em carvão ativado comercial. 2008. Dissertação de Mestrado Engenharia Química, Universidade Estadual do Oeste do Paraná, Toledo PR. 
SEYE, O.; CORTEZ, L. A. B.; GÓMEZ, E. O. Estudo cinético da biomassa a partir de resultados termogravimétricos. Proceedings of the 3. Encontro de Energia no Meio Rural, 2000, SciELO Brasil.

SILVA, J. D. C.; BARRICHELO, L. E. G.; BRITO, J. O. Endocarpos de babaçu e de macaúba comparados à madeira de Eucalyptus grandis para a produção de carvão vegetal. Ipef, v. 34, 1986.

SILVA, M. G. D. et al. Carvão de resíduos de indústria madeireira de três espécies florestais exploradas no município de Paragominas, PA. Acta amaz, v. 37, n. 1, p. 61-70, 2007. ISSN 0044-5967.

SILVERSTEIN, R. M. et al. Spectrometric identification of organic compounds. John Wiley \& Sons, 2014. ISBN 0470616377.

SOUZA, B. O. A.; DE OLIVEIRA, M. D. S. P.; COSTA, D. L. CARACTERIZAÇÃO E AVALIAÇÃO DE FRUTOS DE TUCUMÃ (Astrocaryum Vulgare MART.) ORIUNDOS DE COLETAS EM SÃO CAETANO DE ODIVELAS-PA. Embrapa Amazônia Ocidental. Belém PA. 2010. (14)

STUART, B. Infrared spectroscopy. Wiley Online Library, 2005. ISBN 0471238961.

SUFRAMA, S. D. Z. F. D. M. PROJETO POTENCIALIDADES REGIONAIS: ESTUDO DE VIABILIDADE ECONÔMICA - CUPUAÇU. Manaus Amazonas. 2003

URYCH, B. Determination of Kinetic Parameters of Coal Pyrolysis to Simulate the Process of Underground Coal Gasification (UCG). Journal of Sustainable Mining, v. 13, n. 1, p. 3-9, // 2014. ISSN 2300-3960. Disponível em: < http://www.sciencedirect.com/science/article/pii/S230039601530029X >.

VÁRHEGYI, G. et al. Kinetic modeling of biomass pyrolysis. Journal of Analytical and Applied Pyrolysis, v. 42, n. 1, p. 73-87, 6// 1997. ISSN 0165-2370. Disponível em: < http://www.sciencedirect.com/science/article/pii/S0165237096009710 >.

VASQUES, A. R. Caracterização e aplicação de adsorvente para a remoção de corantes de efluentes têxteis em batelada e colunas de leito fixo. 2008. 153p. Dissertação de Mestrado Programa de Pós-Graduação em Engenharia Química, Universidade Federal de Santa Catarina, Florianópolis - Santa Catarina. 
VASQUES, A. R. et al. Adsorção dos corantes RO16, RR2 e RR141 utilizando lodo residual da indústria têxtil. Eng. Sanit. Ambient, v. 16, n. 3, 2011.

WETTERLUND, E.; SÖDERSTRÖM, M. Biomass gasification in district heating systems - The effect of economic energy policies. Applied Energy, v. 87, n. 9, p. 2914-2922, 2010. ISSN 03062619.

WHITE, J. E.; CATALLO, W. J.; LEGENDRE, B. L. Biomass pyrolysis kinetics: A comparative critical review with relevant agricultural residue case studies. Journal of Analytical and Applied Pyrolysis, v. 91, n. 1, p. 1-33, 5// 2011. ISSN 0165-2370. Disponível em: < http://www.sciencedirect.com/science/article/pii/S0165237011000088 >.

XAVIER, E. A. N., G. ; SILVA, D. C. B. ; VAlE, A. T. ; PIRES, ARMANDO DE AZEVEDO CALDEIRA; GURGEL VERAS, C. A. Analysis of the Productive Chain of Orbignya SP. and Acrocomia Aculeata for Electricity Generation and Sustainable Development of Isolated Communities. 22nd International Conference on Efficiency, Cost, Optimization, Simulation and Environmental Impact of Energy Systems. ECOS 2009, 2009, Foz do Iguaçú.

YANG, H. et al. Characteristics of hemicellulose, cellulose and lignin pyrolysis. Fuel, v. 86, p. 1781-1788, 2007. ISSN 0016-2361.

YOSHIDA, H. H.; DE LISBOA, F. C. COMPARATIVE PERFORMANCE OF A DIESEL CYCLE ENGINE USING BLENDS OF DIESEL AND BIODIESEL. In: ABCM, 22nd International Congress of Mechanical Engineering (COBEM 2013), 2013, Ribeirão Preto, SP, Brazil. ABCM, November 3-7, 2013. 


\section{ANEXOS A - GASEIFICADOR PID}

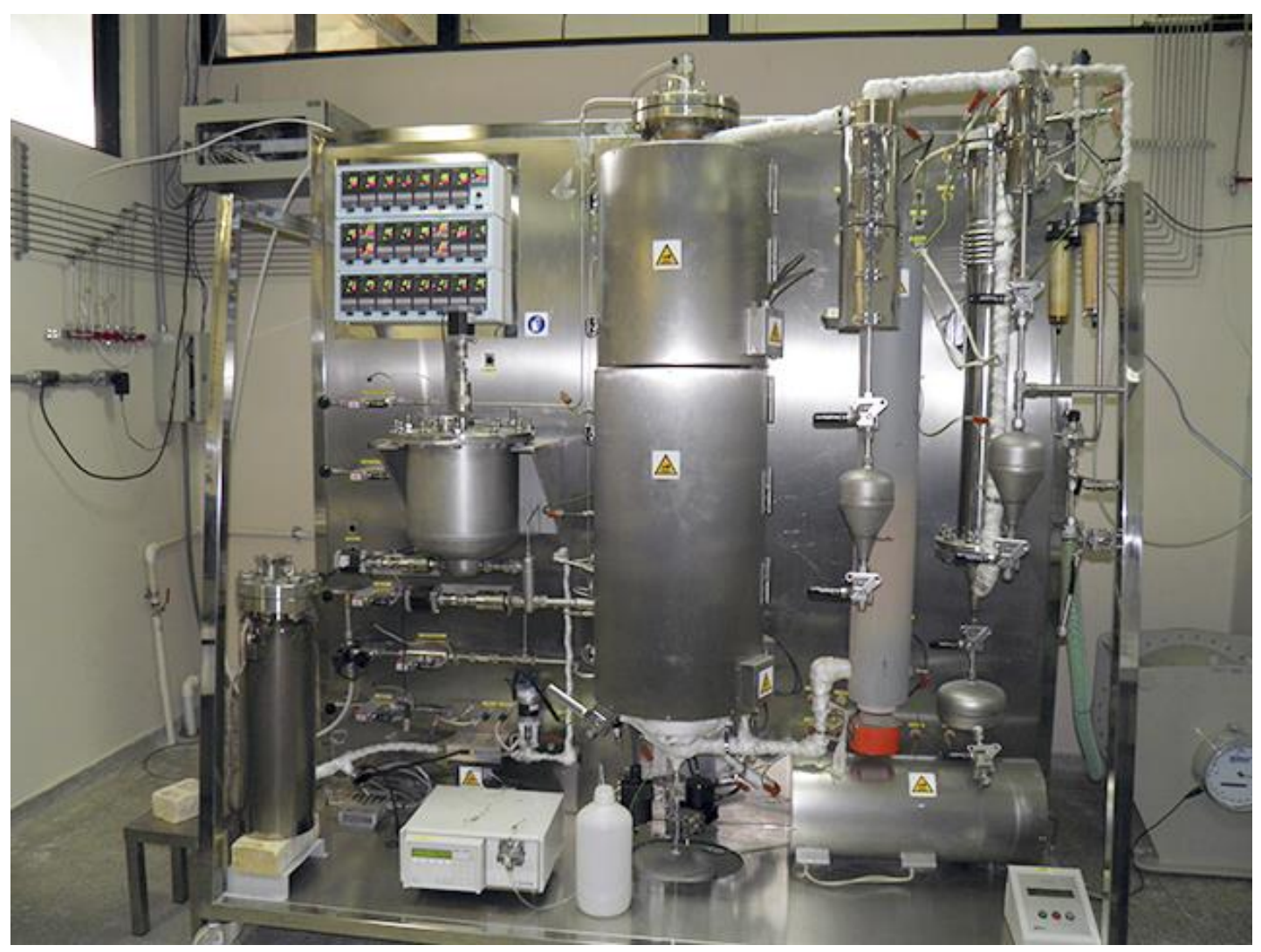

Figura 46 Foto do gaseificador usado nos experimentos

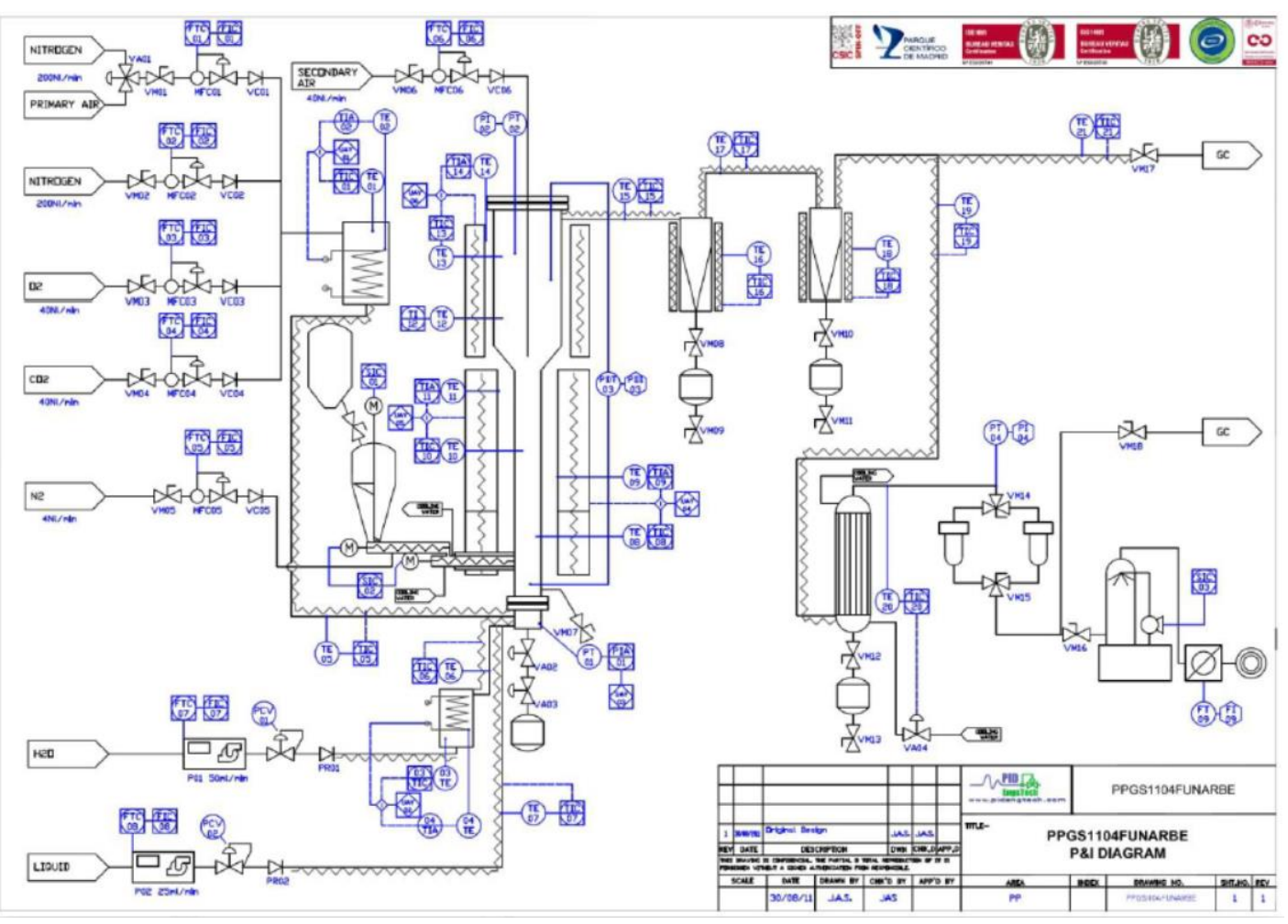

Figura 47 Diagrama de funcionamento da unidade piloto de gaseificação 
4.7 OPERATION RANGE

\begin{tabular}{|c|c|c|c|}
\hline VARIABLE & MIN & MAX & UNIT \\
\hline TEMPERATURE IN PREHEATER & 0 & 400 & ${ }^{\circ} \mathrm{C}$ \\
\hline TEMPERATURE IN REACTOR & 0 & 900 & ${ }^{\circ \mathrm{C}}$ \\
\hline TEMPERATURE IN EVAPORATOR & 0 & 400 & ${ }^{\circ} \mathrm{C}$ \\
\hline TEMPERATURE IN CLEANING SYSTEM & 0 & 400 & ${ }^{\circ} \mathrm{C}$ \\
\hline TEMPERATURE IN EXIT LINE & 0 & 50 & ${ }^{\circ} \mathrm{C}$ \\
\hline PRESSURE & 0 & 0.5 & Barg \\
\hline PRIMARY AIR FLOW RATE & 0 & 200 & NN/min \\
\hline PRIMARY OXYGEN FLOW RATE & 0 & 40 & NV/min \\
\hline PRIMARY NITROGEN FLOW RATE & 0 & 200 & N $/$ min \\
\hline PRIMARY CARBON DIOXIDE & 0 & 40 & $\mathrm{~N} / \mathrm{min}$ \\
\hline SECONDARY AIR FLOW & 0 & 40 & N $/$ min \\
\hline SOLID SYSTEM N ${ }_{2}$ FLOW & 0 & 4000 & Nm/min \\
\hline WATER FLOW & 0 & 50 & mV/min \\
\hline LLQUID FLOW & 0 & 50 & m $v_{\text {min }}$ \\
\hline SOLID FEEDING RATE* & 0 & 1.5 & $\mathrm{~kg} / \mathrm{h}$ \\
\hline
\end{tabular}

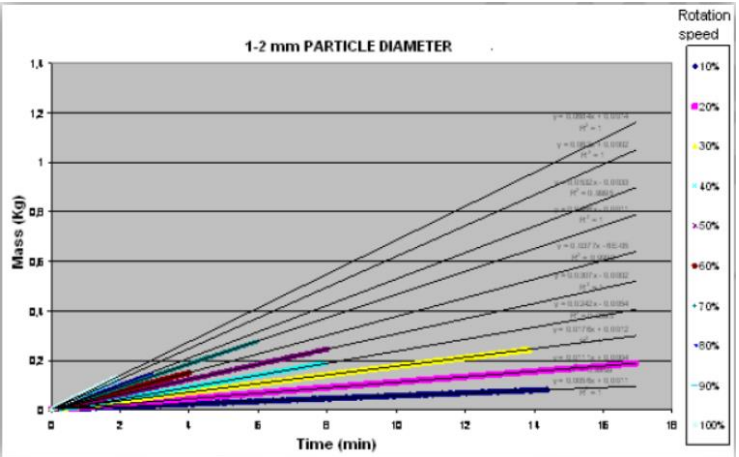

Figura 48 Faixas de operação do gaseificador e Taxa de alimentação de sólidos em função da velocidade dos parafusos

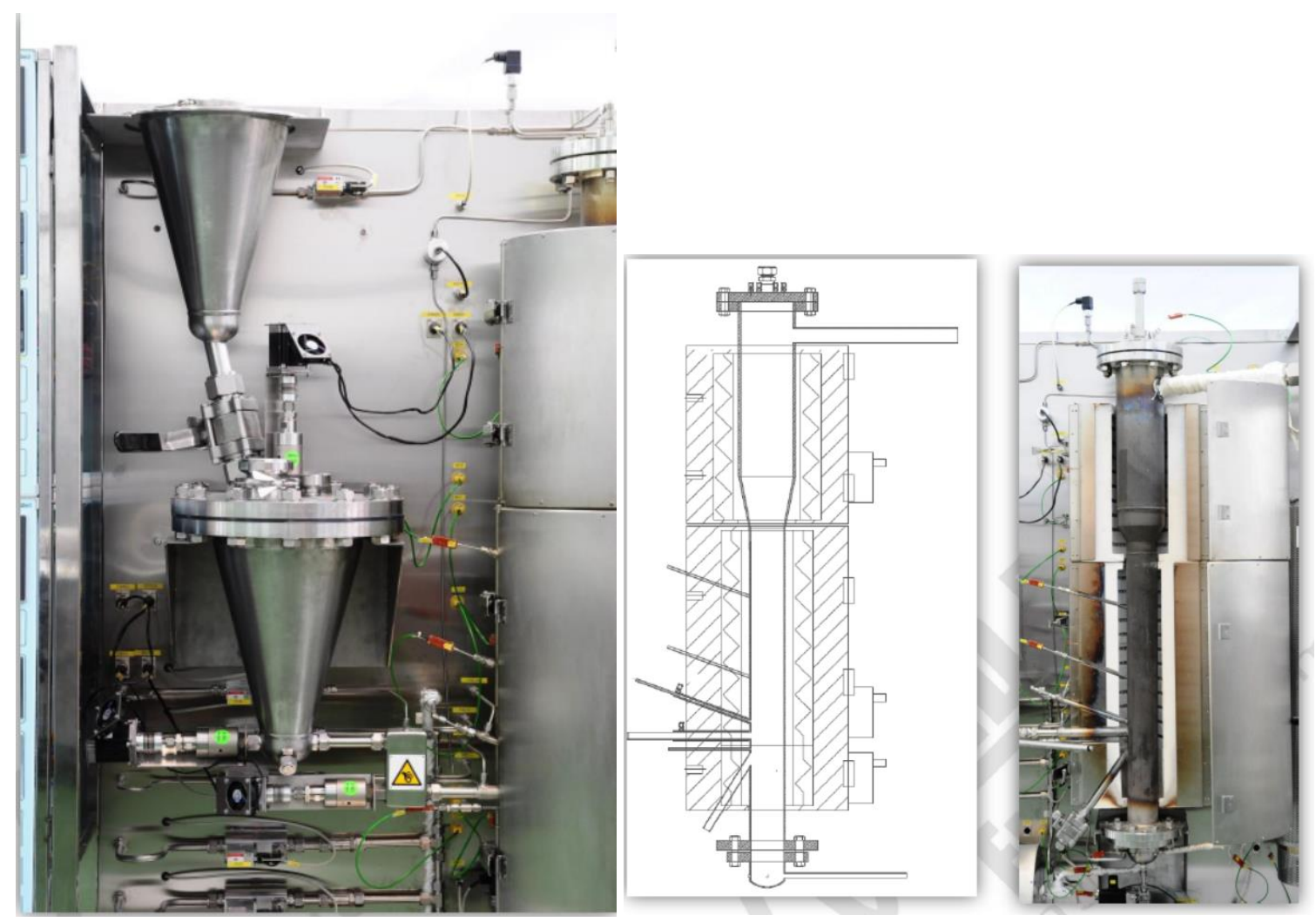

Figura 49 Sistema de alimentação e reator de gaseificação 


\section{APÊNDICE A - PIRÓLISE}

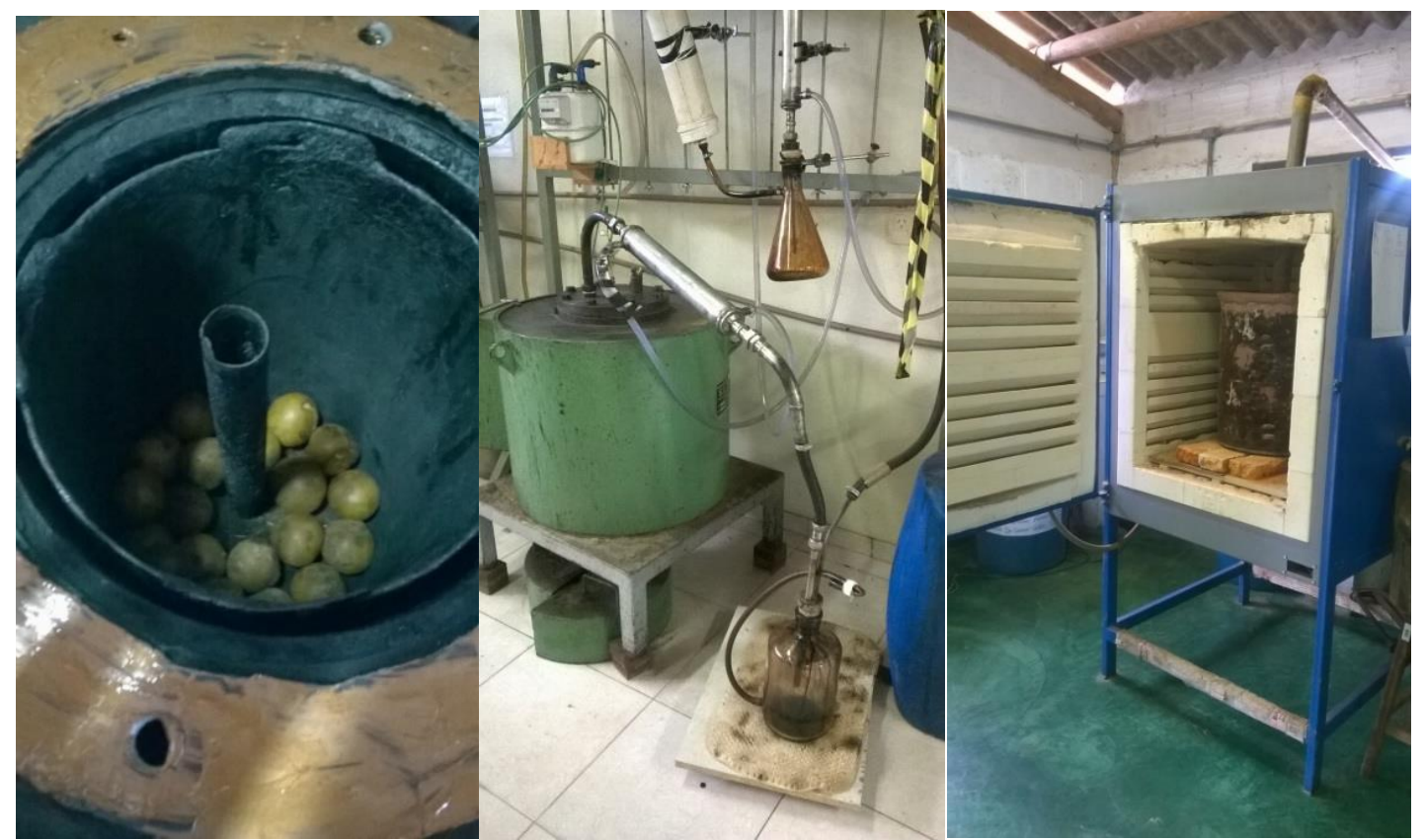

Figura 50 Fotos da retorta elétrica SLFI usada na carbonização piloto e do forno Linn Elektro Therm usado para a carbonização de grandes quantidades de biomassa virgem. Detalhes do cadinho do reator com poço para inserção do termopar e do sistema de condensação de alcatrões. Detalhe da vedação da tampa do reator feita com pasta Molybras Copper P Plus.
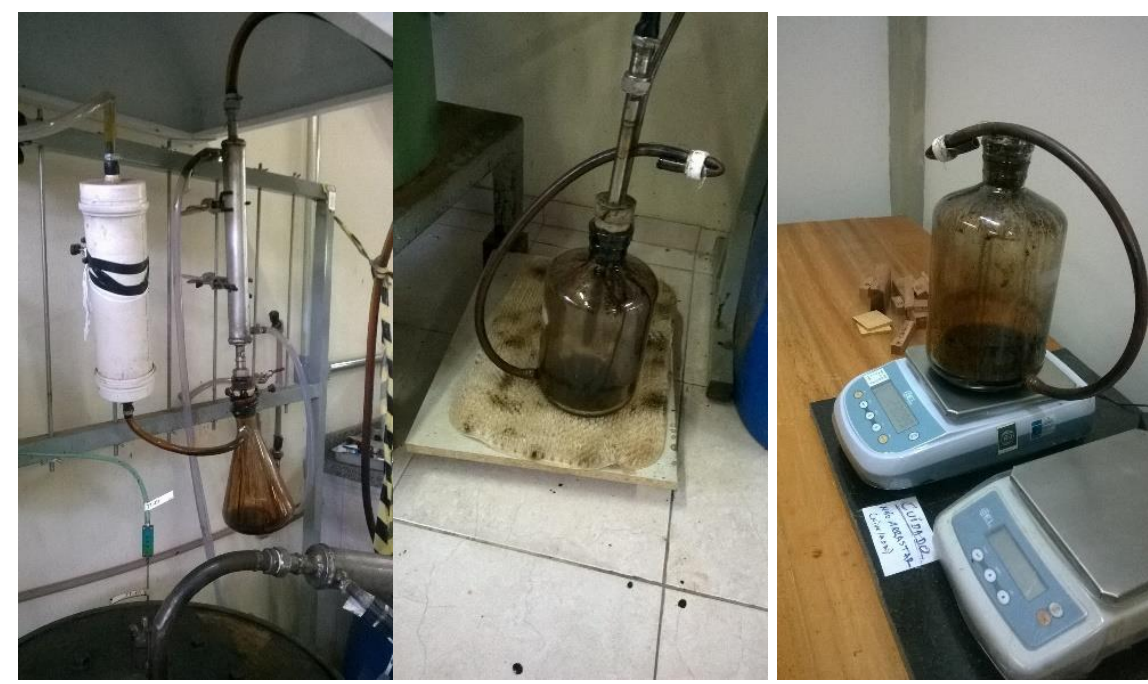

Figura 51 Sistemas de condensação de licor pirolenhoso. 


\section{APÊNDICE B - CARACTERIZAÇÃO}

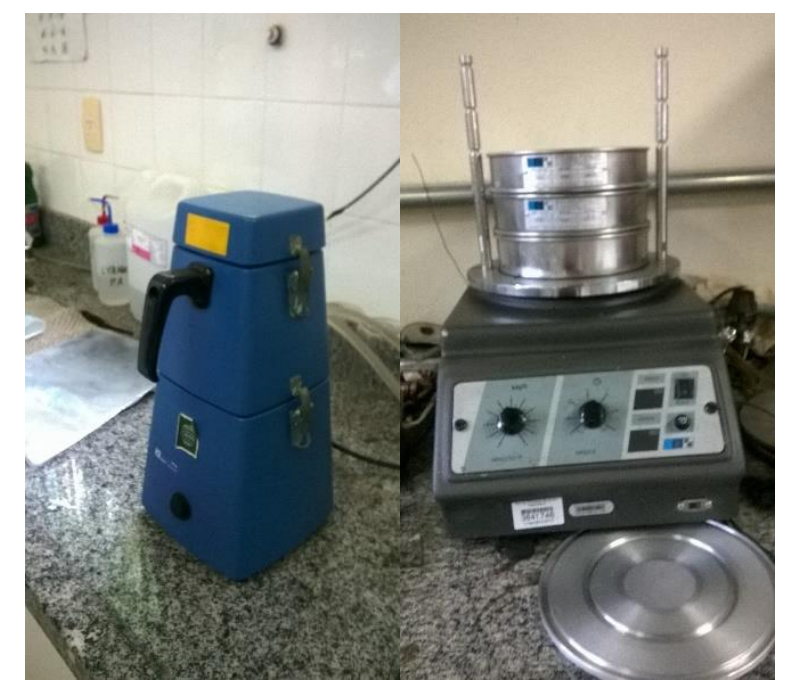

Figura 52 Sistema da moagem e classificação dos carvões

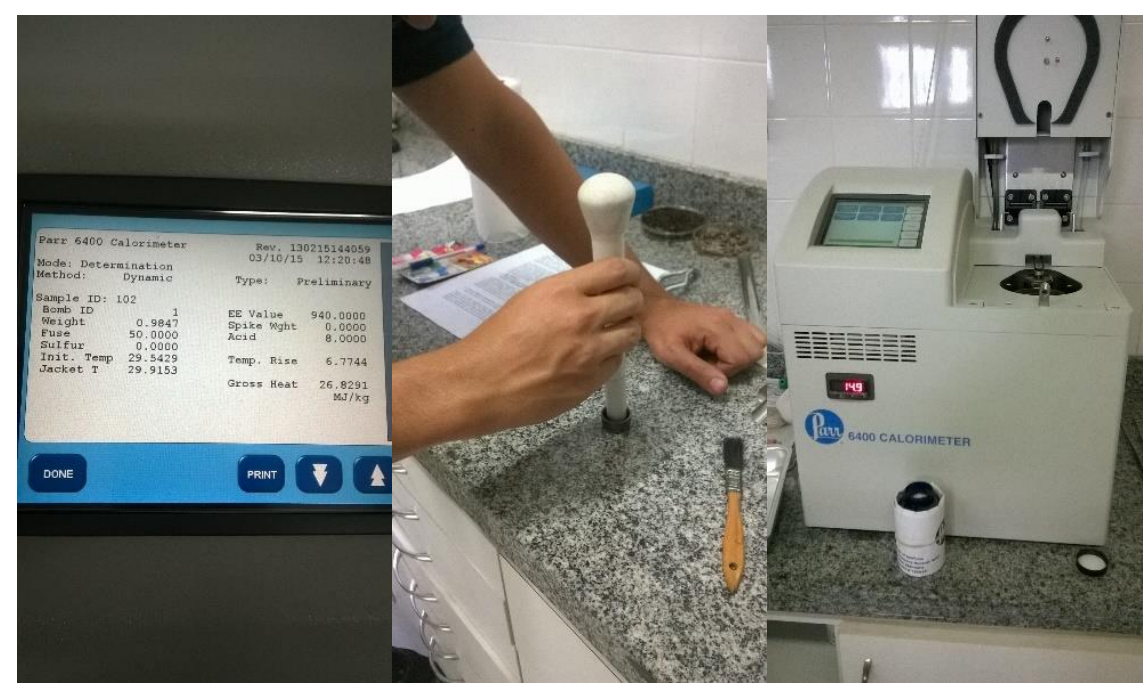

Figura 53 Medição do poder calorífico superior das amostras. 


\section{APÊNDICE B - SIMULAÇÃO PARA GASEIFICAÇÃO}

Script em EES usado para simulação das concentrações dos gases contidos no gás de síntese. Deve-se usar uma análise de sensibilidade em tabela paramétrica variando "phi" para valores dentro da zona de gaseificação $(0,3$ a 0,6$)$.

"Solução por equilíbrio químico da Gaseificação de biomassa - zero dimensional

Biomassa sólida a $300 \mathrm{~K}$ é reagida com uma fração de ar teórico também a $300 \mathrm{~K}$ a reação pode ser escrita:

$$
\mathrm{CxHyOz}+\mathrm{a}(\mathrm{O} 2+3.76 \mathrm{~N} 2)+\mathrm{wH} 2 \mathrm{O}=\mathrm{b} \mathrm{C} 22+\mathrm{c} \mathrm{CO}+\mathrm{d} \mathrm{H} 2 \mathrm{O}+\mathrm{e} \mathrm{N} 2+\mathrm{f} \mathrm{O} 2+1
$$
$\mathrm{H} 2+\mathrm{kCH} 4$

Reação estequiométrica é dada por:

$\mathrm{CxHyOz}+\mathrm{a}(\mathrm{O} 2+3.76 \mathrm{~N} 2)=$ b_stoic $\mathrm{C} 02+$ c_stoic $\mathrm{H} 2 \mathrm{O}+$ e_stoic $\mathrm{N} 2$

Para determinar a temperatura e a composição de equilíbrio nos produtos que estão a 1 bar

Procedimento para buscar a entalpia e o número de Gibbs a uma determinada temperatura"

procedure $h \& g(S \$ ; T: h ; g)$ 


$$
\begin{aligned}
& \text { call NASA }(\mathrm{S} \$ ; \mathrm{T}: \mathrm{cp} ; \mathrm{h} ; \mathrm{s}) \\
& \mathrm{h}=\text { enthalpy }(\mathrm{S} \$ ; \mathrm{T}=\mathrm{T}) \\
& \mathrm{s}=\operatorname{entropy}(\mathrm{S} \$ ; \mathrm{T}=\mathrm{T} ; \mathrm{P}=1[\mathrm{bar}]) \\
& \mathrm{g}:=\mathrm{h}^{-\mathrm{T}^{*} \mathrm{~s}}
\end{aligned}
$$

end h_g

"Função para buscar a entalpia de formação dada a substância"

Function $\mathrm{hf}(\mathrm{S} \$ ; \mathrm{T})$

\section{Call NASA(S\$;:cp;hf;s)}

end hf

"Dados do carvão de Cupuaçu (CEFC)"

$$
\begin{array}{ll}
\mathrm{x}=1 & \text { "quantidade de carbono" } \\
\mathrm{y}=0,34 & \text { "quantidade de hidrogênio" } \\
\mathrm{z}=0,16 & \text { "quantidade de oxigênio" } \\
\mathrm{h}=0,05 & \text { "umidade da biomassa" }
\end{array}
$$

PCS_b=25430 "Poder calorifico da biomassa kJ/kg" 
$\mathrm{w}=\mathrm{M} \_\mathrm{b} * \mathrm{~h} /(\operatorname{MolarMass}(\mathrm{H} 2 \mathrm{O}) *(1-\mathrm{h}))$

"Dados Assumindos"

$\mathrm{k}=0,04998 \quad$ "O Syngas produzido contém 1,7\%(vol) de metano"

f=1e-24 "A quantidade de oxigênio nos produtos é desprezível"

"Estequiometria da reação"

$\mathrm{x}-\mathrm{b}-\mathrm{c}-\mathrm{k}=0$

$\mathrm{y}+2 * \mathrm{w}-2 * \mathrm{~d}-2 * 1-4 * \mathrm{k}=0 \quad$ "Balanço de Hidrogênio"

$\mathrm{z}+2 * \mathrm{a}+\mathrm{w}-2 * \mathrm{~b}-\mathrm{c}-\mathrm{d}-2 * \mathrm{f}=0 \quad$ "Balanço de Oxigênio"

$\mathrm{a} * 3,76 * 2-2 * \mathrm{e}=0 \quad$ "Balanço de Nitrogênio"

"Cálculo da quantidade de ar estequiométrico"

$$
\begin{aligned}
& \text { a_stoic }=b \_s t o i c+\left(c \_s t o i c-z\right) / 2 \\
& \text { b_stoic }=x \\
& \text { c_stoic }=y / 2 \\
& \text { e_stoic }=3,76 * \text { a_stoic }
\end{aligned}
$$

"Total de moles do gás e frações molares" 124 


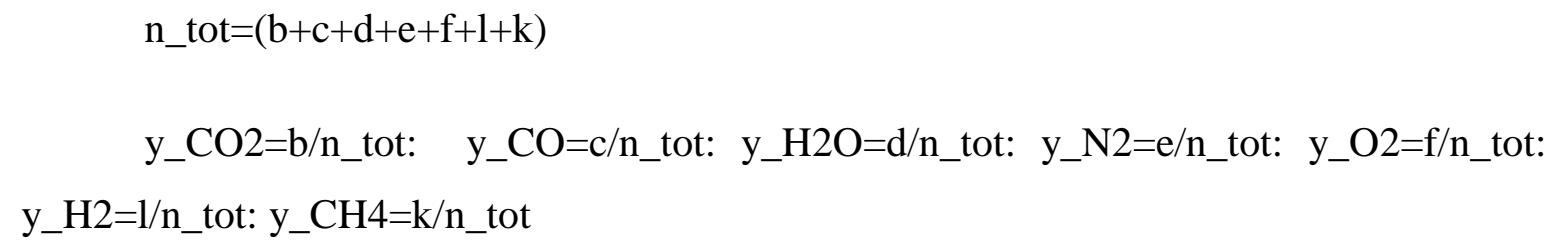

"Ambiente da reação de gaseificação"

a=a_stoic*phi "par é o parâmetro RAZÃO DE AR TEÓRICO - é a variável que rege a variação da quantidade de ar na reação"

$$
\mathrm{R}=\mathrm{R} \# \quad \text { "constante dos gases" }
$$

"As equações a seguir retornam a entalpia (h) e o número de Gibbs (g) para cada espécie química a temperatura T e pressão de referência"

\author{
call h\&g('CO2';T:h_CO2; g|o_CO2) \\ call h\&g('CO';T:h_CO; g|o_CO) \\ call h\&g('N2';T:h_N2; g|o_N2) \\ call h\&g('O2';T:h_O2; g|o_O2) \\ call h\&g('H2';T:h_H2; g|o_H2) \\ call h\&g('H2O';T:h_H2O;g|o_H2O) \\ call h\&g('CH4';T:h_CH4; g|o_CH4)
}

"Estado padrão para o número de Gibbs para as reações $\mathrm{CO}+\mathrm{H} 2 \mathrm{O}$-> CO2+H2 e para $\mathrm{H} 2+0.5 \mathrm{O} 2$-> H2O" 
DELTAG $\mid$ o_1=g|o_CO2+glo_H2-g|o_CO-g $\mid$ o_H2O

DELTAG $\left|\mathrm{o} \_2=\mathrm{g}\right| \mathrm{O} \_\mathrm{H} 2 \mathrm{O}-\mathrm{g}\left|\mathrm{o} \_\mathrm{H} 2-0,5^{*} \mathrm{~g}\right| \mathrm{o} \_\mathrm{O} 2$

"Lei da ação das massa para as reações 1 e 2"

DELTAG $\mid$ o_1 $=-\mathrm{R} * \mathrm{~T} * \ln \left(\mathrm{K} \_1\right)$

DELTAG $\mid 0 \_2=-\mathrm{R} * \mathrm{~T} * \ln \left(\mathrm{K} \_2\right)$

"Definição das constantes de equilíbrio para as reações 1 e 2"

K_1=(c/b)*(d/l) ～"water shift reaction"

$\mathrm{K} \_2=\mathrm{d}^{\wedge} 2 * \mathrm{n} \_$tot $/\left(\mathrm{l}^{\wedge} 2 * \mathrm{f}\right) \quad$ "Oxidação do hidrogênio"

"Dados de entalpia de formação - encontrados na literatura."

M_b=x*MolarMass $(\mathrm{C})+\mathrm{y} * \operatorname{MolarMass}(\mathrm{H})+\mathrm{z} * \operatorname{MolarMass}(\mathrm{O})$

"Massa molecular da biomassa"

h_f_O2=hf('O2';298 [K])

"entalpia do $\mathrm{O} 2$ a $300 \mathrm{~K} "$

h_f_N2=hf('N2';298 [K])

"entalpia do N2 a 300 K"

126 
h_f_H2O=hf('H2O';298 [K])

"entalpia de formação da água (cordeiro, 2009)"

h_f_CO2=hf('CO2';298 [K])

h_f_CxHyOz=PCS_b*M_b+b_stoic*h_f_CO2+e_stoic*h_f_N2+c_stoic*h_f_H2O "entalpia de formação da biomassa"

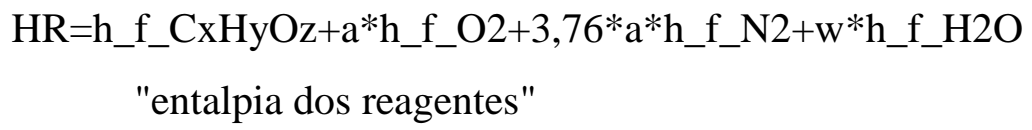

"Entalpia dos produtos"

$\mathrm{HP}=\mathrm{b}^{*} \mathrm{~h} \_\mathrm{CO} 2+\mathrm{c}^{*} \mathrm{~h} \_\mathrm{CO}+\mathrm{d}^{*} \mathrm{~h} \_\mathrm{H} 2 \mathrm{O}+\mathrm{e}^{*} \mathrm{~h} \_\mathrm{N} 2+\mathrm{f} * \mathrm{~h} \_\mathrm{O} 2+\mathrm{l}^{*} \mathrm{~h} \_\mathrm{H} 2+\mathrm{k} * \mathrm{~h} \_\mathrm{CH} 4$

"Aplicando um balanço adiabático para determinar as temperaturas dos produtos"

$\mathrm{HR}=\mathrm{HP}$

"Cálculo das massas"

$\mathrm{m} \_\mathrm{CO}=\left(\mathrm{y} \_\mathrm{CO} * \mathrm{n} \_\right.$tot $) * \operatorname{MolarMass}(\mathrm{CO})$

$\mathrm{m} \_\mathrm{CO} 2=\left(\mathrm{y} \_\mathrm{CO} 2 * \mathrm{n} \_\right.$tot $) * \operatorname{MolarMass}(\mathrm{CO} 2)$

$\mathrm{m} \_\mathrm{H} 2 \mathrm{O}=\left(\mathrm{y} \_\mathrm{H} 2 \mathrm{O} * \mathrm{n} \_\right.$tot $) * \operatorname{MolarMass}(\mathrm{H} 2 \mathrm{O})$

m_N2=(y_N2*n_tot $) * \operatorname{MolarMass}(\mathrm{N} 2)$

m_O2=(y_O2*n_tot $) * \operatorname{MolarMass}(\mathrm{O} 2)$ 


$$
\begin{aligned}
& \text { m_H2=(y_H2*n_tot }) * \operatorname{MolarMass}(\mathrm{H} 2) \\
& \mathrm{m} \_\mathrm{CH} 4=\left(\mathrm{y} \_\mathrm{CH} 4 * \mathrm{n} \_t \text { tot }\right) * \operatorname{MolarMass}(\mathrm{CH} 4)
\end{aligned}
$$

m_tot $=$ m_CO$+m \_C O 2+m \_H 2 O+m \_N 2+m \_O 2+m \_H 2+m \_C H 4$

"Cálculo das frações mássicas"

$$
\begin{aligned}
& \mathrm{x} \_\mathrm{CO}=\mathrm{m} \_\mathrm{CO} / \mathrm{m} \_t \mathrm{t} \\
& \mathrm{x} \_\mathrm{CO} 2=\mathrm{m} \_\mathrm{CO} 2 / \mathrm{m} \_t \mathrm{t} \\
& \mathrm{x} \_\mathrm{H} 2 \mathrm{O}=\mathrm{m} \_\mathrm{H} 2 \mathrm{O} / \mathrm{m} \_\mathrm{tot} \\
& \mathrm{x} \_\mathrm{N} 2=\mathrm{m} \_\mathrm{N} 2 / \mathrm{m} \_\mathrm{tot} \\
& \mathrm{x} \_\mathrm{O} 2=\mathrm{m} \_\mathrm{O} 2 / \mathrm{m} \_\mathrm{tot} \\
& \mathrm{x} \_\mathrm{H} 2=\mathrm{m} \_\mathrm{H} 2 / \mathrm{m} \_ \text {tot } \\
& \mathrm{x} \_\mathrm{CH} 4=\mathrm{m} \_\mathrm{CH} 4 / \mathrm{m} \_t \mathrm{tot}
\end{aligned}
$$

"Cálculo do poder calorífico superior do gás"

$$
\mathrm{PCS}=120 \quad[\mathrm{MJ} / \mathrm{kg}]^{*} \mathrm{x} \_\mathrm{H} 2+10,1[\mathrm{MJ} / \mathrm{kg}]^{*} \mathrm{x} \_\mathrm{CO}+55,5[\mathrm{MJ} / \mathrm{kg}]^{*} \mathrm{x} \_\mathrm{CH} 4 \quad \text { "As }
$$

constantes são os PCS dos gases $\mathrm{H} 2$, $\mathrm{CO}$ e CH4" 


\section{APÊNDICE C - GASEIFICAÇÃO}

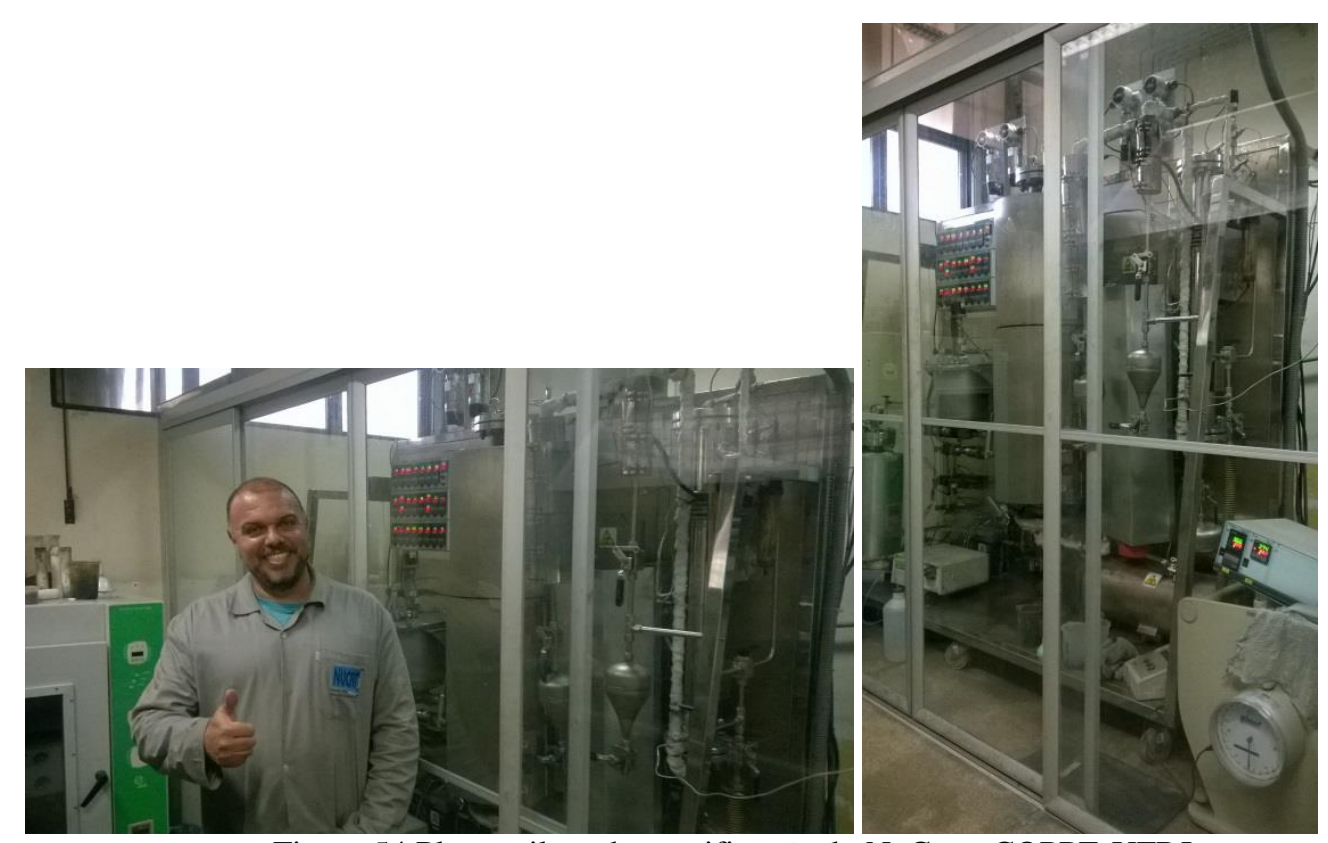

Figura 54 Planta piloto de gaseificação do NuCat - COPPE-UFRJ
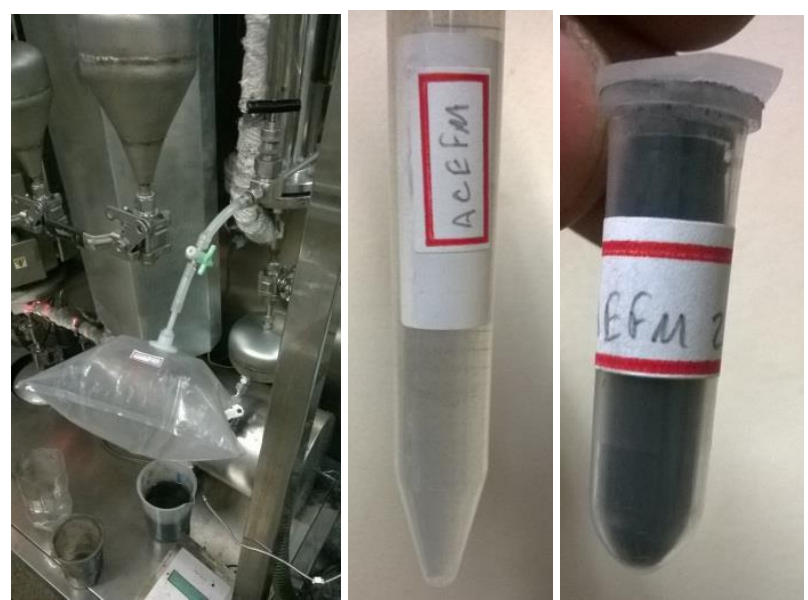

Figura 55 Amostragem do gás de síntese, condensado e finos de carvão arrastado.

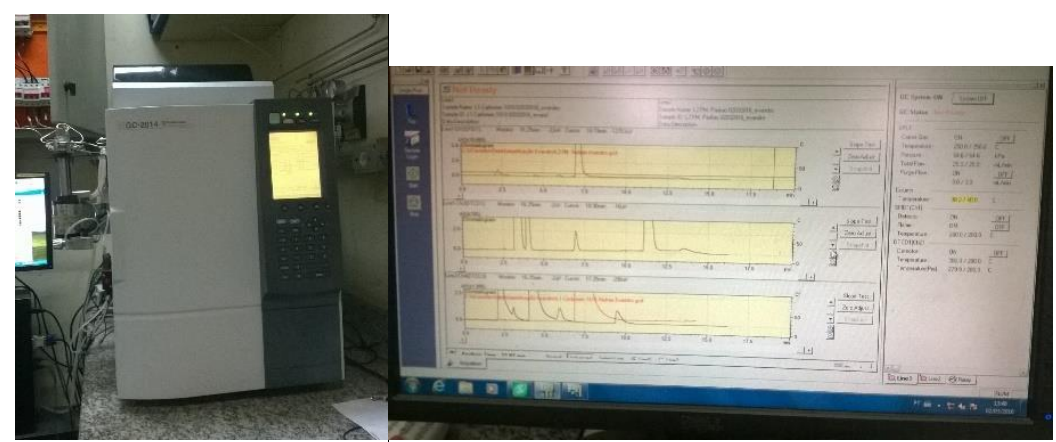

Figura 56 Cromatografia dos gases oriundos do gaseificador 


\section{APENDICE D - ADSORÇÃO DE COR}
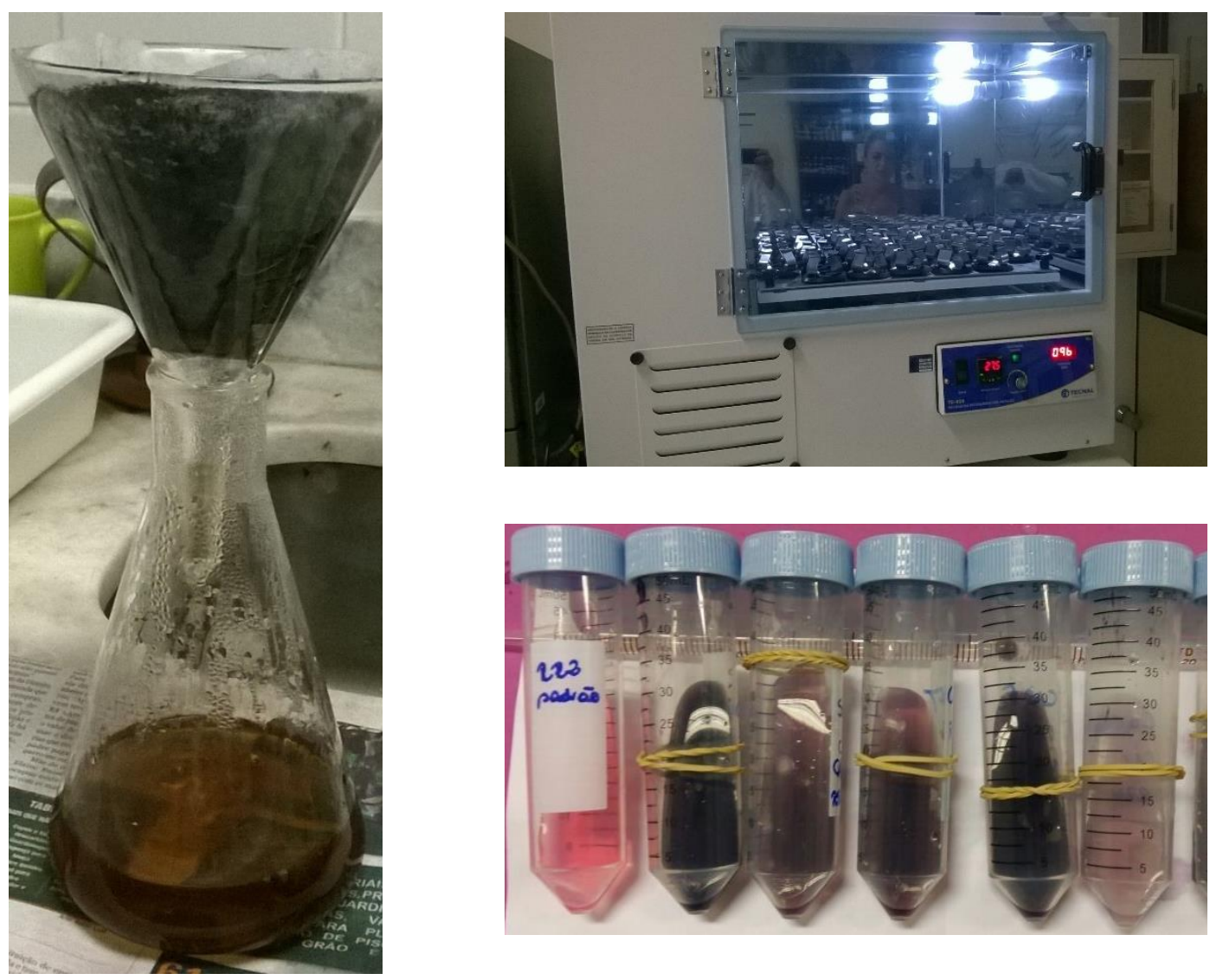

Figura 57 Ensaio de adsorção de cor - corante RR02 